\author{
UNIVERSIDADE DE SÃO PAULO \\ ESCOLA DE ENGENHARIA DE SÃO CARLOS \\ ÁREA DE PÓS-GRADUAÇÃO EM ENGENHARIA MECÂNICA
}

Método da Fronteira Virtual Aplicado em um Problema de Análise Aeroelástica Computacional

Antonio Carlos Henriques Marques

São Carlos

2011 



\author{
UNIVERSIDADE DE SÃO PAULO \\ ESCOLA DE ENGENHARIA DE SÃO CARLOS \\ ÁREA DE PÓS-GRADUAÇÃO EM ENGENHARIA MECÂNICA
}

\title{
Método da Fronteira Virtual Aplicado em um Problema de Análise Aeroelástica Computacional
}

\author{
Antonio Carlos Henriques Marques
}

Orientador: Prof. Dr. Paulo Celso Greco Jr.

Tese apresentada à Escola de Engenharia de São Carlos da Universidade de São Paulo, como parte dos requisitos para a obtenção do título de Doutor em Engenharia Mecânica. Área de concentração: Aeronaves.

São Carlos 
AUTORIZO A REPRODUÇÃO E DIVULGAÇÃO TOTAL OU PARCIAL DESTE TRABALHO, POR QUALQUER MEIO CONVENCIONAL OU ELETRÔNICO, PARA FINS DE ESTUDO E PESQUISA, DESDE QUE CITADA A FONTE.

Ficha catalográfica preparada pela Seção de Tratamento da Informação do Serviço de Biblioteca - EESC/USP

Marques, Antonio Carlos Henriques

Método da fronteira virtual aplicado em um problema de

$\mathrm{M} 357 \mathrm{~m}$ análise aeroelástica computacional / Antonio Carlos Henriques Marques ; orientador Paulo Celso Greco Jr. -Săo Carlos, 2010

Tese (Doutorado - Programa de Pós-Graduaçào em Engenharia Mecanica e Área de Concentraçào em Aeronaves) - Escola de Engenharia de Sào Carlos da Universidade de Sào Paulo, 2010.

1. Métodos numéricos em dinâmica de fluidos. 2. Método da fronteira virtual. 3. DNS. 4. Número de Reynolds ultra baixo. 5. Flutter. I. Titulo. 


\section{FOLHA DE JULGAMENTO}

Candidato(a): Engenheiro Civil ANTÔNIO CARLOS HENRIQUES MARQUES.

Tese defendida e julgada em 18/02/2011 perante a Comissão Julgadora:

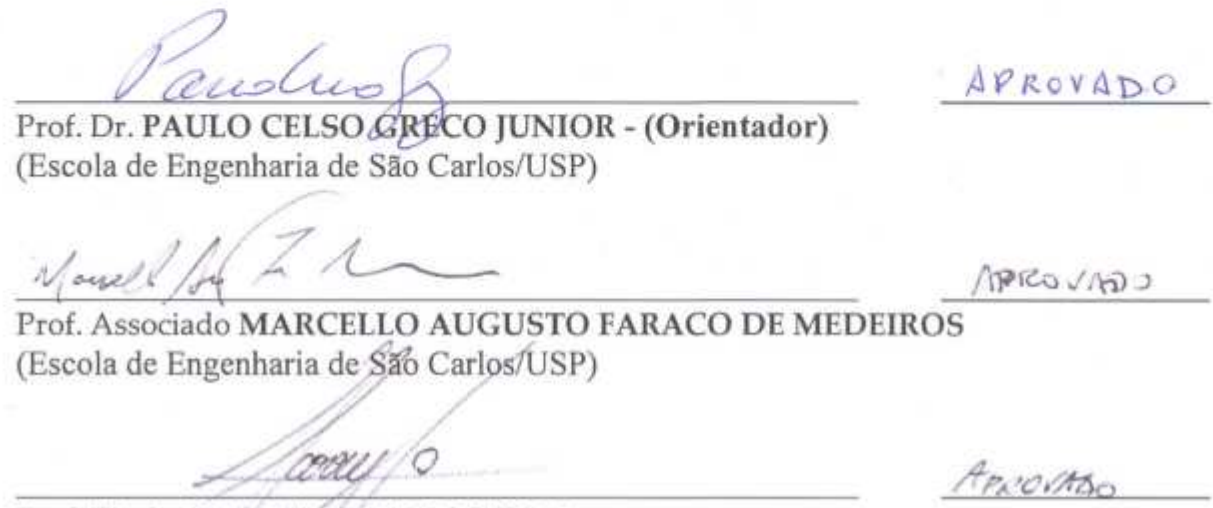

Prof. Titular HARRY EDMAR SCHULZ

(Escola de Engenharia de São Carlos/USP)

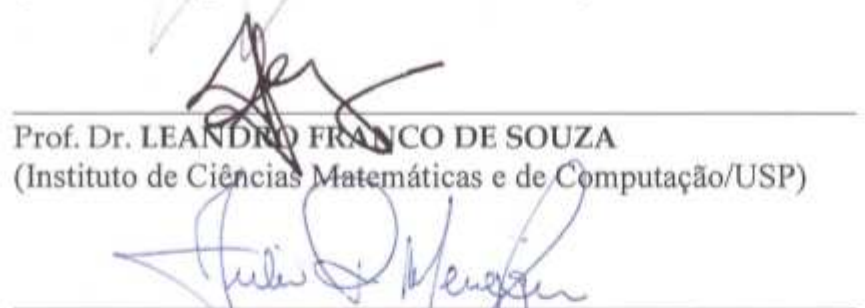

$\triangle P$ Prous Do

Prof. Associado JULIO ROMANO MENEGHINI

(Escola Politécnica/USP)

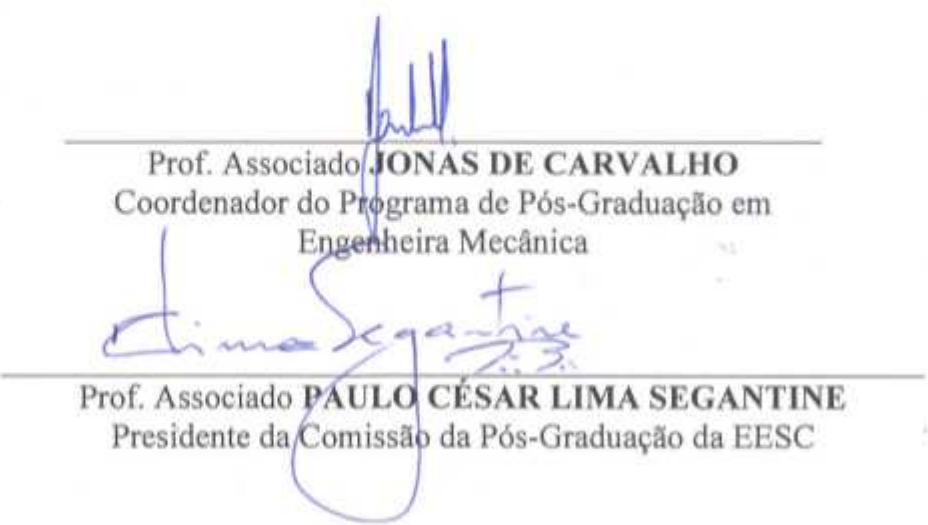





\section{Dedicatória}

A

minha família 



\section{Agradecimentos}

Ao meu orientador, Prof. Paulo Celso Greco, por ter me orientado neste trabalho e pela disposição com que conduziu este tarefa.

Ao Prof. Leandro Franco de Souza, por ter me apresentado a metodologia de fronteiras imersas e contribuído de forma significativa para a realização e elaboração das ferramentas computacionais e pesquisa.

Ao Prof. Marcello Augusto Faraco de Medeiros, pela disposição em contribuir com este trabalho através de minuciosas correções e críticas.

Ao meu colega José Laércio Dorício, pela parceria e companheirismo na pesquisa e desenvolvimento de ferramentas para o tratamento e análise de simulações computacionais.

Aos colegas e técnicos do Laboratório de Aeroelasticidade pela convivência e auxílio que tormaram o trabalho no laboratório uma tarefa mais agradável.

A todos que de forma direta ou indireta contribuiram para a consecução deste trabalho. 



\section{Resumo}

MARQUES, A. C. H. (2011). Método da Fronteira Virtual Aplicado em um Problema de Análise Aeroelástica Computacional. 212p. Tese (Doutorado) - Escola de Engenharia de São Carlos, Universidade de São Paulo.

O estudo do comportamento de um perfil de uma seção aerolástica típica, com Reynolds na faixa de microaeronaves, constitui o principal foco deste trabalho, tomando como objetivo a estimativa de parâmetros do fenômeno de flutter. A pesquisa analisa o escoamento de um fluido sobre um corpo (cilindro e aerofólio) em estado estacionário e oscilante, em escoamento de velocidade constante, e, especificamente, o fenômeno de flutter. As equações de NavierStokes, com termo forçante, são resolvidas pelo método da fronteira virtual para modelagem da interface escoamento/estrutura, representada pela geometria de um corpo de geometria complexa. Na discretização das equações governantes foi utilizado o método de diferenças finitas, sobre malhas deslocadas, com avanço temporal das velocidades do escoamento por meio de um esquema de Runge-Kutta de ordem 4. Os códigos computacionais, para as simulações e a lógica de cálculo, foram criados no contexto deste trabalho. A verificação foi feita através do método da solução manufaturada por meio de um problema fictício, que tem uma solução analítica conhecida, e que satisfaz as condições de contorno implementadas no código.

O modelo da fronteira virtual é testado para os casos de escoamento sobre cilindro de base quadrada, cilindro de base circular e perfil de aerofólio tipo NACA0012, com malhas regular e não regular, e para condições estacionária e sob oscilação forçada. Foi estudado o comportamento da esteira de vórtices, provocados por escoamento uniforme sobre o perfil de aerofólio, através dos coeficientes de arrasto, sustentação e pressão com visualização por meio da vorticidade e linhas de corrente, para vários ângulos de ataque e oscilação forçada com e rotação em torno de um pivô posicionado a 50\% da corda. Finalmente, é apresentada uma determinação numérica das características aeroelásticas para o perfil de aerofólio NACA0012, em escoamento de número de Reynolds ultra baixo $(R e=1.000$, e parâmetros de flutter para um caso de baixa frequência de oscilação.

Palavras-chave: Método da Fronteira Virtual, DNS, número de Reynolds ultra baixo, flutter. 



\section{Abstract}

MARQUES, A. C. H. (2011). Virtual Boundary Method Applied to a Problem of Computational aeroelastic analysis. 212p. Thesis (Ph.D.) - Escola de Engenharia de São Carlos, Universidade de São Paulo.

The behavior study of a profile of a typical aerolastic section, with Reynolds in range of micro aerial vehicle, is the main focus of this work, taking as objective the estimation of parameters of flutter phenomenon. The research analyzes of the flow of a incompressible fluid on a body (cylinder and airfoil profile) at steady state and oscillating with constant speed and, specifically, the flutter phenomenon. The Navier-Stokes equations, with forcing term, are solved by virtual boundary method for modeling interface flow/structure, represented by the geometry of a body of complex geometry. In discretization of the governing equations, the method of finite differences on staggered grid, with temporal advancement of discharge velocity through a Runge-Kutta of order 4 . The computer codes, for simulations guidelines and logic calculation, were created in the context of this work. The verification was done by method of manufactured solution through a fictional problem, which has a known analytical solution, and satisfies the boundary conditions implemented in code.

The model of the virtual boundary is tested for cases of flow over a square cylinder, circular cylinder and profile of a NACA0012 airfoil type, with regular and non-regular meshes, over stationary and forced oscillation conditions. We studied the behavior of vortex wake, caused by uniform flow over the airfoil profile, by the drag, lift and pressure coefficients with view through the vorticity and streamlines for various attack angles and forced oscillation with plunge and pich around a pivot. The pivot was positioned at the geometric airfoil profile (half chord). Finally, it is presented a numerical determination of aeroelastic characteristics for the NACA0012 airfoil profile, flow under ultra low Reynolds number $(R e=1.000)$, and flutter parameters for a case of low oscillation frequency.

keywords: Virtual Boundary Method, DNS, ultra-low Reynolds number, flutter. 



\section{Sumário}

\section{Lista de Figuras}

\section{Lista de Tabelas}

\section{Lista de Símbolos}

1 Introdução $\quad$ p. 31

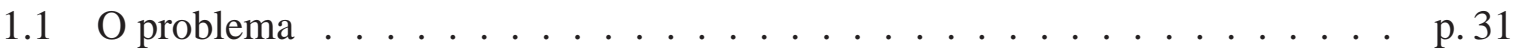

1.2 O método da fronteira virtual $\ldots \ldots \ldots \ldots \ldots \ldots$ p. . . . . . . . . . . . .

1.3 Motivação científica . . . . . . . . . . . . . . . . . . . . p. 39

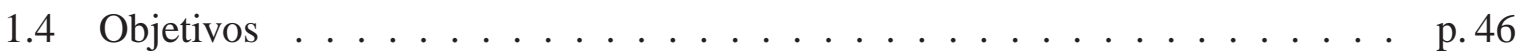

1.5 Organização da tese . . . . . . . . . . . . . . . . . p. 49

1.6 Revisão da literatura . . . . . . . . . . . . . . . . p. 50

2 Formulação matemática $\quad$ p.63

2.1 Adimensionalização . . . . . . . . . . . . . . . . . . . . . p. 64

2.2 Coeficientes usados para análise $\ldots \ldots \ldots \ldots$ p. . . . . . . . . . . .

2.3 Aspectos gerais da formulação do método da fronteira virtual . . . . . . . . p. 67

2.4 Modelagem . . . . . . . . . . . . . . . . . . . . . p. 69

3 Aproximação numérica $\quad$ p.73 
3.1 A solução das equações de Navier-Stokes . . . . . . . . . . . . . . p.73

3.1 .1 Discretização no tempo . . . . . . . . . . . . . p. 76

3.1 .2 O domínio computacional . . . . . . . . . . . p. 79

3.1.3 Discretização no espaço . . . . . . . . . . . . . p. 82

3.1.4 A solução da equação de Poisson para pressão $\ldots$. . . . . . . . . p. 86

3.2 A função delta . . . . . . . . . . . . . . . . . p. 88

3.2.1 Termo forçante na fronteira imersa . . . . . . . . . p. 93

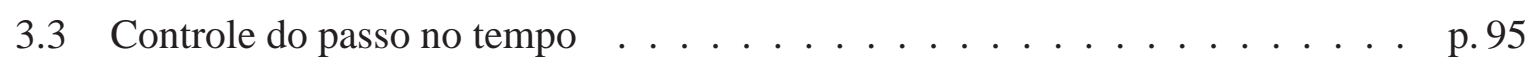

4 Verificação do método numérico e código computacional p.99

4.1 Método da solução manufaturada . . . . . . . . . . . . . . . p. p. 102

4.2 Verificação do código para o domínio euleriano . . . . . . . . . . p. p. 105

4.3 Ordem de convergência de malha de um método numérico . . . . . . . p. 113

4.3.1 Verificação para o modelo de fronteira virtual . . . . . . . . . . . p. 118

5 Validação do método da fronteira virtual p. 121

5.1 Indepedência de malha $\ldots \ldots \ldots \ldots \ldots \ldots$ p. 121

5.2 Aplicações a modelos . . . . . . . . . . . . . . . . . p. 124

5.3 Estudo de escoamento sobre uma seção de um cilindro . . . . . . . . . p. 126

5.3.1 Estudo de escoamento ao redor de uma seção prismática quadrada, estacionária . . . . . . . . . . . . . . p. 127

5.3.2 Estudo de escoamento ao redor de um cilindro de seção circular,

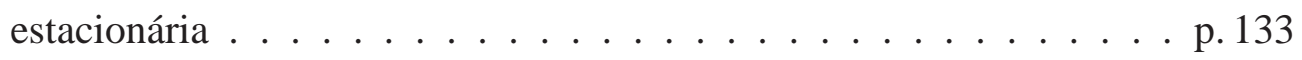


5.3.3 Estudo de escoamento ao redor de um cilindro de seção circular,

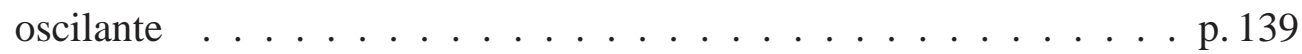

5.4 Estudo de escoamento ao redor de uma seção de aerofólio NACA0012 esta-

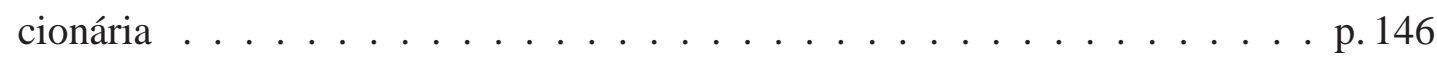

5.4.1 Validação da malha não uniforme através de uma seção circular uniforme estacionária . . . . . . . . . . . . . . . . . p. 147

5.4.2 Perfil de aerofólio NACA $0012 \ldots \ldots$. . . . . . . . . p. 149

5.4.3 Estudo do comportamento de um perfil NACA0012 submetido a escoamento com número de Reynolds ultrabaixo . . . . . . . . . p. 159

5.4.3.1 Configuração, parâmetros do escoamento e resultados ... p. 160

6 Comportamento aerodinâmico de aerofólio submetido à oscilação forçada $\quad$ p. 169

6.1 Estudo de flutter . . . . . . . . . . . . . . . . . p. 174

6.1.1 Modelagem de flutter para um sistema de dois graus de liberdade . . p. 180

6.1.2 Resultados para flutter . . . . . . . . . . . . . p. 193

Conclusão

Referências Bibliográficas 



\section{Lista de Figuras}

1.1 a) Estabilidade Marginal; b) Estabilidade; c) Instabilidade . . . . . . . . . . . . p. 35

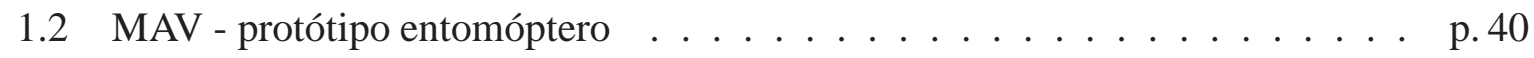

1.3 MAV - protótipo "morphingwing" ............. p. 41

1.4 Protótipo do MAV DelFly . . . . . . . . . . . . . . . . p.43

1.5 Modelo aerolástico com dois graus de liberdade $\ldots \ldots \ldots$. . . . . . . 46

1.6 Representação das malhas euleriana e lagrangiana . . . . . . . . . . . . . p.48

3.1 Célula da malha deslocada . . . . . . . . . . . . p. 81

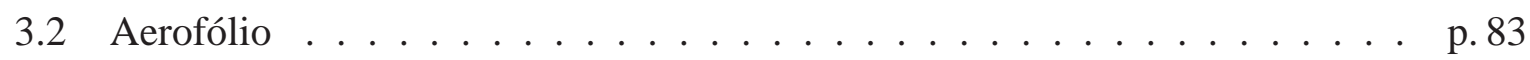

3.3 Malha não regular . . . . . . . . . . . . . . . p. 85

3.4 Molécula de cinco pontos para malha não regularmente espaçada . . . . . . p. 85

3.5 Esboço da função delta usando a equação (3.30). . . . . . . . . . . . . . . p.90

3.6 Esboço da função delta usando a equação (3.32). . . . . . . . . . . . . . p. p. 90

3.7 Esboço da função delta usando a equação (3.33). . . . . . . . . . . . . . p.91

3.8 Esboço da função delta usando a equação (3.34) com $\sigma_{x}=2$ e $\sigma_{y}=2 \ldots \quad \ldots \quad$ p. 92

3.9 Esboço da função delta usando a equação (3.34) $\operatorname{com} \sigma_{x}=0,5$ e $\sigma_{y}=0,5$. . p. 92

4.1 Papel da V\&V dentro da abordagem de modelagem e simulação adotada pelo

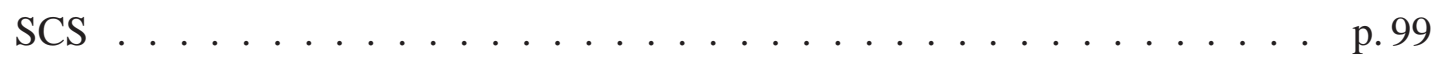

4.2 Gráfico da solução manufaturada para $u(x, y) \ldots \ldots$. . . . . . . . p. 107 
4.3 Gráfico da solução manufaturada para $v(x, y) \ldots \ldots$. . . . . . . . . . p. 108

4.4 Gráfico da solução manufaturada para $p(x, y) \ldots \ldots$. . . . . . . . . p. 108

4.5 Gráfico da função perturbação $\mathscr{P}(x, y) \ldots \ldots$. . . . . . . . . . . . p. 109

4.6 Gráfico do termo fonte $\mathscr{F}_{1}(x, y) \ldots \ldots \ldots \ldots$. . . . . . . . . p. 109

4.7 Gráfico do termo fonte $\mathscr{F}_{2}(x, y) \ldots \ldots \ldots \ldots \ldots$. . . . . . . . 110

4.8 Solução analítica para a componente $u$ da velocidade em vermelho e condição inicial perturbada em preto tracejado . . . . . . . . . . . . . p. 110

4.9 Solução analítica para a componente $u$ da velocidade em vermelho e condição convergida em preto tracejado . . . . . . . . . . . . p. 111

4.10 Solução analítica para a componente $v$ da velocidade em vermelho e condição inicial perturbada em preto tracejado . . . . . . . . . . p. 111

4.11 Solução analítica para a componente $v$ da velocidade em vermelho e condição convergida em preto tracejado . . . . . . . . . . . . . p. 112

4.12 Solução analítica para a pressão $p$ em vermelho e condição inicial perturbada em preto tracejado . . . . . . . . . . . . . . . p. 112

4.13 Solução analítica para a pressão $p$ em vermelho e condição convergida em preto tracejado . . . . . . . . . . . . . . . p. 113

4.14 Convergência para malha $0,1 \ldots \ldots \ldots \ldots \ldots$. . . . . . . . . 116

4.15 Convergência para malha $0,00625 \ldots \ldots \ldots \ldots$. . . . . . . . 116

4.16 Comparação da ordem de convergência de malha com a ordem teórica em escala $\operatorname{logarítmica.~\ldots .~.~.~.~.~.~.~.~.~.~.~.~.~p.~} 117$

4.17 Aplicação de força nas direções $x$ e $y$ e condição para $u, v$ e $p$. . . . . . . p. 119

4.18 Solução convergida das força nas direções $x$ e $y$ e campos $u, v$ e $p . \quad \ldots$. . p. 120 
5.1 Valores do coeficiente de arrasto ao longo do tempo para vários espaçamentos de malha. . . . . . . . . . . . . . . . . . . . p. 122

5.2 Valores do coeficiente de arrasto para vários espaçamentos de malha. . . . . . p. 123

5.3 Distorção produzida pela imposição de velocidade zero no interior da fronteira.p. 124

5.4 Características do canal para simulação . . . . . . . . . . . . p. 126

5.5 Resultado experimental obtido por (LINDQUIST, 2000) - vorticidade, cilindro base quadrada, $\boldsymbol{\aleph}=10 \%$ e $R e=1000$.

5.6 Resultado computacional - vorticidade, cilindro de base quadrada, $\boldsymbol{\aleph}=10 \%$

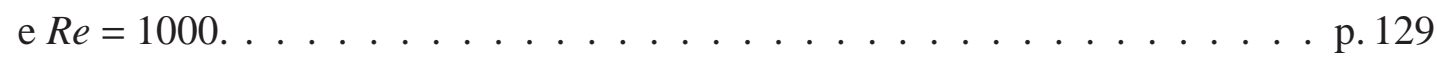

5.7 Distribuição de pressão para o escoamento ao redor de um cilindro quadrado com $\aleph=10 \%$ e número de Reynolds $R e=1000 \ldots \ldots \ldots$. . . . . . . 130

5.8 Sequência de formação de vórtices ao longo do tempo $\left(t_{1}=42 \mathrm{~s}, t_{2}=44 \mathrm{~s}\right.$, $t_{3}=46 s, t_{4}=48 s, t_{5}=50 s$ e $\left.t_{6}=52 s\right)$ - linhas de corrente - cilindro de base quadrada, $\aleph=10 \%$ e $R e=1000 \ldots \ldots \ldots \ldots \ldots \ldots$. . . . . . . . . . . . . .

5.9 Detalhe do perfil da componente $u$ da velocidade - número de Reynolds $R e=$ 1000.

5.10 Comparativo de coeficiente de sustentação para o cilindro de base quadrada, sujeito a escoamento de $R e=1000 \ldots \ldots$. . . . . . . . . . p. 132

5.11 Campo de velocidade para a) $\operatorname{Re}=1, \mathrm{~b}) \operatorname{Re}=10$, c) $\operatorname{Re}=100$ and d) $\operatorname{Re}=400$. . p. 135

5.12 Campo de pressão para a) $\operatorname{Re}=1$, b) $\operatorname{Re}=10$, c) $\operatorname{Re}=100$ and d) $\operatorname{Re}=400$. . . . p. 135

5.13 Vorticidade para a) $\operatorname{Re}=1$, b) $\operatorname{Re}=10$, c) $\operatorname{Re}=100$ and d) $\mathrm{Re}=400$. . . . . . . p. 136

5.14 Linha de corrente para a) $\operatorname{Re}=1$, b) $\operatorname{Re}=10$, c) $\operatorname{Re}=100$ and d) $\operatorname{Re}=400$. . . . p. 136

5.15 Curvas de distribuição de pressão sobre a superfície do cilindro. . . . . . . p. 138

5.16 Comparações do coeficiente de sustentação. . . . . . . . . . . . . . . . p. 139 
5.17 a) Malha computacional, b) malha ampliada próximo ao cilindro e c) Esquema de rotação do clindro

5.18 Evolução de $C_{L}$ e $C_{D}$ : a) $\theta_{\max }=30^{\circ}$ e $f_{s}=0.14$, b) $\theta_{\max }=60^{\circ}$ e $f_{s}=0.14$, c)

$\theta_{\text {max }}=30^{\circ}$ e $f_{s}=0.17$, d) $\theta_{\text {max }}=60^{\circ}$ e $f_{s}=0.17$, e) $\theta_{\text {max }}=30^{\circ}$ e $f_{s}=0.2, \mathrm{f}$ )

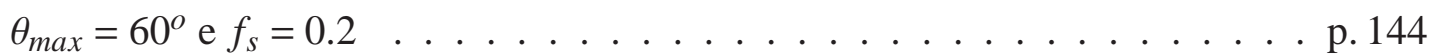

5.19 Modo 2S pré-crítico. $\theta_{\max }=60^{\circ}$ e $F_{S}=0,17 \ldots \ldots \ldots \ldots$ p. 145

5.20 Modo 2S. $\theta_{\max }=60^{\circ}$ e $F_{S}=0,17 \ldots \ldots \ldots \ldots \ldots$ p. . . . . . . . . . . . . . .

5.21 Modo $2 \mathrm{~S}$ pós-crítico. $\theta_{\max }=60^{\circ}$ e $F_{S}=0,17 \ldots \ldots \ldots \ldots$ p. 146

5.22 Detalhe do cilindro no domínio computacional . . . . . . . . . . p. 147

5.23 a) Campo de velocidade para o escoamento ao redor do cilindro, $R e=10 . \mathrm{b}$ ) campo de pressão para o escoamento ao redor do cilindro, $R e=10 \ldots$. . . . . p. 148

5.24 a) Linhas de corrente para o escoamento ao redor do cilindro, $R e=10$. b) Detalhe apresentado por Sanmiguel et al, $R e=10 \ldots \ldots$. . . . . . . . . p. 148

5.25 a) Seção de aerofólio NACA0012 com malha não uniforme b) Detalhe do bordo de fuga . . . . . . . . . . . . . . . p. 151

5.26 a) Campo de pressão, $R e=10$. b) campo de pressão, $R e=100 . \ldots$. . . . . p. 152

5.27 c) Campo de pressão, $R e=800$. a) campo de velocidades, $R e=10 \ldots \ldots$. . . p. 152

5.28 b) Campo de velocidades, $R e=100$. c) campo de velocidades, $R e=800$. . . p. 153

5.29 a) Linhas de corrente, $R e=10$. b) Linhas de corrente, $R e=100 . \ldots$. . . . . p. 153

5.30 a) Campo de velocidades, $R e=800 \ldots \ldots \ldots \ldots$. . . . . . . . . . 154

5.31 a) Campo de velocidade $u$ para a seção de aerofólio NACA0012 com $\alpha=34$ graus: MFV, b) Guermond e Quartapelle (1997) . . . . . . . . . . . . . . . . p. 154

5.32 a) Campo de velocidade para a seção de aerofólio NACA 0012: $\alpha=0$ graus,

b) $\alpha=2$ graus. . . . . . . . . . . . . . . . . . . . . . . . . . 155 
5.33 a) Campo de velocidade para a seção de aerofólio NACA 0012: $\alpha=4$ graus,

b) $\alpha=8$ graus. . . . . . . . . . . . . . . . . . . . . . . . . 155

5.34 a) Campo de velocidade para a seção de aerofólio NACA 0012: $\alpha=16$ graus,

b) $\alpha=34$ graus. . . . . . . . . . . . . . . . . . . . . . . . . . 155

5.35 a) Campo de pressão próximo á seção de aerofólio NACA 0012: $\alpha=0$ graus,

b) $\alpha=16$ graus. . . . . . . . . . . . . . . . . . . . 156

5.36 a) Campo de pressão próximo à seção de aerofólio NACA 0012: $\alpha=34$ graus,

b) resultado apresentado por Guermond e Quartapelle (1997). . . . . . . . . . p. 156

5.37 a) Coeficiente de pressão $C_{p}$ ao longo da superfície da seção de aerofólio NACA 0012: $\alpha=0$ graus, b) $\alpha=2$ graus. . . . . . . . . . . . . . p. 157

5.38 a) Coeficiente de pressão $C_{p}$ ao longo da superfície da seção de aerofólio NACA 0012: $\alpha=4$ graus, b) $\alpha=8$ graus. . . . . . . . . . . . . . . p. 157

5.39 a) Coeficiente de pressão $C_{p}$ ao longo da superfície da seção de aerofólio NACA 0012: $\alpha=16$ graus, b) $\alpha=34$ graus. . . . . . . . . . . . . . . p. 158

5.40 a) Dependencia de $C_{L}$ e $\alpha$; b) Esquema da bolha de separação laminar $($ HORTON 1968) . . . . . . . . . . . . . . . . p. 162

5.41 Campo de velocidade $u-\alpha$ : a) $0^{o}$; b) $2^{o}$; c) $4^{o}$; d) $8^{o}$; e) $10^{o}$; f) $16^{o}$; g) $20^{o}$ e h) $34^{o}$. p. 164

5.42 Campo de vorticidade: a) $\alpha=20^{\circ}$; b) $\alpha=34^{0} \ldots \ldots \ldots$. . . . . . . p. 165

5.43 Linhas de corrente para: a) $\alpha=10^{\circ}$; b) $\alpha=20^{\circ} \ldots \ldots \ldots \ldots$. . . . . . . p. 166

5.44 Espessura da camada limite- MFV $\times$ Xfoil e distribuição do componente $u$ para ângulos de ataque $2^{\circ}, 8^{\circ}$ e $34^{\circ} \ldots \ldots \ldots \ldots$. . . . . . . . . . . . 167

6.1 Modelo para simulação com oscilação forçada . . . . . . . . . . . . . . . . p. 170

6.2 Esquema de combinação de movimentos de elevação e arfagem para a) $f_{r}=1$

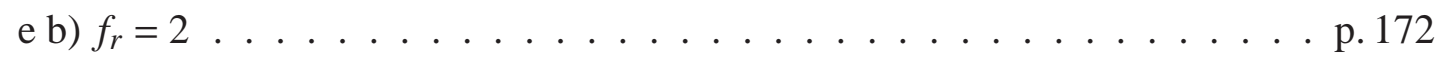


6.3 Distribuição de $C_{D}$ para $\alpha= \pm 2^{\circ}, \alpha= \pm 10^{\circ}$ e $\alpha= \pm 30^{\circ}$ com frequências de $1 \mathrm{~Hz}, 2 \mathrm{~Hz}, 5 \mathrm{~Hz}, 10 \mathrm{~Hz}, 15 \mathrm{~Hz}$ e $20 \mathrm{~Hz} \ldots \ldots \ldots \ldots$. . . . . . . . 173

6.4 Linhas de corrente para os casos de a) $\alpha=-2^{0}, f_{s}=2 \mathrm{~Hz}$, b) $\alpha=-2^{\circ}, f_{s}=$ $5 \mathrm{~Hz}, \mathrm{c}) \alpha=-2^{o}, f_{s}=10 \mathrm{~Hz}$ e d) $\alpha=-2^{o}, f_{s}=15 \mathrm{~Hz} . \ldots \ldots$. . . . . 174

6.5 Sequência de um ciclo para oscilação forçada com $\alpha=10^{\circ}$ e $f_{s}=1 \mathrm{~Hz}$. . . . p. 175

6.6 Sequência de um ciclo para oscilação forçada com $\alpha=30^{\circ}$ e $f_{s}=1 \mathrm{~Hz} \ldots$. . p. 176

6.7 Linhas de corrente para os casos de a) $\alpha=0^{\circ}$, b) $\alpha=30^{\circ}$, c) $\alpha=0^{\circ}$ e d) $\alpha=-30^{0}, \operatorname{com} f_{s}=1 \mathrm{~Hz} \ldots \ldots \ldots \ldots \ldots$. . . . . . . . . . . . . . .

6.8 Resultados computacionais $R e=1200, \alpha=30^{\circ}$ e experimentais (WEBB, 2009)p. 177

6.9 Modelos dinâmicos com a) um grau de liberdade e b) dois graus de liberdade, $($ BISPLINGHOFF, 1955). . . . . . . . . . . . . . . . p. 179

6.10 Empuxo a partir da oscilação forçada. . . . . . . . . . . . . . . p. 181

6.11 Movimentos de arfagem, $\pm 2^{o}$, e elevação de $0,1 c \ldots \ldots \ldots$. . . . . 183

6.12 Evolução do $C_{L}$ para arfagem de $\pm 2^{\circ}$, elevação de $0,1 c$ e frequências de $1 H z$, $2 \mathrm{~Hz}, 5 \mathrm{~Hz}$ e $10 \mathrm{~Hz} \ldots \ldots \ldots \ldots \ldots \ldots \ldots \ldots \ldots$. . . . . . . . . . . . . . . . . . . . . .

6.13 Coeficiente de pressão $C_{P}$ para arfagem de $\pm 2^{\circ}$, elevação de $0,1 c$ e frequências de $1 \mathrm{~Hz}, 2 \mathrm{~Hz}, 5 \mathrm{~Hz}$ e $10 \mathrm{~Hz} . \ldots \ldots \ldots \ldots \ldots$. . . . . . . . . . . . . . . .

6.14 Relação entre as oscilaçãoes de arfagem e elevação e a estabilidade (flutter). .p.191

6.15 Relação entre os tipos de aeronaves (MUELLER, 1999). . . . . . . . . . . p. 193

6.16 Resultados para determinação da frequência reduzida para arfagem de $\pm 2^{\circ}$, elevação de $0,1 c$ e frequências de $0,5 \mathrm{~Hz}, 0,75 \mathrm{~Hz}, 1 \mathrm{~Hz}$ e $2 \mathrm{~Hz} . \ldots$. . . . p. 195

6.1 Velocidade sobre a superfície do cilindro - Benevenutti e Silvestrini (2006) . . p. 213

$6.2 \Delta_{t}$ em função dos parâmetros $\alpha$ e $\beta$ - Buarque, Schettini e Silvestrini (2005) p. 214 


\section{Lista de Tabelas}

3.1 Valores do Número de Strouhal e do passo no tempo para os parâmetros $\alpha_{v}$ e $\beta_{v}$ para escoamento sobre cilindro estacionário. . . . . . . . . . . . p.94

4.1 Erro entre a solução manufaturada $(m)$ e a convergida $(c)$ para $u$, $v$, e $p$ Esquema upwind VONOS de Ordem $2 \ldots \ldots$. . . . . . . . . . . . 115

5.1 Efeito da resolução de malha para esoamento incompressível sobre um cilindro estacionário . . . . . . . . . . . . . . . . . . . p. 122

5.2 Comparação dos coeficientes de arrasto com resultados experimentais e com-

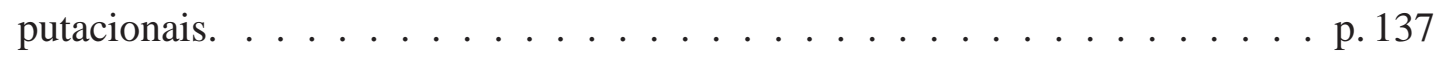

5.3 Valores de $C_{D}, C_{L}$ e $S t$ experimentais e computacionais para o cilindro estacionário. . . . . . . . . . . . . . . . . . . p. 142

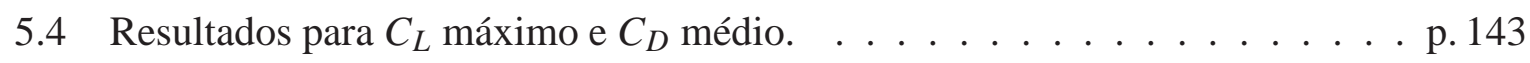

5.5 Comparação do coeficiente de arrasto obtido com os resultados experimentais e computacionais. . . . . . . . . . . . . . . . . p. 149

5.6 Características do escoamento para número de Reynolds . . . . . . . . . . p. 150

5.7 Resultados computacionais para coeficiente de arrasto. . . . . . . . . . . . p. 158

5.8 Resultados computacionais para coeficiente de arrasto e coeficiente de sustentação. . . . . . . . . . . . . . . . . . . . . 162

6.1 Valores de $C_{L}, C_{D}, C_{P}$ e $C_{M}$ obtidos da simulação . . . . . . . . p. 185

6.2 Propriedades do aerofólio usadas nas simulações . . . . . . . . . . . . p. 194 
6.3 Resultados das simulações - sustentação, momento e defasagem . . . . . . . p. 196

6.4 Resultados das simulações - autovalores . . . . . . . . . . . . . . . p. 196 


\section{Lista de Símbolos}

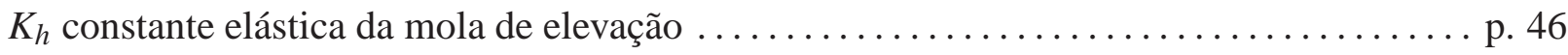

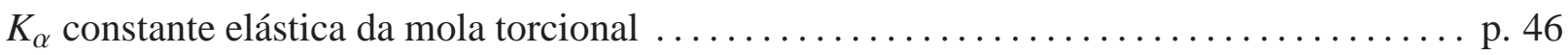

$X_{c m}$ distância ao centro de massa do aerofólio $\ldots \ldots \ldots \ldots \ldots \ldots \ldots \ldots \ldots \ldots \ldots \ldots \ldots \ldots \ldots \ldots \ldots \ldots \ldots$

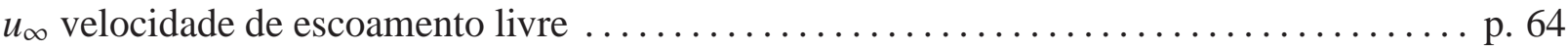

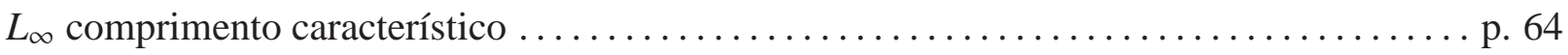

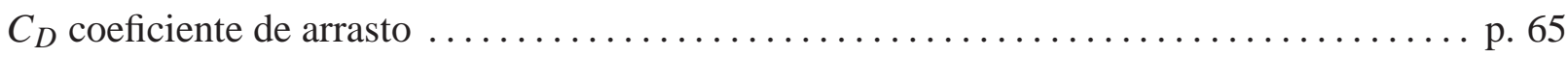

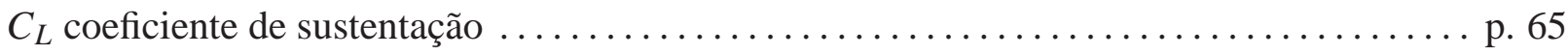

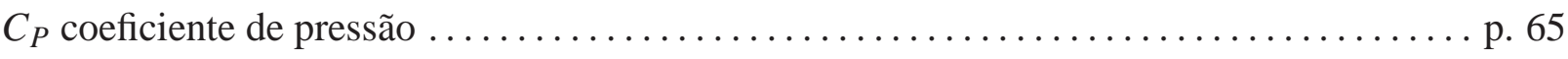

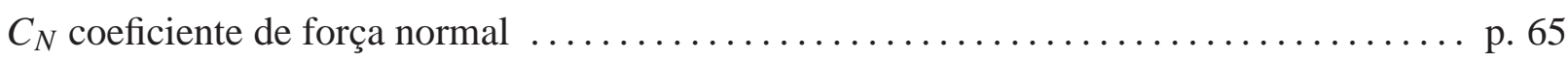

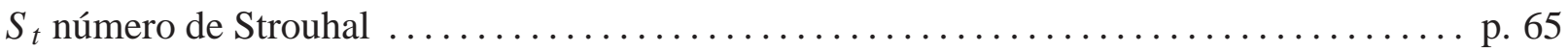

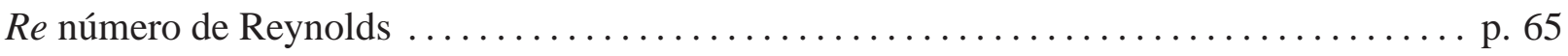

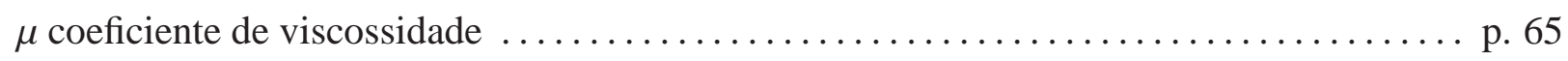

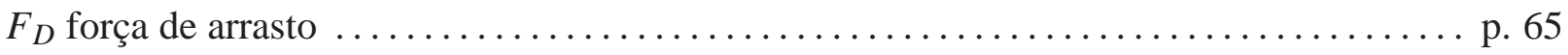

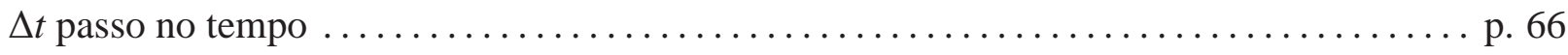

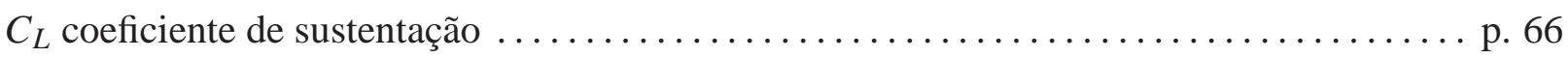

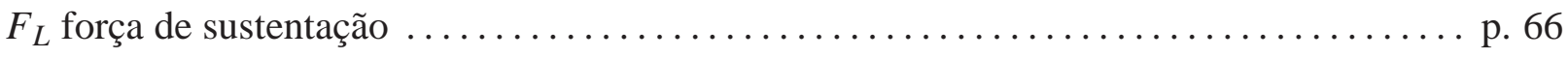




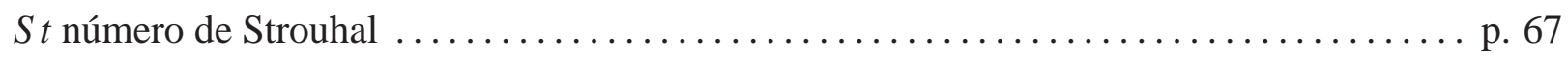

$f_{s}$ freqüência natural de oscilação do corpo $\ldots \ldots \ldots \ldots \ldots \ldots \ldots \ldots \ldots \ldots \ldots \ldots \ldots \ldots \ldots \ldots \ldots \ldots \ldots \ldots$

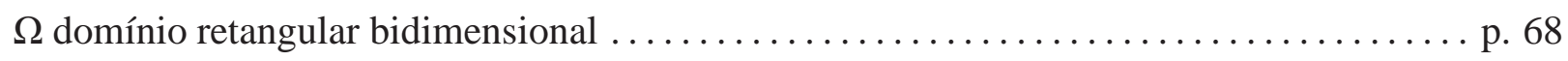

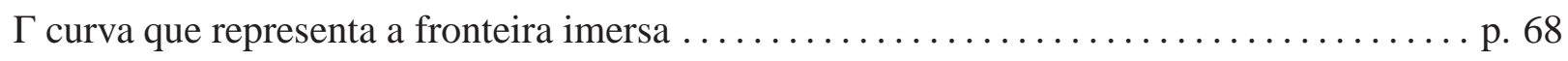

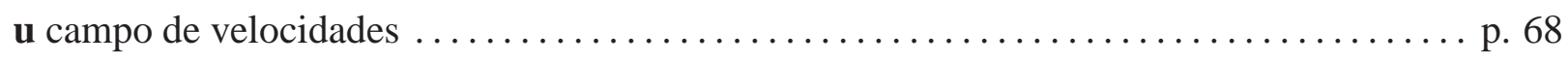

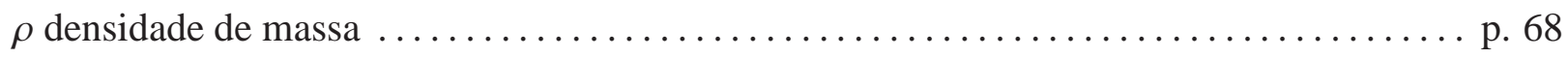

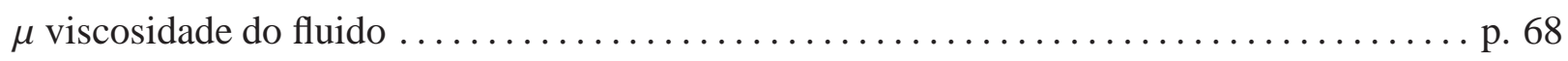

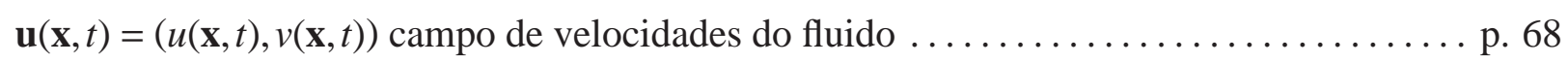

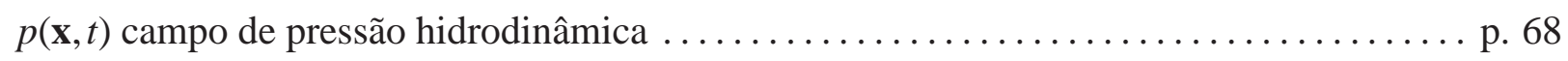

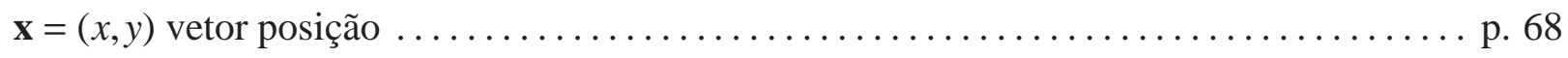

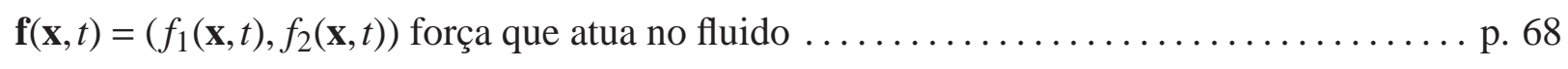

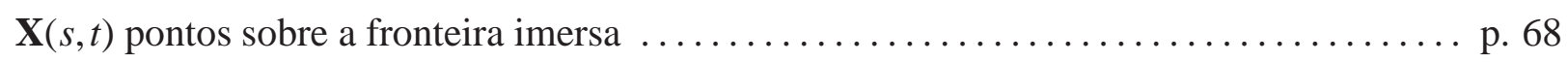

$\mathbf{F}(s, t)=\left(F_{1}(s, t), F_{2}(s, t)\right)$ força exercida na fronteira imersa $\ldots \ldots \ldots \ldots \ldots \ldots \ldots \ldots \ldots \ldots$

$\delta$ função que descreve a interação fluido-estrutura $\ldots \ldots \ldots \ldots \ldots \ldots \ldots \ldots \ldots \ldots \ldots \ldots \ldots \ldots \ldots \ldots \ldots \ldots \ldots$

$\kappa:$ Estágios do método de Runge-Kutta. $\ldots \ldots \ldots \ldots \ldots \ldots \ldots \ldots \ldots \ldots \ldots \ldots \ldots \ldots \ldots \ldots \ldots \ldots$

$\zeta_{i}$ variável do método do gradiente biconjugado $\ldots \ldots \ldots \ldots \ldots \ldots \ldots \ldots \ldots \ldots \ldots \ldots \ldots \ldots \ldots \ldots$

$\varsigma_{i}$ variável do método do gradiente biconjugado $\ldots \ldots \ldots \ldots \ldots \ldots \ldots \ldots \ldots \ldots \ldots \ldots \ldots \ldots \ldots \ldots \ldots$

$\alpha_{v}$ constante do método da fronteira virtual $\ldots \ldots \ldots \ldots \ldots \ldots \ldots \ldots \ldots \ldots \ldots \ldots \ldots \ldots \ldots \ldots \ldots \ldots \ldots \ldots$ 
$\beta_{v}$ constante do método da fronteira virtual

p. 93

$\tau$ : Parâmetro de segurança para a estabilidade.

p. 97

$Q$ : Solução da equação diferencial parcial.

$\xi$ : Domínio computacional.

p. 103

$\mathscr{F}(\xi, t)$ : Termo fonte da equação diferencial.

p. 103

$\mathscr{G}(\xi, t)$ : Termo fonte da condição de contorno.

p. 103

$Q^{e}$ : Solução manufaturada da equação diferencial parcial.

p. 103

$Q^{c}$ : Solução convergida da equação diferencial parcial.

p. 104

$\mathscr{E}\left(Q^{c}, Q^{e}\right)$ : Erro entre a solução convergida e a solução manufaturada exata. p. 104

$\mathscr{P}(x, y)$ : Função de perturbação.

p. 107

$\varsigma$ : Ordem de precisão do método numérico.

p. 113

$r$ : Taxa de refinamento da malha.

p. 114

$\aleph$ : razão de bloqueio

p. 125

$\gamma:$ parâmetro de distanciamento do cilindro em relação à borda do canal p. 126

$V:$ Velocidade de flutter.

p. 179

$\omega_{f}$ : Frequência de flutter.

$I_{\alpha}:$ Momento de inércia de rotação.

p. 180

$M_{y}:$ Momento aerodinâmico

p. 180

$I_{\alpha}:$ Momento de inércia de arfagem p. 186 
$I_{c m}:$ Momento estático de massa.

$f_{h}$ : Frequência natural de translação. . . . . . . . . 190

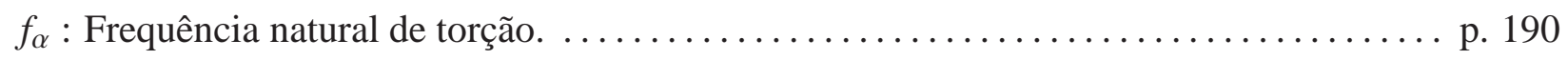




\section{$1 \quad$ Introdução}

O foco desta tese é o estudo da viabilidade do uso do método da fronteira virtual em problemas aerolásticos. Julga-se interessante, no entanto, situar o trabalho, em relação ao número de Reynolds utilizado, dentro do setor aeronáutico. Espera-se também que esse exercício possa ser útil em futuros trabalhos com micro-aeronaves.

Este trabalho busca uma solução numérica computacional para problemas que envolvam uma superfície (fronteira), estacionária ou não, imersa em um escoamento incompressível de fluido viscoso. Neste tipo de problema, um dos fenômenos que ocorre é o de formação e desprendimento de vórtices provocado pelo escoamento ao redor do corpo imerso. Uma característica deste fenômeno é a geração de variações de pressão na superfície do corpo imerso com indução de oscilações no corpo devido aos esforços dinâmicos. Estas oscilações são importantes para a determinação do comportamento de estruturas quanto ao arrasto e sustentação. Outro comportamento que pode advir dos esforços dinâmicos é o flutter. Esta introdução é uma explanação das várias etapas que vão da discussão à aplicação de um método de fronteira imersa a um problema prático com implicações em aeroelasticidade.

\subsection{O problema}

O estudo de problemas derivados da interação entre estruturas e fluidos constitui uma área de pesquisa multidisciplinar que envolve o estudo do movimento dos fluidos e suas consequências sobre as superfícies de atuação bem como a reação dos corpos que sofrem os esforços provocados pelos fluidos. Quando o fluido estudado é o ar, a denominação mais comum 
usada em engenharia é Aeroelasticidade, cujo estudo envolve a detecção de problemas tais como divergência, reversão de comandos, buffeting e flutter. O estudo destes e outros fenômenos importantes dentro da área de aeroelasticidade podem ser encontrados em referências clássicas como Bisplinghoff, Ashley e Halfman (1955) e Dowell, Jr., Scanlan e Sisto (1989).

Com os avanços da computação, o desenvolvimento de novos materiais, maior compreensão dos fenômenos aerodinâmicos de voo, aliado ao progresso em micro-tecnologia, surge a idéia de desenvolver micro-aeronaves não tripuladas, ou seja, micro-robôs voadores. Admitindo-se que se consiga aeronaves do tamanho de um dedo polegar, tais robôs poderiam ser utilizados em missões de busca e salvamento, monitoramento de tráfego, controle de incêndio, inspeção de vida selvagem, inspeção de linhas de força, fotografia aérea, sensoriamento remoto de superfície (por exemplo observações sísmicas), em detecção de substâncias prejudiciais ou poluentes em áreas de difícil acesso (tubulações por exemplo), ou em qualquer espaço perigoso para seres humanos, etc. As micro-aeronaves, na natureza, poderiam ser comparadas a insetos. Do ponto de vista da aerodinâmica, este tipo de aeronave tem comportamento diverso das de grande porte. Naquelas, o modelo físico trabalha, por exemplo, com um fluido "quase" invíscido, com altas velocidades e até mesmo ondas de choque. Neste, o modelo tem que considerar fluido viscoso (mesmo em se tratando de ar) e baixas velocidades. Este modelo pode ser aproximado pelo voo dos insetos como mostrado por Ellington (1984) e Sane (2006).

No entanto, os insetos grandes e pequenos pássaros não voam seguindo as leis convencionais da aerodinâmica clássica pois os princípios do voo de insetos são muito diferentes dos fundamentos de voo para aviões de asa fixa. Não é propósito do presente trabalho reproduzir os mecanismos de voo de pássaros e insetos. É interessante, no entanto, fazer uma breve análise de efeitos que também poderiam estar presentes na aerodinâmica de microaeronaves. No curso da evolução, os insetos dominaram o espaço aéreo e foram capazes, por exemplo, de pairar, um feito difícil. Diferentemente do voo das aeronaves de asa fixa, que pode ser analisado com aerodinâmica de estado estacionário (a sustentação é gerada pela diferença de pressão causada pelo escoamento do ar que se move mais rapidamente sobre o extradorso do que pelo intradorso em meio a um fluido quase sem viscosidade), os insetos voam em um mar de vórtices, 
rodeados por minúsculos turbilhões e redemoinhos que são criados quando movem suas asas, Sane (2003). A interação entre as asas e os fluxos circunvizinhos produzem um mecanismo de voo robusto que é difícil de ser reproduzido com nossa tecnologia atual. Uma diferença importante entre pairar e voo à frente é que pairando os insetos produzem fluxos de vórtices complexos e instáveis gerados pela agitação e rotação das asas. Os vórtices começam e param nas extremidades das asas e, ao se deslocarem, interagem produzindo sustentação de forma não trivial. A análise aerodinâmica de insetos pairando tratada por Rayner (1979), revisada posteriormente por Sane e Dickinson (2001) e Sane (2003) dentre outros autores, é baseada em suposições de estado quase estacionário.

Os turbilhões criados pelas asas de insetos os mantêm em voo. Wang, Birch e Dickinson (2004) definem três princípios para explicar como os insetos ganham força de sustentação:

- estol atrasado - o inseto bate a asa para frente com um alto ângulo de ataque, cortando o ar em um ângulo mais íngreme que uma asa de avião comum. Em ângulos tão íngremes, uma aeronave com asas fixas iria estolar e perder a sustentação. Já a asa de um inseto cria um turbilhão na direção frontal que permanece na superfície da asa para criar sustentação;

- circulação em rotação - ao término do movimento, a asa do inseto gira para trás, criando um movimento giratório que ergue o inseto, semelhante ao movimento que ergue uma bola de tênis;

- captura de esteira - conforme a asa se move pelo ar, deixa redemoinhos ou turbilhões de ar atrás dela. Quando o inseto gira sua asa para o movimento de retorno, corta sua própria esteira, capturando energia o bastante para se manter em voo.

Pela aerodinâmica de estado estacionário, o voo de pássaros e insetos pode ser comparado a pás de hélice ou rotores porque as asas geram sustentação pelo ar continuamente empurrado para baixo. Dois importantes modelos aerodinâmicos foram propostos para o voo de insetos, Ellington (1984), e de pássaros, Rayner (1979), e serviram para o extenso trabalho da teoria de rotores. Estes modelos focalizaram, principalmente, a esteira de perturbações, no 
campo distante do agitar de asas, como uma abstração conceitual de um disco atuador com modificações apropriadas para responder às mudanças dos ângulos de ataque e outros fatores de correção para o voo. Embora promissor em caracterizar alguns fenômenos de interesse (por exemplo: a formação e propagação da esteira de vórtices) e determinação de valores médios para parâmetros tais como potência, eficiência, etc, os investigadores subsequentes não conseguiram conectar os resultados obtidos em campos distantes da asas ao campo próximo das asas por meio da aerodinâmica do agitar de asas, principalmente devido à falta do entendimento das principais componentes de geração da força aerodinâmica para elevados ângulos de ataque. Ultimamente, vários pesquisadores procuraram detalhar as medidas aerodinâmicas, tais como: o efeito de rotação de asas, Dickinson (1994); sustentação e arrasto no bater de asas, Sane e Dickinson (2001); aerodinâmica do voo de insetos, Sane (2003) e Wang (2000); e estrutura de fluxo e produção de forças devido à geração de vórtices, Birch, Dickson e Dickinson (2004).

Um problema de considerável interesse prático é a estimação da variação no tempo das forças aerodinâmicas atuantes em corpos oscilantes, Scanlan (2000). Devido às complicações geométricas das asas e perfís aeronáuticos, a determinação dos coeficientes aerodinâmicos associados à oscilação é usualmente feito em túnel de vento. Com o desenvolvimento da Dinâmica de Fluidos Computacional e os avanços dos novos computadores, é possível, através de simulação, aproximar esses coeficientes para aerofólios usando a teoria aerolástica clássica, Maître, Scanlan e Knio (2003). O problema aeroelástico dinâmico é caracterizado pela presença de forças inerciais oscilatórias. A exatidão com que se pode prever o comportamento aeroelástico dinâmico de uma aeronave depende em muito das suposições adotadas na estruturação teórica e dos dados necessários para uma boa previsão do fenômeno. Pode-se ressaltar três problemas aeroelásticos dinâmicos: o buffeting, as cargas de rajadas de vento e o flutter.

O termo buffeting é aplicado em aeroelasticidade para o fenômeno de oscilações irregulares da aeronave ou de seus componentes estruturais, causadas por movimentos turbulentos do ar ou pela separação de escoamento em torno da própria aeronave. As cargas de rajadas de vento ocorrem devido à presença de fluxos atmosféricos que modificam o carregamento nas superfícies de sustentação. As componentes de velocidade deste fluxo, perpendiculares à 
componente de velocidade do escoamento sobre a superfície de sustentação, alteram o ângulo de ataque efetivo das superfícies e, por sua vez, a sustentação. Flutter é outro importante problema aeroelástico dinâmico e pode ser definido como uma instabilidade dinâmica autoinduzida, e será o fenômeno a ser tratado como aplicação neste trabalho. A melhor tradução para a língua portuguesa é drapejamento e que, em engenharia aeronáutica e doravante neste trabalho, é citado apenas na terminologia inglesa. A flexibilidade da estrutura permite que ela se deforme consideravelmente sob a ação do carregamento aerodinâmico devido ao escoamento. Estas deformações provocam alterações na distribuição do carregamento aerodinâmico. Mudanças no carregamento aerodinâmico produzem deformações estruturais adicionais e assim sucessivamente. Este comportamento interativo continua até que convirja, ou seja, os efeitos dissipativos predominam eliminando a oscilação, ou que divirja, ou seja, o processo torna-se instável e pode acontecer avarias ou danos permanentes na estrutura, vide figura (1.1), conforme Bisplinghoff, Ashley e Halfman (1955). Basicamente, as perturbações aerodinâmicas advindas deste processo, auto-induzido apresentam comportamento oscilatório e, quando apresentam divergência, indicam a ocorrência do fenômeno de flutter.

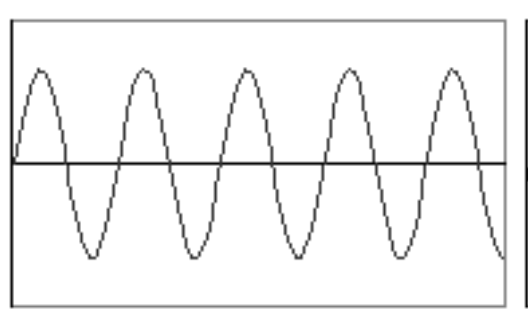

(a)

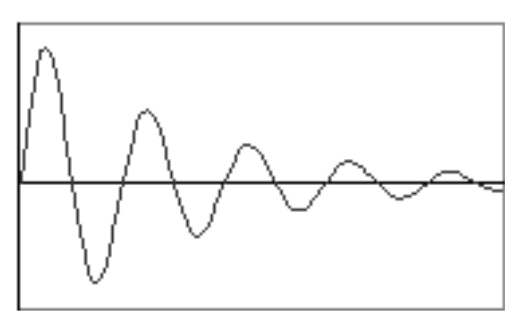

(b)

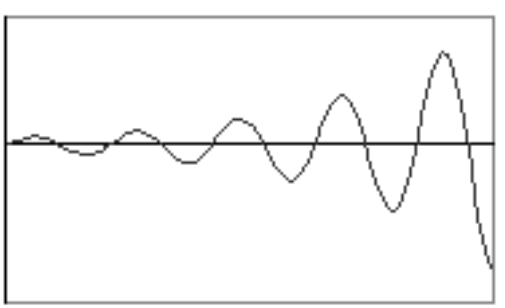

(c)

Figura 1.1: a) Estabilidade Marginal; b) Estabilidade; c) Instabilidade

Os tipos de flutter se dividem em clássicos e os não clássicos, conforme Rocha (2003). O flutter clássico está associado com o escoamento potencial e, usualmente, mas não necessariamente, envolve o acoplamento de dois ou mais graus de liberdade. O flutter não clássico, que é difícil de ser analisado com base apenas na teoria, pode envolver separação de escoamento, escoamento periódico, condições de estol e vários efeitos de atraso de resposta no tempo entre as forças aerodinâmicas e o movimento. O mais significativo tipo de flutter clássico é o escoamento em torno de uma asa considerada como um escoamento potencial. Flutter de flexão-torção, flexão-aileron e torção-aileron são tipos de flutter com dois graus de 
liberdade envolvidos (modos de vibração). Quando a asa sofre flexão e torção e os ailerons são significativamente envolvidos, temos o flutter denominado de flexão-torção-aileron. Embora o flutter seja restrito à superfícies de sustentação, a deformação elástica da fuselagem pode afetar significativamente a velocidade crítica. O tail flutter surge do comportamento elástico da empenagem e normalmente envolve um grande número de graus de liberdade. Outro tipo de flutter aparece em aeronaves que levam munições externamente e é denominado wing-withstore flutter. A adição de casulos externos à aeronave provoca significativas mudanças nas características dinâmicas e frequentemente efeitos adversos nas propriedades de flutter causam drásticas reduções na velocidade crítica (aquela associada à sustentação de uma aeronave e que depende do ângulo de ataque).

Em velocidades de voo muito altas, a deformação do revestimento da fuselagem pode exibir um tipo de flutter que está associado ao deslocamento dos painéis na direção normal a esta superfície. Este flutter é chamado de panel flutter e difere do flutter convencional pelo menos por dois aspectos: é um fenômeno inteiramente supersônico e as não-linearidades estruturais, associadas com os limites aerodinâmicos, tendem a limitar fortemente as amplitudes de flutter. Um outro tipo de flutter que ocorre no escoamento potencial é o Propeller-rotor/whirl flutter. O mecanismo básico na instabilidade whirl flutter é o acoplamento giroscópico de arfagem e guinada no sistema de hélice. Um tipo não clássico de flutter é o que está associado ao escoamento separável e é chamado de stall flutter. O stall flutter pode ocorrer em uma superfície de sustentação quando esta opera com alto ângulo de ataque no escoamento durante, ao menos, parte de cada ciclo de oscilação. Ele ocorre principalmente no flutter de um grau de liberdade em uma oscilação torcional e um grande número de parâmetros pode ter enorme influência neste fenômeno de flutter, entre eles podemos citar: número de Reynolds, frequência reduzida, localização do eixo torcional e forma do aerofólio. Pela existência de todos estes parâmetros, as não-linearidades aerodinâmicas e o escoamento separável complicam imensamente uma previsão teórica do flutter para este caso. 


\subsection{O método da fronteira virtual}

A aerodinâmica pode ser definida como uma ciência aplicada que estuda a interação entre o escoamento de ar e corpos imersos neste escoamento. Normalmente são corpos de geometria complexa (perfís aerodinâmicos) cuja simulação computacional do escoamento na vizinhança é feito através da discretização das equações governantes sobre malhas curvilíneas (estruturadas ou não estruturadas) ajustadas ao corpo, fazendo com que as fronteiras geométricas do corpo imerso coincidam com as fronteiras do domínio computacional. Nestes casos, a transformação das equações governantes para o sistema de coordenadas curvilíneas, a eficiência e a qualidade da malha computacional estão intimamente ligadas à complexidade da geométrica, conforme Ye, Mittal, Udaykumar e Shyy (1999), e pode resultar em um sistema complexo que pode ter grande influência na estabilidade e convergência do método numérico e, consequentemente, sobre o código computacional. Uma das alternativas é a adoção de um esquema cartesiano onde as equações governantes são discretizadas sobre uma malha cartesiana que não tem, necessariamente, conformidade com a fronteira do corpo imerso. Para simular escoamentos onde há essa interação pode-se utilizar métodos como os de fronteira imersa, conforme afirma Peskin (2002).

Os métodos de fronteiras imersas (Immersed Boudary Method, Virtual boundary Method, Physical Virtual Model, Immersed Interface Method, etc) admitem um campo de força (virtual ou não) devido ao corpo imerso no escoamento sem alterar o domínio cartesiano computacional. Estes métodos simplificam a geração da malha, mantém a solução das equações governantes em coordenadas cartesianas e corpos de formas arbitrárias podem ser adicionados ao domínio computacional sem a necessidade de reconstrução da malha, conforme proposto por MohdYusof (1998). Apesar destas vantagens, não se encontram muitos trabalhos utilizando o métodos de fronteiras imersas aplicados ao estudo de problemas em aeroelasticidade na literatura atual, mas sim métodos baseados em volumes finitos com malhas não estruturadas. Linnick (1999) utilizou o método da fronteira virtual para estudar o efeito de atuadores sobre estruturas 
aeronáuticas. Esse fato motiva o estudo e aplicação dos métodos de fronteiras imersas a essa classe de problemas, assim como estudos em análises aeroelásticas e flutter.

O método da fronteira virtual é um método derivado do método da fronteira imersa. $\mathrm{O}$ método da fronteira imersa foi proposto por Peskin (1972) e foi desenvolvido para resolver problemas envolvendo interações entre fluido e estrutura. A idéia do método é utilizar uma malha regular euleriana para representar o fluido em conjunto com uma malha lagrangiana para representar a fronteira imersa composta por elementos de mola que obedecem à uma lei elástica (normalmente Lei de Hooke). O escoamento ao envolver a fronteira imersa aplica-lhe uma força e a fronteira imersa exerce uma força de reação sobre o fluido e ao mesmo tempo se move com a velocidade local do fluido. A interação entre o fluido e a fronteira imersa pode ser modelada através de uma aproximação da função delta Dirac, conhecida como função delta discreta, que é o núcleo do método. Essa abordagem tem sido aplicada ao estudo da dinâmica dos fluidos em válvulas cardíacas nos trabalhos de Peskin (1972), McQueen, Peskin e Yellin (1982), Meisner, McQueen, Ishida, Vetter, Bortolotti, Strom, Frater, Peskin e Yellin (1985) e Lai e Peskin (2000). O método também foi aplicado ao estudo do nado de enguias, bactérias e escoamentos com partículas em suspensão respectivamente por Fauci e Peskin (1988), Dillon, Fauci e Gaver (1995) e Fogelson e Peskin (1988).

Goldstein, Handler e Sirovich (1993) utilizaram uma abordagem denominada método da fronteira virtual para simular escoamentos turbulentos. Essa abordagem compartilha o mesmo espírito do método da fronteira imersa, porém resolve problemas com fronteiras rígidas ao invés de problemas com fronteiras elásticas. A idéia primordial do método é tratar a superfície da estrutura como uma fronteira virtualmente imersa em um fluido que aplica uma força sobre o campo do fluido de forma que seja interpretado a existência de uma barreira impedindo o escoamento. O fluido enxerga o corpo através das forças de pressão e cisalhamento que existem sobre sua superfície (campo de força) se o conjunto modelado das forças estiver correto, ou seja, se representar realmente o fenômeno físico que está sendo modelado. No trabalho de Saiki e Biringen (1996) o método da fronteira virtual foi aplicado à simulação de escoamentos uniformes ao redor de cilindros estacionários ou móveis utilizando-se um termo de 
força retroalimentado (feedback forcing term) de forma a alcançar, iterativamente, o "conjunto correto" de forças que representam o modelo físico. O método da fronteira virtual foi também aplicado ao estudo de estabilidade em escoamentos turbulentos com geometrias complexas no trabalho de Lee (2003). Silva, Silveira-Neto e Damasceno (2003) propuseram o Modelo Físico Virtual (PVM Physical Virtual Model), que é uma variação do método da fronteira virtual, cuja idéia principal consiste no cálculo da força na interface estrutura/fluido sem as constantes $a d$ hoc que usualmente são ajustadas para o tipo de fluxo e método numérico utilizados. Tem este nome porquê é baseado apenas nas leis de conservação.

O Modelo Físico Virtual, Silva, Silveira-Neto e Damasceno (2003), tem a vantagem das equações governantes serem discretizadas sobre malha computacional cartesiana, que simplifica a geração da malha e mantém a simplicidade das equações governantes em coordenadas cartesianas, além de incorporar uma técnica do método da fronteira imersa: é que a fronteira imersa, representada por uma malha lagrangiana, não necessariamente se alinha e tampouco depende da malha euleriana, onde o fluido é representado. Isto permite simular escoamentos com fronteiras móveis, geometrias complicadas ou mudanças topológicas. Como a malha cartesiana subjacente não depende da localização da fronteira imersa, não há necessidade de reconstrução ou refinamento local da malha, uma vez que esses procedimentos são caros com relação ao tempo computacional.

\subsection{Motivação científica}

O termo Micro Veículo Aéreo (MAV - Micro Air Vehicle) pode ser interpretado erroneamente se observado literalmente, pois a tendência é pensar em uma aeronave de tamanho "micro". Na verdade um micro veículo aéreo não é uma aeronave em miniatura, mas sim uma classe de pequenos veículos aéreos (inicialmente militares) com tamanho médio em torno 15 centímetros (em comprimento, altura e largura) com características próprias como robôs aéreos, como máquinas providas de seis graus-de-liberdade cuja mobilidade pode deslocar uma carga útil (por controle remoto ou não) e que pode executar uma variedade de missões. Embora a 
limitação possa parecer um pouco arbitrária, deriva de considerações físicas e tecnológicas. Das relações produzidas por essas considerações, a relação entre peso total e número de Reynolds é a mais expressiva para tratar os fenômenos aeronáuticos, pois, devido às pequenas dimensões do veículo e velocidades, o regime é significativamente de número de Reynolds ultrabaixo e fundamental para o comportamento físico dos MAV's - um ambiente mais comum a pequenos pássaros e grandes insetos. Assim, o tratamento usual dispendido para a aerodinâmica clássica (asa fixa, altos números de Reynolds e escoamento compressível) não se aplica a esse novo tipo de "aeronave". É necessário recorrer ao estudo feito pelos naturalistas ao voo dos pequenos pássaros e grandes insetos, vide por exemplo o "entomopter project" ${ }^{1}$, fig. (1.2), e o "morphing project" ${ }^{2}$, figura (1.3).

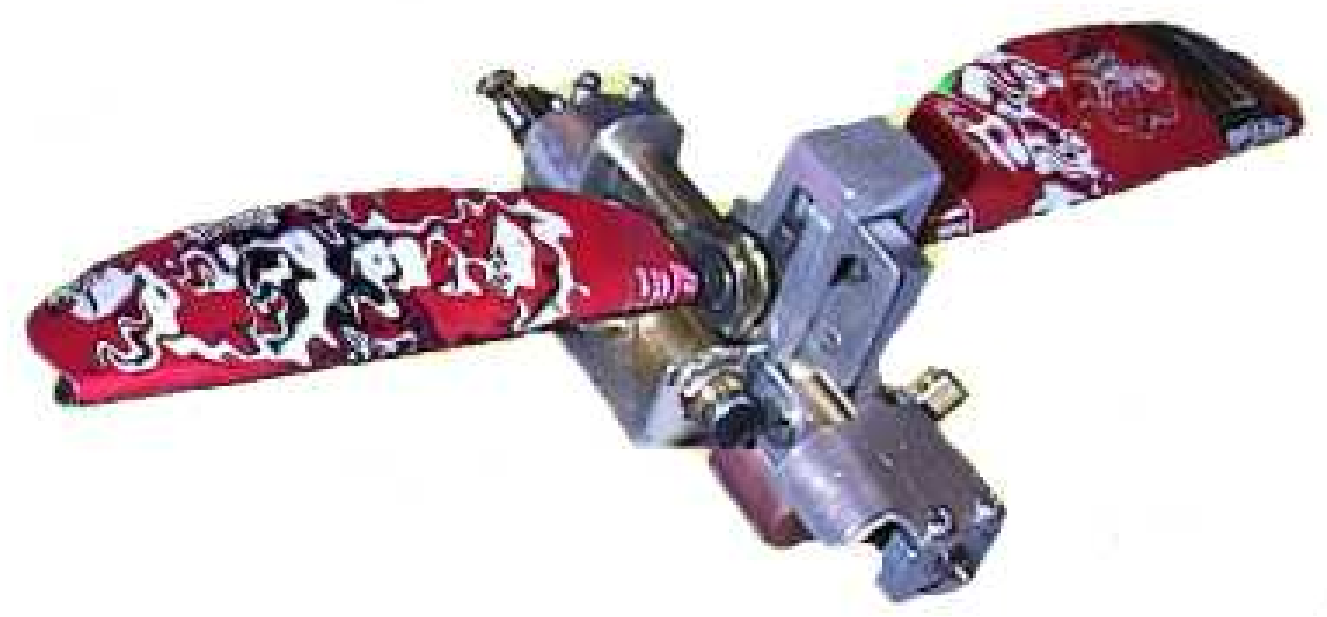

Figura 1.2: MAV - protótipo entomóptero

Alguns modelos de MAV estão sendo projetados para imitar o voo de um inseto grande e possuem as seguintes partes básicas: fuselagem - assim como em uma aeronave maior, a fuselagem é o casco da máquina e abriga a fonte de energia e o tanque principal de combustível. Todos os outros componentes do MAV são conectados à fuselagem; asas - há duas asas, dianteira e traseira, que são acopladas por um pivô na fuselagem, usando uma configuração em X. Essas asas são feitas com um filme fino. Nervuras flexíveis, são acopladas às asas na junção

\footnotetext{
${ }^{1}$ Desenvolvido por Robert C. Michelson, engenheiro pesquisador do Aerospace, Transportation and Advanced Systems Laboratory (ATAS-CCRF) do Georgia Tech Research Institute

${ }^{2}$ Desenvolvido pela University of Florida
} 


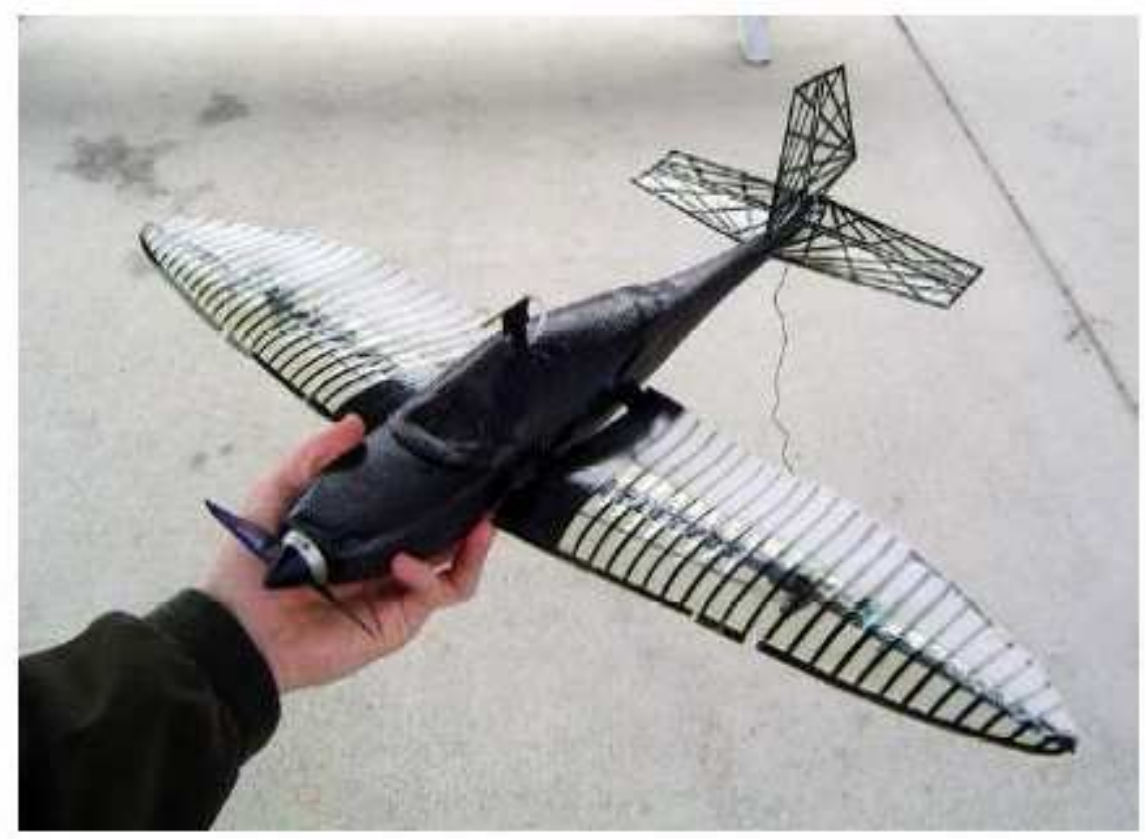

Figura 1.3: MAV - protótipo "morphingwing"

com a fuselagem, para dar-lhes as curvas necessárias para gerar a força de sustentação, tanto no movimento ascendente quanto no descendente; músculo químico recíproco (RCM) - um motor compacto ligado às asas para criar seu movimento; sensores - há sensores que permitem evitar obstáculos, para baixo e para os lados; câmera - uma câmera ou um sensor olfativo. Essa câmera ou sensor detectaria obstáculos ou rastrearia os odores até seu ponto de origem; mecanismo de direcionamento sobre superfícíes - auxiliará a navegação quando o MAV for usado para missões no solo; pernas/pés - também chamadas de locomotores de superfície, essas partes fornecem inércia contra rolamento e armazenamento auxiliar de combustível. Este modelo de MAV utiliza uma reação química como fonte de energia. Um fluido é injetado em uma câmara monopropulsora, causando uma reação química que libera um gás. A pressão criada por esse gás empurra um pistão na fuselagem, e esse pistão é ligado às asas duplas por um pivô, o que as faz bater rapidamente. Uma parte do gás é liberada por passagens na asa e pode ser usado para alterar a força de sustentação em qualquer uma das asas, permitindo que o veículo vire. Em um veículo com esse tamanho (de 10 a 20 cm), cada parte deve realizar várias tarefas. Por exemplo, uma antena de rádio ligada à parte traseira do veículo também pode 
funcionar como um estabilizador. As pernas poderiam armazenar combustível para realizar ajustes na distribuição do peso e no equilíbrio do veículo durante o voo.

Por quê usar um MAV? Porque os MAV's podem ser operados localmente para atender demandas imediatas, quer sejam de uma unidade de combate ou de uma unidade de pesquisa, reconhecimento e controle. Apesar das restrições de peso e volume, espera-se, com a tecnologia, desenvolver e integrar todos os elementos físicos e componentes necessários para sustentar esta nova modalidade de voo, o que requererá um nível sem precedentes de integração entre os componentes dos sistemas do MAV. O que se espera dos Micro Veículos Aéreos é que sejam capazes de uma gama extensiva de missões úteis em um raio de atuação em torno de $10 \mathrm{~km}$, que permaneça em voo por até uma hora, que alcance velocidades de 10 a $20 \mathrm{~m} / \mathrm{s}$ e que seja capaz de transmitir imagens ao vivo tanto durante o dia quanto durante a noite.

A integração física dos componentes de um MAV é um desafio, pois o problema fica mais difícil à medida que o tamanho do veículo decresce ou que aumenta a complexidade funcional. Espera-se que as dificuldades sejam superadas com o crescente desenvolvimento tecnológico nas áreas de sistemas microeletrônicos e da integração funcional dos diversos componentes físicos, como por exemplo as asas podem servir como antenas ou como sensores, a fonte de potência pode ser integrada com a estrutura de fuselagem, e assim por diante. No entanto, o controle de voo ainda é a área tecnológica que abriga o maior número de incertezas para o desenvolvimento de um MAV. Forças e momentos relativamente grandes podem ser produzidos pelo ambiente de voo e são difíceis de predizer mesmo sob condições de voo normais. Efeitos de instabilidade devido às correntes de ar que surgem das variações atmosféricas ou devido às manobras do veículo são mais pronunciados quanto menor for o MAV, pois a inércia é relativamente pequena. Uma tendência comum em animais alados é que os menores viajam mais lentamente e tendem a ter uma relação mais alta entre a área de asa e o seu peso. Dada a envergadura limitada disponível, um MAV tem que apresentar área de asa relativamente alta por meio de corda maior, isto é, usando configurações com baixo alongamento (envergadura dividida pela área projetada), tal como, por exemplo, a encontrada 
em borboletas, ver figura $1.4^{3}$. A rigor, os MAV's devem ser estudados com aerodinâmica tridimensional, mas devido à falta de dados disponíveis e custos computacionais, muitas vezes trabalha-se com modelos bidimensionais e consequentemente o modelo matemático fica menos adequado para representar o o modelo físico. Se o tamanho pequeno é um requisito essencial

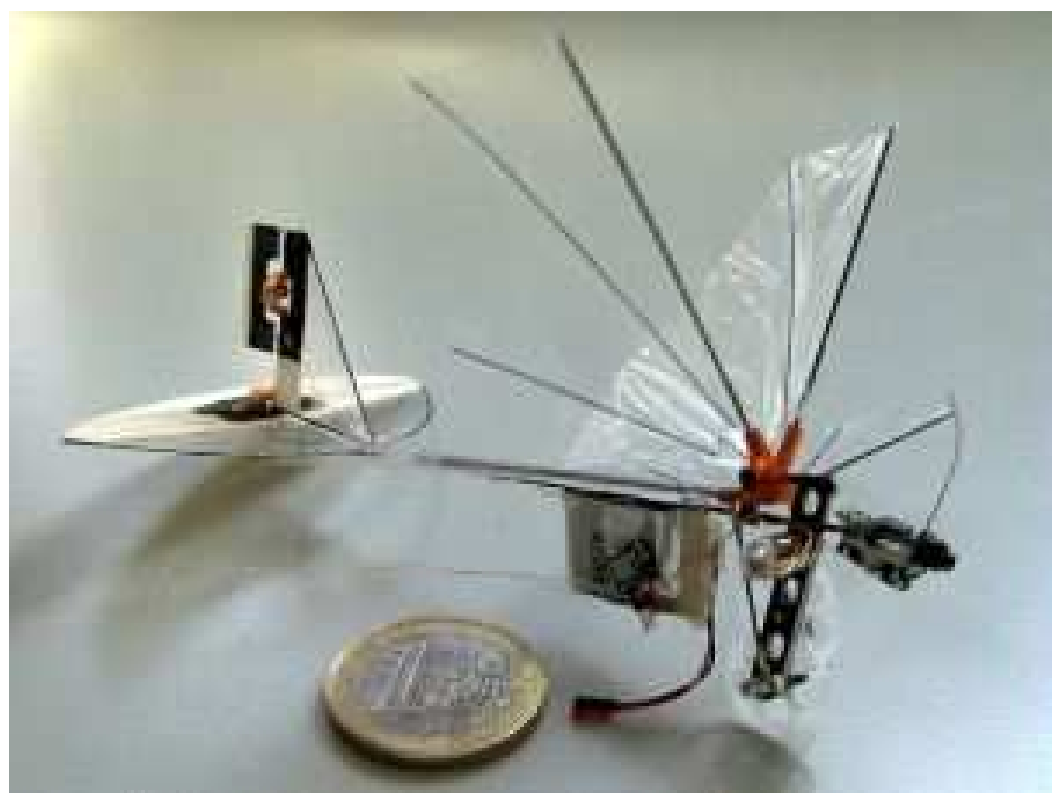

Figura 1.4: Protótipo do MAV DelFly

e foi conseguido pela tecnologia usada e pelas características de sua missão, os problemas aerodinâmicos resultantes devido aos distintos regimes de voo também são cruciais no projeto de um MAV. Pequenas varições no projeto de um MAV provocam variações significativas para fabricação do protótipo, além das falhas por trabalhar com escalas reduzidas. Desta forma, grande parte dos ajustes que teriam que ser feitos durante os testes em túnel de vento são corrigidos pelas simulações computacionais e pode-se otimizar o projeto com a adoção de soluções aerodinâmicas alternativas sem aumentos de custo significativos.

Alguns modelos aerodinâmicos analíticos foram apresentados, como os propostos por Liu e Kawachi (1998) e Zbikowski (2002), e na área de dinâmica de fluidos computacional temos simulações do fluxo da agitação de asas de insetos discutidos por Liu, Kawachi, Ellington, Berg e Willmott (1998) e Wang, Birch e Dickinson (2004), além de aplicações mais sofisticadas como as apresentadas por Maybury e Lehman (2004) e Miller e Peskin (2004). Estes experimentos

\footnotetext{
${ }^{3} \mathrm{O}$ projeto DelFly é conduzido pela Delft University of Technology
} 
melhoraram muito o entendimento dos mecanismos de produção de campos de força próximo da agitação das asas e consequentemente dos mecanismos aerodinâmicos associados. Assim, através da compreensão do fenômeno físico, pode-se melhorar os modelos aerodinâmicos para melhor eficiência dos já consagrados e propor novos modelos para se alcançar novas aplicações.

Neste trabalho procuraremos, através de modelagem computacional aeroelástica, capturar o comportamento, por meio de simulação bidimensional, de uma seção de asa em número de Reynolds equivalente ao de um MAV, comparável às condições de voo de um inseto grande. A aproximação consiste, basicamente, na resolução das equações de Navier-Stokes, pela formulação do método da fronteira virtual, da interação fluido-estrutura de um perfil aerodinâmico, com oscilações forçadas, imerso em um escoamento viscoso, sujeito a vários ângulos de ataque, principalmente nos dois graus de liberdade mais significativos para o fenômeno de flutter (elevação e rotação).

A modelagem computacional para resolução das equações de Navier-Stokes, pela formulação do método da fronteira virtual (interação fluido-estrutura) de um perfil aerodinâmico imerso em um escoamento viscoso, tem se mostrado bastante eficiente para aproximar fenômenos não estacionários, muitos deles relacionados com corpos imersos de geometria conhecida e já tratado em trabalhos tais como:

a) escoamento sobre um cilindro estacionário: Marques, Doricio, Bueno, Greco Júnior e Souza (2006), Silva, Silveira-Neto e Damasceno (2003), Peskin (2002) e Saiki e Biringen (1996);

b) escoamento sobre um cilindro com oscilação: Doricio, Marques e Greco Júnior (2007), Stewart, Leontini, Hourigan e Thompson (2005), Williamson e Govardhan (2004), H.M.Blackburn e Henderson (1999), Williamson e Roshko (1988), Lu e Dalton (1996) e Meneghini e Bearman (1995);

c) escoamento sobre um cilindro com rotação: Padrino e Joseph (2006), Mittal e Kumar (2003), Sung e Yoo (2003), Barnes (2000), Baek e Sung (1998); 
d) comportamento de um perfil NACA12 sujeito a oscilação forçada: Bueno, Doricio, Marques, de Paula, Catalano e Greco Júnior (2007).

Apesar dos resultados serem promissores, existem certas limitações e dificuldades na aplicação do método da fronteira virtual, que devem ser lembrados, quando da aplicação como ferramenta de apoio no projeto de um perfil aeronáutico:

- o modelo considerado neste trabalho é bidimensional e não tridimensional como seria esperado para a modelagem de uma asa de um inseto grande;

- o modelo pode apresentar problemas de estabilidade dependendo da escolha da função de distribuição do campo de força que substitui a estrutura no meio fluido;

- o problema envolve diferentes comprimentos de escala e isto torna difícil capturar certos efeitos relacionados a detalhes geométricos do perfil aeronáutico, por exemplo, a espessura do bordo de fuga;

- o cálculo computacional considera o número de Reynolds fixo durante a simulação, o que não acontece quando do voo de um inseto grande.

A primeira limitação é a mais restritiva, pois o fenômeno físico tem característica tridimensional. A restrição não é dada apenas pelo modelo, mas também pela disponibilidade de recursos computacionais (máquinas e softwares) que possam simular tais modelos. Nos últimos anos, vários pesquisadores que trabalham com os métodos de fronteiras imersas têm desenvolvido novas ferramentas e modelos tridimensionais, Grigoriadis, Bartzis e Goulas (2004), Gilmanov, Sotiropoulos e Balaras (2003), Lee e Leveque (2003), Fadlun, Verzicco, Orlandi e Mohd-Yusof (2000), e outros. A segunda limitação tem recebido bastante contribuições mas ainda é sensível à escolha dos parâmetros $\alpha_{v}$ e $\beta_{v}$ e devem ser adequadas para uma formulação implícita conveniente do método da fronteira virtual. As limitações terceira e quarta, na verdade, não são limitações do modelo, mas sim limitações relacionadas aos computadores em termos de velocidade e capacidade de operação de dados. No caso de um MAV que seja modelado a partir de um inseto grande, a espessura da asa do inseto é da ordem de $0,5 \mathrm{~mm}$ para uma envergadura 
de $15 \mathrm{~cm}$ e alta frequência de agitação. Neste caso seria necessária uma malha computacional muito fina para capturar o fenômeno próximo da asa.

Este trabalho foi motivado em encontrar uma solução aproximada do fenômeno com um "baixo custo" computacional através de uma formulação conveniente para o método da fronteira virtual de forma a contribuir para o projeto e manufatura de perfís aeronáuticos de MAV's.

\subsection{Objetivos}

Neste trabalho, o modelo do fenômeno de flutter está reduzido ao acoplamento dos modos de vibrar de flexão e de torção. Isto é razoável mesmo quando a análise envolve mais de dois graus de liberdade, pois, segundo Hancock, Wright e Simpson (1985), neste tipo de flutter os modos de vibrar mais representativos são os modos principais de flexão e torção. O modelo dinâmico-estrutural mais simples para representar um sistema aerolástico é a seção típica bidimensional de um perfil aerodinâmico, ou seja, um aerofólio com o movimento representado por dois graus de liberdade: rotação em torno do eixo elástico e flexão vertical, figura (1.5).

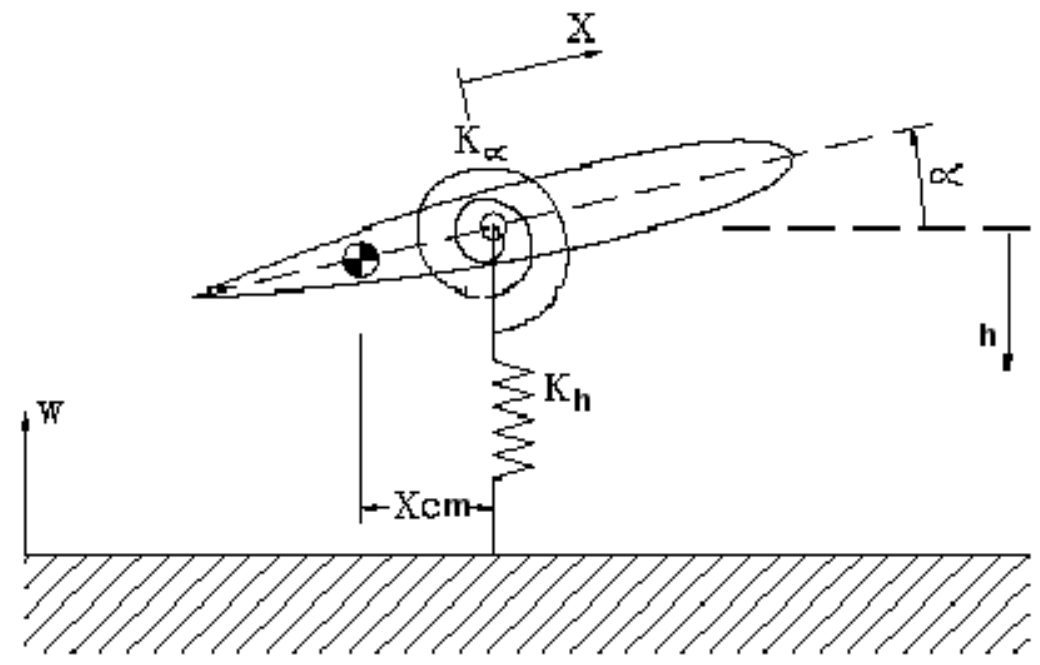

Figura 1.5: Modelo aerolástico com dois graus de liberdade

Nesse modelo, o aerofólio está apoiado em uma mola de constante elástica $K_{h}$ e sujeito a uma mola torcional de constante $K_{\alpha}$ distantes do centro de massa $X_{c m}$ e cuja ação da velocidade do escoamento gera um ângulo $\alpha$ com o eixo de referência $X$, vide Dowell, Jr., Scanlan e 
Sisto (1989, p.55). Quando a velocidade de escoamento do ar está abaixo da velocidade crítica para a ocorrência de flutter, cada um dos graus de liberdade do aerofólio apresenta respostas decrescentes, no tempo, às perturbações. Acima da velocidade crítica, a resposta passa a ser crescente e o movimento dos dois graus de liberdade ocorre em uma mesma frequência, resultante do acoplamento dos modos de vibrar de flexão e torção, vide Hancock, Wright e Simpson (1985) e Greco Júnior (1996).

Procuraremos qualificar e quantificar o fenômeno de flutter não para escoamentos compressíveis ( referência ao número de Mach), mas para escoamentos incompressíveis (referência ao número de Reynolds). Para aeronaves cujo tamanho real não exceda 0,20 metros o número de Reynolds é de ordem inferior a 2000.

O método da fronteira virtual resolve as equações de Navier-Stokes com um termo de força aplicado à fronteira imersa para um escoamento incompressível em fluido de massa específica constante e viscoso. O corpo (prisma de base quadrada ou cilíndrica e aerofólio) sofre movimento de translação e rotação procurando reproduzir os dois graus de liberdade. A integração das equações para o fluido é resolvida na malha computacional euleriana. Os pontos da fronteira são fixados ao longo do movimento através do fluido por meio de uma malha lagrangiana, figura (1.6). Em cada passo no tempo o método usa a configuração da fronteira, conhecida no início do passo no tempo e desconhecida no final do passo no tempo, para calcular as forças na fronteira. Estas forças são então aplicadas aos pontos da malha do fluido próximos da fronteira. Como o fluido é incompressível, há a distribuição dos efeitos da fronteira para o fluido por meio do campo de pressão e a velocidade do fluido é atualizada. A nova velocidade do fluido é usada para atuar sobre a fronteira em movimento no novo passo no tempo.

Este trabalho foi concebido para, através da aplicação do método da fronteira virtual, produzir uma simulação numérica computacional de problemas que apresentam interação entre um perfil aeronáutico não estacionário imerso (fronteira imersa) em um escoamento incompressível de um fluido viscoso. Considera-se a fronteira imersa com massa desprezível e infinitamente fina, mas capaz de exercer força ao fluido, o qual será matematicamente 


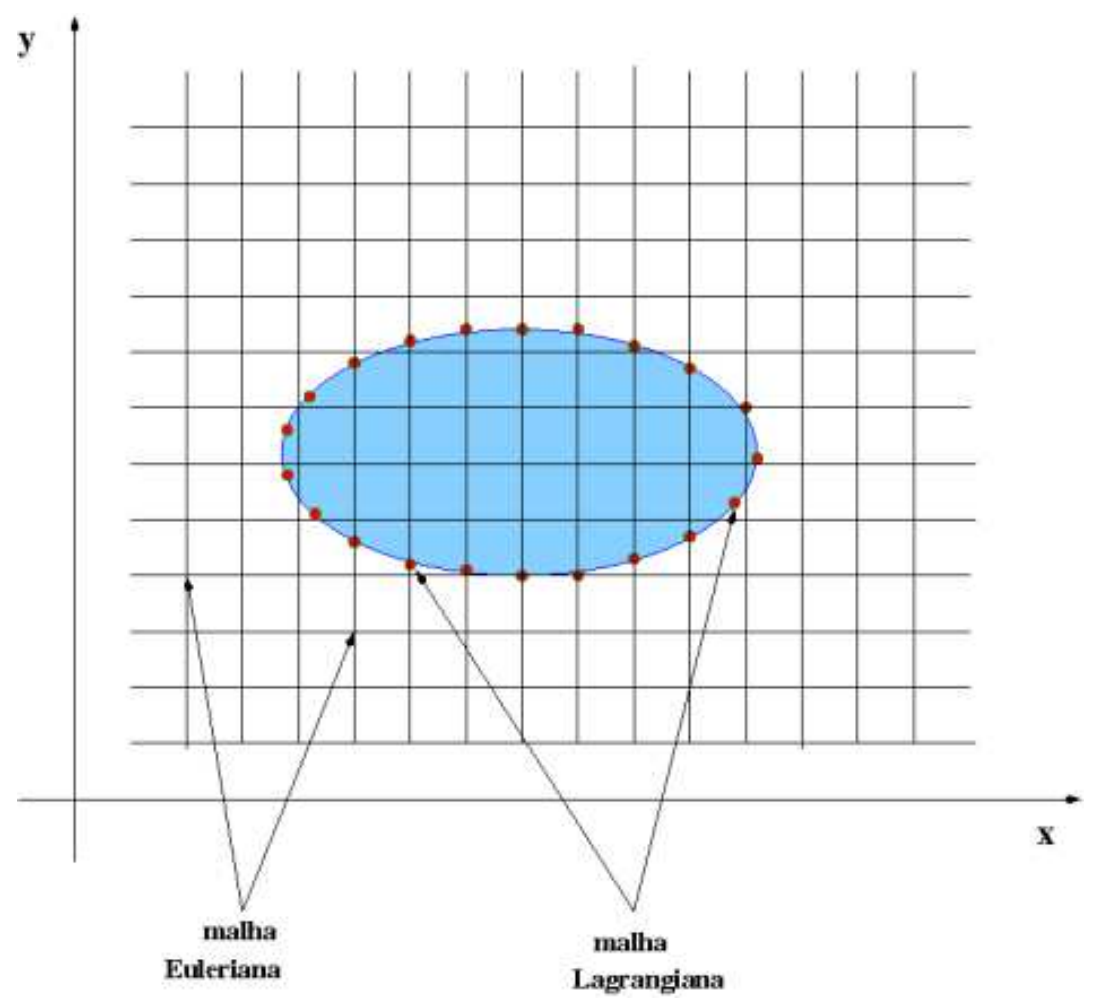

Figura 1.6: Representação das malhas euleriana e lagrangiana

modelado pelas equações de Navier-Stokes para o caso de escoamento não-estacionário e fluido incompressível. A força atua somente na região da fronteira e desvanece-se ao se afastar dela. Neste contexto, os objetivos principais deste trabalho são:

- implementar a resolução do método da fronteira virtual para um perfil aeronáutico que é forçado a se deslocar com dois graus de liberdade através da imposição de frequências de rotação e translação de forma a obter o comportamento do perfil sob condições de oscilação forçada.

- discutir a adoção dos parâmetros para o modelo: a função de interação entre o campo de força e o escoamento (função $\delta$ ); as características do domínio e de geração da malha computacional; e condições de estabilidade (CFL) para o modelo.

- obter as derivadas aerodinâmicas, a serem usadas para previsão do caso clássico de flutter, através da solução numérica das equações de Navier-Stokes, caso não-estacionário e incompressível. 


\subsection{Organização da tese}

A tese está dividida em sete partes, que estão descritas resumidamente nesta seção. A introdução aborda o problema conceitual de um MAV e os vários temas que compõem a solução do problema através de uma descrição sumária do modelo físico de um inseto grande e do modelo computacional para tratamento e modelagem matemática.

O primeiro capítulo apresenta a modelagem e formulação do problema para duas dimensões contendo o escoamento e a fronteira imersa no fluido e trata das aplicações aeroelásticas e do modelo simplificado do fenômeno de flutter.

O segundo capítulo apresenta o método, as técnicas e a formulação matemática, ou seja a aproximação numérica adotada para malha uniforme, as equações de movimento e as convenientes variações da malha computacional.

O terceiro capítulo apresenta e discute a verificação do método da fronteira virtual e do código computacional através do método da solução manufaturada.

O quarto capítulo discute a validação do método da fronteira virtual por meio de simulações e resultados da literatura, mais especificamente os casos do cilindro de seção quadrada imerso em um canal, cilindro de seção circular estacionário, cilindro de seção circular oscilante e perfil NACA0012 estacionário com vários ângulos de ataque.

O quinto capítulo apresenta e discute os resultados de simulação para o comportamento de um perfil aerodinâmico submetido à oscilação forçada, relevante para a compreensão do fenômeno de flutter.

Esta tese finaliza com conclusão, onde são discutidas possíveis extensões e considerações para o método da fronteira virtual além de potenciais aplicações para o estudo do fenômeno de flutter e outras aplicações. 


\subsection{Revisão da literatura}

O modelo matemático estabelecido para o escoamento incompressível de fluido newtoniano viscoso é o sistema de equações de Navier-Stokes,

$$
\begin{array}{r}
\delta_{t} \mathbf{u}-v \Delta \mathbf{u}+\mathbf{u} \cdot \Delta \mathbf{u}+\nabla \mathbf{p}=\mathbf{f}, \\
\nabla \cdot \mathbf{u}=0,
\end{array}
$$

em alguma região $\Omega \times(0, T)$ com apropriadas condições inicial e de fronteira. Trataremos de escoamento "laminar", ou seja, escoamentos com número de Reynolds na faixa de $R e \leq 2.300$ (em casos especiais Re até 40.000) com $R e \approx \overline{\mathbf{u}} \bar{l} / v$, para escoamentos sobre corpos imersos, estacionários e submetidos à oscilação forçada. A solução numérica do sistema envolve dificuldades típicas:

- escoamentos com estruturas complicadas $\Rightarrow$ malhas finas;

- $R e>>1 \Rightarrow$ malhas anisotrópicas e refinadas localmente nas camadas limites;

- dominância de efeitos não-lineares $\Rightarrow$ problemas de estabilidade;

- restrição $\nabla \cdot \mathbf{u}=\mathbf{0} \Rightarrow$ solução implícita; e

- quantidade sensível $\Rightarrow$ solução através de malha adaptativa.

A previsão exata do escoamento requer grande poder computacional, particularmente de $2 \mathrm{D}$ para 3D, de estacionário para não estacionário e de resultados qualitativos para resultados quantitativamente precisos. Os principais objetivos do desenvolvimento de ferramentas para simulação de escoamentos laminares são:

- rapidez - cálculos de escoamentos não estacionários em minutos ou horas;

- economia - simulações em wokstations;

- flexibilidade - "solver" de aplicação geral; e 
- precisão - controle adaptativo do erro.

Os métodos de solução para escoamentos com essas características são inúmeros, mas para simulações em variáveis primitivas u (campo de velocidades) e p (campo de pressão), os mais usados são "Método das Diferenças Finitas - MDF", "Método dos Volumes Finitos - MVF" e "Método dos Elementos Finitos - MEF" que possuem alta flexibilidade computacianal e rigorosa análise de erro matemático. De forma resumida as características desses métodos são:

\section{Método das Diferenças Finitas - MDF}

- aproximação das equações de Navier-Stokes por diferenças finitas;

- fácil implementação;

- problemas ao longo de superfícies complexas;

- difícil análise de estabilidade e convergência; e

- difícil adaptação de malha.

\section{Método dos Volumes Finitos - MDF}

- aproximação das equações de Navier-Stokes por um sistema de equações conservativas;

- pode ser aplicado a qualquer tipo de malha;

- boa adaptação à geometrias complexas; e

- dificuldade de desenvolvimento em 3D de métodos de ordem superior a 2;

\section{Método dos Elementos Finitos - MEF}

- as equações de Navier-Stokes são resolvidas na forma integral;

- baseado na conservação das "propriedades físicas";

- implementação é complexa porém genérica;

- não há problemas em se aplicar o MEF em domínios irregulares; e

- fácil refinamento nas regiões de interesse.

Os detalhes desta classificação superficial e são objeto de discussão muito controversa sobre os prós e os contras dos diferentes métodos e suas variantes. No entanto, este conflito é parcialmente resolvido, em muitos casos quando aplicados em malhas genéricas. O modelo mais utilizado hoje é o de volumes finitos. A solução dos modelos de escoamento tornam-se complicados à medida que se preocupam com problemas de aplicação prática, como no caso de escoamentos com presença de interfaces complexas. Nestes casos, malhas genéricas nem 
sempre são eficientes e as soluções compreendem modelos que agregam metodologias numéricas comprovadamente eficientes para a solução das equações diferenciais e uma formulação específica para solução do problema.

Corpos imersos representam uma ampla faixa de problemas práticos devido à sua complexidade e a interação entre os corpos e o fluido. Conforme Silva, Silveira-Neto e Damasceno (2003), os problemas não estacionários mais comuns envolvem vibração da estrutura imersa, a qual induz oscilação no escoamento e oscilação induz vibração na estrutura imersa, que é o mais conhecido problema de interação fluido-estrutura. Esta classe de problemas é difícil de analisar usando métodos clássicos devido à geometria complexa do corpo imerso e seu movimento dentro do fluido. A simulação direta de um escoamento líquido-sólido é difícil se o domínio ocupado pelo fluido é irregular e muda com o movimento das partículas. Mais ainda se as partículas sofrem advecção devido ao fluido e exercem força sobre o fluido de forma que a interação corpo-fluido requer o cálculo das forças de cisalhamento na interface fluido/corpo (derivadas do campo de escoamento).

O princípio geral dos métodos de fronteiras imersas é resolver a interação fluido/estrutura por meio das equações de velocidade do escoamento, dentro e fora das fronteiras, impondo que a velocidade do fluido e das partículas são igualadas pelas forças distribuídas ao longo da fronteira, ou ainda, as forças são distribuídas sobre a região ocupada pela fronteira (variações mais recentes dos métodos).

A maioria dos métodos de fronteiras imersas deriva ou do método da fronteira imersa, Peskin (1972), ou do método da fronteira virtual, Goldstein, Handler e Sirovich (1993). O trabalho pioneiro apresentado por Peskin (1972), resumidamente, é um método computacional para resolver as equações do movimento através das características do escoamento. Essa técnica consiste em substituir a geometria de interesse pelo seu efeito no escoamento. Em outras palavras, ao invés de se definir pontos de uma malha como sendo a superfície de um corpo para neles especificar condições de contorno para o método numérico, o método adiciona às equações que descrevem o escoamento termos de força correspondentes à presença do corpo. 
Desta forma, as únicas condições de contorno necessárias são especificadas longe da geometria de interesse (teoricamente no infinito). Beyer Júnior (1992) aplicou a técnica desenvolvida por Peskin para modelar o problema da cóclea (bidimensional) resolvendo as equações de Navier-Stokes na presença de fronteiras imersas e apresentou um estudo sobre o erro de translação para diversos tipos de funções delta suavizadas. Para analisar a eficiência do método desenvolvido por Peskin, Beyer Júnior e Leveque (1992) desenvolveram um método para solução de problemas de escoamentos incompressíveis em regiões irregulares e demonstraram que a precisão do método da fronteira imersa depende da escolha apropriada da função delta discreta.

Partindo do modelo de Peskin, Goldstein, Handler e Sirovich (1993) utilizaram a técnica de fronteiras imersas para modelar escoamentos incompressíveis viscosos sobre corpos de geometria fixa. Nesse trabalho, estudaram escoamentos ao redor de cilindros circulares bidimensionais e escoamentos turbulentos em canais tridimensionais para analisar fenômenos de rugosidade e turbulência. Essa técnica recebeu o nome de método da fronteira virtual e a força de superfície foi modelada através de um termo clássico de controle proporcional para impor a condição de não escorregamento na parede. O princípio do método da fronteira virtual reside então na aplicação de um campo de força ao fluido tal que a velocidade do fluido seja a mesma da fronteira imersa. Este é o modelo virtual clássico para condição de fronteira sem escorregamento (no-slip). Do escoamento sobre o corpo resulta uma força normal na superficíe do corpo (pressão) e também, devido à condição de não escorregamento, uma força de cisalhamento no fluido. Inversamente, a superfície exerce uma força na direção oposta à do escoamento. No caso de não-escorregamento, esta força localizada é que obriga o fluido a permanecer sobre a superfície imersa, isto é, o fluido é "visto" através da pressão e da força de cisalhamento que atuam sobre a fronteira imersa. Inicialmente o campo de pressão é desconhecido e deve ser calculado usando a velocidade na fronteira para determinar a distribuição de força com retroalimentação por meio de uma função de força adicionada às equações de momento. 
Os métodos de fronteiras imersas definem uma malha sobre a geometria de interesse caracterizando sua interface com o escoamento. Essa malha é chamada de lagrangiana e seus pontos são fixos à geometria e acompanham seus movimentos. Nos pontos desta malha calcula-se um termo de força que é contabilizado nas equações do escoamento e distribuído para outra malha. Esta outra malha é chamada de euleriana e seus pontos não acompanham a geometria nem as partículas do escoamento. Ela fixa o sistema de referência ou ainda o domínio computacional no caso da dinâmica de fluidos computacional. Essa malha é responsável por armazenar as propriedades do escoamento e servir de base para a solução das equações do escoamento. A relevância desta metodologia para tratamento de problemas não estacionários reside no fato de que basta evoluir a malha lagrangiana de uma maneira determinada a cada passo no tempo, o que representa muito pouco sob o aspecto de custo computacional em comparação com outras metodologias até então. As técnicas anteriormente utilizadas para abordagem desse tipo de problema envolvem a movimentação de malhas eulerianas e ao acréscimo do custo de geração de uma malha nova a cada passo no tempo. Desta forma, a diferença entre a velocidade do fluido na malha euleriana, interpolada para a localização de um ponto da malha lagrangiana, e a velocidade nesse ponto, considerando a movimentação do corpo rígido, será o sinal de erro. A força de superfície nesse ponto lagrangiano é calculada como sendo proporcional a esse sinal de erro e proporcional à integral desse sinal de erro no tempo.

Um dos mecanismos usados pelos métodos de fronteiras imersas para superar o problema de inserção do corpo no campo do escoamento é usar uma malha regular euleriana para a simulação do escoamento e uma malha lagrangiana acoplada para representar a fronteira imersa, onde a fronteira imersa exerce uma força singular sobre o fluido e pode se mover independentemente da malha euleriana. No trabalho de Fogelson e Peskin (1988), que trata de sedimentação de partículas deformáveis sujeitas à um escoamento stokesiano, cada partícula é representada por um conjunto de pontos lagrangianos dispostos sobre uma interface fluidopartícula. As equações de momento são resolvidas para todos os pontos da malha euleriana e os pontos que representam as partículas movem-se com a mesma velocidade local do fluido. Esta 
velocidade é perturbada pelo termo de densidade de força que é calculado sobre os pontos da malha lagrangiana e distribuídos sobre os pontos vizinhos da malha euleriana. A distribuição do campo de força tem modelo não-linear e efeitos viscosos entre o fluido e as interfaces sólidas. Conhecendo o campo de força euleriano, o domínio computacional pode ser visto sem a interface sólida.

O método da fronteira virtual representa a fronteira imersa usando pontos discretizados por uma malha lagrangiana nos quais a densidade de força é computada, baseada na posição da fronteira, e distribuída ao conjunto de pontos da malha cartesiana (euleriana), que representa a discretização do escoamento, por meio de uma função delta discreta proporcional à largura da malha. As equações de Navier-Stokes com o termo de força são avançadas no tempo na malha euleriana usando o método da projeção descrito por Harlow e Welch (1965). As velocidades são atualizadas ignorando-se os termos do gradiente de pressão da componente de transporte das equações de Navier-Stokes, em seguida aplica-se o método da projeção para calcular a pressão e impõe-se a condição de incompressibilidade no campo de velocidades. As velocidades resultantes são interpoladas para os pontos lagrangianos usando a mesma função delta. Os pontos são deslocados baseados no campo de velocidades e o processo se repete. Resumidamente, este método está baseado no cálculo do campo de força sobre uma seqüência de pontos lagrangianos, os quais representam a interface (fronteira). Neste modelo não há constantes "ad hoc" e não se necessita de um algoritmo especial para capturar os pontos próximos da fronteira.

Estes dois métodos (fronteira imersa e fronteira virtual) são praticamente os mesmos quando se emprega uma fronteira rígida com condição de não-escorregamento e estacionária. Quando a fronteira sofre deslocamentos ou deformações, o método da fronteira virtual sofre fortes restrições por causa da grande diminuição do passo no tempo devido à solução da enorme matriz de rigidez resultante da interação fluido/estrutura ou devido à condição de estabilidade que exige um número de $\mathrm{CFL}^{4}$ muito baixo (da ordem de $10^{-2}$ ), Lee (2003). Esta restrição

\footnotetext{
${ }^{4}$ Número de Courant-Friedrich-Levy. A condição CFL é uma condição de convergência das equações diferenciais parciais, não confundir com a estabilidade numérica. Como resultado desta condição, a passagem do tempo deve ser abaixo de um certo valor para garantir que a simulação não produza resultados incorretos.
} 
foi contornada por Fadlun, Verzicco, Orlandi e Mohd-Yusof (2000) que propuseram uma aproximação em que o campo de força que atua na fronteira imersa seja discretizado em uma malha independente da malha que representa o domínio do escoamento (malhas lagrangiana e euleriana) e, se a malha que contém os pontos da fronteira for disposta entre os pontos da malha do domínio computacional, o método não sofre restrições do passo no tempo. Desta forma, a velocidade no primeiro ponto, externo à interface, é calculada por uma interpolação linear da velocidade no segundo ponto e a velocidade na superfície do corpo. A força no primeiro ponto externo é calculada usando as equações de Navier-Stokes sem ajustes de constantes, mas este método requer um algorítmo especial para identificar os pontos da malha sobre os quais a força deve ser ajustada. Kim, Kim e Choi (2001) modificaram este método usando uma malha escalonada e adicionando uma fonte de massa e um momento de força que satisfaz a continuidade nas proximidades dos pontos de fronteira de forma a garantir não-escorregamento, no entanto depende fortemente da escolha dos pontos da fronteira onde a condição de nãoescorregamento é imposta e o esquema de interpolação usado.

Para escoamentos incompressíveis a baixo número de Reynolds, a escolha pelo uso do método da fronteira imersa ou do método da fronteira virtual está diretamente ligado às características de deformação da interface. No método da fronteira imersa os nós que compõem a interface imersa se comportam como ligados por molas que obedecem à lei de Hooke. Se a interface for rígida ou sofrer pequenas defomações, o método mais eficiente é o da fronteira virtual, pois o método da fronteira imersa necessitaria de uma constante de mola muito alta (a rigor $k \rightarrow \infty$ ) para que os nós que compõem a fronteira permanececem na posição especificada para uma superfície rígida. Se a interface sofrer grandes deformações, o método a ser aplicado é o da fronteira imersa, já que o modelo do método da fronteira virtual não prevê deformação entre os nós que compõem a estrutura. Então, para os casos de simulação de problemas que tratam de escoamentos sobre superfícies rígidas, o método da fronteira virtual torna-se mais atrativo à medida que podemos dispor das várias melhorias desenvolvidas para os algorítmos de fronteiras imersas com a simplificação da imposição do campo de força máximo para interpretação da fronteira imersa. 
A simulação de problemas em fluidodinâmica envolve, além do algorítmo para modelagem das equações governantes e interação fluido-estrutura, outras escolhas que também determinam a eficiência e eficácia da simulação tais como a geração da malha, as condições de contorno e estabilidade e convergência, dentre outros. Nos modelos para solução de equações diferenciais parciais a discretização do domínio computacional é um fator determinante e a escolha da malha está diretamente ligada à eficiência do método. Uma malha, quanto à sua forma de indexação, pode ser estruturada ou não estruturada. Tipicamente, malhas não estruturadas são mais facilmente adaptadas à geometrias complexas. Porém, a indexação indireta provoca um custo computacional mais elevado do que a indexação direta. Para que as malhas estruturadas sejam adaptadas a geometrias arbitrárias é necessário que as equações sejam escritas em coordenadas generalizadas ao invés de coordenadas cartesianas que é a apresentação usual. Isso porque é necessário que pelo menos uma das direções coordenadas acompanhe a geometria de interesse para a aplicação das condições de contorno. Normalmente essa geometria não é uma reta e fica impraticável o uso de coordenadas cartesianas. A transformação para coordenadas generalizadas implica em aumento do custo computacional, quando comparada ao uso de coordenadas cartesianas, devido à inclusão na formulação de termos de métrica e maior complexidade de geração de malhas. Embora esse custo não seja maior do que o associado ao uso de malhas não estruturadas, ele é maior do que o associado ao uso de malhas cartesianas.

Com o intuito de facilitar a implementação de malhas, Harlow e Welch (1965) desenvolveram o método MAC (marker and cell) para simular escoamentos internos e externos com superfícies livres com o emprego de partículas marcadoras para identificar a posição da superfície livre do fluido e difundiram o uso de malha deslocada para resolver dificuldades na discretização das equações de escoamentos incompressíveis. Esse método usa o método da projeção, proposto por Chorin (1968), computacionalmente eficiente para a solução de escoamento incompressível de fluido viscoso. A partir desse trabalho, Bell, Collela e Glaz (1989) desenvolveram um método de projeção de segunda ordem para as equações de Navier-Stokes, para escoamento incompressível, com um melhor acoplamento entre os passos convecçãodifusão e projeção obtendo uma discretização com precisão de segunda ordem. Viecelli (1969) 
e Viecelli (1971) propuseram extensões ao método MAC para tratar domínios com fronteiras curvas e móveis. Uma forma mais completa do método MAC foi proposta por Tomé e McKee (1994), método GENSMAC, que é uma extensão do método MAC para domínios gerais com superfície livre e que inclui método da projeção, ou dos passos fracionados, com malhas deslocadas para o acoplamento velocidade-pressão.

Guermond e Quartapelle (1997) abordam uma série de questões numéricas relacionadas à análise e implementação do método da projeção e seus derivados que podem ser classificados em três categorias: métodos de correção de pressão, métodos de correção de velocidade e os métodos de separação consistentes. Para cada classe de esquemas, resultados de convergência teórica e numérica disponíveis na literatura e alguns resultados essenciais podem ser encontrados em Almgren, Bell e Szymczak (1996).

Além dos problemas de geração de malha, a convergência e velocidade de convergência do método são fatores muito importantes. Varonos e Bergeles (1998) apresentaram um esquema upwind de ordem variável para discretização dos termos convectivos da equação de NavierStokes. O esquema é uma combinação dos esquemas $Q U I C K$ e $B S O U$ e tende a ser de segunda ordem, além disso é conservativo.

Alguns trabalhos aprofundaram características para aplicações dos métodos de fronteiras imersas e tornaram possíveis implementações mais robustas e eficientes. Alguns deles serviram de balizas para melhorias no código desenvolvido para as simulações neste trabalho:

1. Peskin e Printz (1993) introduziram uma metodologia para a construção de um operador de divergência dos coeficientes de diferenças finitas, a partir da escolha de um esquema de interpolação. O operador é baseado em diferenças centrais aplicado às equações de Navier-Stokes incompressível em conjunto com o método da fronteira imersa.

2. Mohd-Yusof (1998) desenvolveu um método de fronteira imersa para escoamentos em geometrias complexas. Utilizou diferenças finitas na formulação velocidade-vorticidade para simulação em um canal turbulento e analisou a convergência do método. 
3. Jung e Peskin (2001) examinaram escoamentos dirigidos por bombeamento sem válvulas através das equações de Navier-Stokes incompressível bidimensional na forma Euleriana e o método da fronteira imersa para representar as forças na estrutura.

4. Peskin (2002) apresentou um desenvolvimento matemático para o método da fronteira imersa. Peskin também apresentou postulados sobre a função delta discreta que conduz a uma versão única da mesma. O método de discretização temporal utilizado no trabalho é o método de Runge-Kutta de segunda ordem.

5. Lee e Leveque (2003) desenvolveram um método de fronteira imersa modificado para resolver o problema de precisão próximo à fronteira imersa com estudos sobre a precisão e a ordem de convergência do método numérico. Esse método foi implementado utilizando as equações de Navier-Stokes incompressível bidimensional através da técnica de volumes finitos com o método da projeção para impor a condição de incompressibilidade.

Outros trabalhos, como por exemplo Arthurs, Moore, Peskin, Pitman e Layton (1998), tratam de um modelo bidimensional para escoamento arterial e transporte de massa (resolveram as equações de Navier-Stokes incompressível com esquema upwind para os termos inerciais e com um método espectral para os termos viscosos); Bottino (1998) desenvolveu uma técnica numérica para modelar redes viscoelásticas passivas, tais como o citoesqueleto de actina das amebas, utilizando o método da fronteira imersa e equações de Navier-Stokes incompressível com a técnica de diferenças finitas.

Mais especificamente sobre o método da fronteira virtual, os trabalhos buscaram modelos a partir de superfícies complexas fixas. Para validação de resultados computacionais, um modelo muito usado em experimentos é o caso do cilindro estacionário imerso em um escoamento. Trabalhos experimentais, como os de Williamson (1980) e Williamson e Roshko (1988), mostram os efeitos da esteira de formação de vórtices e resultados para comparação da eficiência computacional. Computacionalmente, Saiki e Biringen (1996) aplicaram o método da fronteira virtual para a simulação numérica de escoamentos uniformes estacionários e móveis em cilindros utilizando um método de diferenças finitas de alta ordem para baixos 
números de Reynolds. Benevenutti e Silvestrini (2006) e Buarque, Schettini e Silvestrini (2005) trazem estudos da precisão computacional para o método da fronteira virtual quanto aos parâmetros $\alpha_{v}$ e $\beta_{v}$ e comportamento de velocidade e número de Strouhal. Silva, SilveiraNeto e Damasceno (2003) aplicaram o método da fronteira virtual para a simulação numérica de um escoamento uniforme sobre um cilindro com condição de não-escorregamento na interface fluido-estrutura e a discretização feita pelo método de diferenças finitas. Para prismas de base quadrada, Lindquist, Almeida, Mansur e Neto (2000) apresentam dados experimentais e Davis e Moore (1982) apresentam resultados de simulações computacionais para o número de Reynolds $R e=100$ que é tratado nesta tese.

Como extensões do problema do cilindro imerso, Sung e Yoo (2003) e Baek e Sung (1998) estudaram a formação de vórtices em regiões formadas por um cilindro oscilante com seção circular para baixos números de Reynolds. Este tipo de problema foi simulado para validar o método da fronteira virtual onde a superfície imersa sofre apenas rotação, um dos graus de liberdade a serem estudados no fenômeno de flutter a ser discutido na última parte desta tese.

A necessidade de captura dos fenômenos de dinâmica de fluidos em corpos imersos delgados, como por exemplo o bordo de fuga de um perfil de aerofólio, exige malhas mais refinadas e consequentemente maior tempo computacional. A partir dos trabalhos de Turkel (1986) e Manteuffel e White (1986), para o método de diferenças finitas, a aproximação por malha estruturada convencional é mais vantajosa que a escolha de malha conforme devido às dificuldades de transformação das equações governantes para coordenadas curvilíneas e problemas de instabilidade, convergência e precisão do processo numérico. Rojas, Casanova, Pino e Feria (2005) trata deste problema e apresenta uma alternativa de geração de malha não uniforme cartesiana e que foi implementada para as simulações onde o tempo computacional se torna crítico, como no caso de um perfil de aerofólio.

O presente código computacional usado para as simulações computacionais foi verificado a partir dos trabalhos de Roache (1998) que propõe o método da solução manufaturada, também usado no trabalho de Silva, Medeiros e Souza (2010). Dentro da área de aerodinâmica, Linnick 
e Fasel (2003) apresentaram um método de fronteira imersa de alta ordem para escoamentos bidimensionais incompressíveis utilizando as equações de Navier-Stokes na formulação função corrente-vorticidade, com esquema de Runge-Kutta de segunda e quarta ordem para integração no tempo e o esquema de diferenças finitas de quarta ordem para a discretização espacial, para simulação de atuadores. Nesta tese, foi usado o esquema de Runge-Kutta de quarta ordem para integração temporal.

Próximo da área de microaeronaves, Miller e Peskin (2004) apresentaram um estudo numérico para simulação de voo de insetos para número de Reynolds entre 8 e 128 utilizando o método da fronteira imersa. Meûlen (2006) apresenta um realatório crítico sobre o medelo de fronteiras imersas e perspectivas para a aplicação do modelo em aerodinâmica para um perfil de aerofólio com multi-elementos. Para o estudo de aplicação de perfis mais adequados ao uso em MAV's, Anderson, Streitlien, Barret e Triantafyllou (1998) apresenta um estudo em que os movimentos de aerofólios têm combinados arfagem e mergulho. Este estudo realizou uma ampla gama de variação de parâmetros, incluindo o número de Strouhal, amplitudes de mergulho, e ângulo de fase entre os movimentos de arfagem e mergulho, a fim de encontrar a maior eficiência para a propulsão de microaeronaves. Além disso, faz considerações para os principais mecanismos que regem a dinâmica de aerofólios para auxiliar a busca parâmetros ótimos. O estudo também apresentou uma série de visualizações do escoamento com a finalidade de vincular os fenômenos ao coeficiente de empuxo e à formação da esteira de vórtices de von Kármán. Dentro dessa procura por parâmetros ótimos, o perfil de aerofólio NACA0012 é uma escolha popular, pois essa classe de aerofólios é mais convencional e foi desenvolvida para utilização em aeronaves de asa fixa convencional. No entanto, com um problema tão pouco convencional (MAV's), busca-se na natureza novamente a inspiração sobre como construir essas asas de MAV's com movimento. Neste aspecto, a análise de estruturas de voo com oscilação harmônica é uma primeira aproximação para fenômeno tão complexo como o voo de pássaros e borboletas.

O escoamento instável sobre as asas de pequena dimensão tem-se tornado importante recentemente, tanto para o estudo de aves e voo de insetos, bem como para desenvolver 
modelos avançados em aerodinâmica de MAV's. As escalas envolvidas em rajadas e manobras ágeis fazem as pequenas asas suscetíveis a separação laminar, que pode reforçar ou destruir a sustentação, dependendo da manobra. Por exemplo, alguns insetos e pássaros usam a forma e o movimento de suas asas para manter a alta sustentação. Os ganhos potenciais de desempenho observado nesse tipo de locomoção é um problema interessante de controle para modelos na área de MAV's. Nesse aspecto, o fenômeno de flutter tem relevância. Para análise do fenômeno de flutter, as bases propostas por Dowell, Jr., Scanlan e Sisto (1989) e Bisplinghoff, Ashley e Halfman (1955) foram atualizadas e implementações computacionais como Peiró, Galvanetto e Chantharasenawong (2010), Dietz, Schewe e Mai (2004) e Rostami, Saghafian1, Sedaghat e Miansari (2010) tratam do tema considerando os movimentos oscilatórios forçados de elevação e arfagem, independentemente, e extraindo as propriedades de fluter através de autovalores. 


\section{Formulação matemática}

As equações de Navier-Stokes são um conjunto de equações que descrevem o movimento das substâncias fluidas tais como líquidos e gases. Estas equações estabelecem que mudanças na quantidade de movimento e aceleração de uma partícula fluida são simplesmente o produto das mudanças na pressão e forças viscosas dissipativas atuando dentro do fluido, originadas na interação molecular. São aplicadas para descrever e modelar a física de um grande número de fenômenos tais como o clima, corrente oceânicas, escoamentos da água em canais, movimentos das estrelas dentro da galáxia, escoamento ao redor de aerofólios, propagação de fumaça em incêndios, etc. As equações de Navier-Stokes consideram que o fluido é um meio contínuo (continuum).

As equações de Navier-Stokes fundamentam-se em três princípios: conservação da massa, conservação da quantidade de movimento e conservação da energia ${ }^{1}$. Quando tratamos de escoamentos isotérmicos, como é o caso neste trabalho, o termo da variação de energia é desconsiderado e as equações de Navier-Stokes para escoamento incompressível, transiente, bidimensional, para um fluido de massa específica, $\rho$, constante, são apresentadas na formulação velocidade-pressão como:

$$
\begin{gathered}
\frac{\partial u}{\partial t}+u \frac{\partial u}{\partial x}+v \frac{\partial u}{\partial y}=-\frac{1}{\rho} \frac{\partial p}{\partial x}+v\left(\frac{\partial^{2} u}{\partial x^{2}}+\frac{\partial^{2} u}{\partial y^{2}}\right) \\
\frac{\partial v}{\partial t}+u \frac{\partial v}{\partial x}+v \frac{\partial v}{\partial y}=-\frac{1}{\rho} \frac{\partial p}{\partial y}+v\left(\frac{\partial^{2} v}{\partial x^{2}}+\frac{\partial^{2} v}{\partial y^{2}}\right) \\
\frac{\partial u}{\partial x}+\frac{\partial v}{\partial y}=0
\end{gathered}
$$

\footnotetext{
${ }^{1}$ Detalhes de como, a partir desses três princípios, obter as equações que modelam um escoamento podem ser obtidos em Fortuna (2000) e Anderson (1995)
} 
No caso do escoamento com uma fronteira imersa, há a adição de um termo forçante para a modelagem da interação fluido-estrutura e as equações governantes passam a ter a seguinte forma:

$$
\begin{gathered}
\frac{\partial u}{\partial t}+u \frac{\partial u}{\partial x}+v \frac{\partial u}{\partial y}=-\frac{1}{\rho} \frac{\partial p}{\partial x}+v\left(\frac{\partial^{2} u}{\partial x^{2}}+\frac{\partial^{2} u}{\partial y^{2}}\right)+f_{x} \\
\frac{\partial v}{\partial t}+u \frac{\partial v}{\partial x}+v \frac{\partial v}{\partial y}=-\frac{1}{\rho} \frac{\partial p}{\partial y}+v\left(\frac{\partial^{2} v}{\partial x^{2}}+\frac{\partial^{2} v}{\partial y^{2}}\right)+f_{y} \\
\frac{\partial u}{\partial x}+\frac{\partial v}{\partial y}=0
\end{gathered}
$$

e em termos vetoriais,

$$
\begin{aligned}
& \frac{\partial \vec{u}}{\partial t}+(\vec{u} \cdot \nabla) \vec{u}=-\nabla p+\frac{1}{R e} \nabla^{2} \vec{u}+\vec{f}, \\
& \nabla \cdot \vec{u}=0
\end{aligned}
$$

\subsection{Adimensionalização}

A adimensionalização das equações é feita considerando-se duas dimensões características do problema: $u_{\infty}$ e $L_{\infty}$ que são a velocidade característica (por exemplo a velocidade de escoamento livre) e o comprimento característico (como por exemplo o diâmetro do cilindro ou o comprimento da corda de um aerofólio imersos em um escoamento). As variáveis adimensionalizadas são:

$$
\begin{gathered}
u^{*}=\frac{u}{u_{\infty}}, v^{*}=\frac{v}{u_{\infty}} \\
x^{*}=\frac{x}{L_{\infty}}, y^{*}=\frac{y}{L_{\infty}} \\
t^{*}=\frac{t}{\frac{L_{\infty}}{u_{\infty}}}=\frac{u_{\infty} t}{L_{\infty}} \\
p^{*}=\frac{p}{\rho u_{\infty}^{2}}
\end{gathered}
$$




\subsection{Coeficientes usados para análise}

O nosso principal interesse é analisar, através do campo de velocidades, a interação entre fluido-estrutura, o que é normalmente mostrado através do $C_{D}$, coeficiente de arrasto; do $C_{L}$, coeficiente de sustentação; $C_{P}$, coeficiente de pressão; $C_{N}$, coeficiente de força normal; e $S_{t}$, número de Strouhal, que estão relacionados às características do escoamento, normalmente caracterizado pelo número de Reynolds ou número de Mach.

-Número de Reynolds - O número de Reynolds, Re, para escoamento foi definido como

$$
R e=\frac{\rho \mathbf{u}_{\infty} L_{\infty}}{\mu},
$$

onde $v$ é o coeficiente de viscosidade do fluido.

- Coeficiente de arrasto - O coeficiente de arrasto é definido como

$$
C_{D}=\frac{F_{D}}{\frac{1}{2} \rho \mathbf{u}_{\infty}^{2} L_{\infty}},
$$

onde $F_{D}$ é a força de arrasto. A força de arrasto de corpo submerso em um escoamento advém de duas fontes: da distribuição de pressão ao longo do corpo e das tensões de cisalhamento provocadas pela interação fluido-estrutura. Podemos determinar a força de arrasto por, pelo menos, três formas:

(1) Através da componente na direção $x$ da força aplicada pela superfície ao fluido. Pela terceira lei do movimento de Newton,

$$
F_{D}=-\int_{\Omega} \mathbf{f}_{1} d \mathbf{x}=-\int_{0}^{L_{b}} \mathbf{F}_{1} d s
$$

onde $\mathbf{f}_{1}$ e $\mathbf{F}_{1}$ são as componentes na direção $x$ das tensões $\mathbf{f}$ e $\mathbf{F}$, respectivamente.

(2) No método numérico, antes de cada passo no tempo, atualiza-se o campo de velocidade no domínio $\Omega_{B}$ de forma que $\mathbf{u}_{x \rightarrow \infty} \rightarrow=u_{\infty}$. Assim, a componente do momento na direção $x$ pode ser calculada como

$$
\Delta M=\int_{\Omega_{B}} \rho\left(\mathbf{u}_{\infty}-\mathbf{u}_{1}\right) d \mathbf{x},
$$


então, variando o momento, a força de arrasto pode ser calculada por

$$
F_{D}=\frac{\Delta M}{\Delta t}
$$

onde $\Delta t$ é o passo no tempo, dado pela escala de tempo adimensional

$$
T=\frac{\mathbf{u}_{\infty} t}{1 / 2 L_{\infty}}
$$

(3) A forma integral da componente das equações do momento na direção $x$ em um fluido no domínio $\Omega_{0}$ pode ser descrita como

$$
\frac{\partial}{\partial t} \int_{\Omega_{0}} \rho u_{1} d \mathbf{x}+\int_{\partial \Omega_{0}} \rho u_{1} \mathbf{n} \cdot \mathbf{n} d s=-\int_{\Omega_{0}} p n_{1} d \mathbf{x}+\int_{\partial \Omega_{0}} \mu\left(\frac{\partial u_{1}}{\partial x_{j}}+\frac{\partial u_{j}}{\partial x_{1}}\right) n_{j} d s+\int_{\Omega_{0}} p f_{1} d \mathbf{x}
$$

que para o caso estacionário fica

$$
\int_{\partial \Omega_{0}} \rho u_{1} \mathbf{n} \cdot \mathbf{n} d s=-\int_{\Omega_{0}} p n_{1} d \mathbf{x}+\int_{\partial \Omega_{0}} \mu\left(\frac{\partial u_{1}}{\partial x_{j}}+\frac{\partial u_{j}}{\partial x_{1}}\right) n_{j} d s+\int_{\Omega_{0}} p f_{1} d \mathbf{x}
$$

então a força de arrasto será dada por

$$
F_{D}=-\int_{\Omega_{0}} p f_{1} d \mathbf{x}=\int_{\partial \Omega_{0}} \rho u_{1} \mathbf{n} \cdot \mathbf{n} d s-\int_{\Omega_{0}} p n_{1} d s+\int_{\partial \Omega_{0}} \mu\left(\frac{\partial u_{1}}{\partial x_{j}}+\frac{\partial u_{j}}{\partial x_{1}}\right) n_{j} d s,
$$

tomando qualquer domínio $\Omega_{0}$ que contenha o corpo e basta calcular a integral de linha sobre a superfície.

-Coeficiente de sustentação - O coeficiente de sustentação, $C_{L}$, é definido como

$$
C_{L}=\frac{F_{L}}{\frac{1}{2} \rho \mathbf{u}_{\infty}^{2} L_{\infty}}
$$

onde $F_{L}$ é a força de sustentação que é calculada usando a componente $y$ da densidade de força euleriana ou a força lagrangiana como

$$
F_{L}=-\int_{0}^{L_{b}} \mathbf{f}_{2} d \mathbf{y}=-\int_{\Omega} \mathbf{F}_{2} d s
$$

onde $\mathbf{f}_{2}$ e $\mathbf{F}_{2}$ são as componentes na direção $y$ das densidades de força $\mathbf{f}$ e $\mathbf{F}$, respectivamente. 
•coeficiente de pressão - a distribuição de pressões sobre a superfície do "corpo imerso" pode ser expressa através de um parâmetro identificado como Coeficiente de Pressão $\left(C_{p}\right)$ dado pela expressão:

$$
C_{p}=\frac{p-p_{\infty}}{\frac{1}{2} \rho U_{\infty}^{2}}
$$

onde $p$ é a pressão em cada ponto da fronteira imersa, $p_{\infty}$ é a pressão do escoamento livre, $\rho$ é a massa específica e $U_{\infty}$ é a velocidade de escoamento livre. Vale lembrar que $C_{p}=1$ no ponto de estagnação.

De acordo com o objetivo desejado, também pode-se determinar:

- coeficiente de força normal -O coeficiente de força normal é definido como

$$
C_{N}=\frac{F_{N}}{\frac{1}{2} \rho \mathbf{u}_{\infty}^{2} L_{\infty}},
$$

onde $F_{N}$ é a força normal. A força normal atuante em corpo submerso em um escoamento é a componente normal da resultante de força aerodinâmica atuante no corpo perpendicular à corda do aerofólio (ANDERSON, 1985) e advém de duas fontes: da distribuição de pressão ao longo do corpo e das tensões de cisalhamento provocadas pela interação fluido-estrutura.

-Número de Strouhal - é um número adimensional que relaciona as oscilações de um escoamento com a sua velocidade média. O número de Strouhal $S t$ mede a frequência de formação dos vórtices de von Kármánn na esteira do corpo quando o escoamento passa de estável para instável e o corpo começa a produzir vórtices:

$$
S t=\frac{f_{s} L_{\infty}}{u_{\infty}}
$$

onde $f_{s}$ é a frequência natural de oscilação para o corpo estacionário.

\subsection{Aspectos gerais da formulação do método da fronteira virtual}

Seja $u_{\infty}$ a velocidade de escoamento livre de um escoamento, distante de um corpo, ao longo de uma linha de corrente. Considere também um ponto arbitrário I no domínio físico, 
onde $p, T, \rho$ e u são a pressão local, a temperatura local, a massa específica local e a velocidade local nesse ponto. Todas essas variáveis são propriedades do ponto $I$ e variam de ponto a ponto no domínio físico. Considere um escoamento incompressível de fluido homogêneo, viscoso e caloricamente perfeito em um domínio retangular bidimensional $\Omega$ contendo uma fronteira imersa na forma de uma curva fechada simples $\Gamma$ (LAI; PESKIN, 2000). Matematicamente, esta curva tem massa e superfície desprezíveis, como uma "fatia" muito fina do corpo imerso, de forma a se comportar, apenas como um gerador de força no sistema fluido-estrutura. Esta consideração é possível ao fazermos uma distinção entre as partes de fluido e as partes da estrutura, onde, nesta última, são aplicadas as forças adicionais que, para o caso de escoamento viscoso, o campo de velocidades $\mathbf{u}$ satisfaça $\nabla \cdot \mathbf{u}=0$. A configuração desta curva pode ser representada na forma paramétrica como $\mathbf{X}(s, t), 0 \leq s \leq L_{b}, \mathbf{X}(0, t)=\mathbf{X}\left(L_{b}, t\right)$, onde $s$ é um ponto na superfície da fronteira imersa. Letras maiúsculas são usadas para representar o vetor de variáveis na malha lagrangiana. Matematicamente as equações governantes são dadas por:

$$
\begin{gathered}
\rho\left(\frac{\partial \mathbf{u}}{\partial t}+\mathbf{u} \cdot \nabla \mathbf{u}\right)+\nabla p=\mu \Delta \mathbf{u}+\mathbf{f}, \\
\nabla \cdot \mathbf{u}=0, \\
\mathbf{f}(\mathbf{x}, t)=\int_{0}^{L_{b}} \mathbf{F}(s, t) \delta^{2}(\mathbf{x}-\mathbf{X}(s, t)) d s, \\
0 \approx \frac{\partial \mathbf{X}(s, t)}{\partial t}=\mathbf{u}(\mathbf{X}(s, t), t)=\int_{\Omega} \mathbf{u}(\mathbf{x}, t) \delta(\mathbf{x}-\mathbf{X}(s, t)) d \mathbf{x}, \\
\mathbf{u}(\mathbf{x}, t) \rightarrow \mathbf{u}_{\infty} \operatorname{com}|x| \rightarrow \infty
\end{gathered}
$$

As equações (2.26) e (2.27) são as equações de Navier-Stokes para o escoamento incompressível de um fluido viscoso com densidade de massa constante. Nas equações (2.26) a (2.30), $\rho$ é a constante de densidade do fluido; $\mu$ é a constante de viscosidade do fluido; $\mathbf{u}(\mathbf{x}, t)=(u(\mathbf{x}, t), v(\mathbf{x}, t))$ é o campo de velocidade do fluido; $p(\mathbf{x}, t)$ é o campo de pressão hidrodinâmica; $\mathbf{x}=(x, y)$ é o vetor posição e $\mathbf{f}(\mathbf{x}, t)=\left(f_{1}(\mathbf{x}, t), f_{2}(\mathbf{x}, t)\right)$ é a força que atua no fluido (com relação a $d \mathbf{x}=d x d y$ - variáveis no domínio euleriano). $\mathbf{X}(s, t)$ são os pontos sobre a fronteira imersa e $\mathbf{F}(s, t)=\left(F_{1}(s, t), F_{2}(s, t)\right)$ é a força exercida na fronteira imersa (com relação a $d s$ - variáveis no domínio lagrangiano). A força $\mathbf{F}(s, t)$ na fronteira deve ter magnitude tal que 
a velocidade $\mathbf{u}(\mathbf{x}, t)$ na fronteira satisfaça a condição de não-escorregamento e pode ser expressa como

$$
\begin{gathered}
\mathbf{F}\left(\mathbf{X}(s, t)=\alpha_{v} \int_{0}^{t}\left(\mathbf { U } \left(\mathbf{X}(s, t)-\mathbf{V}(\mathbf{X}(s, t)) d t+\beta_{v}(\mathbf{U}(\mathbf{X}(s, t)-\mathbf{V}(\mathbf{X}(s, t))\right.\right.\right. \\
\mathbf{f}(\mathbf{x}, t)=\int_{\Omega} \mathbf{F}\left(\mathbf{X}(s, t) \delta^{2}(\mathbf{x}-\mathbf{X}(s, t) d \mathbf{x},\right.
\end{gathered}
$$

onde $\mathbf{U}$ e $\mathbf{V}$ são assim representados para conexão com o método de Runge-Kutta de ordem 4 a ser mostrado em (3.1.1). As constantes $\alpha_{v}$ e $\beta_{v}$ serão escolhidas com magnitude suficientemente grande de forma a ajustar a velocidade do fluido e a velocidade próxima da interface de forma a se obter o comportamento físico esperado do escoamento. $\delta^{2}\left(\mathbf{x}-\mathbf{x}_{\mathbf{S}}\right)$ é uma função delta de Dirac (que será vista em 3.2), $\mathbf{X}(s)$ são os pontos lagrangianos dispostos sobre a fronteira imersa, $\mathbf{F}(\mathbf{X}(s), t)$ é a densidade de força lagrangiana (a qual é diferente de zero somente nos pontos da fronteira imersa) e f(x,t) é a força euleriana. As equações (2.28) e (2.29) descrevem a interação entre o fluido e a fronteira imersa, através da função delta de Dirac - $\delta$, da malha euleriana do domínio do escoamento para a malha lagrangiana da fronteira imersa, $\delta(\mathbf{x}-\mathbf{X}(s, t)) d s$ e, analogamente, da fronteira para o fluido, $\delta(\mathbf{x}-\mathbf{X}(s, t)) d \mathbf{x}$. A função Delta de Dirac em ambas as equações é um funcional composto por duas outras funções delta, $\delta(\mathbf{x})=\delta(x) \delta(y)$. A equação (2.28) representa a força aplicada ao fluido pela fronteira imersa, enquanto a equação (2.29) representa o movimento da fronteira imersa como uma reação ao escoamento.

\subsection{Modelagem}

O princípio do método da fronteira virtual consiste na aplicação de um campo de força ao fluido de modo a representar o corpo imerso como uma fronteira imersa, com a mesma forma e velocidade. Este é o modelo clássico do método da fronteira virtual para condição de fronteira não escorregadia. O método da fronteira virtual, (SAIKI; BIRINGEN, 1996), designa uma classe de métodos de contorno onde os cálculos são efetuados em uma malha cartesiana que não se adapta à forma do "corpo virtual” que serve como obstáculo ao escoamento. As condições de contorno na superfície do corpo não são impostas diretamente. Ao invés disso, um termo extra, chamado de termo forçante, é adicionado às equações governantes. O comportamento de 
escoamentos incompressíveis pode ser descrito através das equações de Navier-Stokes, as quais passam por um processo de acoplamento dos campos de pressão e de velocidade de modo a solucioná-las adequadamente

O modelo de método da fronteira virtual apresentado neste trabalho usa diferenças finitas nas malhas euleriana e lagrangiana para a interação entre o fluido e a estrutura. Duas malhas distintas são necessárias para discretizar: uma malha bidimensional para representar o escoamento e uma malha de pontos para representar a fronteira imersa. Seja $\Omega=[0, L] \times[0, L]$ o domínio do escoamento. As variáveis do fluido são definidas na malha euleriana $N \times N$ com $\mathbf{x}=\left(x_{i}, y_{j}\right)=(i h, j h)$ for $i, j=0,1, \ldots, N-1$, onde $h=\Delta x=\Delta y=\frac{L}{N}$ é o comprimento de cada intervalo da malha. Por outro lado, usa-se o conjunto de $M$ pontos lagrangianos $\mathbf{X}=\left(X_{k}, Y_{k}\right)$ com $k=0,1, \ldots, M-1$ para discretizar a fronteira imersa, com espaçamento inicial entre os pontos $\Delta s=\frac{L_{b}}{M}$, onde $L_{b}$ é a curva de comprimento $\Gamma$. A força exercida na fronteira é definida nestes pontos. É importante observar que os pontos na malha euleriana, que representam o fluido, são fixos, enquanto os pontos da malha lagrangiana, que representam a fronteira imersa, podem ser móveis. Usou-se um esquema explícito, onde a força exercida na fronteira é calculada no início de cada passo no tempo, com $n+1=t_{n}+\Delta t$ (LAI; PESKIN, 2000) e a solução numérica é dada por:

1. O campo de força é calculado nos pontos lagrangianos com as condições iniciais. A força $\mathbf{F}^{n}(s)$ é calculada usando $\mathbf{X}^{n}(s)$ na fronteira imersa e depois a força $\mathbf{F}^{n}(s)$ é usada no campo de força do fluido para determinar $\mathbf{f}^{n}(\mathbf{x})$, usando as seguintes equações:

$$
\begin{gathered}
\mathbf{F}^{n}(s)=\mathbf{S}^{n}\left(\mathbf{X}^{n}\right), \\
\mathbf{f}^{n}(\mathbf{x})=\sum_{s} \mathbf{F}^{n}(s) \delta_{h}^{2}\left(\mathbf{x}-\mathbf{X}^{n}(s)\right) \Delta s,
\end{gathered}
$$

onde a função delta discretizada é dada por:

$$
\delta_{h}^{2}(\mathbf{x})=\delta_{h}(x) \delta_{h}(y)
$$

em que a função $\delta$ será analisada no próximo capítulo (3.2). 
2. As equações de Navier-Stokes, definidas por (2.26) e (2.27) com o termo forçante $\mathbf{f}^{n}(\mathbf{x})$ para atualizar o campo de velocidades $\mathbf{u}^{n+1}(\mathbf{x})$, é resolvido por um método de RungeKutta de integração no tempo de quarta ordem de precisão.

As variáveis espaciais (acoplamento de pressão e velocidade) são resolvidas usando o método da projeção descrito por Harlow e Welch (1965) e modificado por Bell, Collela e Glaz (1989) e Almgren, Bell e Szymczak (1996), onde as derivadas convectivas são resolvidas usando o esquema de alta ordem (“up-wind”) VONOS, descrito por Varonos e Bergeles (1998).

3. A velocidade $\mathbf{u}^{n+1}$ é interpolada nos pontos da fronteira imersa e a função de feedback é atualizada usando:

$$
\begin{aligned}
& \mathbf{U}^{n+1}(s)=\sum_{\mathbf{x}} \mathbf{u}^{n+1}(\mathbf{x}) \delta_{h}^{2}\left(\mathbf{x}-\mathbf{X}^{n}(s)\right) h^{2}, \\
& \mathbf{F}\left(\mathbf{X}(s, t)=\alpha_{v} \int_{0}^{t}\left(\mathbf { U } ^ { \mathbf { n } + \mathbf { 1 } } \left(\mathbf{X}(s, t)-\mathbf{V}^{\mathbf{n}+\mathbf{1}}(\mathbf{X}(s, t)) d t+\beta_{v}\left(\mathbf { U } ^ { \mathbf { n } + \mathbf { 1 } } \left(\mathbf{X}(s, t)-\mathbf{V}^{\mathbf{n}+\mathbf{1}}(\mathbf{X}(s, t)),\right.\right.\right.\right.\right.
\end{aligned}
$$

onde $\delta_{h}^{2}$ é a função discreta, definida em (2.35) e (3.30). Na (3.18), $\mathbf{X}^{n+1}(s)$ foi calculada usando o método de diferenças finitas centradas de segunda ordem.

De forma resumida, a solução numérica das equações governantes é dada por:

1. Calcular o campo de força $\mathbf{F}(\mathbf{X}(s), t)$, sobre os pontos lagrangianos $\mathbf{X}(s)$, usando (2.33) e as condições iniciais com as constantes $\alpha_{v}$ e $\beta_{v}$.

2. Distribuir a força $\mathbf{F}(\mathbf{X}(s), t)$ na malha euleriana usando a Eq.(2.31).

3. Avançar no tempo usando um método de Runge-Kutta de ordem 4 para o cálculo do campo de velocidades do fluido;

4. Atualizar os campos de pressão e de força.

5. Verificar se $\left\|\mathbf{E}_{\mathbf{s}}\right\|_{\infty} \leq 10^{-6}$ onde $\mathbf{E}_{s}=\|\mathbf{U}(s)\|_{2}$. Se verdadeiro, ir para o passo 6, senão, voltar para o passo 1. 
6. Verificar a continuidade usando (2.27).

7. Avançar um intervalo de tempo e voltar ao passo 1. 


\section{Aproximação numérica}

A aproximação numérica da solução de uma equação a derivadas parciais pode ser obtida pela transformação de um problema contínuo em um problema discreto finito. No caso de equações parciais o problema tem uma dificuldade adicional do número de variáveis independentes ser maior que 1, isto é, o domínio deixa de ser um intervalo e passa a ser uma região do plano ou do espaço. A transformação é realizada tanto no domínio da solução quanto na função incógnita e equação. No domínio ela é obtida pela subdivisão deste em um conjunto de pontos (discretização) - malha. A transformação da função incógnita e da equação são obtidas pela avaliação nos pontos da malha e pela aproximacão das derivadas por diferenças finitas. As equações que modelam o movimento de uma fronteira imersa (campo de força que se comporta como uma fronteira, no caso do Método da fronteira Virtual) bidimensional em um escoamento incompressível de fluido viscoso podem ser divididas em dois grupos: um que descreve o movimento do fluido e outro a interação entre o fluido e a fronteira imersa. Da mesma forma, a descrição da aproximação numérica pode ser dada em duas partes: a discretização das equações de Navier-Stokes e a discretização das equações da interação fluido-estrutura.

\subsection{A solução das equações de Navier-Stokes}

A solução numérica das equações de Navier-Stokes compreende a variação espacial e a variação temporal, ou seja, calcula-se os valores das variáveis no domínio espacial e depois avança-se no tempo. Tanto a variação espacial quanto a variação temporal dependem do modelo de discretização adotado para manutenção das condições de convergência e estabilidade do método de solução. Neste trabalho, a solução numérica das equações de navier-Stokes, para 
fluido viscoso e escoamento incompressível, é feita por um método da projeção apresentado por Bell, Collela e Glaz (1989), a partir dos métodos da projeção propostos por Chorin (1968). Ao contrário do caso compressível, no caso incompressível a pressão não carrega relevância termodinâmica e é função apenas da restrição da continuidade, equação (2.27). Alguns autores, como Almgren, Bell e Szymczak (1996) trabalham com o conceito de projeção aproximada onde e dada uma tolerância para a continuidade, $\nabla \cdot \mathbf{u}$ da ordem de $O\left(h^{2}\right)$.

A idéia central dos métodos de projeção é obter o campo de pressão inteiramente pela introdução de um operador que projete a velocidade sobre o espaço dos campos vetoriais. A partir do teorema da decomposição de Hodges, para o caso periódico, temos que "todo campo vetorial $w$ definido em um retângulo periódico $\omega$ pode ser unicamente decomposto na forma" $w=\mathbf{u}^{\mathbf{d}}+\nabla \psi$, onde $\nabla \cdot \mathbf{u}=0$ com $\mathbf{u}^{\mathbf{d}}$ e $\psi$ periódicos. De acordo com Roma (1996), para um produto interno usual de um escalar por um campo vetorial satisfazendo a equação em $w$ é possível demonstrar que $\nabla \cdot \mathbf{u}=0$, isto é, o campo vetorial $\mathbf{u}^{\mathbf{d}}$ é ortogonal ao gradiente da função escalar $\psi$. A transformação que toma $w$ em $\mathbf{u}^{\mathbf{d}}$ é linear e pode ser denotada por $\mathcal{P}$, que é um operador projeção ortogonal desde que $\mathcal{P}^{2}=\mathcal{P}$ e que $\mathcal{P}$ seja auto-adjunto. Em termos do operador projeção $\mathcal{P}$, as equações de Navier-Stokes, escritas por:

$$
\begin{gathered}
\frac{\partial \mathbf{u}}{\partial t}+\nabla p=\mu \Delta \mathbf{u}-\mathbf{u} \cdot \nabla \mathbf{u}+\mathbf{F}, \\
\nabla \cdot \mathbf{u}=0
\end{gathered}
$$

podem ser reescritas como:

$$
\mathbf{u}_{\mathbf{t}}=\mathcal{P}(\mu \Delta \mathbf{u}-[(\mathbf{u} \cdot \nabla) \mathbf{u}]+\mathbf{F})
$$

que pode ser interpretado como uma equação de evolução para a velocidade no espaço de divergência dos campos vetoriais. Os termos não-lineares de advecção serão obtidos explicitamente através dos valores conhecidos do campo de velocidades $\mathbf{u}$, do termo forçante $\mathbf{F}$ 
e da aproximação para $\nabla p$ do passo anterior. A partir do método de projeção proposto por Bell, Collela e Glaz (1989), seja a $m^{\text {th }}$ iteração do procedimento descrita como:

$$
\begin{aligned}
\frac{\mathbf{u}^{*, m}-\mathbf{u}^{n}}{\Delta t}+\frac{\nabla p^{n+\frac{1}{2}}}{\rho} & =\frac{\mu}{\rho} \Delta\left(\frac{\mathbf{u}^{*, m}+\mathbf{u}^{n}}{2}\right)-[(\mathbf{u} \cdot \nabla) \mathbf{u}]^{n+\frac{1}{2}}+\frac{\mathbf{F}^{n+\frac{1}{2}, m-1}}{\rho}, \\
\frac{\mathbf{u}^{n+\frac{1}{2}, m}-\mathbf{u}^{n}}{\Delta t}+\frac{\nabla p^{n+\frac{1}{2}, m}}{\rho} & =\frac{\mathbf{u}^{*, m}-\mathbf{u}^{n}}{\Delta t}+\frac{\nabla p^{n+1, m-1}}{\rho} \\
\nabla \cdot \mathbf{u}^{n+1, m} & =0
\end{aligned}
$$

Aplicando o operador $\mathcal{P}$ à equação (3.5), temos:

$$
\frac{\mathbf{u}^{n+1, m}-\mathbf{u}^{n}}{\Delta t}=\mathcal{P}\left(\frac{\mathbf{u}^{*, m}-\mathbf{u}^{n}}{\Delta t}+\frac{\nabla p^{n+\frac{1}{2}, m-1}}{\rho}\right) .
$$

Para esse processo iterativo é necessário uma estimativa inicial para $\nabla p$ e, eventualmente, para F no tempo $t^{n+1}$. Uma estimativa inicial para o gradiente de pressão é:

$$
\nabla p^{n+\frac{1}{2}, 0}= \begin{cases}0 & , n=0 \\ \nabla p^{n-1} & , n \geq 1\end{cases}
$$

Para o campo $\mathbf{F}$ é conveniente assumir que

$$
\mathbf{F}^{n+\frac{1}{2}, m-1}=\frac{1}{2}\left(\mathbf{F}^{n, m-1}+\mathbf{F}^{n+1, m-1}\right)
$$

se o termo forçante depende de um valor desconhecido da velocidade no instante $t^{n+1}$ ou, de outro modo,

$$
\mathbf{F}^{n+\frac{1}{2}, m-1}=\mathbf{F}^{n+\frac{1}{2}, m-2}=\cdots=\mathbf{F}^{n+\frac{1}{2}, 0}=\mathbf{F}^{n+\frac{1}{2}}
$$

tomando-se o divergente de ambos os lados da equação (3.5) e usando a equação (3.6), a equação de Poisson será dada por

$$
\nabla \cdot\left(\frac{\nabla p^{n+\frac{1}{2}, m}}{\rho}\right)=\nabla \cdot\left(\frac{\mathbf{u}^{*, m}-\mathbf{u}}{\Delta t}+\frac{\nabla p^{n+\frac{1}{2}, m-1}}{\rho}\right),
$$

Resolvida a equação de Poisson (3.11), o campo de velocidade $\mathbf{u}^{n=1, m}$ e determinado através de:

$$
\mathbf{u}^{n+1, m}=\mathbf{u}^{*, m}-\frac{\Delta t}{\rho} \nabla\left(p^{n+\frac{1}{2}, m}-p^{n+\frac{1}{2}}, m-1\right),
$$

que é o segundo passo da projeção. 
A solução discreta do método da projeção gera erros. Enquanto é observada a taxa de convergência da velocidade, a precisão para a pressão é degradada por dois efeitos: um erro numérico na camada limite devido ao passo da projeção e um erro global devido à alternância ou modos parasitas presentes na discretização da condição de incompressibilidade. Wetton (1997) detalha esses erros através de análise assintótica. Enquanto o método proposto por Chorin (1968) apresenta erros da ordem de $\left(O h^{2}\right)$ para a velocidade e $\left(O h^{\frac{1}{4}}\right)$ para a pressão, o método proposto por Bell, Collela e Glaz (1989) apresenta erro da ordem de $\left(O \Delta t^{3}\right)$, ou seja, segunda ordem para a velocidade e primeira ordem para a pressão.

\subsubsection{Discretização no tempo}

A discretização temporal das equações de Navier-Stokes está intimamente relacionada com o custo computacional e a qualidade pretendida para os resultados. A escolha do método utilizado deve considerar a precisão dos resultados, o tempo de execução da simulação e o consumo de memória computacional. O termo método de Runge-Kutta é utilizado para denotar fórmulas derivadas inicialmente por Runge (1895) e Heun (1900) e mais tarde modificadas por Kutta (1901). A modificação de Kutta das fórmulas de Runge também é conhecida pelo nome de método de Runge-Kutta. Os métodos de Runge-Kutta são comumente utilizados para a discretização temporal, sendo principais os de segunda, terceira e quarta ordem. Williamson (1980) introduziu um esquema de Runge-Kutta de baixa armazenagem (Low-Storage Runge Kutta), que necessita armazenar 2 vezes o número de pontos da malha por variável, respectivamente. No presente trabalho foi utilizado o esquema de quarta ordem definido por quatro estágios e conhecido como método clássico de Runge-Kutta de ordem 4 e que necessita de $4 \mathrm{~N}$ 
locações para armazenagem. O método de Runge-Kutta de ordem 4 é dado abaixo ${ }^{1}$, para cada passo no tempo $n$ :

$$
\begin{aligned}
& \mathbf{V}^{(0)}=\mathbf{V}^{(n)} \\
& \mathbf{V}^{(1)}=\mathbf{V}^{(0)}-\frac{\Delta t}{2} P v^{(0)} \\
& \mathbf{V}^{(2)}=\mathbf{V}^{(0)}-\frac{\Delta t}{2} P v^{(1)} \\
& \mathbf{V}^{(3)}=\mathbf{V}^{(0)}-\Delta t P v^{(2)} \\
& \mathbf{V}^{(4)}=\mathbf{V}^{(0)}-\frac{\Delta t}{6}\left(P v^{(0)}+2 P v^{(1)}+2 P v^{(2)}+P v^{(3)}\right) \\
& \mathbf{V}^{(n+1)}=\mathbf{V}^{(4)}
\end{aligned}
$$

onde $\mathbf{V}^{(0)}, \mathbf{V}^{(1)}, \mathbf{V}^{(2)}, \mathbf{V}^{(3)}$ e $\mathbf{V}^{(4)}$ são as propriedades do fluido, definidas pela equação (2.27), nos estágios intermediários do método de Runge-Kutta, e $\mathbf{V}^{(n+1)}$ é o valor das propriedades do fluido calculadas no tempo $t=t+\Delta t$. Esse esquema numérico é de ordem 4 de precisão no tempo e é estável para números de Courant-Friedrichs-Lévi (CFL), de acordo com Lele (1992), até

$$
\Delta t \leq \frac{2,85 \Delta x}{2,324 U_{\infty}}
$$

No algoritmo abaixo, cada estágio do método de Runge-Kutta é representado pela letra $\kappa$ e $n+1=t_{n}+\Delta t$ representa o instante de tempo avançado pelo intervalo de tempo $\Delta t$, calculado pelo método numérico.

\section{Estágio preliminar do método de Runge-Kutta:}

1. Inicializam-se as variáveis lagrangianas da fronteira virtual em $\kappa=0 \mathrm{com}$ o valor dessas mesmas variáveis no tempo $t=t_{n}$ :

$$
\begin{aligned}
& \mathbf{F}^{(0)}(s)=\mathbf{F}^{n}(s), \\
& \mathbf{U}^{(0)}(s)=\mathbf{U}^{n}(s),
\end{aligned}
$$

${ }^{1}$ Ver detalhes no trabalho de Doricio (2009) 
2. Inicializam-se as variáveis eulerianas em $\kappa=0$ :

$$
\begin{aligned}
\mathbf{f}^{(0)}(\mathbf{x}) & =\mathbf{f}^{n}(\mathbf{x}) \\
\mathbf{V}^{(0)}(\mathbf{x}) & =\mathbf{V}^{n}(\mathbf{x})
\end{aligned}
$$

Após o estágio preliminar do método de Runge-Kutta, realizam-se os estágios intermediários utilizando-se $\kappa=1,2,3,4$.

Estágios intermediários do método de Runge-Kutta $(\kappa=1,2,3,4)$ :

1. Impõe-se a força lagrangiana $\mathbf{F}^{(\kappa+1)}(s)$, exercida na estrutura utilizando a configuração $\mathbf{X}^{(\kappa)}(s)$ aos pontos da fronteira virtual:

$$
\mathbf{F}^{(\kappa+1)}(s)=\mathbf{S}^{(\kappa)}\left(\mathbf{X}^{(\kappa)}\right)
$$

2. Interpola-se a força lagrangiana $\mathbf{F}^{(\kappa+1)}(s)$ no campo de força euleriano do fluido para determinar $\mathbf{f}^{(\kappa+1)}(\mathbf{x})$ :

$$
\mathbf{f}^{(\kappa+1)}(\mathbf{x})=\sum_{s} \mathbf{F}^{(\kappa+1)}(s) \delta_{h}^{2}\left(\mathbf{x}-\mathbf{X}^{(\kappa)}(s)\right) \Delta s
$$

3. Resolvem-se as equações de Navier-Stokes definidas pelas equações (2.26)-(2.27) com o termo de força $\mathbf{f}^{(\kappa+1)}(\mathbf{x})$ no estágio $(\kappa+1)$ do método de Runge-Kutta dado pela equação (3.13).

4. Interpola-se a velocidade euleriana $\mathbf{u}^{(\kappa+1)}(\mathbf{x})$ para os pontos lagrangianos da fronteira imersa:

$$
\mathbf{U}^{(\kappa+1)}(s)=\sum_{\mathbf{x}} \mathbf{u}^{(\kappa+1)}(\mathbf{x}) \delta_{h}^{2}\left(\mathbf{x}-\mathbf{X}^{(\kappa)}(s)\right) h^{2} .
$$

onde $\delta_{h}^{2}$ é a função delta suavizada, definida nas equações (3.29)-(3.30).

5. Atualiza-se a função de feedback $\mathbf{F}^{(\kappa+1)}(s)$ utilizando o método de Runge-Kutta dado pela equação (3.13):

$$
\mathbf{F}^{(\kappa+1)}(\mathbf{X}(s), t)=\alpha_{v} \int_{0}^{t}\left(\mathbf{U}^{(\kappa+\mathbf{1})}(\mathbf{X}(s), t)-\mathbf{V}^{(\kappa+\mathbf{1})}(\mathbf{X}(s), t)\right) d t+\beta_{v}\left(\mathbf{U}^{(\kappa+\mathbf{1})}(\mathbf{X}(s), t)-\mathbf{V}^{(\kappa+\mathbf{1})}(\mathbf{X}(s), t)\right) .
$$


6. Atualiza-se o campo de pressão pelo método da projeção: $p=\tilde{p}+p_{c}$, $\operatorname{com} \tilde{p}=$ $p\left(\mathbf{x}, t_{n}\right)$ e $p_{c}=$ pressão corretiva calculada através da relação $\left.\frac{\partial(u-\tilde{u})}{\partial t}=-\nabla p_{c}\right)$, que pode ser visto com maiores detalhes no trabalho de Harlow e Welch (1965).

Atualiza-se as variáveis do tempo $t=t_{n}$ para o tempo $t=t_{n}+\Delta t$ :

1. Atualiza-se as variáveis lagrangianas em $t=t_{n}+\Delta t$ utilizando o valor delas no estágio $\kappa=4$ do método de Runge-Kutta:

$$
\begin{aligned}
& \mathbf{F}^{n+1}(s)=\mathbf{F}^{(4)}(s), \\
& \mathbf{U}^{n+1}(s)=\mathbf{U}^{(4)}(s),
\end{aligned}
$$

2. Atualiza-se as variáveis eulerianas em $t=t_{n}+\Delta t$ :

$$
\begin{aligned}
\mathbf{f}^{n+1}(\mathbf{x}) & =\mathbf{f}^{(4)}(\mathbf{x}), \\
\mathbf{V}^{n+1}(\mathbf{x}) & =\mathbf{V}^{(4)}(\mathbf{x})
\end{aligned}
$$

Esse estágio conclui o algoritmo de marcha no tempo para as equações de Navier-Stokes com termo forçante definidas no Capítulo 2.

\subsubsection{O domínio computacional}

O problema a ser resolvido pelo método da fronteira virtual envolve a formulação do problema em um domínio físico retangular, convenientemente dimensionado de forma regular ou não regular em todas as direções. Então é natural se pensar em uma malha computacional através da divisão do domínio em um vetor $M \times N$ de células computacionais retangulares cuja largura e altura são $\Delta x$ e $\Delta y$ respectivamente. Escoamentos incompressíveis modelados pelas equações de Navier-Stokes, (2.26) e (2.27), caracterizam-se pela necessidade da solução de uma equação de Poisson para a pressão a cada passo no tempo. O fato da massa específica $\rho$ não variar com a pressão $p$ introduz um forte acoplamento entre a pressão e a velocidade, causando dificuldades para a solução do sistema de equações. O objetivo, então, é determinar 
um campo de pressões que, quando inserido nas equações do movimento, origine um campo de velocidades que satisfaça a equação da conservação da massa. Conforme Fortuna (2000), normalmente, as principais dificuldades na solução numérica desses escoamentos são:

A restrição global $\nabla \cdot \mathbf{u}=0$ deve ser satisfeita a cada passo no tempo, o que não permite que os valores de $\mathbf{V}^{\mathbf{n}+\mathbf{1}}$ sejam determinados por um método que não necessite da solução de um conjunto de equações acopladas, ou seja, métodos explícitos exigem a solução de um sistema de equações.

Não há condições de fronteira física para a pressão, ou seja, deve-se utilizar condições de fronteira apropriadas à solução numérica da equação de Poisson para a pressão.

Na literatura podemos encontrar, basicamente, dois tipos de discretização: com malha e sem malha. Neste trabalho vamos usar discretização com malha. Os valores para as incógnitas $u, v, p$ e $f$ são armazenadas em cada nó da malha. Malhas nas quais as incógnitas são armazenadas no mesmo ponto são denominadas co-localizadas, mas quando podemos escolher a posição em que cada variável do escoamento é armazenada, ao invés de colocá-las em um único ponto, conforme Fortuna (2000), podemos usar modelos de segunda ordem em $p$ sem o risco de encontrarmos campos oscilatórios de pressão causados pela discretização. Malhas nas quais as variáveis são armazenadas em posições diferentes são denominadas deslocadas. Existem várias formas de se distribuir as variáveis $u, v, p$ e $f$ quando não se exige que estejam armazenadas na mesma posição. Harlow e Welch (1965) propuseram uma malha deslocada que é composta por células bidimensionais, com arestas $\delta_{x}$ e $\delta_{y}$, onde, para cada célula $(i, j)$,

- A pressão $p$ é armazenada no centro;

- A componente $u$ da velocidade na direção $x$ é armazenada nas faces esquerda e direita que distam $\pm \frac{\Delta_{x}}{2}$ do centro;

- A componente $v$ da velocidade na direção $y$ é armazenada nas faces superior e inferior que distam $\pm \frac{\Delta_{y}}{2}$ do centro 


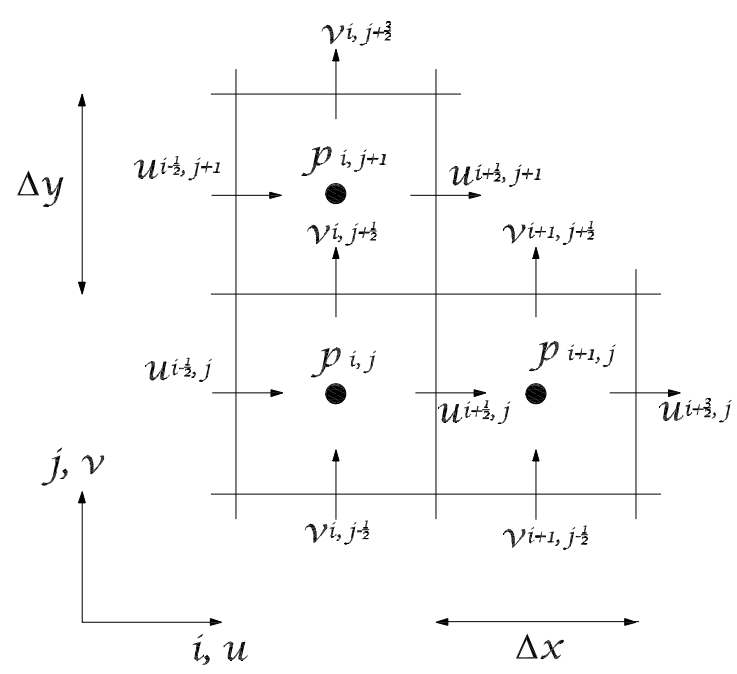

Figura 3.1: Célula da malha deslocada

A discretização das equações de Navier-Stokes em malha deslocada é semelhante à discretização de uma EDP em malha co-localizada ${ }^{2}$. A equação da continuidade é discretizada sobre o centro da célula, no ponto $i, j$, a equação de quantidade de movimento na direção $x$ é discretizada sobre a posição $i+1 / 2, j$ e a equação de quantidade de movimento na direção $y$ é discretizada sobre a posição $i, j+1 / 2$. Para estimar a velocidade de convecção $\widetilde{\mathbf{u}}$ temos que considerar que as propriedades do escoamento em um ponto $(i, j)$ qualquer dependem fortemente das propriedades do escoamento a montante desse ponto, ou seja, o esquema de discretização dos termos convectivos depende da direção local do escoamento. Em função da velocidade estimada pode-se definir diferentes funções de interpolação para os valores das propriedades no centro da i-ésima célula. Neste trabalho, usamos um esquema híbrido combinando a precisão da discretização por diferenças centrais na região do escoamento, onde o número de Péclet é menor que 2, com a discretização upwind VONOS, (VARONOS; BERGELES, 1998), onde o número de Péclet é maior que 2. Já foi visto que o campo de pressões no escoamento incompressível satisfaz uma equação de Poisson e deve ser resolvida a cada instante de tempo, ou seja, os métodos numéricos, em variáveis primitivas devem resolver um sistema linear a cada passo no tempo. Neste trabalho usamos como base o método GENSMAC, desenvolvido por Tomé e McKee (1994), que

\footnotetext{
${ }^{2}$ detalhes passo a passo da discretização para a equação de quantidade de movimento e dos termos convectivos podem ser encontrados em Fortuna (2000), capítulo 6
} 
- é um método baseado no método MAC (marker and cell), desenvolvido por Harlow e Welch (1965);

- é um método explícito;

- tem uma rotina para mudança automática de passo no tempo;

- usa a técnica de gradiente conjugado para resolver a equação de Poisson (no presente trabalho também foi usado o método do gradiente biconjugado);

- a discretização temporal das equações de quantidade de movimento é baseada no método de Euler explícito (no presente trabalho foi usado método de Runge-Kutta de ordem 4);

- para correção da pressão, estima-se um campo inicial de velocidades com base nos campos de pressão e velocidades da iteração anterior. Com estes campos de velocidades estimados, calcula-se o campo da correção da pressão e em seguida, obtém-se o novo campo de velocidades que satisfaz a equação da continuidade;

- os termos que envolvem velocidades são discretizados no nível de tempo $n$ e o termo envolvendo a pressão é discretizado no nível de tempo $n+1$;

- a derivada temporal é discretizada por diferenças progressivas; e

- permite diversas configurações de fronteiras de entrada e saída.

A princípio não seria necessário usar um método mais caro, computacionalmente, como GENSMAC, que foi desenvolvido para simulações com superfícies livres, mas foi escolhido por permitir trabalhar com contornos de geometria complexa e possibilitar o acréscimo de um módulo para trabalhar com malha não regular, que será usado quando das simulações com fronteiras imersas que têm superfície muito delgada.

\subsubsection{Discretização no espaço}

Fenômenos que envolvem perfís delgados ou contornos complexos exigem tratamentos específicos ou abordagem computacional diferenciada. A discretização do domínio computacional é determinante para a eficiência da solução numérica adotada, pois superfícies delgadas exigem "malha fina" para capturar numericamente as variações do fenômeno. Malha fina exige 
maiores recursos computacionais, principalmente quando as equações governantes são NavierStokes. Para o método de diferenças finitas, a aproximação por malha estruturada convencional é mais vantajosa que a escolha de malha conforme devido às dificuldades de transformação das equações governantes para coordenadas curvilíneas e problemas de instabilidade, convergência e precisão do processo numérico Rojas, Casanova, Pino e Feria (2005).

Uma escolha natural para esse tipo de problema seria a abordagem por malha blocoestruturada, onde a parte delgada seria muito refinada e as regiões mais distantes seriam pouco refinadas. No entanto, esta alternativa exige estratégias de interpolação para os valores das varáveis quando da passagem de um bloco para outro e mais uma vez surgem os problemas de instabilidade, convergência e precisão do processo numérico. Neste trabalho apresentamos uma alternativa entre a opção pela malha conforme e a malha bloco-estruturada.

Considere um domínio irregular curvilíneo bidimensional, por exemplo um aerofólio, figura (3.2). O objetivo é gerar uma malha que tenha refinamento suficiente para capturar os efeitos do

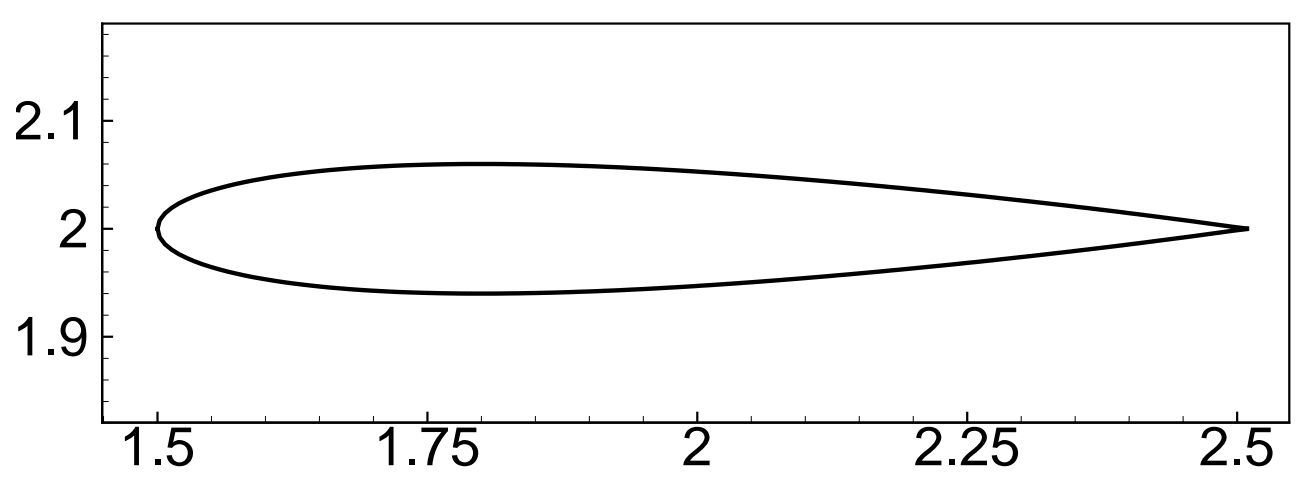

Figura 3.2: Aerofólio

escoamento em regiões críticas, por exemplo no bordo de fuga do aerofólio. Para tanto, a parte mais extrema do aerofólio deve ter um número de células computacionais que não permitam entrelaçamento de campos de força, pois haveria geração de efeitos espúrios. A nossa alternativa foi estabelecer uma região bastante refinada, suficiente para envolver a fronteira imersa, e, a partir dela, ir aumentando o tamanho das células computacionais de forma a não produzir saltos que necessitem de uma função interpoladora para a aproximação dos valores das variáveis. Uma 
função natural a ser aplicada é uma função linear. A rotina retira o tamanho da região refinada do comprimento de cada dimensão do domínio bidimensional, divide o resto por dois e aplica uma relação linear para variar a dimensão da célula computacional até atingir os limites do domínio computacional. Dessa forma podemos ter uma malha bastante refinada na região de maior interação fluido-estrutura e bastante esparsa quando distante ou quando mais próximo do "escoamento livre". O domínio é dado por um produto Cartesiano $\left[x_{\frac{1}{2}, X_{M+\frac{1}{2}}}\right] \times\left[y_{\frac{1}{2}, y_{M+\frac{1}{2}}}\right]$ e cada célula tem seu centro em

$$
\mathbf{x}_{\mathbf{i}, \mathbf{j}}=\left(x_{\frac{1}{2}}+\left(i-\frac{1}{2}\right) \Delta x, y_{\frac{1}{2}}+\left(j-\frac{1}{2}\right) \Delta y\right)
$$

para $1 \leq i \leq M$ e $1 \leq j \leq N$. Para manter a forma dos operadores próximo das "borda" do domínio, uma camada adicional de células é colocada do lado de fora do domínio para garantir as condições de fronteira e são chamadas células fantasmas (ghost cells), cujos centros são dados por $\left(x_{0}, y_{j}\right),\left(x_{M+1}, y_{j}\right)$ para $0 \leq j \leq N+1$, e $\left(x_{i}, y_{0}\right),\left(x_{i}, y_{N+1}\right)$ para $0 \leq i \leq M+1$. A locação de cada uma das variáveis $\mathbf{u}=(u, v)$ e $\mathbf{p}$ foi feita pelo Método GENSMAC, apresentado por Tomé e McKee (1994). Nessa discretização, as células do domínio são consideradas volumes de controle de massa onde as variáveis pressão e divergência são posicionadas no centro da célula e as variáveis velocidade, termo de força e gradiente de pressão têm seus componentes verticais posicionados no meio da aresta horizontal da célula e seus componentes horizontais são posicionados no meio da aresta vertical, figura (3.3). A malha resultante, figura (3.3), concentra os nós com a precisão desejada na região de interesse e as técnicas para programação são relativamente simples e a armazenagem dos pontos na forma matricial não apresenta novidades. As equações do escoamento foram discretizadas em diferenças finitas para malha não regular a partir dos trabalhos de Turkel (1986) e Manteuffel e White (1986). Nesses trabalhos, são apresentadas a primeira derivada e a segunda derivada na forma centrada com erro de truncamento de primeira ordem e Manteuffel mostrou que a precisão de segunda ordem pode ser obtida, em malhas não regulares, sempre que o erro de truncamento local for de 


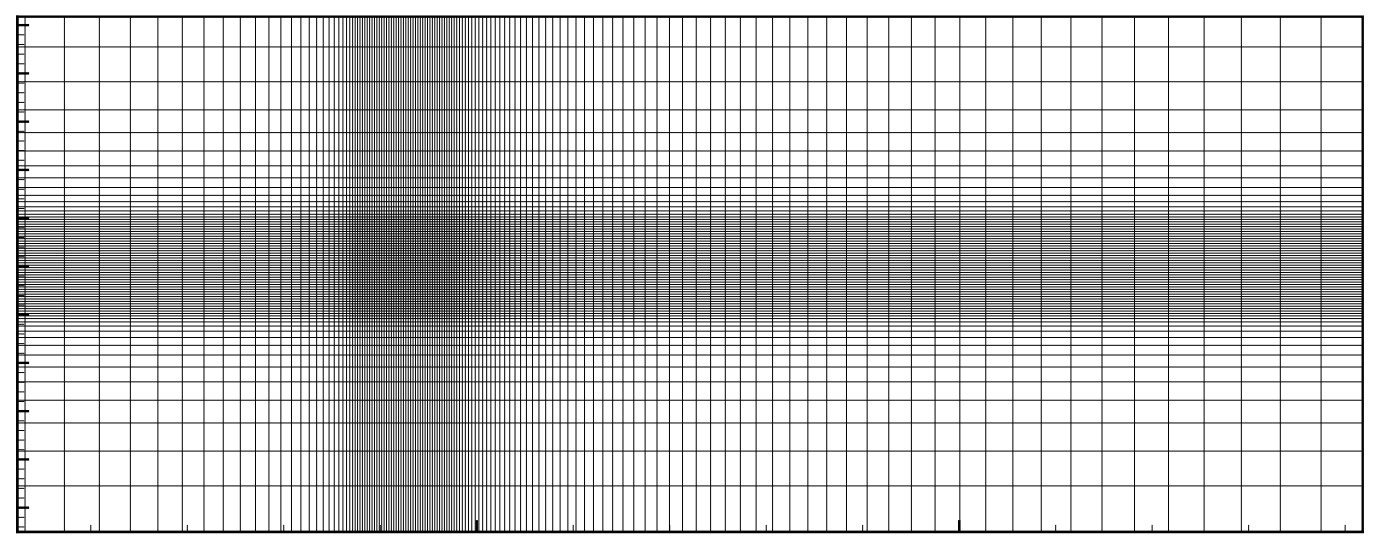

Figura 3.3: Malha não regular

baixa ordem e que a variação da malha variar linearmente e de forma "suave“ “ 3 . A discretização de cinco pontos da equação de Poisson para a molécula computacional, figura 3.4, é dada por

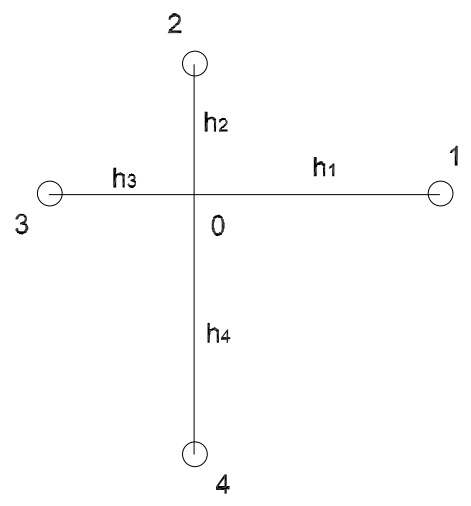

Figura 3.4: Molécula de cinco pontos para malha não regularmente espaçada

$$
\phi_{\mathbf{0}}=\alpha_{0} \mathbf{U}_{\mathbf{0}}+\alpha_{1} \mathbf{U}_{\mathbf{1}}+\alpha_{2} \mathbf{U}_{\mathbf{2}}+\alpha_{3} \mathbf{U}_{\mathbf{3}}+\alpha_{4} \mathbf{U}_{\mathbf{4}}
$$

onde os coeeficientes $\alpha$ são dados por

$$
\alpha_{0}=-2\left(\frac{1}{h_{1} h_{3}}\right) ; \alpha_{1}=\frac{2}{h_{1}\left(h_{1}+h_{3}\right)} ; \alpha_{2}=\frac{2}{h_{2}\left(h_{2}+h_{4}\right)} ; \alpha_{3}=\frac{2}{h_{3}\left(h_{1}+h_{3}\right)} ; \alpha_{4}=\frac{2}{h_{4}\left(h_{3}+h_{4}\right)}
$$

\footnotetext{
${ }^{3}$ O termo suave, conforme Manteuffel e White (1986) pode ser entendido como um gradiente linear que não ultrapasse a relação até $2 \times 1$
} 
A aproximação de segunda ordem para os operadores divergente e gradiente é dado por

$$
\begin{gathered}
(D \mathbf{u})_{i, j}=\frac{u_{i+\frac{1}{2}, j}-u_{i-\frac{1}{2}, j}}{\Delta x}+\frac{v_{i, j+\frac{1}{2}}-v_{i, j-\frac{1}{2}}}{\Delta y} \\
(G p)_{i, j}=\left(\frac{p_{i, j}-p_{i-1}, j}{\Delta x}, \frac{p_{i, j}-p_{i, j-1}}{\Delta y}\right),
\end{gathered}
$$

onde os índices de tempo foram suprimidos para melhor clareza. A forma discreta da equação de Poisson para pressão obtida apartir da equação (3.11) é dada por

$$
\left(\frac{L p}{\rho}\right)_{i, j}^{n+\frac{1}{2}, m}=D \cdot\left(\frac{\mathbf{u}_{i, j}^{*, m}-\mathbf{u}_{i, j}^{n}}{\Delta t}+\frac{G p_{i, j}^{n+\frac{1}{2}, m-1}}{\rho}\right),
$$

onde $L$ é a discretização do laplaciano para 5 pontos

$$
(L p)_{i, j}^{n+\frac{1}{2}, m}=(D \cdot G p)_{i, j}^{n+\frac{1}{2}, m}=\frac{p_{i, j-1}^{n+\frac{1}{2}, m}+p_{i+1, j}^{n+\frac{1}{2}, m}+p_{i, j+1}^{n+\frac{1}{2}, m}+p_{i-1, j}^{n+\frac{1}{2}, m}-4 p_{i, j}^{n+\frac{1}{2}, m}}{\Delta x \Delta y}
$$

As condições para a resolução das equações (3.24) e (3.25) são apresentadas por Turkel (1986) e Manteuffel e White (1986) que mostram uma técnica para a solução da equação de Poisson para a pressão em malhas não regulares.

\subsubsection{A solução da equação de Poisson para pressão}

A equação de Poisson para a pressão é parte fundamental no método da projeção. Para a solução da equação de Poisson foi utilizada a técnica de gradiente biconjugado. O método do gradiente conjugado não é aplicado a sistemas não simétricos porque os vetores residuais não podem ser feitos ortogonais com poucas iterações. Como alternativas pode-se usar o método dos resíduos mínimos generalizados (GMRES) ou o método do gradiente bi-conjugado (BiGC), todos sem a aplicação de pré-condicionamento. Estes métodos são selecionados em função de algumas características que se deseja, tais como, existência ou não de simetria (CG), verificação de robustez e compatibilidade com métodos clássicos. A literatura mostra que o GMRES é o método mais robusto com o menor número de iterações comparativamente aos outros métodos. Entretanto é um método exigente no que se refere ao armazenamento, principalmente devido à construção interna de um subespaço de reinicialização. O método do 
gradiente biconjugado usa uma outra abordagem, trocando a sequência ortogonal dos resíduos por duas sequências mutuamente ortogonais, ao preço de não mais realizar a minimização. As relações de atualização dos resíduos no método do gradiente conjugado (CG) são aumentadas no método do gradiente biconjugado (BiCG) por relações que são semelhantes, mas utilizam $\mathbf{A}^{T}$ ao invés de $\mathbf{A}$. O método atualiza duas sequências de resíduos:

$$
\begin{gathered}
\mathbf{r}_{i+1}=\mathbf{r}_{i}-\zeta_{i} \mathbf{A} \mathbf{p}_{i}, \\
\tilde{\mathbf{r}}_{i+1}=\tilde{\mathbf{r}}_{i}-\zeta_{i} \mathbf{A}^{T} \tilde{\mathbf{p}}_{i}
\end{gathered}
$$

e duas sequências de direção de procura:

$$
\begin{aligned}
& \mathbf{p}_{i+1}=\mathbf{r}_{i+1}+\varsigma_{i+1} \mathbf{p}_{i}, \\
& \tilde{\mathbf{p}}_{i+1}=\tilde{\mathbf{r}}_{i+1}+\varsigma_{i+1} \tilde{\mathbf{p}}_{i}
\end{aligned}
$$

com os valores de $\zeta$ e $\varsigma$ iguais a:

$$
\begin{aligned}
\zeta_{i} & =\frac{\tilde{\mathbf{r}}_{i+1}^{T} \mathbf{r}_{i+1}}{\tilde{\mathbf{p}}_{i}^{T} \mathbf{r}_{i}}, \\
\zeta_{i} & =\frac{\tilde{\mathbf{r}}_{i+1}^{T} \mathbf{r}_{i+1}}{\tilde{\mathbf{r}}_{i}^{T} \mathbf{r}_{i}}
\end{aligned}
$$

Se a matriz do sistema for simétrica definida positiva a convergência do BiCG será a mesma do método CG, mas com o dobro do custo a cada iteração. Se a matriz for não simétrica, mas a redução da norma do resíduo for significativa, o método é comparável ao GMRES completo. Mas dependendo do sistema a convergência pode ser irregular e, em alguns casos, o método pode não convergir. Existem estratégias para contornar estas deficiências que envolvem a reinicialização do método ou utilizando outra forma de decomposição. $\mathrm{O}$ BiCG requer o cálculo do produto matriz por vetor $A p_{i}$, do produto transposto $A^{T} \tilde{p}_{i}$, dois produtos internos, e cinco operações de atualização. A matriz transposta, portanto, deve estar disponível. Os produtos matriz por vetor podem ser implementados em ambientes paralelos onde a utilização da cópia da matriz na forma transposta facilita a implementação, mas duplica a necessidade de armazenamento. O algoritmo do BiCG pode ser encontrado em Fischborn, Kuo-Peng, Sadowsky, Bastos, Trevisan e Gavioli (2006). Além dos vetores e escalares idênticos 
aos utilizados no algoritmo do método do gradiente conjugado, no algoritmo do método do gradiente biconjugado aparecem os vetores $\tilde{\mathbf{p}}_{\mathbf{i}}, \tilde{\mathbf{r}}_{\mathbf{i}}$ e $\tilde{\mathbf{z}}_{\mathbf{i}}$ nas iterações 1 e $i-1$, significando direção de procura, o resíduo e o resíduo $\mathbf{M}$-ortogonal, conjugados, respectivamente.

\subsection{A função delta}

A função $\delta$ usada nas equações (2.28) e (2.29), na forma bidimensional, é dada pelo produto de duas funções de uma variável, tal que:

$$
\delta(\mathbf{x})=\frac{1}{h^{2}} \phi\left(\frac{x_{1}}{h}\right) \phi\left(\frac{x_{2}}{h}\right)
$$

onde $x_{1}$ e $x_{2}$ são os componentes cartesianos de $\mathbf{x}$ e, depois de suavizada, é dada por:

$$
\delta_{h}(r)= \begin{cases}\frac{1}{8 h}\left(3-\frac{2|r|}{h}+\sqrt{1+\frac{4|r|}{h}-\frac{4 r^{2}}{h^{2}}}\right), & |r| \leq h, \\ \frac{1}{8 h}\left(5-\frac{2|r|}{h}-\sqrt{-7+\frac{12|r|}{h}-\frac{4 r^{2}}{h^{2}}}\right), & h \leq|r| \leq 2 h, \\ 0, & 2 h \leq|r| .\end{cases}
$$

A função delta suavizada definida pela equação (3.30) satisfaz duas condições de quantidade de movimento discreta, (PESKIN, 2002), com suporte para quatro células nas direções $x$ e $y$, isto é, com suporte para 16 células da malha na geometria bidimensional. Além disso, satisfaz os postulados das funções delta estabelecidos por Peskin (2002):

$$
\begin{cases}\delta(r) \in C^{0} & \forall r \in \mathfrak{R}, \\ \delta(r)=0 & \text { para }|r| \geq 2, \\ \sum_{j \operatorname{par}} \delta(r-j)=\sum_{j \text { impar }} \delta(r-j)=\frac{1}{2} & \forall r \in \mathfrak{R}, \\ \sum_{j}(r-j) \delta(r-j)=0 & \forall r \in \mathfrak{R}, \\ \sum_{j}[\delta(r-j)]^{2}=c & \forall r \in \mathfrak{R},\end{cases}
$$

onde $c$ é uma constante independente de $r$.

No entanto, Griffith e Peskin (2005) apresentam duas outras formas para a função delta. A primeira delas satisfaz quatro condições de quantidade de movimento discreta com suporte para 
seis espaçamentos de células em $x$ e $y$ e os postulados das funções delta de Peskin e a equação (3.30) é dada por

$$
\delta(r)= \begin{cases}\frac{61}{112}-\frac{11}{42}|r|-\frac{11}{56}|r|^{2}+\frac{1}{12}|r|^{3}+\frac{\sqrt{3}}{336}(243+1584|r|- & \\ \left.748|r|^{2}-1560|r|^{3}+500|r|^{4}+336|r|^{5}-112|r|^{6}\right)^{\frac{1}{2}}, & 0 \leq|r|<1, \\ \frac{21}{16}+\frac{7}{12}|r|-\frac{7}{8}|r|^{2}+\frac{1}{6}|r|^{3}-\frac{3}{2} \delta(|r|-1), & 1 \leq|r|<2, \\ \frac{9}{8}-\frac{23}{12}|r|+\frac{3}{4}|r|^{2}-\frac{1}{12}|r|^{3}+\frac{1}{2} \delta(|r|-2), & 2 \leq|r|<3, \\ 0, & 3 \leq|r| .\end{cases}
$$

A segunda forma para a função delta, Griffith e Peskin (2005), é uma função cúbica com suporte para quatro células em cada direção $x$ e $y$ e também satisfaz quatro condições de quantidade de movimento discreta. Da equação (3.29), essa função é dada por:

$$
\delta(r)= \begin{cases}1-\frac{1}{2}|r|-|r|^{2}+\frac{1}{2}|r|^{3}, & 0 \leq|r|<1, \\ 1-\frac{11}{6}|r|+|r|^{2}-\frac{1}{6}|r|^{3}, & 1 \leq|r|<2, \\ 0, & 2 \leq|r| .\end{cases}
$$

A função delta definida pela equação (3.33) apesar de satisfazer quatro condições de quantidade de movimento discreta, não satisfaz todos os postulados descritos por Peskin (2002) e pode causar oscilações não físicas próximo à parede da estrutura. Linnick (1999) aproximou a função delta por uma função Gaussiana em todo o domínio $\Omega$ do fluido. Essa função delta suavizada, em geometrias bidimensionais, é dada por:

$$
\delta_{h}^{2}(\mathbf{x})=\frac{1}{\pi \sigma_{x} \sigma_{y}} \exp \left[-\left(\frac{x}{\sigma_{x}}\right)^{2}-\left(\frac{y}{\sigma_{y}}\right)^{2}\right],
$$

A rigor, a força exercida pela estrutura no fluido, devido à interação fluido-estrutura, é uma força de superfície localizada e não atua como uma força de campo (PESKIN, 2002). Entretanto, a utilização da função delta definida pela equação (3.34) faz com que a força exercida pela estrutura seja transferida para todo o domínio computacional do fluido, fazendo com que o termo fonte das equações governantes se comporte como uma força de campo. 


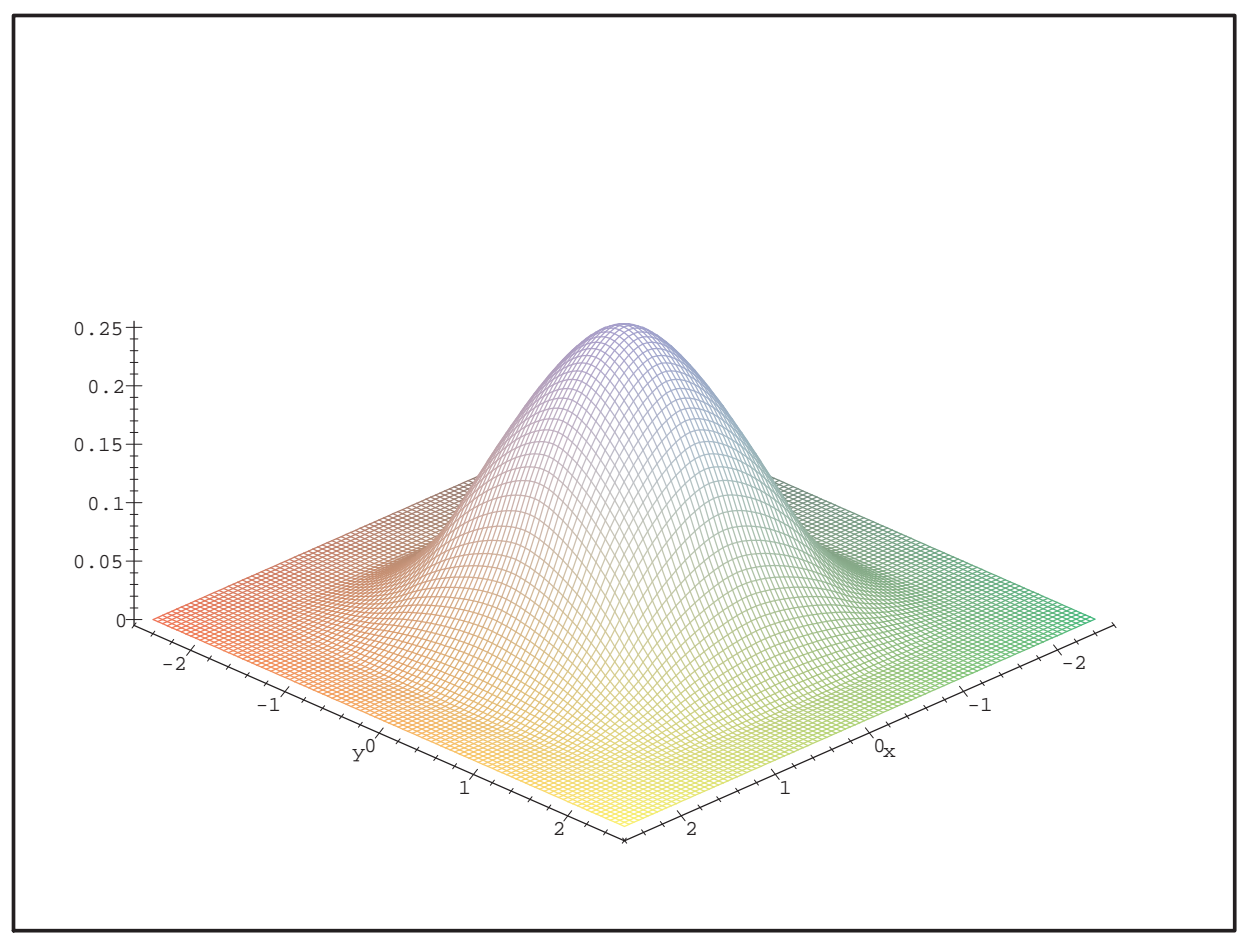

Figura 3.5: Esboço da função delta usando a equação (3.30).

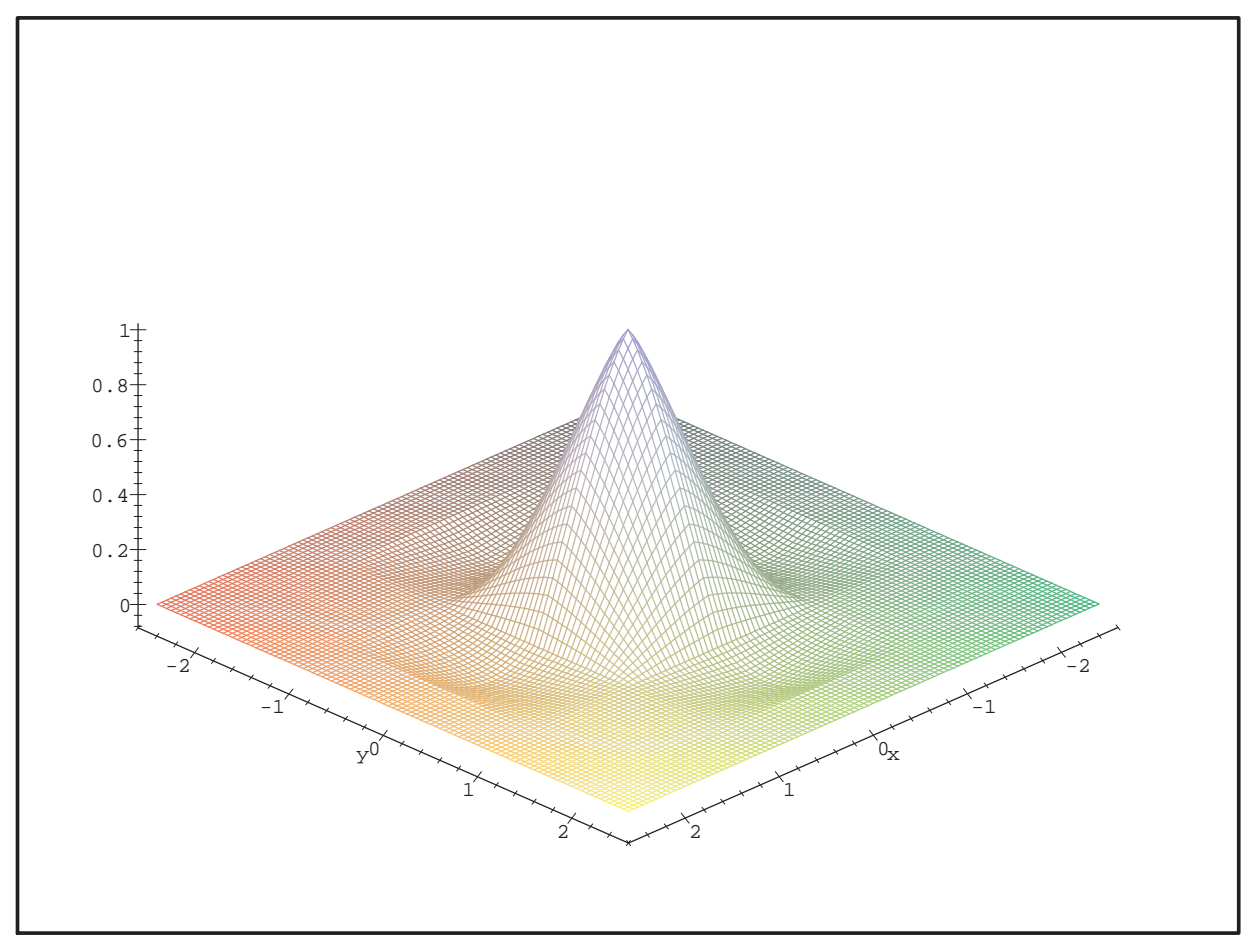

Figura 3.6: Esboço da função delta usando a equação (3.32). 


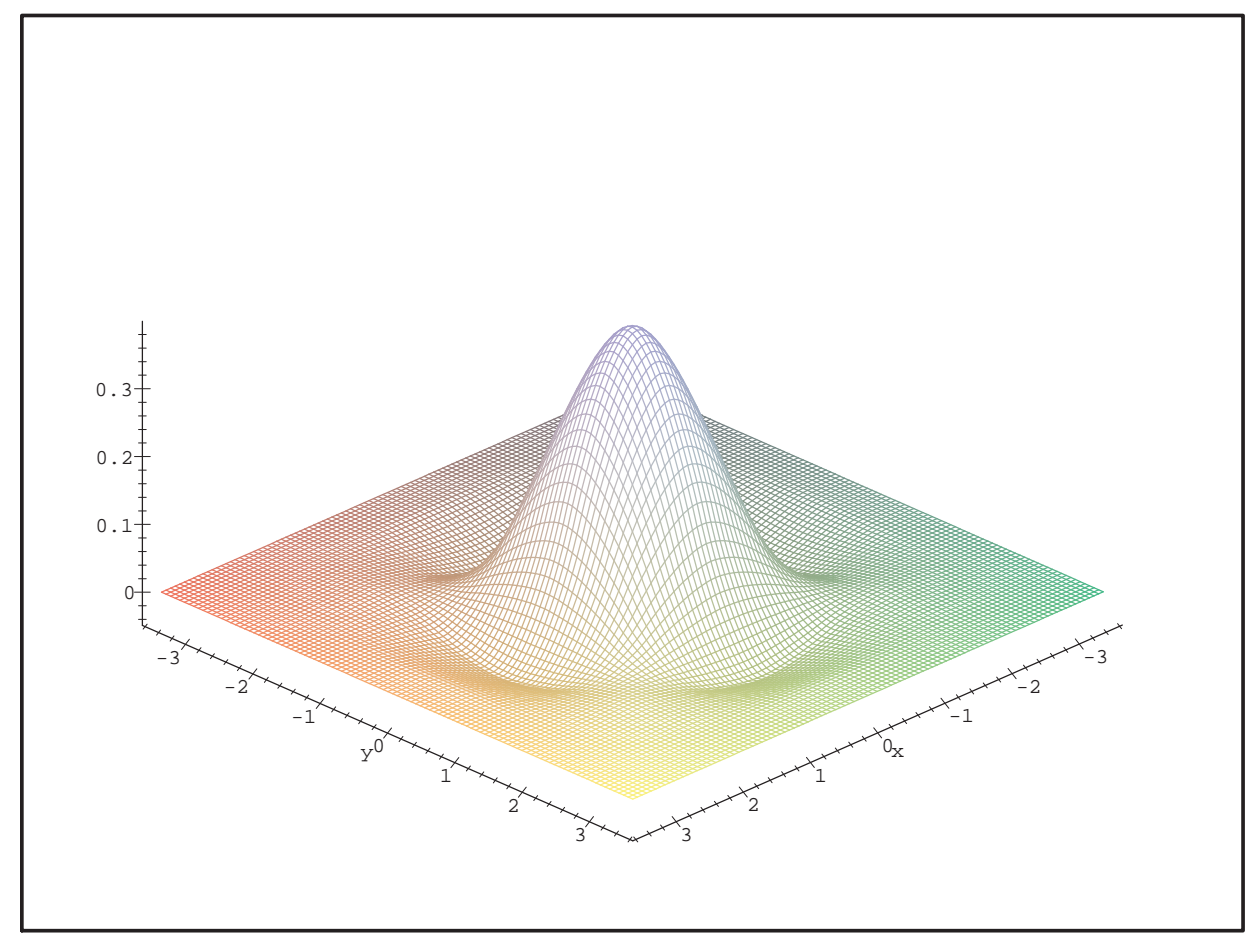

Figura 3.7: Esboço da função delta usando a equação (3.33).

Para Souza (2005) a função delta (3.34) é truncada para produzir suporte de malha de quatro células em cada direção $x$ e $y$. Nesse caso, a função delta não satisfaz as seguintes propriedades, (PESKIN, 2002):

$$
\begin{gathered}
\int \delta^{2}(\mathbf{x}-\mathbf{X}) d \mathbf{x}=1, \\
\int(\mathbf{x}-\mathbf{X}) \delta^{2}(\mathbf{x}-\mathbf{X}) d \mathbf{x}=0,
\end{gathered}
$$

e, conforme Griffith e Peskin (2005),

$$
\int_{\Omega} f_{x} d \mathbf{x} \neq \int_{0}^{L_{b}} F_{x} d s \text { e } \int_{\Omega} f_{y} d \mathbf{y} \neq \int_{0}^{L_{b}} F_{y} d s,
$$

resultando em cálculos incorretos do arrasto e da sustentação por meio da integração no domínio lagrangiano.

Nesse trabalho utilizou-se a função delta definida pela equação (3.30) porque faz com que a influência da fronteira na vizinhança da estrutura seja minimizada e não apresenta o inconveniente da função gaussiana. 


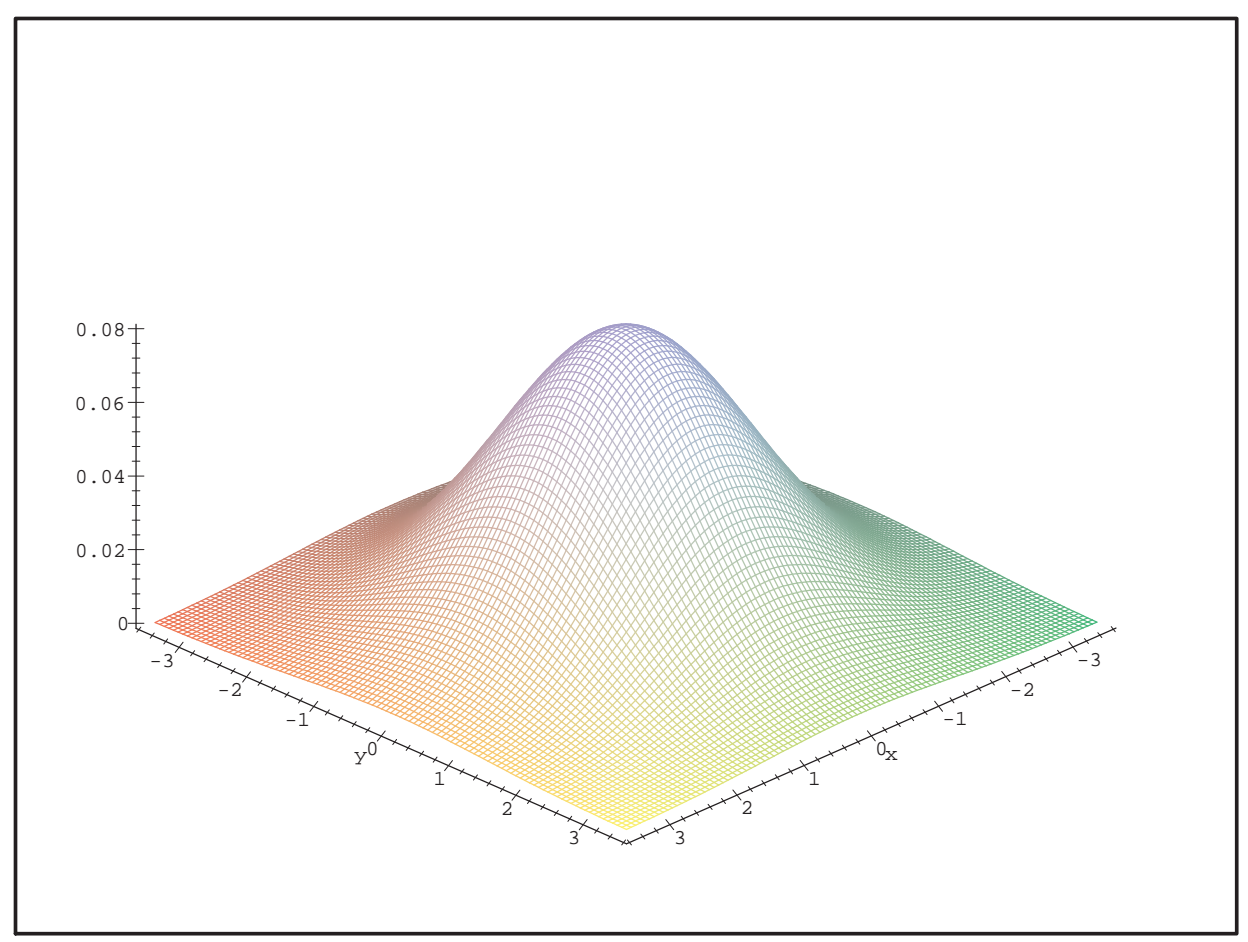

Figura 3.8: Esboço da função delta usando a equação (3.34) com $\sigma_{x}=2$ e $\sigma_{y}=2$.

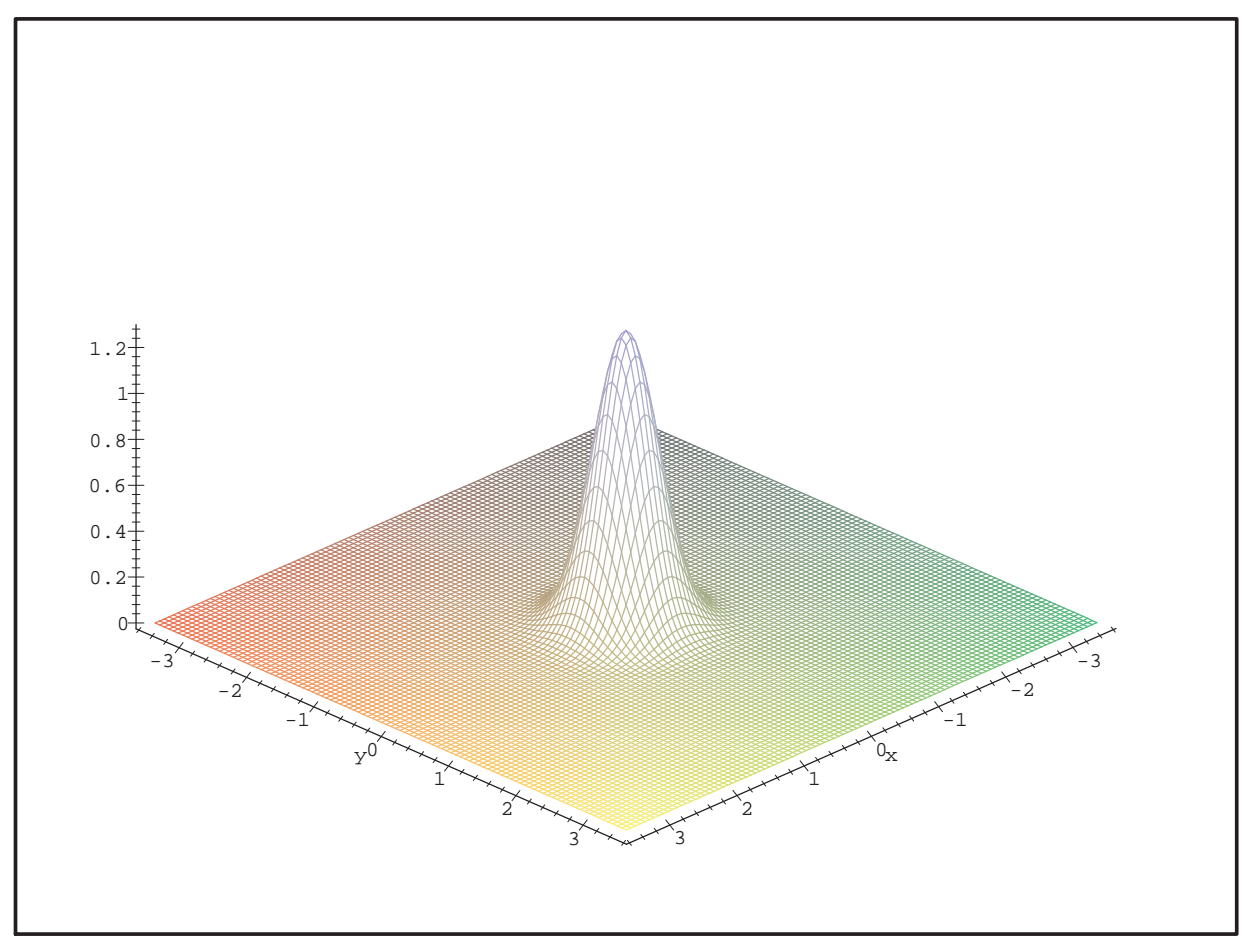

Figura 3.9: Esboço da função delta usando a equação (3.34) $\operatorname{com} \sigma_{x}=0,5$ e $\sigma_{y}=0,5$. 


\subsubsection{Termo forçante na fronteira imersa}

No método da fronteira virtual proposto por Goldstein, Handler e Sirovich (1993), o termo forçante é calculado usando a expressão (2.31):

$$
\mathbf{F}(s, t)=\alpha_{v} \int_{0}^{t}[\mathbf{u}(s, t)-\mathbf{u}(\mathbf{X}(s, t), t)] d t+\beta_{v}[\mathbf{u}(s, t)-\mathbf{u}(\mathbf{X}(s, t), t)],
$$

$\alpha_{v}$ e $\beta_{v}$ devem ser ajustadas de forma a se obter o comportamento físico desejado do escoamento. Os parâmetros $\alpha_{v}$ e $\beta_{v}$ estão diretamente ligados à modelagem das forças que simulam o corpo imerso e à magnitude do passo de tempo de integração $\Delta_{t}$. Assim, quanto melhor o ajuste destes parâmetros, mais capaz será o modelo do corpo imerso em simular o corpo real de forma que a velocidade do escoamento nos pontos de contato fluido-estrutura seja igual a zero. Vale lembrar que tal escolha também implicará na restrição ao passo de tempo, que afeta o tempo total de execução da simulação.

Para verificação do efeito das constantes $\alpha_{v}$ e $\beta_{v}$ sobre a simulação computacional, é apresentado o caso clássico do escoamento sobre um cilindro circular bidimensional com adimensionalização feita por meio do diâmetro $D$ do cilindro, igual a $L_{\infty}$ na formulação. Para número de Reynolds 400 (escolhido conforme proposto por Saiki e Biringen (1996)) foram obtidos alguns resultados para valores do número de Strouhal a partir da variação dos parâmetros $\alpha_{v}$ e $\beta_{v}$ e passo no tempo, conforme mostrado na tabela (5.4). Pode-se constatar que diminuindo a magnitude das constantes $\alpha_{v}$ e $\beta_{v}$ há aumento do número de Strouhal e distanciamento dos valores experimentais e de outras simulações.

Quando $\alpha_{v}$ e $\beta_{v}$ são escolhidos negativos e com magnitude adequada, a velocidade u na fronteira tende a zero, conforme Lai e Peskin (2000). O trabalho de Benevenutti e Silvestrini (2006) mostra que quanto maior o valor de $\alpha_{v}$, em módulo, $\left(\alpha_{v}=-50000\right.$ e $\left.\beta_{v}=-30\right)$ menor será o valor da velocidade do fluido nos pontos fluido-estrutura. O trabalho de Buarque, Schettini e Silvestrini (2005) mostra que quanto maior o valor do parâmetro $\alpha_{v}$ menor o valor do passo no tempo $\Delta_{t}$, inclusive com a indicação de que se $\alpha \rightarrow \infty$ então $\Delta_{t} \rightarrow$ zero. Pela comparação desses resultados, a influência do parâmetro $\alpha_{v}$ é mais determinante que a influência do parâmetro 
Tabela 3.1: Valores do Número de Strouhal e do passo no tempo para os parâmetros $\alpha_{v}$ e $\beta_{v}$ para escoamento sobre cilindro estacionário.

\begin{tabular}{c|c|c|c}
\hline \multicolumn{2}{c|}{ Parâmetros } & St - Número de Strouhal & Passo no tempo \\
\hline & $\alpha_{v}=-500000$ e $\beta_{v}=-5000$ & 0,2195 & 0,0005 \\
simulação & $\alpha_{v}=-50000$ e $\beta_{v}=-500$ & 0,2232 & 0,0075 \\
computacional & $\alpha_{v}=-5000$ e $\beta_{v}=-50$ & 0,2247 & 0,020 \\
neste trabalho & $\alpha_{v}=-500$ e $\beta_{v}=-5$ & 0,2248 & 0,150 \\
& & 0,22 & - \\
\hline \multicolumn{2}{c}{ computacional Saiki e Biringen (1996) } & 0,20 & - \\
\hline
\end{tabular}

$\beta_{v}$ tanto para o passo de tempo $\Delta_{t}$ quanto para a velocidade no ponto fluido-estrutura. Estes resultados estão mostrados no Apêndice B.

Lai e Peskin (2000) mostraram que o método da fronteira imersa reproduz os mesmos resultados que o da fronteira virtual se a constante $\beta_{v}$ for 0 e se a componente elástica da fronteira $K_{s}$ for muito alta, ou seja, tão grande que consiga impedir o deslocamento de um ponto da fronteira em relação aos outros pontos da fronteira, ou seja, a componente $\mathbf{F}(s, t)$ da eq. (2.28) sendo "grande" vai impor que a força na fronteira atenda a condição de não-escorregamento. De forma análoga no método da fronteira virtual, podemos escolher um valor para o parâmetro $\alpha_{v}$ de forma a considerar o parâmetro $\beta_{v}=0$ e conseguirmos um valor para o passo no tempo que não inviabilize o tempo computacional da simulação nem produza distorções nos resultados. Neste trabalho o valor escolhido foi $\alpha_{v}=-220.000$.

No método da fronteira virtual, o campo de força lagrangiano baseado somente nas equações de quantidade de movimento, as equações de Navier-Stokes são calculadas para todos os pontos da malha lagrangiana e a força $\mathbf{F}(\mathbf{x})$ deve ser avaliada sobre a interface usando o campo de velocidades u e o campo de pressão $\mathbf{p}$. Neste cálculo deve-se levar em conta que a velocidade do 
fluido deve ser a mesma da interface, de forma a se garantir a condição de não-escorregamento. As derivadas espaciais da velocidade e pressão são calculadas usando a velocidade e pressão obtidas pelas equações eq. (2.26) e (2.27).

Discretamente, o termo forçante é susceptível à maior ou menor distribuição do campo de força às células vizinhas. A função delta foi desenvolvida para garantir que os dados interpolados satisfaçam as condições de quantidade de movimento discreta. A função delta usada por Goldstein, Handler e Sirovich (1993), $\vec{f}(x, t)=\vec{f}\left(x_{s}, t\right) e^{-\left[\left(i-i_{s}\right)^{2}+\left(j-j_{s}\right)^{2}+\left(k-k_{s}\right)^{2}\right]}$, apresenta um esquema de representação de fronteira virtual em que os pontos adjacentes, dispostos a um espaçamento de malha, $\Delta$, de distância, devem sofrer, pelo menos, $37 \%$ da força central enquanto os pontos distantes dois espaçamentos de malha devem receber nenhuma influência (valores para norma $L^{2}$ para a função gaussiana até 5 espaçamentos podem ser encontrados no trabalho de Silvestrini e Lamballais (2000)). Da distribuição gaussiana, o segundo ponto adjacente receberia $1,83 \%$ da força central. Ao truncarmos essa função devemos tomar um cuidado especial para garantir que o erro entre a integral e o valor unitário seja adequado ao modelo numérico, de forma a não introduzir propagação do erro de truncamento.

$$
\left|1-\iint_{-n \Delta}^{n \Delta} \delta(x, y) d x d y\right|<\text { admissivel } .
$$

Outra característica associada à distribuição do campo de força refere-se à adequada representação da fronteira imersa para a mnutenção das características do escoamento e não permitir "permeabilidade", ou seja, uma má representação da fronteira imersa acarreta escoamento através fronteira e consequente perda do modelo. A função dada pela eq. (3.30), ao ser truncada no raio de duas células, garante um erro da ordem de $10^{-8}$, ou seja, suficiente para evitar o problema de truncamento comentado nesta subseção.

\subsection{Controle do passo no tempo}

A cada ciclo computacional ou a cada instante de tempo $t$ é necessário um critério de estabilidade para controlar o passo no tempo de modo a assegurar que o método numérico 
não amplifique os erros de truncamento devido à discretização espacial do método de marcha no tempo. O controle é feito utilizando a condição de estabilidade para as equações de NavierStokes (TOMÉ; MCKEE, 1994) composta por duas restrições - CFL (Courant-Friedrichs-Lévi) e viscosidade - e a condição de estabilidade do Método da Fronteira Virtual (GOLDSTEIN, 1993).

Critério de estabilidade para as equações de Navier-Stokes:

$$
\Delta t_{1}=\min \left(\Delta t_{v i s c}, \Delta t_{u}, \Delta t_{v}\right)
$$

onde

$$
\begin{aligned}
\Delta t_{v i s c} & =\frac{A_{1}}{2 v} \cdot \frac{\delta x^{2} \delta y^{2}}{\delta x^{2}+\delta y^{2}}, \\
\Delta t_{u} & =A_{2} \cdot \frac{\delta x}{2 u_{\max }}, \\
\Delta t_{v} & =A_{2} \cdot \frac{\delta y}{2 v_{\max }},,
\end{aligned}
$$

onde $\Delta t$ é o passo no tempo, $\delta x$ e $\delta y$ são os espaçamentos da malha nas direções $x$ e $y, v$ é a viscosidade e $A$ um valor tal que $0 \leqslant A \leqslant 1$.

Os critérios dados pelas equações (3.40) e (3.41) asseguram que nenhuma partícula de fluido escoe pela distância de mais de uma célula no domínio computacional em um intervalo de tempo $\Delta t$.

Critério de estabilidade do método da fronteira virtual:

$$
\Delta t_{2} \leq \frac{-\beta_{v}-\sqrt{\left(\beta_{v}^{2}-2 \alpha_{v}\right)}}{\alpha_{v}} 2,85
$$

onde $\alpha_{v}$ e $\beta_{v}$ são os parâmetros escolhidos e 2,85 é uma constante que depende do problema e advém do critério de estabilidade do esquema de Runge-Kutta. Esse critério assegura a estabilidade da fronteira virtual. 
O critério de estabilidade do método numérico deve respeitar as restrições impostas pelas equações (3.38) e (3.42) simultaneamente. Portanto:

$$
\Delta t=\tau \min \left(\Delta t_{1}, \Delta t_{2}\right),
$$

onde $\tau$ é um parâmetro de segurança escolhido para garantir a estabilidade do método numérico. O parâmetro $\tau$ é necessário pois a estabilidade do método numérico também depende das condições de contorno empregadas. Esse critério de estabilidade é uma aproximação para o passo no tempo estável. Nesse trabalho $\tau \in[0,4 ; 0,8]$. 


\section{Verificação do método numérico e código computacional}

A Society for Computer Simulation (SCS) definiu os conceitos de Verificação e Validação, V\&V. As definições são as seguintes:

- Verificação do Modelo: comprovação de que um modelo computadorizado (modelo computacional ou código) representa um modelo conceitual dentro dos limites especificados de precisão.

- Validação do Modelo: comprovação de que um modelo computadorizado dentro de seu domínio de aplicação possui uma gama satisfatória de precisão compatível com a aplicação pretendida para o modelo.

Esquematicamente, O modelo conceitual em CFD é constituido pela equações diferenciais,

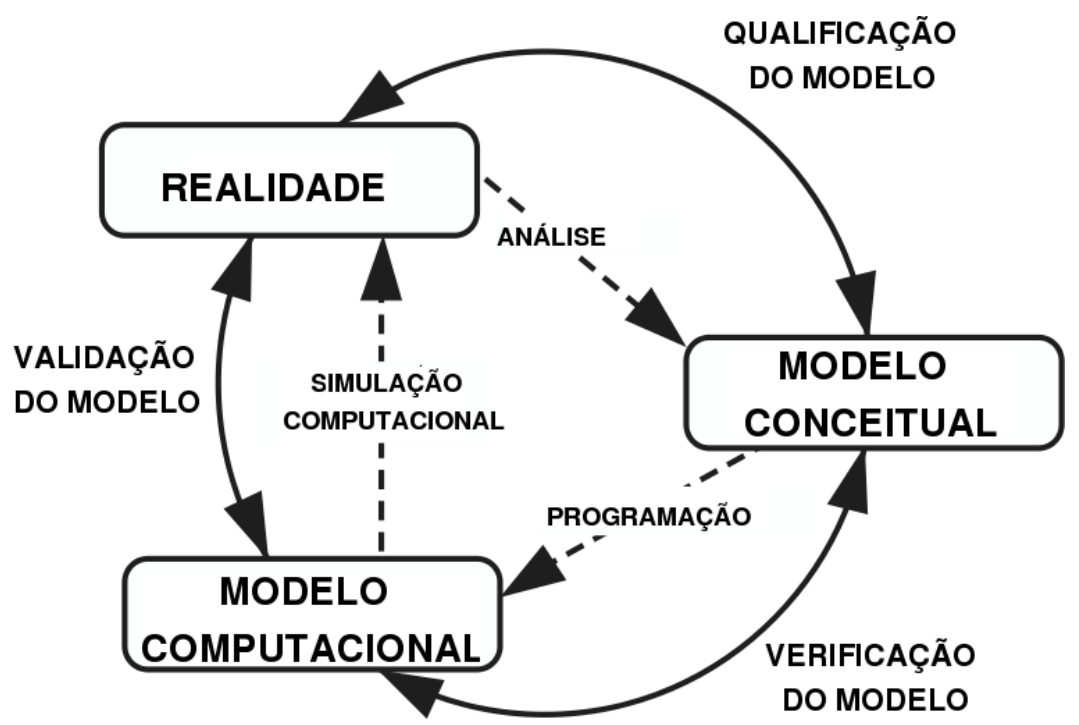

Figura 4.1: Papel da V\&V dentro da abordagem de modelagem e simulação adotada pelo SCS 
que descrevem o sistema físico, equações auxiliares e condições iniciais e de contorno. A Qualificação do modelo refere-se á determinação da adequação do modelo conceitual para fornecer um nível aceitável de concordância com o domínio da aplicação pretendida.

A validação do método numérico está relacionada aos erros de modelagem. O modelo matemático de um problema físico, normalmente, exige simplificações e restrições e essas simplificações produzem erros que podem fazer com que a solução modelada não corresponda à solução do fenômeno físico. O processo de validação envolve a comparação de resultados computacionais com resultados experimentais para determinar se o método computacional é capaz de resolver ou representar adequadamente o fenômeno físico.

A verificação do código está relacionada aos erros computacionais de implementação e discretização. É um processo para identificar fontes de erros na simulação numérica tais como erros de arredondamento (associados à precisão de máquina) e erros de discretização (associados ao modelo de discretização).

Conforme Oberkampf e Trucano (2002) verificação ${ }^{1}$ e validação ${ }^{2}$ são os principais meios para avaliar a precisão e confiabilidade em simulações computacionais. De acordo com estes autores, questões fundamentais em verificação e validação devem ser observadas, tais como: verificação do código versus verificação da solução; validação do modelo versus validação da solução; distinção entre erro e incerteza; fontes de erro e incerteza, e relação entre a validação e previsão.

Um dos objetivos da verificação é a identificação dos erros de programação. Na verificação, a exatidão de uma solução computacional é medida principalmente em relação a dois tipos de soluções muito precisas: soluções analíticas e soluções numéricas altamente precisas. A

\footnotetext{
${ }^{1}$ De acordo com o Institute of Electrical and Electronics Engineers (IEEE), é o processo de avaliação dos produtos de uma fase de desenvolvimento de software para garantir que estes cumpram os requisitos definidos para eles na fase anterior. De acordo com o Comitê de padronização em CFD do American Institute of Aeronautics and Astronautics (AIAA), é o processo de determinação de que um modelo de implementação representa fielmente o descrito pelo modelo conceitual e sua solução

${ }^{2}$ De acordo com o Institute of Electrical and Electronics Engineers (IEEE), é o processo de teste de um programa computacional com avaliação dos resultados para garantir a conformidade com requisitos específicos. De acordo com o Comitê de padronização em CFD do American Institute of Aeronautics and Astronautics (AIAA), é o processo de determinação do grau que um modelo é rigorosamente a representação do mundo real a partir da perspectiva das utilizações do modelo.
} 
estratégia de validação é fundamental para avaliar a precisão dos resultados computacionais comparados com os dados experimentais através da quantificação do erro e incerteza para as duas alternativas. Para quantificar o erro da solução numérica, deve-se dispor de uma grande quantidade de dados com grande precisão (benchmark). Estes dados podem referir-se tanto a soluções analíticas quanto a soluções numéricas altamente precisas. Infelizmente, soluções altamente precisas são disponíveis apenas para problemas de modelos simplificados. A Verificação, assim, fornece elementos de prova (fundamentação) de que o modelo conceitual (matemática do continuum) é resolvido corretamente pela Matemática Discreta consubstanciado no código computacional.

De forma esquemática e de acordo com o Guide for Verification and Validation in Computational Solid Mechanics (available through ASME publications as V\&V 10-2006), por definição, é necessário estabelecer a confiança no modelo computacional através de dois processos fundamentais:

- Verificação do código - se o modelo matemático e o algoritmo de solução estão trabalhando corretamente;

> Verificação do cálculo - se a solução discreta do modelo matemático é precisa.

Em dinâmica de fluidos computacional, o erro é definido como $E=u_{\text {exata }}-u_{\text {discreta }}$, onde $u_{\text {exata }}$ é a solução matematicamente exata do modelo conceitual dado pelas equações diferenciais parciais definidas para um conjunto de condições iniciais e de fronteira; e $u_{\text {discreta }}$ é a solução numérica de uma dada aproximação numérica para as mesmas equações diferenciais parciais e conjunto de condições iniciais e de fronteira, produzidas por um dado código computacional em um dado computador. Considera-se que $u_{\text {exata }}$ e $u_{\text {discreta }}$ são campos escalares e que $E$ depende da discretização, simbolizada pelas características de espaçamento $h$ da malha, como por exemplo, se uni, bi ou tridimensional, se tem variação espacial, se é adaptativa no tempo ou se é dependente de parâmetros da discretização temporal. $E$ sempre dependerá do problema particular escolhido para estudo em dinâmica de fluidos computacional. 
Seja $u_{h, \tau \rightarrow 0}$, no limite quando $h \rightarrow 0$ e $\tau \rightarrow 0$, a solução exata de um mapeamento discreto de equações diferenciais parciais e suas condições iniciais e de fronteira. O erro estimado $E$ pode ser escrito como

$$
E \leq\left\|u_{\text {exata }}-u_{h, \tau \rightarrow 0}\right\|+\left\|u_{h, \tau \rightarrow 0}-u_{h, \tau, I, c}\right\|<\epsilon
$$

onde $u_{h, \tau, I, c}$ é a solução discreta usando um determinado algorítmo para uma dada malha com espaçamento $h$, espaçamento no tempo $\tau$ parâmetro de convergência iterativa $I$ e computador $c$. $\epsilon$ é um número muito pequeno escolhido arbitrariamente e de acordo com a precisão numérica requerida.

O primeiro termo da equação (4.1) $\left\|u_{\text {exata }}-u_{h, \tau \rightarrow 0}\right\|$ é o erro introduzido pela solução exata das equaccões discretas. Normalmente este termo é zero para esquemas numéricos estáveis, lineares, fortemente consistentes e com equações diferenciais parciais lineares de coeficientes constantes. O segundo termo da equação (4.1) é a principal causa para a verificação da performance de cálculo. Este termo é diferente de zero devido a: $h, \tau$ e $I$ serem finitos; a precisão aritmética ser finita; e a erros de operação do código computacional. Trabalhar com o segundo termo na equação (4.1) é o principal objetivo para verificação dos cálculos (avaliação da precisão da solução), embora outros elementos de verificação do código, tal como qualidade de engenharia de software, contribuem para a redução da possibilidade de erro não conhecido. No presente trabalho faremos a verificação do código e da solução e também a validação.

\subsection{Método da solução manufaturada}

O "Método da Solução Manufaturada" desenvolvido por Roache (1998) e estudado por Roy, Nelson e Ober (2004), Bond, Knupp e Ober (2005) é um teste particular de verificação de ampla aplicabilidade. Nesta abordagem de construção para testar problemas com uma forma específica de função, a solução é assumida como satisfazendo uma equação diferencial parcial de interesse. Esta função é inserida na equação diferencial parcial, e todas as derivadas são computadas analiticamente, manualmente ou através de software. A equação é rearranjada 
tal que todos os termos restantes em excesso daqueles da equação diferencial parcial original são agrupados em um termo de força. Este termo é, então, simplesmente acrescentado à equação diferencial parcial original de forma que a solução da função satisfaça exatamente à nova equação diferencial parcial, ou seja, as equações diferenciais governantes são modificadas conduzindo a solução para uma solução manufaturada pré-estabelecida. Por exemplo, nas equações de Navier-Stokes este termo fonte pode ser considerado como um termo de força, ou seja, um novo termo no lado direito.

De acordo com Bond, Knupp e Ober (2005) a Solução Manufaturada pode ser melhor aplicada em malhas finas quando as propriedades de transporte viscoso $\mu$ e $\kappa$ (viscosidade e condutividade térmica) causam fluxos viscoso e convectivo de mesma magnitude. Se o fluxo viscoso for significavamente menor que o fluxo convectivo, os erros presentes no código para a equação da quantidade de movimento (momentum) ou para o cálculo do fluxo térmico podem não ser observáveis no Método da Solução Manufaturada, a não ser que a malha seja muito fina.

Considere as equações diferenciais parciais escritas como segue:

$$
\mathscr{L}(Q, \xi, t)=\mathscr{F}(\xi, t)
$$

com condições de contorno dadas por:

$$
\mathscr{B}(Q, \xi, t)=\mathscr{G}(\xi, t)
$$

onde $Q$ é a solução da equação diferencial parcial, $\xi$ representa o domínio computacional e, $\mathscr{F}(\xi, t)$ e $\mathscr{G}(\xi, t)$ são termos fonte que dependem do domínio computacional e do tempo, mas não dependem da solução $Q$. Cada variável do escoamento, representada em $Q$, é atribuída a alguma função contínua, por exemplo trigonométrica, exponencial, polinomial ou combinações dessas funções. Esse conjunto de soluções é representado por $Q^{e}(x, y)$. Estas soluções manufaturadas são substituídas na equação diferencial parcial contínua para gerar os termos fonte:

$$
\mathscr{F}(\xi, t)=\mathscr{L}\left(Q^{e}, \xi, t\right), \quad \mathscr{G}(\xi, t)=\mathscr{B}\left(Q^{e}, \xi, t\right)
$$


Os termos fonte $\mathscr{F}$ e $\mathscr{G}$ modificam as equações governantes para:

$$
\mathscr{L}(Q, \xi, t)=\mathscr{L}\left(Q^{e}, \xi, t\right), \quad \mathscr{B}(Q, \xi, t)=\mathscr{B}\left(Q^{e}, \xi, t\right)
$$

Devido à introdução dos termos fonte, a solução numérica $Q^{c}$ da equação (4.5) deve convergir para a solução exata $Q^{e}$. Isto ocorrerá se a implementação e a discretização das equações governantes estiverem corretas. Além disso, a ordem de convergência de malha deve ser verificada comparando a diferença entre a solução convergida $Q^{c}$ com a solução exata $Q^{e}$ utilizando uma norma qualquer, ou seja

$$
\mathscr{E}\left(Q^{c}, Q^{e}\right)=\left\|Q^{c}-Q^{e}\right\|
$$

O erro $\mathscr{E}\left(Q^{c}, Q^{e}\right)$ é utilizado para calcular a ordem de convergência de malha do método numérico, através da equação (4.17). Se a ordem numérica concordar com a ordem teórica, então pode-se dizer que o código está verificado. Isto é, livre de erros de implementação. As soluções manufaturadas podem ser quaisquer funções diferenciáveis de classe $C^{n}, \operatorname{com} n$ grande o suficiente de tal forma que os termos de erro de truncamento da expansão em séries de Taylor, das variáveis discretizadas, não sejam nulos. Em geral, é mais prático utilizar funções de classe $C^{\infty}$, como senos e cossenos, que são infinitamente diferenciáveis. Porém, em alguns casos, as anti-derivadas dessas funções não existem, e nesse caso, as funções polinomiais são a solução. Ao escolher as soluções manufaturadas, deve-se tomar o cuidado para evitar singularidades em algumas regiões do domínio, como por exemplo, fazer divisão por zero ou tomar a raiz quadrada de números negativos.

As seis etapas requeridas para implementação do método da solução manufaturada são:

passo 1 - escolher a forma das equações governantes;

passo 2 - escolher a forma da solução manufaturada;

passo 3 - aplicar a solução manufaturada às equações governantes e gerar analiticamente o termo de força; 
passo 4 - discretizar as equações e resolvê-las para vários níveis de malha usando condições de contorno analíticas e termo de força da solução manufaturada;

passo 5 - avaliar o erro global da discretização na solução numérica; e

passo 6 - determinar se a ordem observada da solução coincide com a ordem formal de precisão.

\subsection{Verificação do código para o domínio euleriano}

O Método da Fronteira Virtual, utilizado neste trabalho, foi implementado utilizando a linguagem de programação $C^{++}$orientada a objeto em sistema operacional Linux (distribuição Ubuntu) otimizado para processadores com arquitetura i586 (família Pentium da Intel). A verificação do sistema de equações Eulerianas é feita utilizando o Método da Solução Manufaturada, cuja finalidade é detectar fontes de erro de implementação no método numérico e verificar se o sistema de equações governantes é resolvido corretamente. A verificação do código é feita utilizando as soluções analíticas para as componentes $u$ e $v$ da velocidade e para a pressão $p$ a partir da equação geral, conforme Roy, Nelson e Ober (2004)

$$
\phi(x, y)=\phi_{0}+\phi_{x} f_{s}\left(\frac{a_{\phi x} \pi x}{L}\right)+\phi_{y} f_{s}\left(\frac{a_{\phi y} \pi y}{L}\right)+\phi_{x y} f_{s}\left(\frac{a_{\phi x y} \pi x y}{L^{2}}\right)
$$

onde $\phi=u, v$ ou $p$, respectivamente $u$-velocidade, $v$-velocidade e pressão e $f_{s}($.$) representa$ uma função seno ou cosseno. Roy et al mostram uma tabela com as constantes utilizadas para os códigos Wind e Premo com condição de Dirichlet. Neste trabalho as condições de fronteira são: condição de Dirichlet na entrada (inflow) $\operatorname{com} u=1$ e $v=0$ e saída (outflow); e condição do tipo Neumann nas paredes com $u=0$ (não escorregamento) e $\delta \mathbf{v}=0$. Devido a esta condição as equações ficam mais complicadas pois temos que encontrar uma função que atenda a condição 
de Neumman e a partir dela conseguir, através de integração, uma primitiva que também atenda a condição de Dirichlet. As funções estão escritas abaixo para $t=0$ :

$$
\begin{aligned}
u(\mathbf{x}, 0)= & \left(\left(\frac{y^{3}}{3}\right) \cos \left(\frac{x}{2}\right)-y^{2} \cos \left(\frac{x}{2}\right)-2 y^{2} \cos \left(\frac{y}{2}\right)+16 \cos \left(\frac{y}{2}\right)+8 y \operatorname{sen}\left(\frac{y}{2}\right)-12 \operatorname{sen}\left(\frac{y}{2}\right)\right. \\
& \left.+6 y \cos \left(\frac{y}{2}\right) x(x-3)\right) / 200+1 \\
v(\mathbf{x}, 0)= & -x(x-3) \frac{\left(-\operatorname{sen}\left(\frac{x}{2}\right)\left(\frac{y^{4}}{24}\right)+\operatorname{sen}\left(\frac{x}{2}\right)\left(\frac{y^{3}}{4}\right)\right)}{200}-\left(\operatorname { c o s } \left(\frac{x}{2} \frac{y^{4}}{12}-r m \cos \left(\frac{x}{2}\right) \frac{y^{3}}{2}-4 y^{2} \operatorname{sen}\left(\frac{y}{2}\right)+96 \operatorname{sen}\left(\frac{y}{2}\right)\right.\right. \\
& \left.\left.-32 y \cos \left(\frac{y}{2}\right)+48 \cos \left(\frac{y}{2}\right)+12 y \operatorname{sen}\left(\frac{y}{2}\right)\right) \frac{x-3}{200}\right)-\left(\cos \left(\frac{x}{2}\right) \frac{y^{4}}{12}-\cos \left(\frac{x}{12}\right) \frac{y^{3}}{2}\right)-4 y^{2} \operatorname{sen}\left(\frac{y}{2}\right) \\
& \left.+96 \operatorname{sen}\left(\frac{y}{2}\right)-32 y \cos \left(\frac{y}{2}\right)+48 y \cos \left(\frac{y}{2}\right)+12 y \operatorname{sen}\left(\frac{y}{2}\right) \frac{x}{200}\right)+\operatorname{sen}(2 \mathrm{x}), \\
p(\mathbf{x}, 0)= & \frac{\left(\operatorname{sen}(\mathrm{x}) \frac{y^{3}}{3}-\frac{3}{2} \operatorname{sen}(\mathrm{x}) y^{2}+y^{2} \operatorname{sen}(\mathrm{y})-2 \operatorname{sen}(\mathrm{y})+2 \cos (\mathrm{y}) y-3 \cos (\mathrm{y})-3 y \operatorname{sen}(\mathrm{y})\right) x^{2}(x-3)}{30},
\end{aligned}
$$

As soluções manufaturadas definidas pelas equações (4.8), (4.9) e (4.10) foram escolhidas de forma a garantir a existência das anti-derivadas e o não aparecimento de singularidades no domínio computacional. Os termos fonte $\mathscr{F}$ das equações governantes são o resultado da diferenciação analítica da solução manufaturada geral. Os valores de $\mathscr{F}_{1}$ para $u$ e $\mathscr{F}_{2}$ para $v$ e $\mathscr{F}_{3}$ para $p$ são determinados substituindo-se os valores de $u, v$ e $p$ fornecidos pelas equações (4.8), (4.9) e (4.10) nas equações governantes:

$$
\begin{aligned}
& \nabla \cdot \vec{u}=0 \\
& \frac{\partial \vec{u}}{\partial t}+\vec{u} \cdot \nabla \vec{u}=-\nabla p+\frac{1}{R e} \nabla_{2} \vec{u}
\end{aligned}
$$

Os resultados estão mostrados no Apêndice A. As figuras 4.2 a 4.4 mostram o gráfico das soluções manufaturadas. As figuras 4.6 e 4.7 mostram o gráfico dos termos fonte calculados a 
partir das soluções manufaturadas. As condições iniciais em $t=0$ são calculadas utilizando a solução analítica juntamente com uma função de perturbação:

$$
\begin{aligned}
& \mathbf{u}_{\text {pertur }}(\mathbf{x}, 0)=\mathbf{u}-\mathscr{P}(x, y) \\
& \mathbf{v}_{\text {pertur }}(\mathbf{x}, 0)=\mathbf{v}+\mathscr{P}(x, y) \\
& \mathbf{p}_{\text {pertur }}(\mathbf{x}, 0)=\mathbf{p}+\mathscr{P}(x, y)
\end{aligned}
$$

onde $\mathscr{P}(x, y)$ é a função perturbação dada por:

$$
\mathscr{P}(x, y)=\frac{1}{5} x(x-3) y(y-3)(\operatorname{sen}(x)-\cos (y))
$$

O gráfico da função perturbação dada pela equação (4.13) é mostrado na figura 4.5.

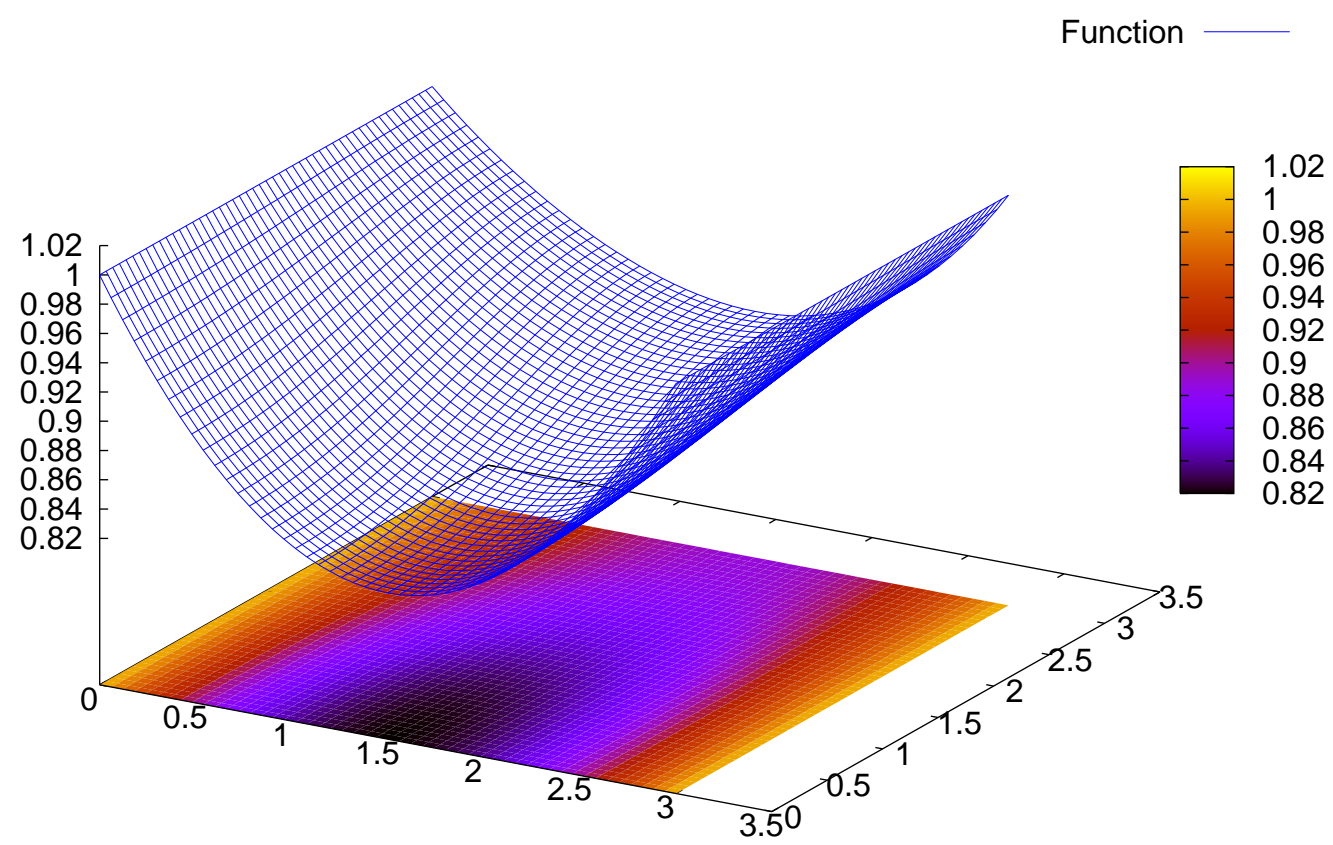

Figura 4.2: Gráfico da solução manufaturada para $u(x, y)$ 


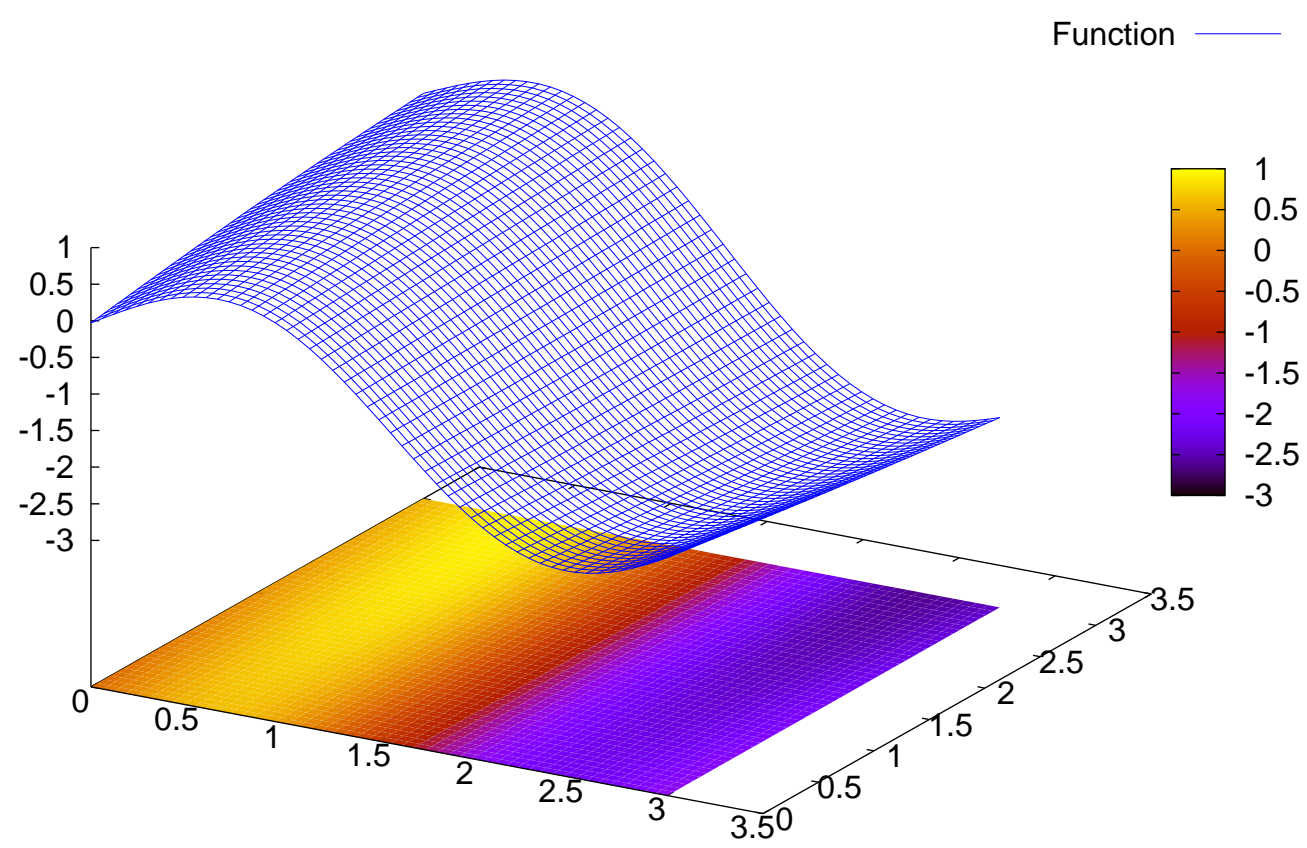

Figura 4.3: Gráfico da solução manufaturada para $v(x, y)$

Function

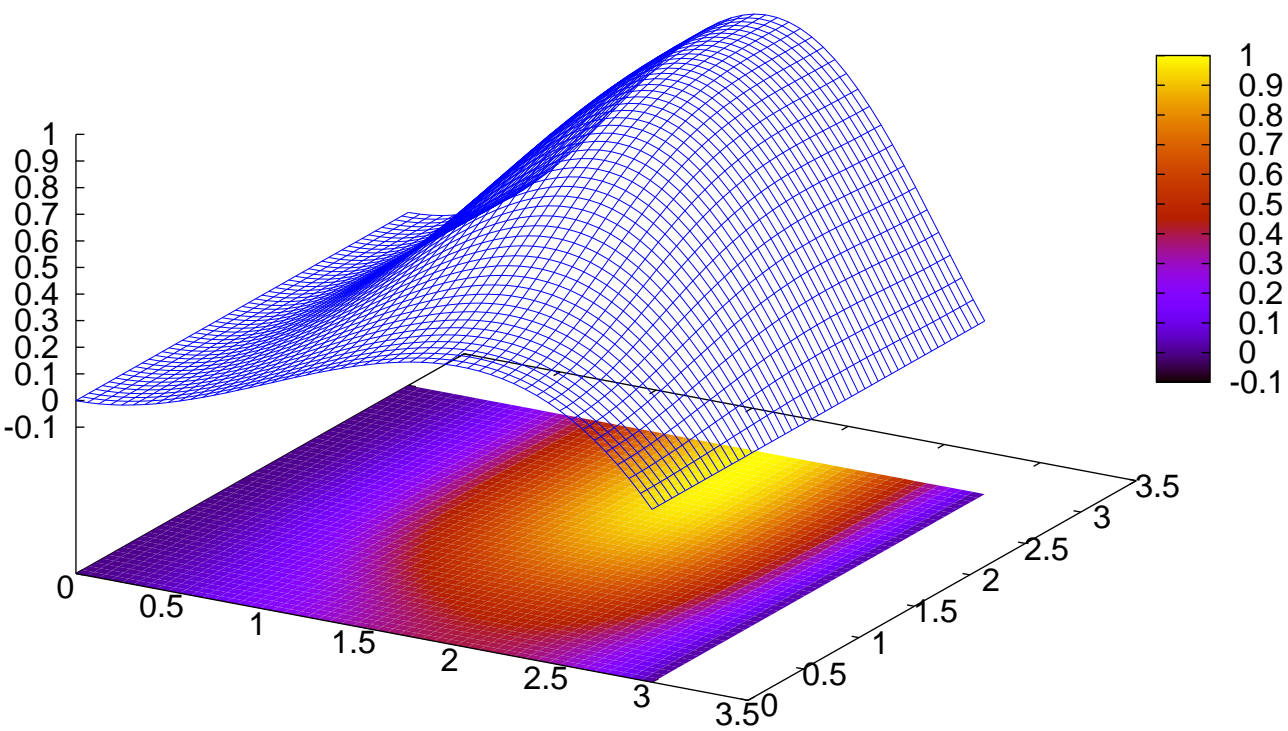

Figura 4.4: Gráfico da solução manufaturada para $p(x, y)$ 
Function

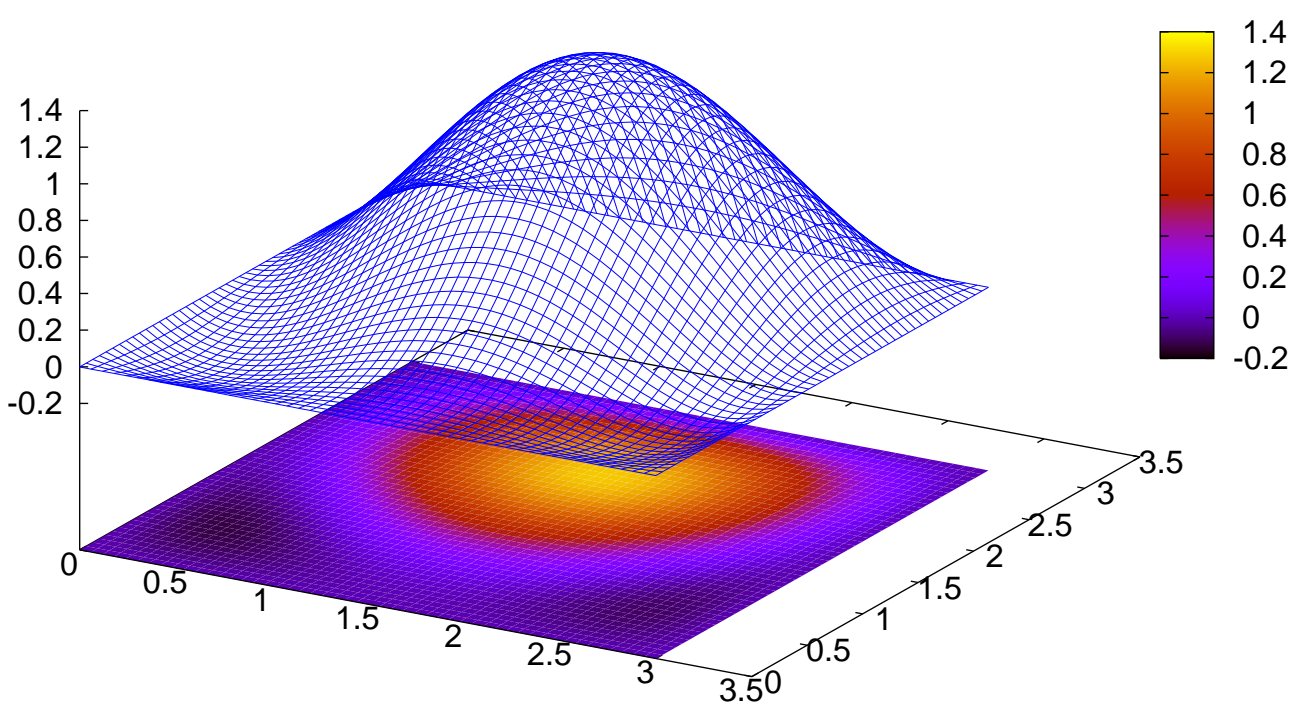

Figura 4.5: Gráfico da função perturbação $\mathscr{P}(x, y)$.

Function

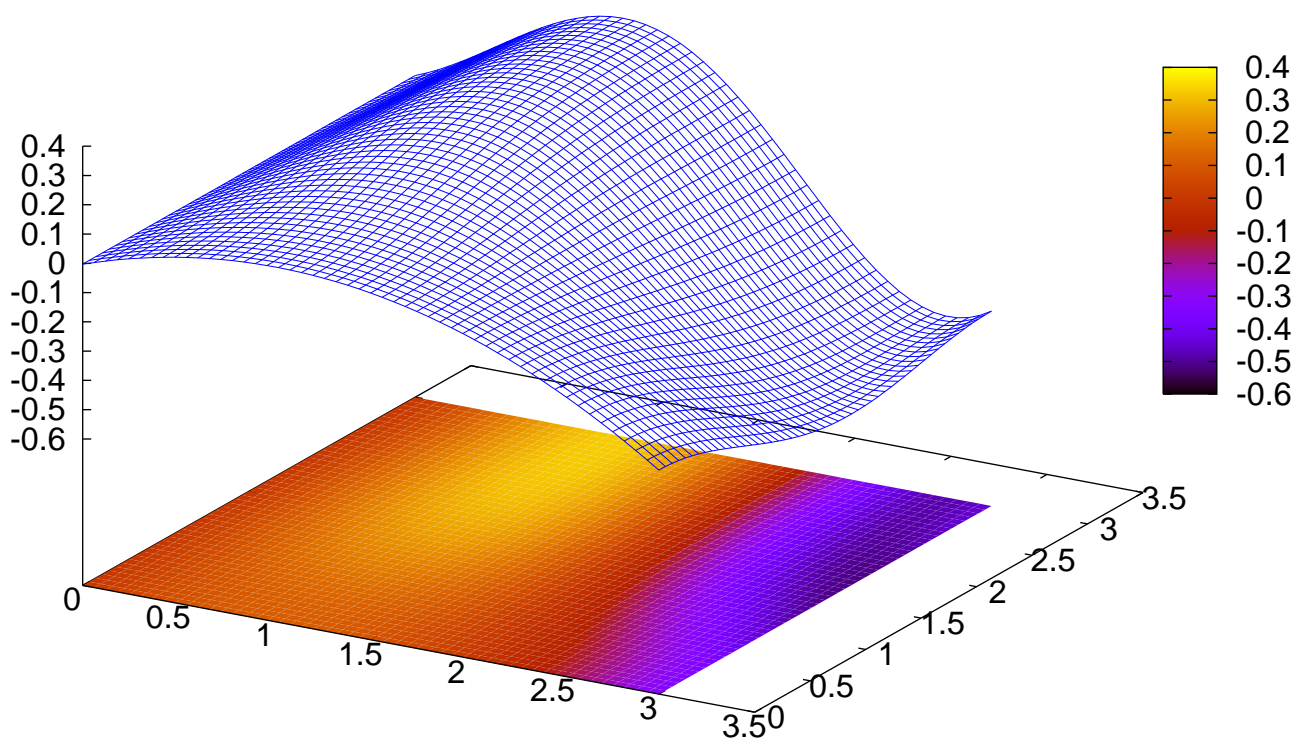

Figura 4.6: Gráfico do termo fonte $\mathscr{F}_{1}(x, y)$. 
Function

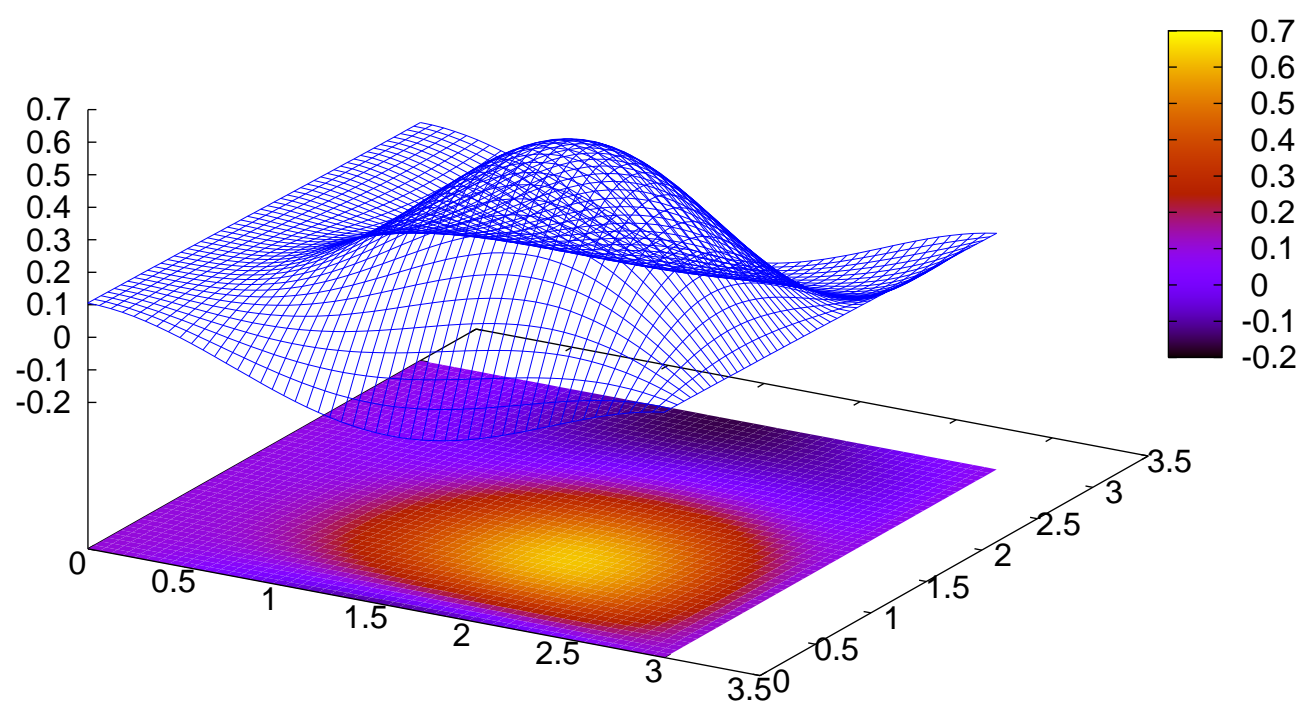

Figura 4.7: Gráfico do termo fonte $\mathscr{F}_{2}(x, y)$.

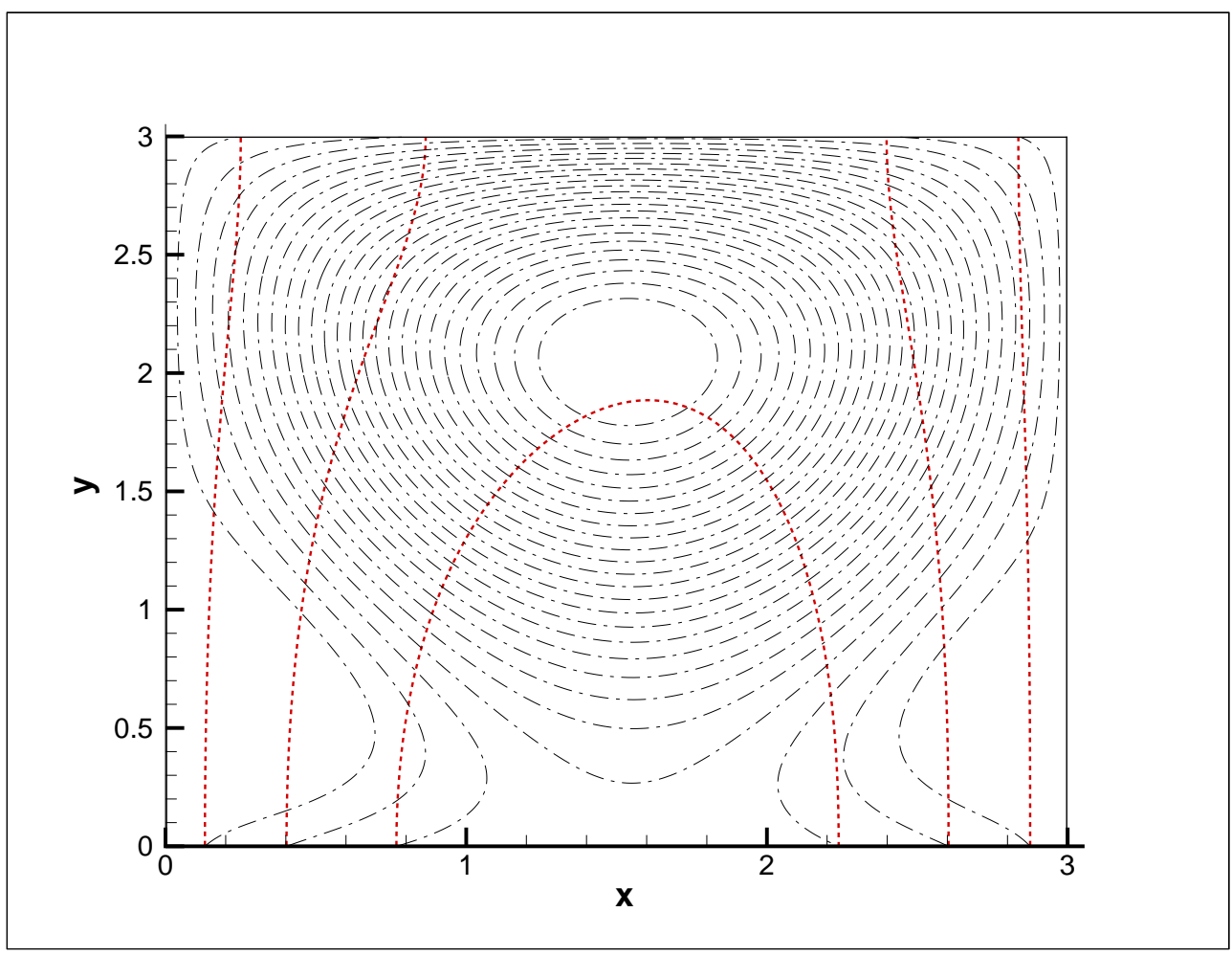

Figura 4.8: Solução analítica para a componente $u$ da velocidade em vermelho e condição inicial perturbada em preto tracejado 


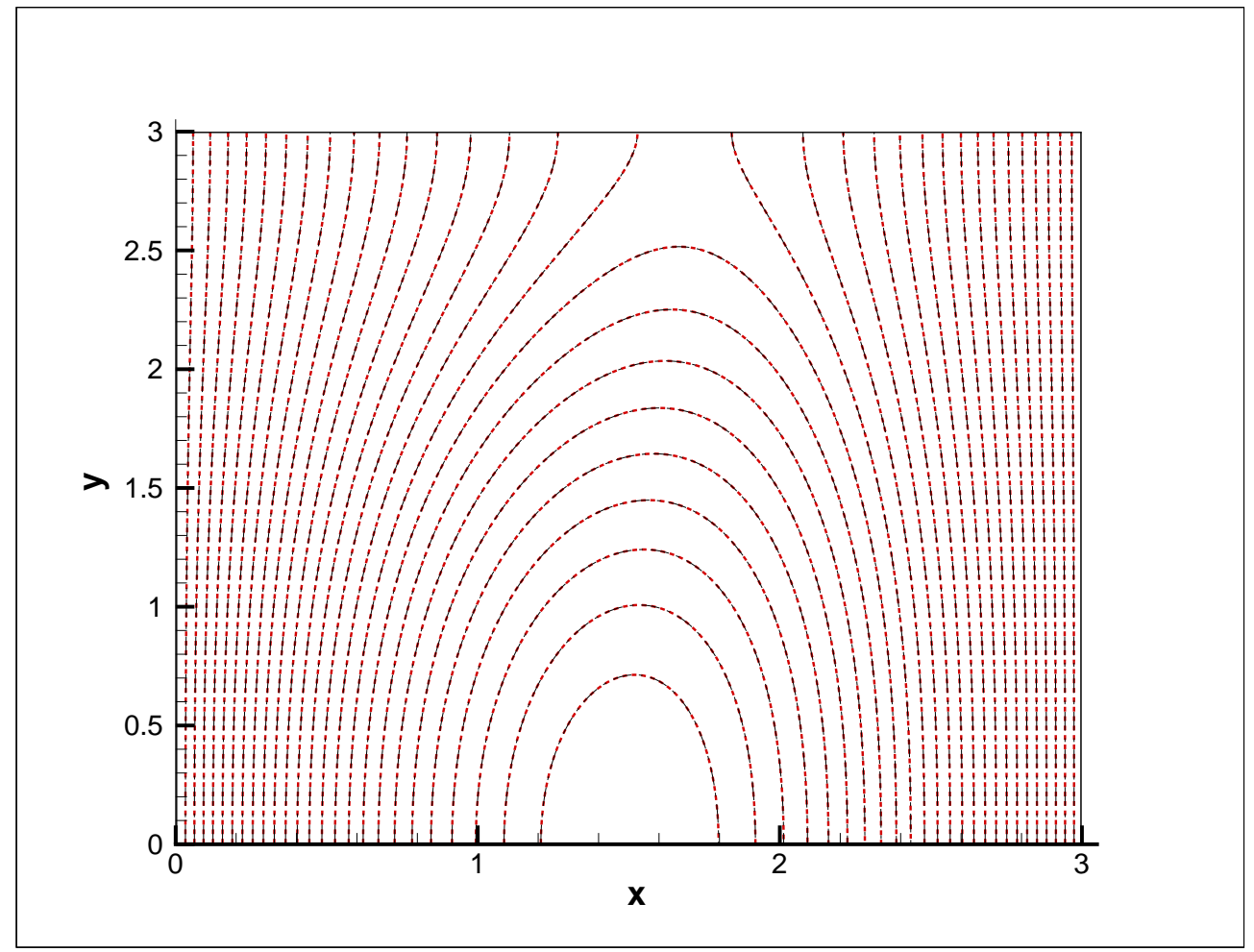

Figura 4.9: Solução analítica para a componente $u$ da velocidade em vermelho e condição convergida em preto tracejado

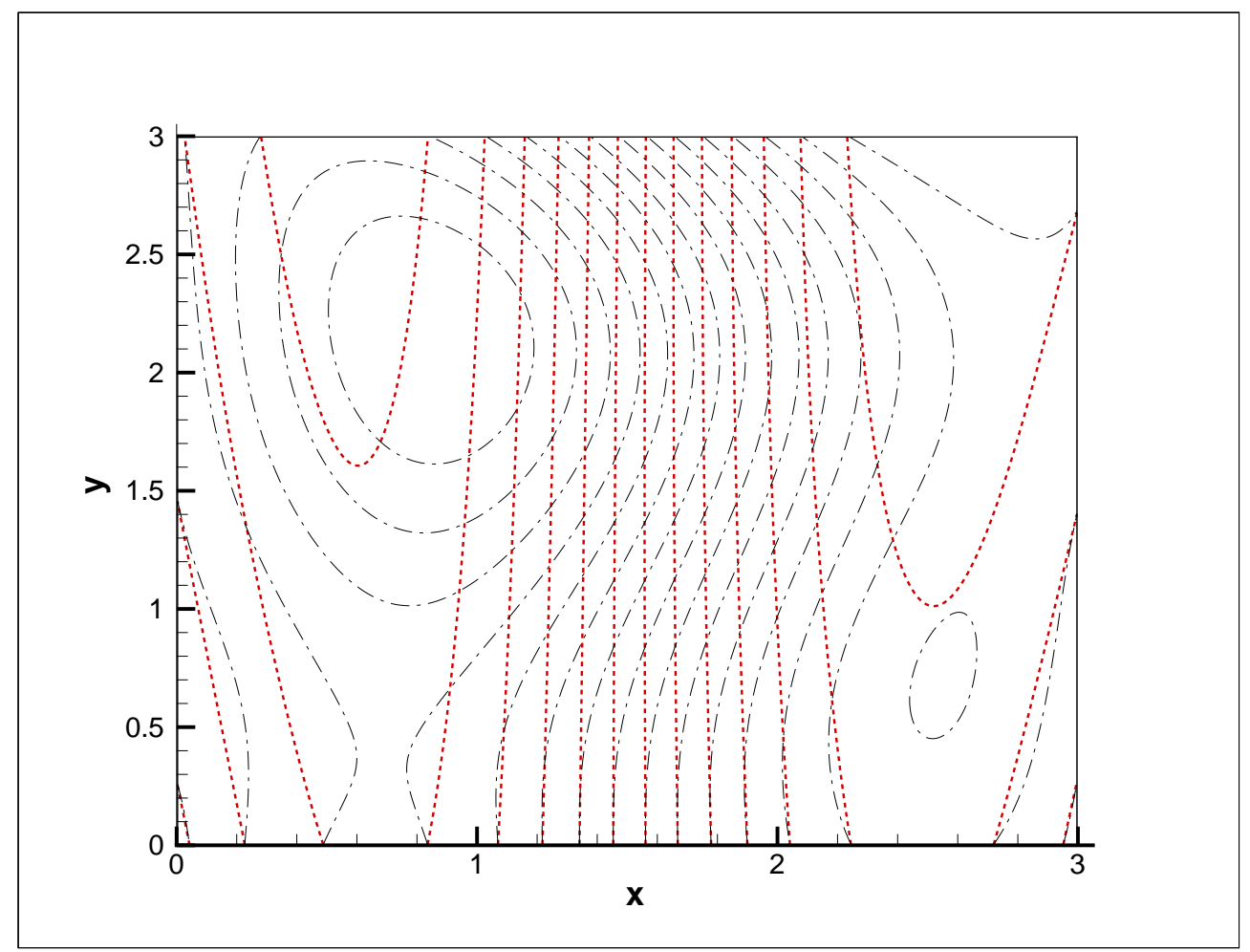

Figura 4.10: Solução analítica para a componente $v$ da velocidade em vermelho e condição inicial perturbada em preto tracejado 


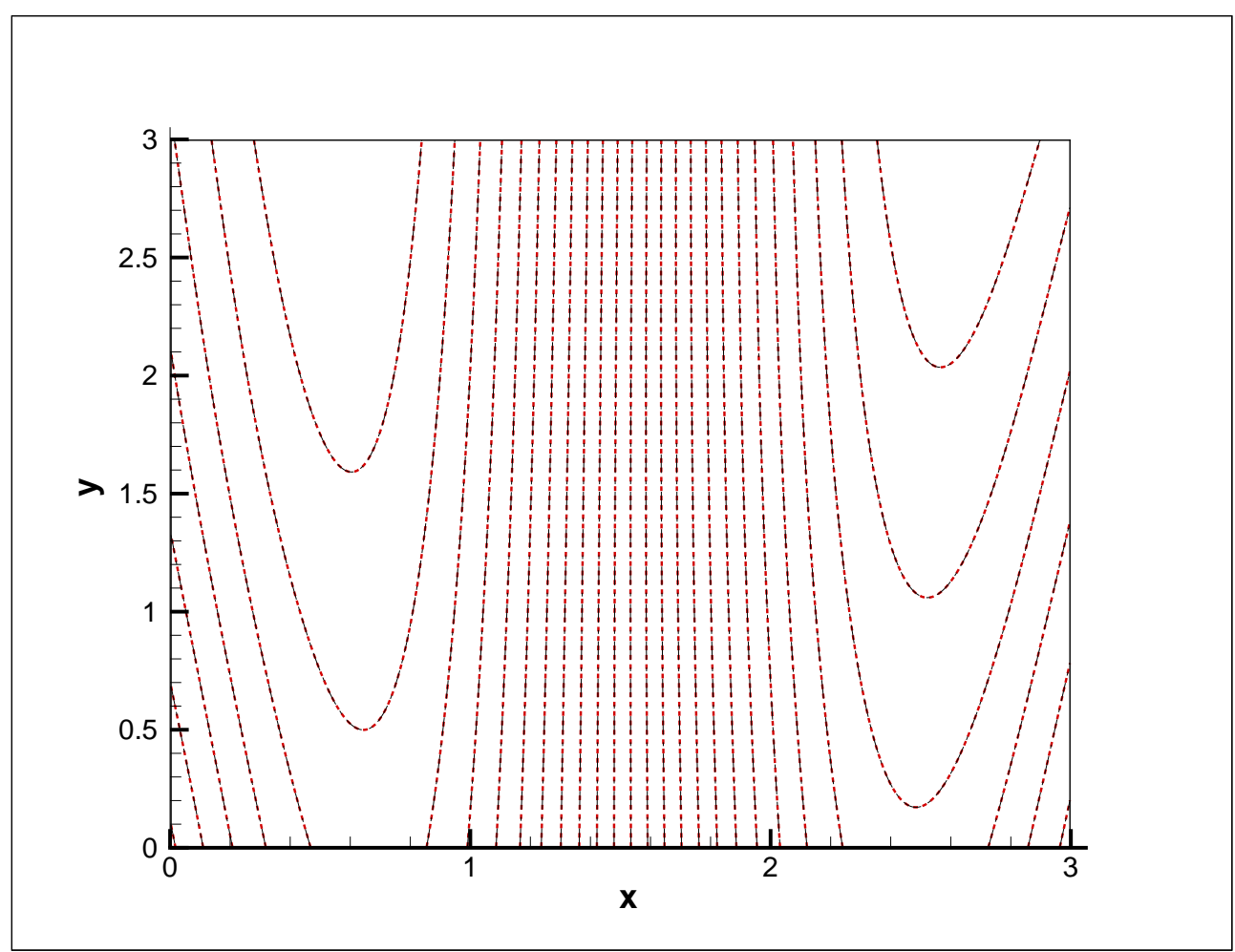

Figura 4.11: Solução analítica para a componente $v$ da velocidade em vermelho e condição convergida em preto tracejado

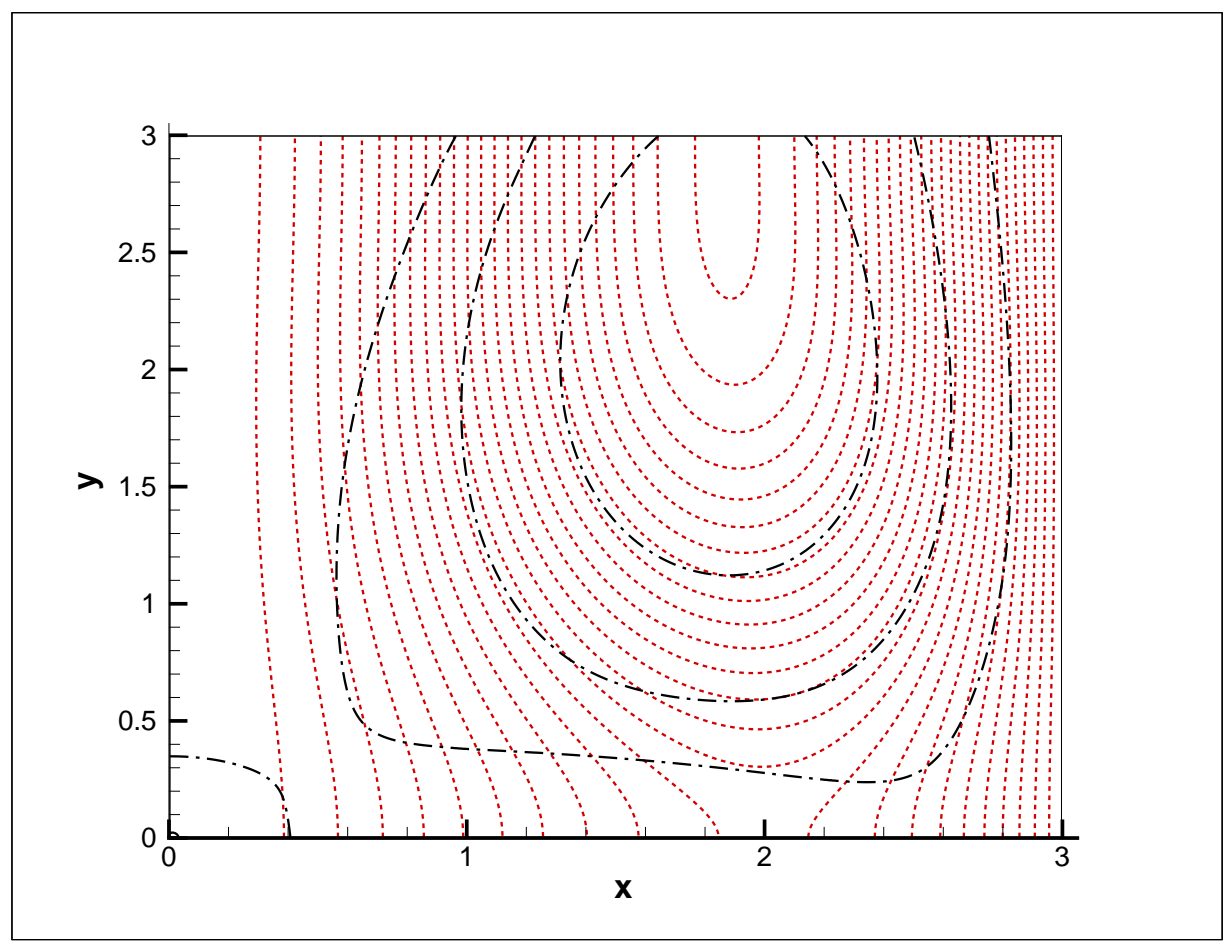

Figura 4.12: Solução analítica para a pressão $p$ em vermelho e condição inicial perturbada em preto tracejado 


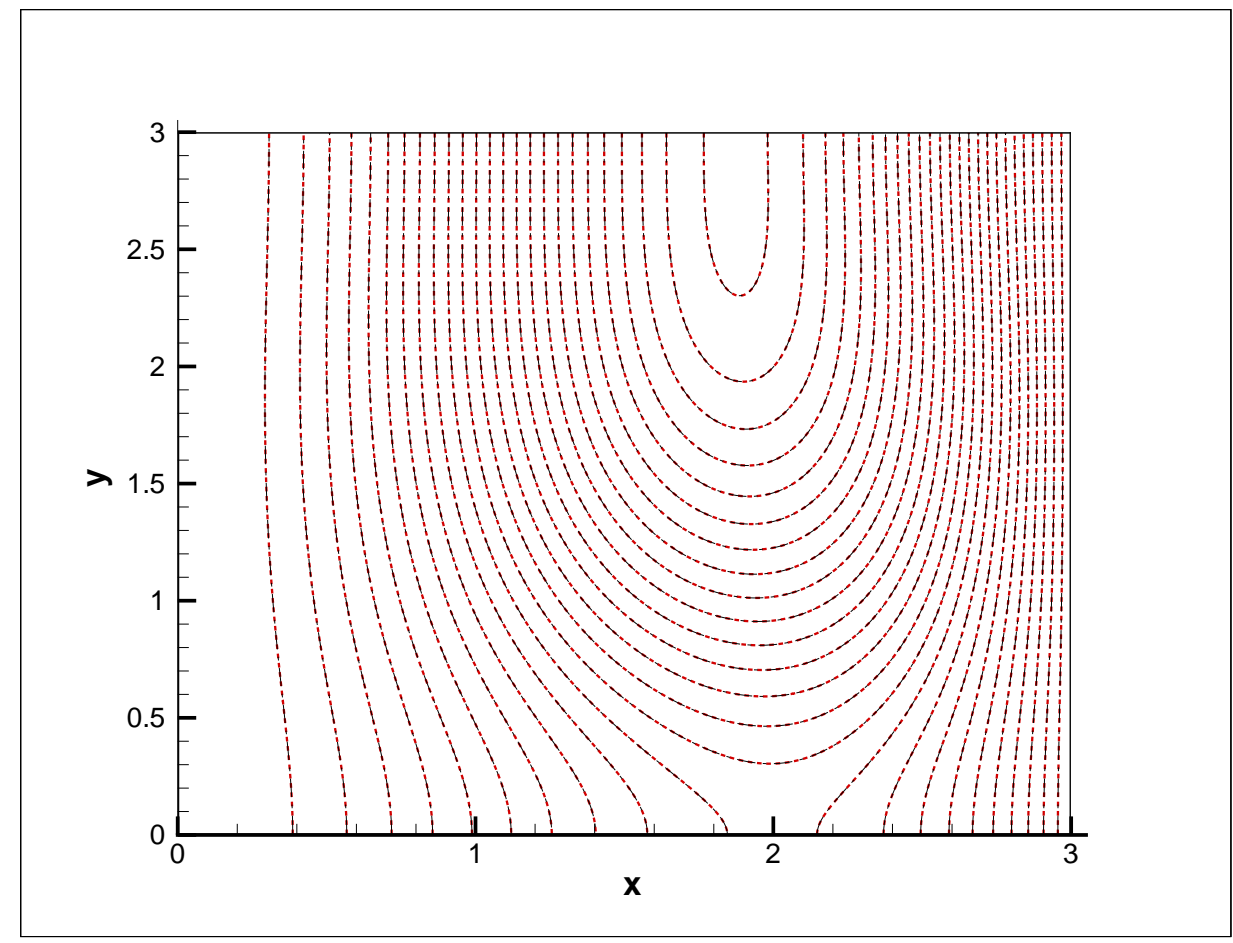

Figura 4.13: Solução analítica para a pressão $p$ em vermelho e condição convergida em preto tracejado

\subsection{Ordem de convergência de malha de um método numérico}

Considere uma variável de interesse $\mathscr{I}$ representando, por exemplo, a velocidade, ou a pressão, ou a energia, etc. Se a solução exata $\mathscr{I}^{e}$ é conhecida, então, para um epaçamento de malha $h$, a variável $\mathscr{I}$ pode ser expandida em séries de Taylor gerando a seguinte série infinita:

$$
\mathscr{I}(h)=\mathscr{I}^{e}+A_{1} h^{1}+A_{2} h^{2}+\ldots+A_{n} h^{n}+\ldots
$$

Se a implementação de um código numérico é de ordem 2 , então $A_{1}=0$ e $A_{2} \neq 0$. Truncando a série de Taylor a partir do termo $\varsigma$ tem-se:

$$
\mathscr{I}(h)=\mathscr{I}^{e}+A h^{\varsigma},
$$

onde $A$ e $\varsigma$ são incógnitas. Se a implementação do código é de ordem 2, então o coeficiente $\varsigma \rightarrow 2$ quando a malha é refinada. Se uma solução exata $\mathscr{I}^{e}$ é conhecida então existem duas 
incógnitas na equação (4.14). Essas incógnitas são os coeficientes $A$ e $\varsigma$. Logo, são necessárias soluções em duas malhas distintas para determinar o valor dessas incógnitas, ou seja,

$$
\begin{aligned}
& \mathscr{I}\left(h_{1}\right)=\mathscr{I}^{e}+A h_{1}^{\varsigma}, \\
& \mathscr{I}\left(h_{2}\right)=\mathscr{I}^{e}+A h_{2}^{\varsigma} .
\end{aligned}
$$

A incógnita $A$ é removida dividindo a equação (4.15) pela equação (4.16), resultando em:

$$
\left(\frac{h_{2}}{h_{1}}\right)^{\varsigma}=\frac{\mathscr{I}\left(h_{2}\right)-\mathscr{I}^{e}}{\mathscr{I}\left(h_{1}\right)-\mathscr{I}^{e}} .
$$

Isolando ৎ nessa equação, a ordem de precisão é dada por:

$$
\varsigma=\frac{\log \frac{\mathscr{I}\left(h_{2}\right)-\mathscr{I}^{e}}{\mathscr{I}\left(h_{1}\right)-\mathscr{I}^{e}}}{\log \frac{h_{2}}{h_{1}}} .
$$

Se porventura a solução exata $\mathscr{I}^{e}$ não é conhecida, então são necessárias soluções em três malhas distintas com espaçamentos $h_{1}, h_{2}$ e $h_{3}$ :

$$
\mathscr{I}\left(h_{1}\right)=\mathscr{I}^{e}+A h_{1}^{\varsigma}, \quad \mathscr{I}\left(h_{2}\right)=\mathscr{I}^{e}+A h_{2}^{\varsigma}, \quad \mathscr{I}\left(h_{3}\right)=\mathscr{I}^{e}+A h_{3}^{\varsigma} .
$$

Removendo $A$ e $\mathscr{I}^{e}$, obtém-se a seguinte equação para a ordem de precisão:

$$
\varsigma=\frac{\log \frac{\mathscr{I}\left(h_{3}\right)-\mathscr{I}\left(h_{2}\right)}{\mathscr{I}\left(h_{2}\right)-\mathscr{I}\left(h_{1}\right)}}{\log r},
$$

onde $r$ é a taxa de refinamento da malha definida por $h_{2}=r h_{1}$ e $h_{3}=r h_{2}$.

Para verificação do código foram usadas cinco malhas regulares, onde $\Delta x=\Delta y=0.1$, $\Delta x=\Delta y=0.05, \Delta x=\Delta y=0.025, \Delta x=\Delta y=0.00125$ e $\Delta x=\Delta y=0.00625$, denominadas respectivamente por Malha 0.1, Malha 0.05, Malha 0.025, Malha 0.0125 e Malha 0.006255 com um domínio retangular de tamanho $3 \times 3$ unidades adimensionais. As figuras 4.8 a 4.13 mostram a comparação entre a solução analítica e a solução analítica com condição inicial perturbada para a componente $u$ da velocidade, para a componente $v$ da velocidade e para a pressão $p$ na Malha 0.00625 . 
O código computacional foi executado com a condição inicial perturbada dada pelas equações (4.12) e com os termos fontes dados pelas equações do Anexo A até atingir a convergência numérica. O erro numérico entre a solução analítica manufaturada e a solução convergida foi avaliado nas seis malhas e os resultados foram utilizados para determinar a ordem de convergência de malha através do processo descrito na Seção 4.3.

As figuras (4.14) e (4.15) mostran o erro de convergência para as variáveis $u, v$ e $p$ para uma malha "grossa" e para uma malha "fina". Pode-se notar que a ordem de grandeza do erro é maior quanto mais grossa a malha.

Tabela 4.1: Erro entre a solução manufaturada $(m)$ e a convergida $(c)$ para $u, v$, e $p$ - Esquema upwind VONOS de Ordem 2

\begin{tabular}{l|c|c|c}
\hline \hline Malha & $\left\|u^{m}-u^{c}\right\|_{L_{\infty}}$ & $\left\|v^{m}-v^{c}\right\|_{L_{\infty}}$ & $\left\|p^{m}-p^{c}\right\|_{L_{\infty}}$ \\
\hline \hline Malha 1 & $9,65 \times 10^{-5}$ & $1,10 \times 10^{-4}$ & $1,86 \times 10^{-4}$ \\
Malha 2 & $2,53 \times 10^{-5}$ & $2,89 \times 10^{-5}$ & $4,90 \times 10^{-5}$ \\
Malha 3 & $6,47 \times 10^{-6}$ & $7,85 \times 10^{-6}$ & $1,33 \times 10^{-5}$ \\
Malha 4 & $1,81 \times 10^{-6}$ & $2,13 \times 10^{-6}$ & $3,44 \times 10^{-6}$ \\
Malha 5 & $4,78 \times 10^{-7}$ & $5,64 \times 10^{-7}$ & $9,26 \times 10^{-7}$ \\
& & & \\
\hline \hline
\end{tabular}

Os resultados mostrados pelas figuras 4.8 a 4.13 e pela Tabela 4.1 indicam que o método numérico convergiu para a solução analítica manufaturada e que o erro devido à malha está dentro da precisão esperada para todas as variáveis. O método numérico VONOS implementado apresenta ordem do erro variando entre 1 e 2 e a figura 4.16 mostra a ordem de convergência de malha comparada com a ordem de convergência teórica. Pode-se notar que ordem de convergência de malha alcançada está muito próxima de dois, ou seja, o erro decai com ordem teórica quase 2.

Uma ideia para generalização da verificação seria incluir no domínio computacional um obstáculo de geometria complexa e submeter o modelo do método da fronteira virtual ao método da solução manufaturada. Naturalmente o método da solução manufaturada já valida o modelo com o termo de força do método da fronteira imersa. No entanto, a inclusão de um obstáculo, 


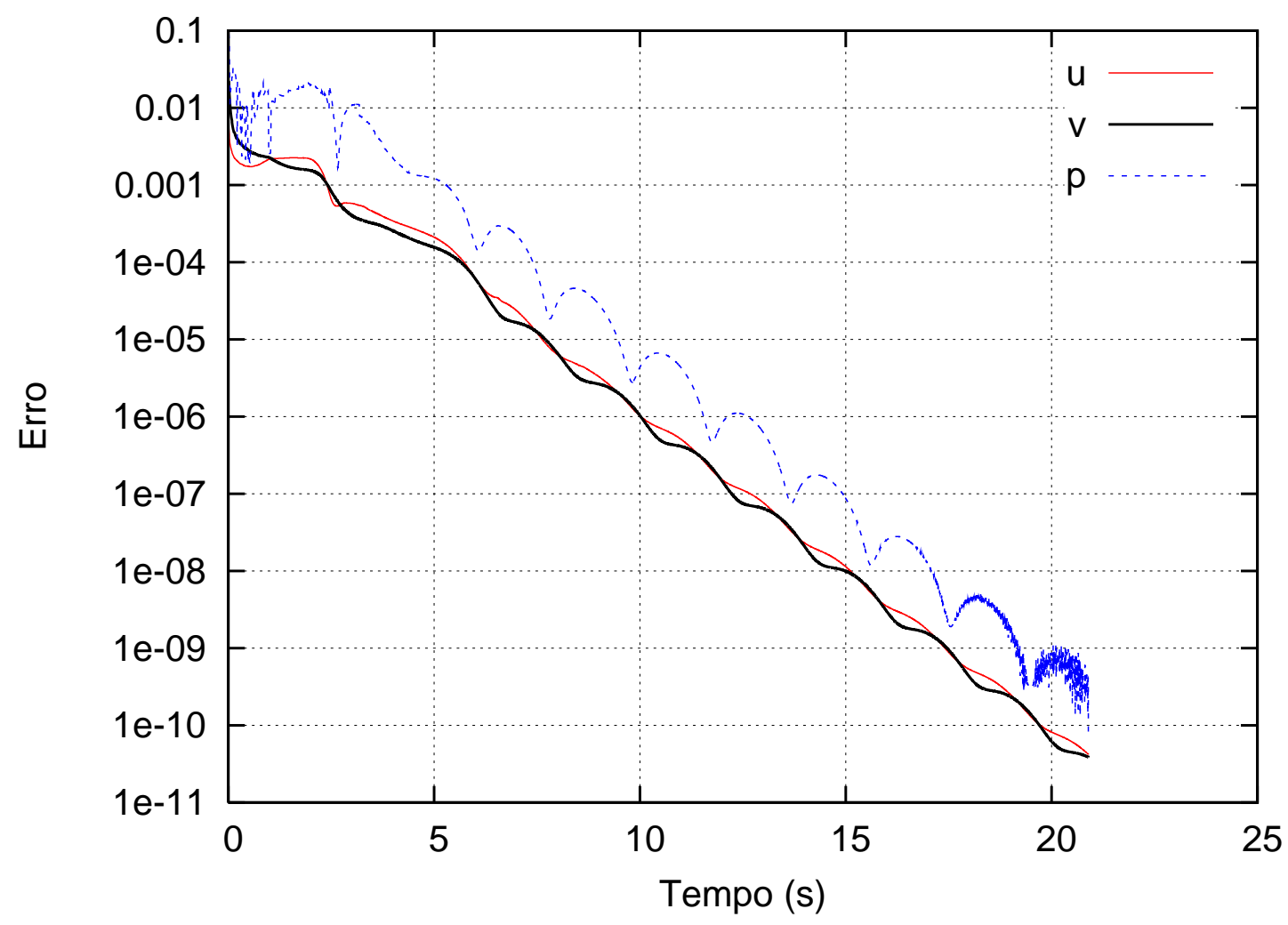

Figura 4.14: Convergência para malha 0,1.

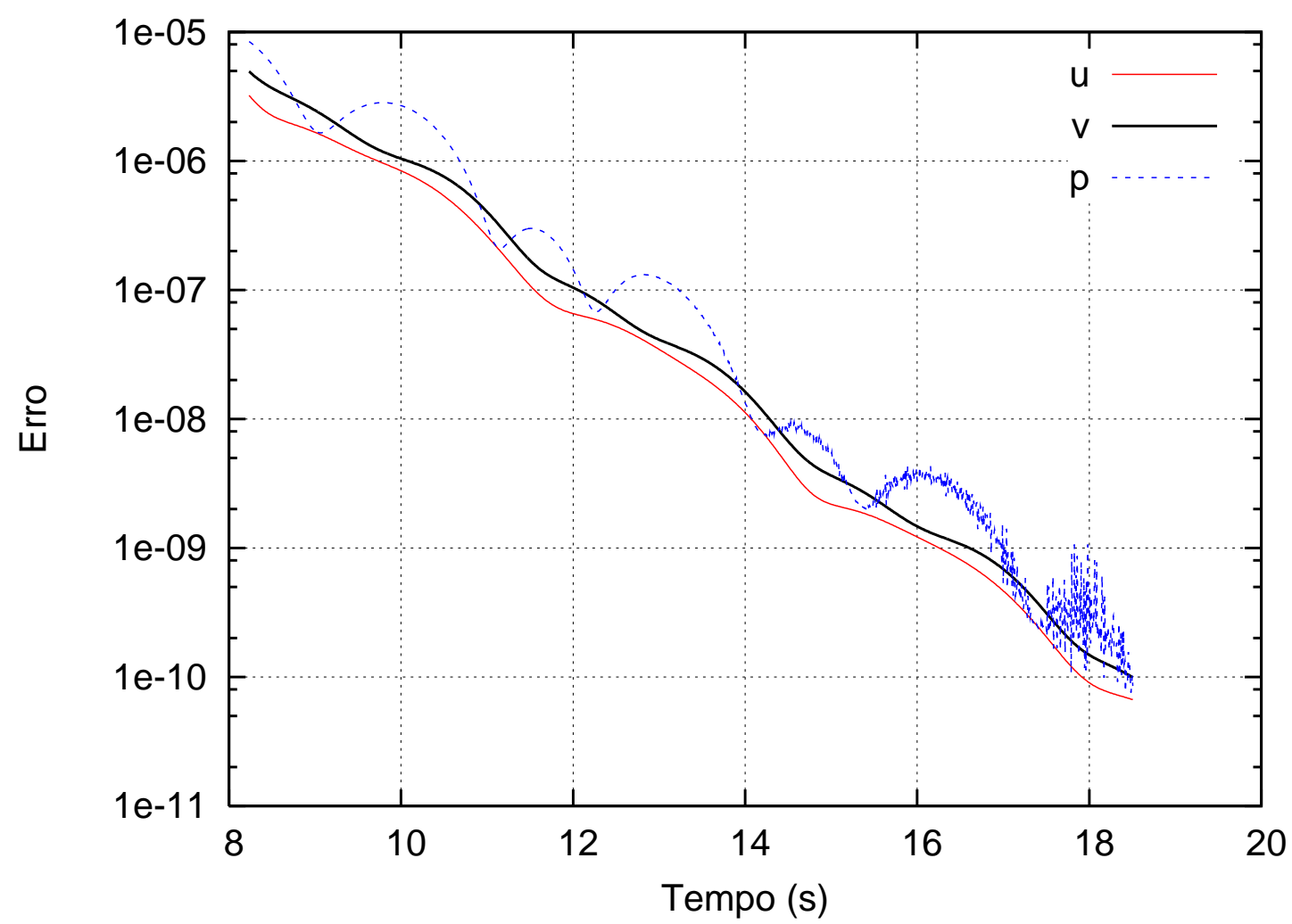

Figura 4.15: Convergência para malha 0,00625. 


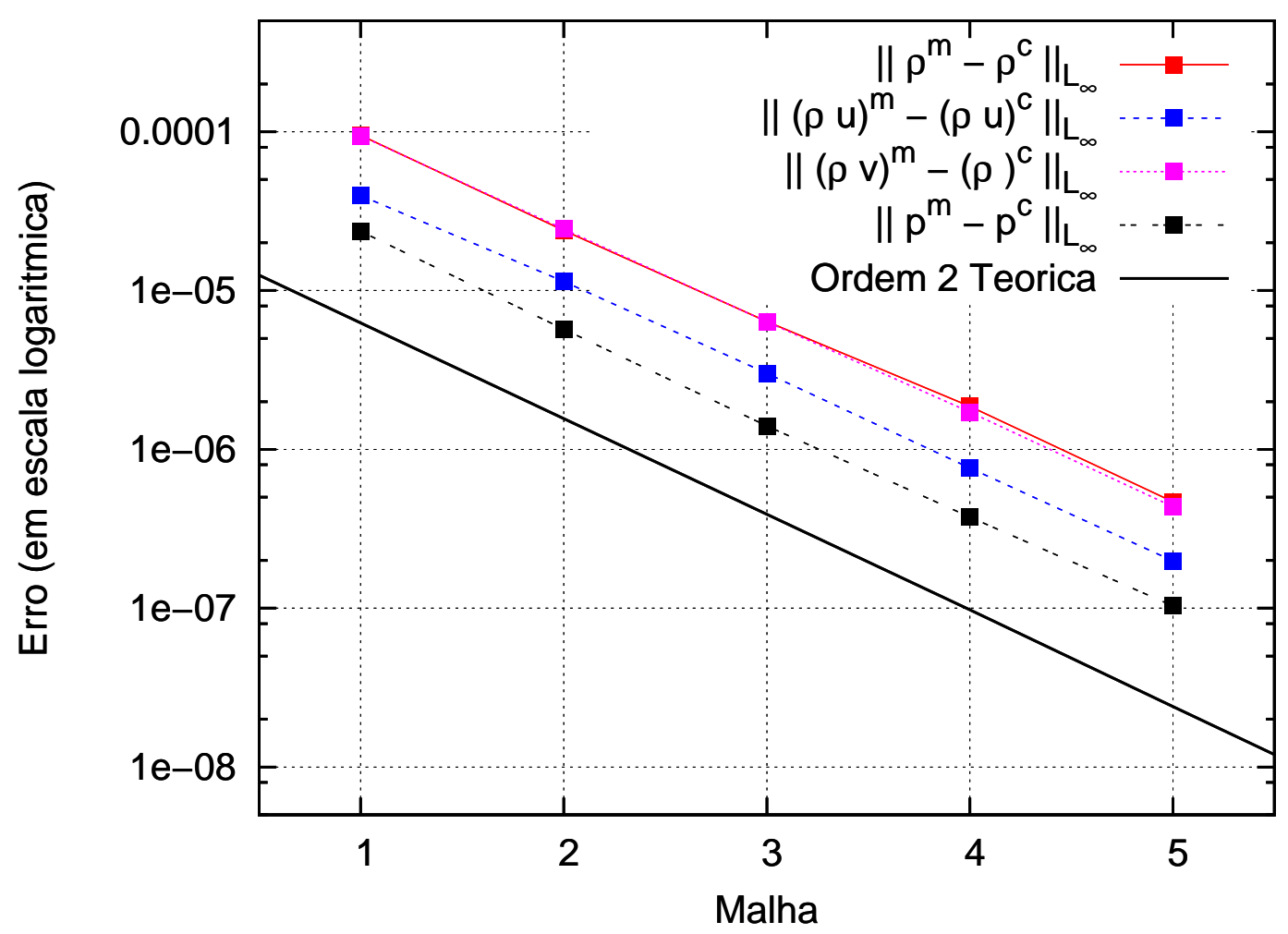

Figura 4.16: Comparação da ordem de convergência de malha com a ordem teórica em escala logarítmica.

de geometria complexa, ao escoamento necessitaria de, pelo menos, mais duas equações para garantir que a velocidade do escoamento na fronteira imersa seja zero. Por exemplo:

> equação na direção $u$. A equação teria que ser diferente de zero na entrada do canal, zero sobre a fronteira (não necessariamente zero dentro da fronteira) e diferente de zero na saída do canal.

- equação na direção $v$. A equação terá que obececer à condição de Neumann nas fronteiras do canal $\left(\frac{\partial v}{\partial y}=0\right)$ e, ao mesmo tempo, pelo menos, ser zero sobre a fronteira imersa.

No caso da equação na direção $u$ seria trabalhoso a sua determinação, mas muito menos complexa que a equação na direção $v$. Apesar das tentativas, o intento não obteve êxito.

A partir dos resultados apresentados na Tabela 5.4 e na figura 4.16 pode-se concluir que o código numérico para as equaçãoes sujeitas a um termo de força está livre de erros de implementação, então verificado. 


\subsubsection{Verificação para o modelo de fronteira virtual}

A verificação do modelo que leva em conta a interação fluido-estrutura, fronteira imersa, apresenta uma dificuldade: a solução analítica terá, também, que considerar as condições da fronteira imersa. Para isso é necessário manufaturar uma solução com as condições de contorno impostas pela fronteira imersa, pois o método da solução manufaturada consiste na seleção de uma solução analítica arbitrária que atenda a todos as condições de contorno. Uma alternativa para verificação foi, a partir da verificação do domínio euleriano, impor que a fronteira imersa seja "permeável" exatamente da solução convergida, ou seja, a fronteira virtual não exerce mais uma condição de velocidade zero na fronteira, mas sim permite exatamente os valores de velocidade já simulados na solução convergida. Aplica-se então a perturbação aos campos de $u, v$ e $p$ de forma a que a fronteira impeça essa perturbação. Tem-se assim uma restrição às velocidades $u$ e $v$ acarretando variação na pressão $p$ que, por sua vez, alterara os campos de força $f_{x}$ e $f_{y}$ (consequentemente os termos forçantes) e ao final haverá ou não a convergência para a solução convergida. Um problema nesse tipo de estratégia é que não se consegue essa permeabilidade por meio de uma função genérica, uma condição única para a fronteira como um todo, mas sim através de rotina computacional para cada caso com imposição da velocidade em cada ponto da fronteira de forma a conseguir barrar apenas o "excesso" do campo de velocidades. A figura 4.17 mostra a reação da fronteira à perturbação e a figura 4.18 mostra a solução convergida. 


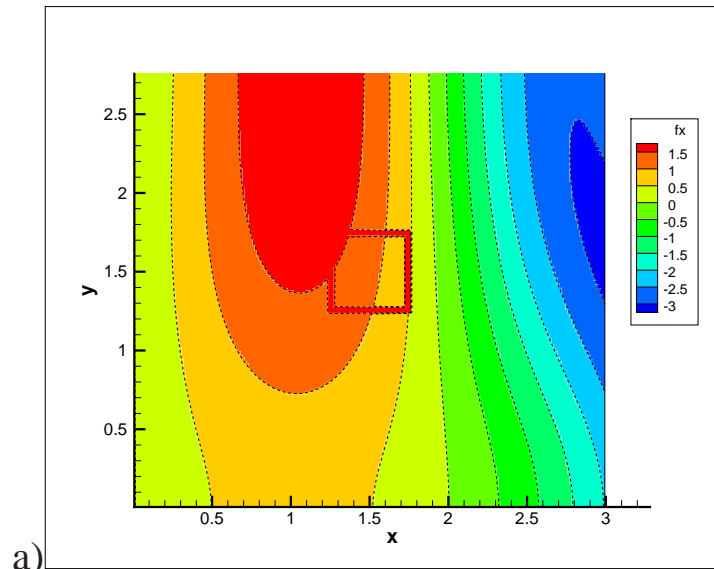

b)
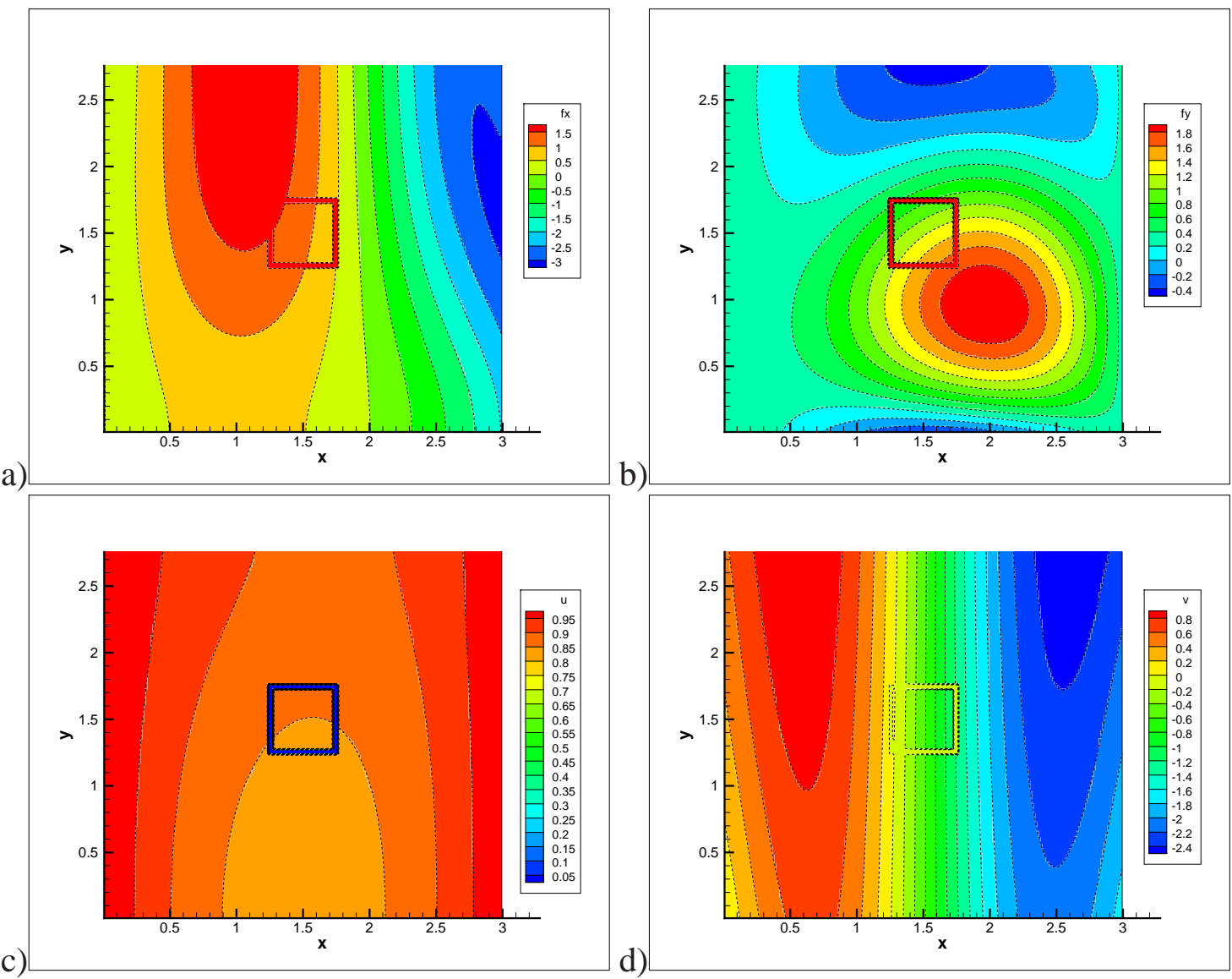

e)

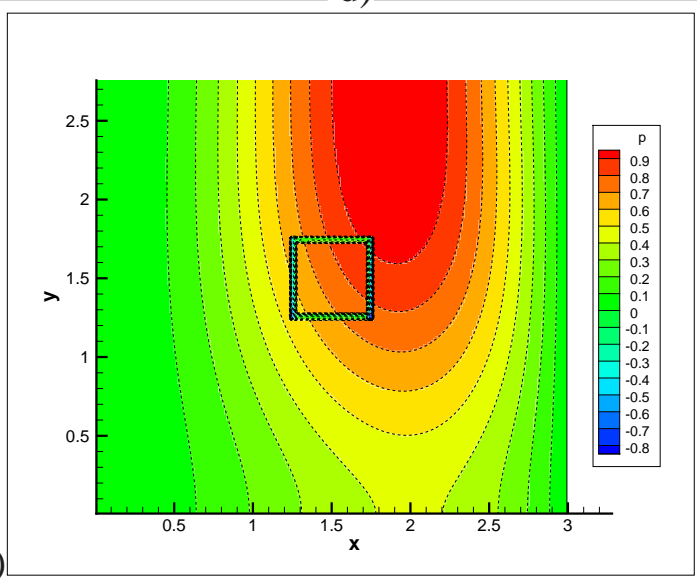

Figura 4.17: Aplicação de força nas direções $x$ e $y$ e condição para $u, v$ e $p$. 
a)
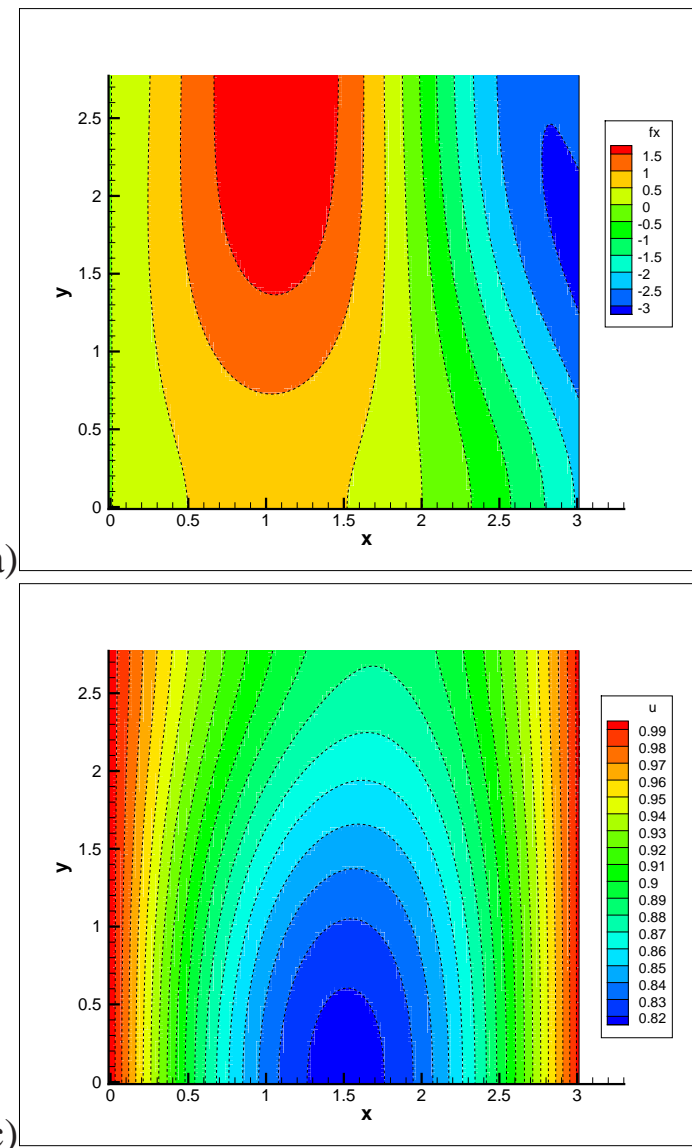

b)

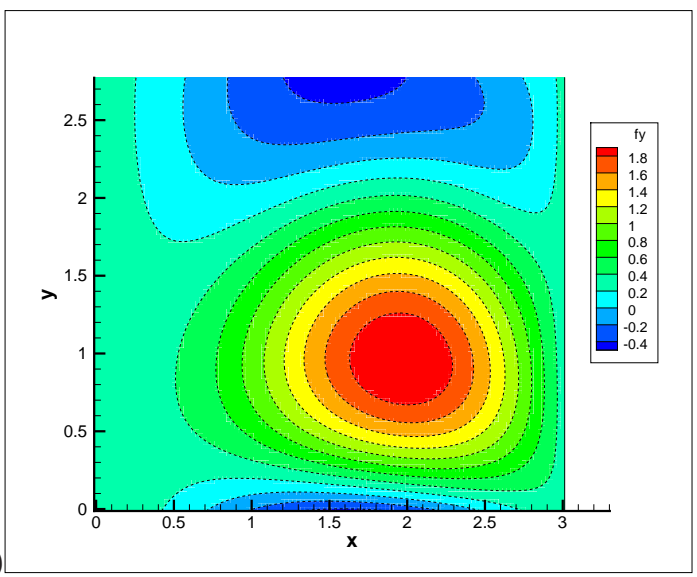

d)

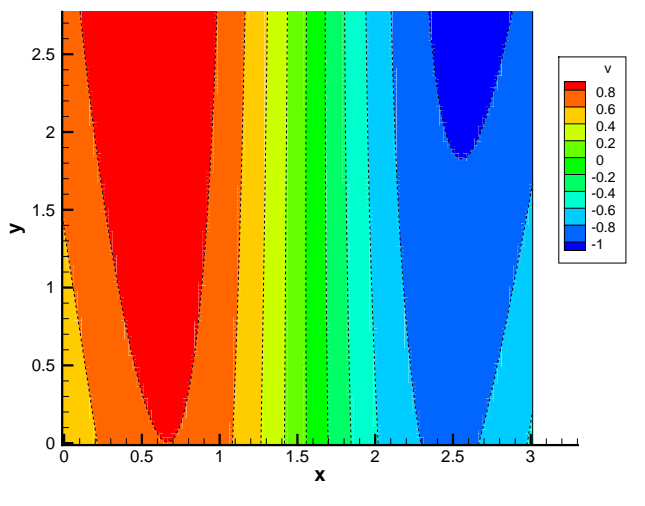

e)

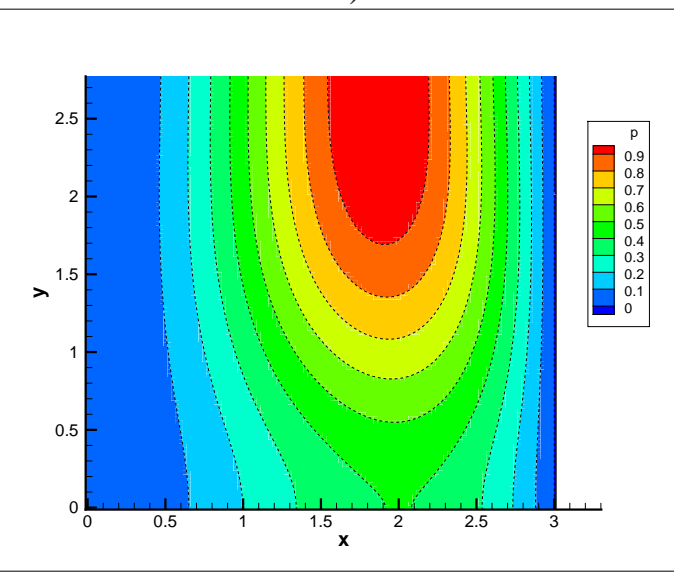

Figura 4.18: Solução convergida das força nas direções $x$ e $y$ e campos $u, v$ e $p$. 


\section{Validação do método da fronteira virtual}

\subsection{Indepedência de malha}

Conforme Anderson (1995), a geração da malha computacional é tida frequentemente como uma das partes importantes e que requer criteriosa escolha, pois a qualidade da malha possui um papel direto na qualidade da solução e do tempo necessário para obtê-la. Este aspecto torna-se especialmente importante se os problemas forem mal condicionados, não-lineares, e/ou análise de fenômenos considerados transitórios. Deste ponto de vista, a avaliação da independência da malha é essencial porque fornece algumas indicações de quão adequada uma discretização é para o tipo de análise em questão. Normalmente a necessidade de verificação da independência de malha é obrigatória para todas as malhas, mas principalmente para as não estruturadas e há várias maneiras de calcular a qualidade de elementos individuais e como quantificar a qualidade geral de uma malha.

Para analisar os efeitos da independência de malha, no método da fronteira virtual, foram realizadas simulações de escoamento sobre um cilindro estacionário, com número de Reynolds 100, para vários espaçamentos de malha e observou-se os valores dos coeficientes de arrasto e de sustentação ao longo do tempo, conforme a tabela (5.1).

Para melhor clareza, foram colocados valores médios de coeficiente de arrasto para as malhas, com exceção da malha mais fina para visualização da ordem de grandeza do efeito da oscilação devido à esteira de vórtices. Como esperado, a resolução da malha afeta significativamente a precisão, ou seja, à medida que a malha é mais refinada maior a aproximação dos 
Tabela 5.1: Efeito da resolução de malha para esoamento incompressível sobre um cilindro estacionário

\begin{tabular}{l|c|c|c}
\hline \hline Malha & Espaçamento & $C_{D}$ médio & $C_{L}$ médio \\
& & & \\
\hline \hline Malha 1 & 0,20 & 3,3975 & 0,003 \\
Malha 2 & 0,15 & 2,1290 & $-0,0001$ \\
Malha 3 & 0,10 & 1,9459 & 0,00005 \\
Malha 4 & 0,075 & 1,5794 & $10^{-11}$ \\
Malha 5 & 0.05 & 1,4958 & $10^{-12}$ \\
Malha 6 & 0.025 & 1,4192 & $10^{-13}$ \\
Malha 7 & 0.0125 & 1,3812 & $10^{-14}$ \\
Malha 8 & 0.00625 & 1,3662 & $10^{-15}$ \\
\hline Experimental & 1,43 & - \\
\hline Zham, 1922 & 1,28 & - \\
Tritton, 1959 & 1,24 & - \\
Clift et al, 1978
\end{tabular}

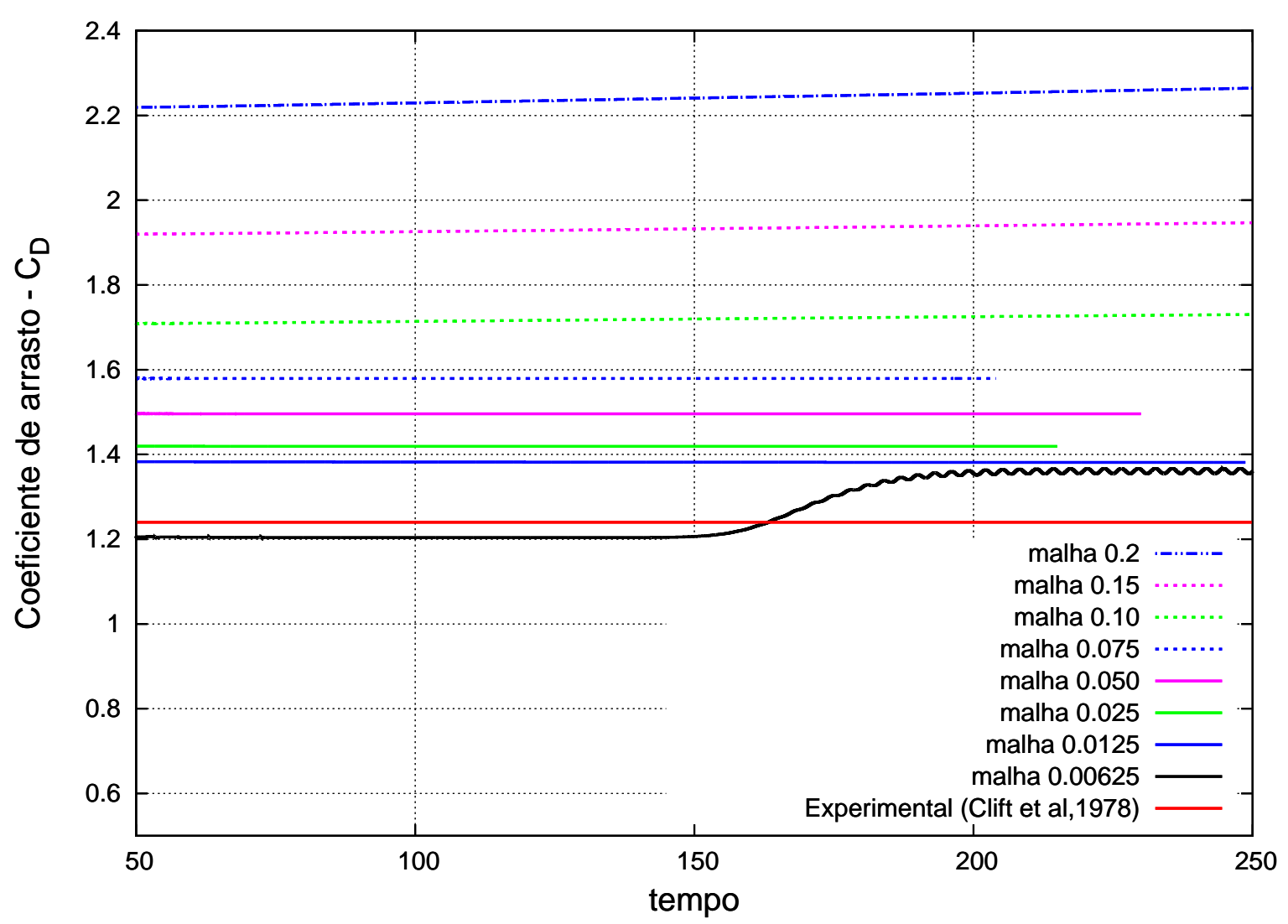

Figura 5.1: Valores do coeficiente de arrasto ao longo do tempo para vários espaçamentos de malha. 


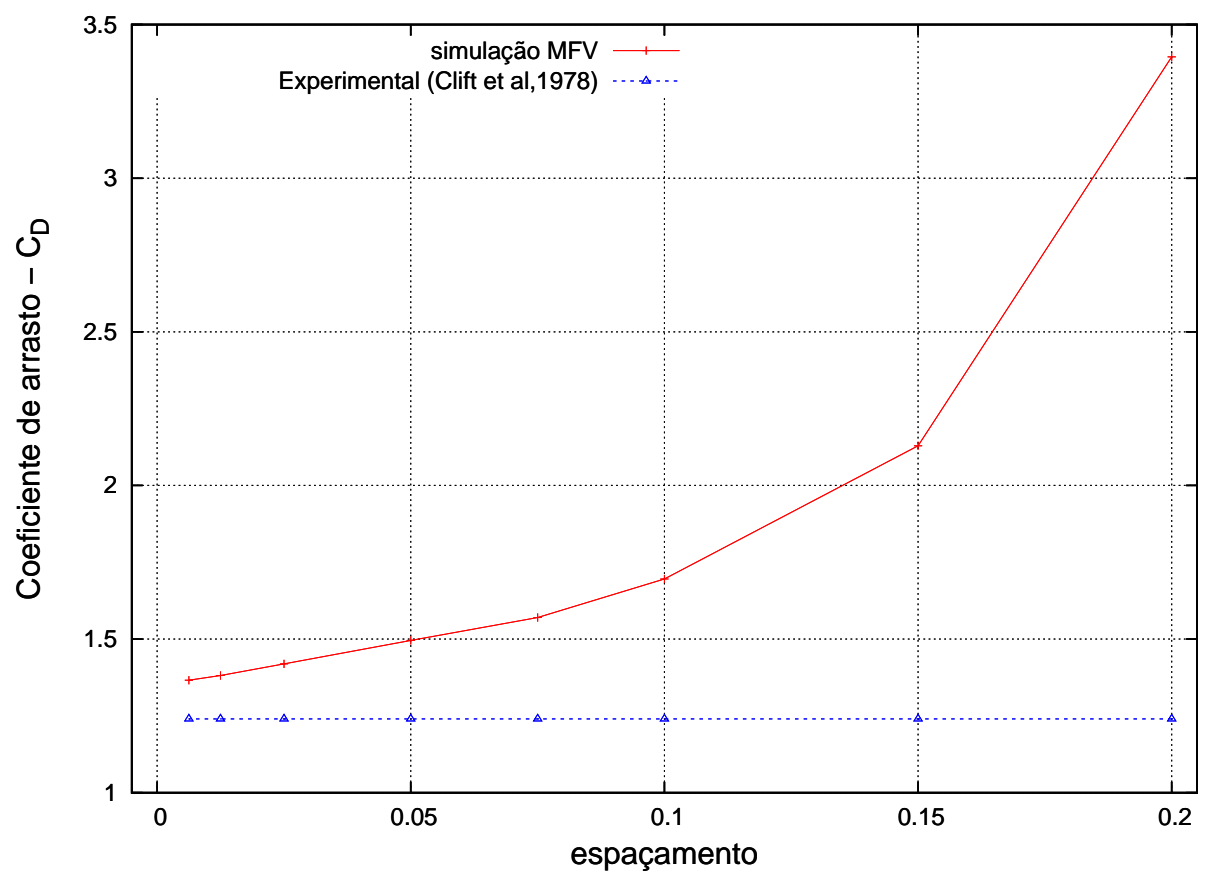

Figura 5.2: Valores do coeficiente de arrasto para vários espaçamentos de malha.

valores de $C_{D}$ e $C_{L}$ aos valores de referência, como pode-se observar na figura 5.1 e figuras 5.2. Uma outra forma de avaliar a independência de malha é a observação do comportamento do campo de velocidades ao longo do tempo em um determinado ponto da malha, como mostrado no trabalho de Buarque, Schettini e Silvestrini (2005) - Apêndice B deste trabalho.

Durante a avaliação da independência de malha foi testada uma alternativa para redução do tempo computacional de simulação que consiste em impor campo de velocidade zero nas células interiores à fronteira virtual. Pôde-se observar mais claramente que essa alternativa produz uma distorção para baixo nos valores convergidos para o coeficiente de arrasto, como por exemplo na simulação de um aerofólio tipo NACA0012 submetido ao escoamento com número de Reynolds 1000, conforme podemos verificar na figura (5.3).

A parte à esquerda do degrau foi simulada impondo-se velocidade zero dentro da fronteira imersa e a parte da direita sem a imposição. 


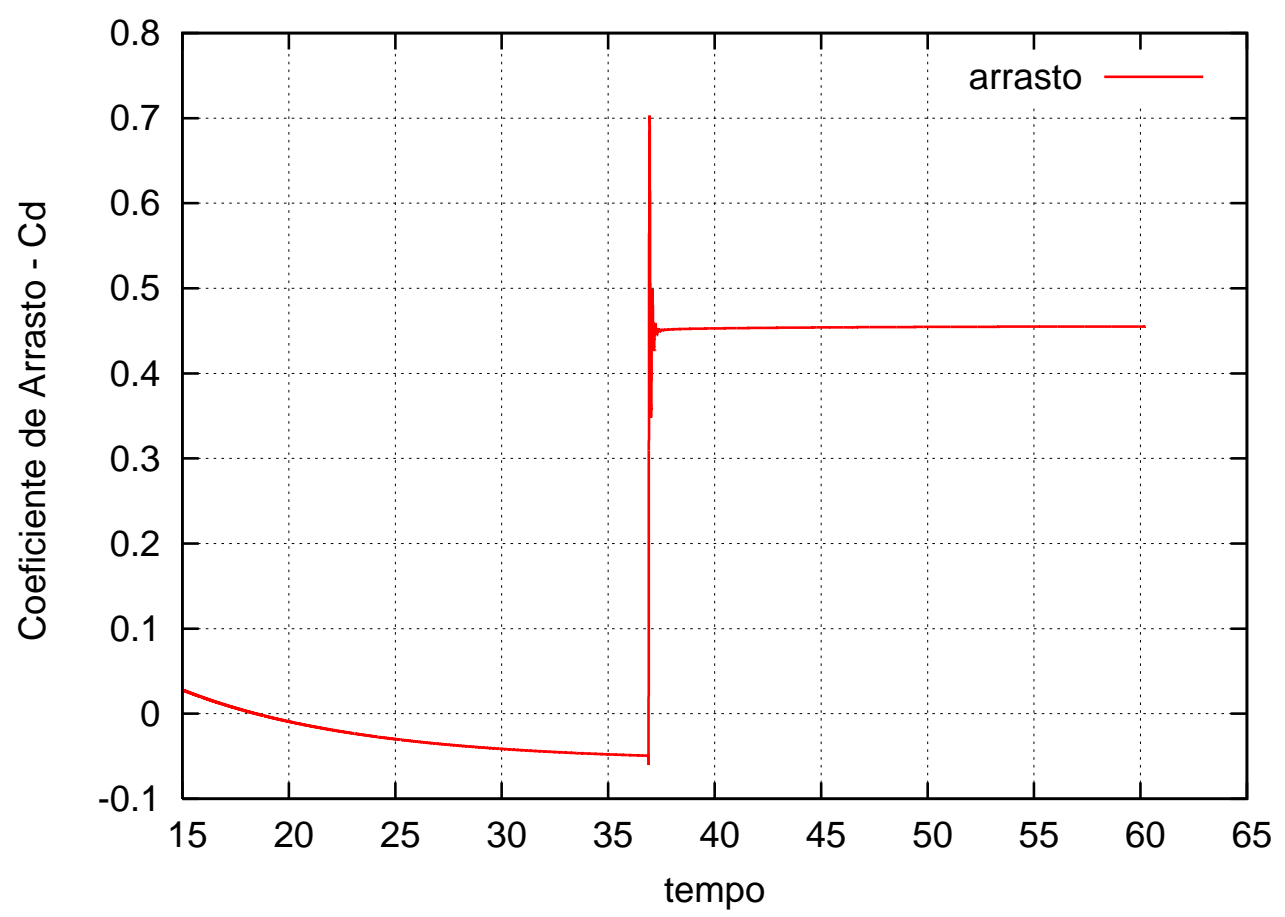

Figura 5.3: Distorção produzida pela imposição de velocidade zero no interior da fronteira.

\subsection{Aplicações a modelos}

Conforme Oberkampf e Trucano (2002), nenhuma das partes da verificação resolve a questão da adequação dos modelos selecionados para representar o realidade de interesse. A adequação é o domínio da Validação, ou seja, é a mecânica (Física) incluída nos modelos suficiente para fornecer respostas confiáveis às questões levantadas no problema? É necessário cotejar os resultados das simulações com os testes físicos obtidos por experimentos e ainda considerar que a comparação entre os resultados simulados e os resultados experimentais é uma evidência da "validade", mas por si só não resolve o problema da confiabilidade do modelo físico do problema, pois deve-se levar em conta a "incerteza" associada a cada dos modos de obtenção de resultados.

Dada a escassez de dados experimentais para o caso específico do perfil de aerofólio tipo NACA0012 submetido a oscilação forçada em meio a escoamento de fluido viscoso a número de Reynolds ultrabaixo, procuraremos validar o modelo de fronteira virtual através de casos que apresentam resultados numéricos e experimentais disponíveis na literatura. Para a validação do método, serão estudados os casos de escoamento sobre: 
- seção cilindrica

(i) seção prismática de base quadrada, estacionária,

(ii) seção circular, estacionária,

(iii) seção circular, oscilante,

- perfil de aerofólio tipo NACA0012, estacionário, submetido a alguns ângulos de ataque

Para as simulações computacionais, o domínio ideal de cálculo é aquele onde seus limites estão tão distantes da região de interesse que as condições artificiais de contorno não influenciam as características do escoamento ou do fenômeno em estudo. No entanto, esse domínio ideal requer, quase sempre, um tempo de simulação computacional excessivamente grande, o que leva à escolha de um domínio que influencie minimamente no escoamento de forma a não comprometer os resultados. Para a validação, a simulação deverá levar em conta não só os parâmetros considerados importantes nos experimentos como também as características dos modelos numéricos.

Consideremos um canal plano com paredes retilíneas separadas por uma distância $H$ (ou Ly), contendo um cilindro (circular ou prismático) cuja posição dista de $s$ das paredes do canal. De acordo com Kit, Nikitin, Shmidt e Yakhot (2004), a distância de posicionamneto do cilindro em relação às bordas do canal pode influenciar na formação de vórtices e consequentemente nos valores dos coeficientes de arrasto e sustentação quando simula-se escoamentos incompressíveis de fluidos viscosos. Consideramos também um fluido incompressível de massa específica $\rho$ e viscosidade cinemática $v$ escoando, com velocidade média constante $u$, pelo canal. O problema é governado por três parâmetros adimensionais:

1 - o número de Reynolds,

2 - a razão de bloqueio $\boldsymbol{\aleph}$ definida como a razão entre a área projetada do corpo imerso no escoamento $\left(A_{c p}\right)$ e a área total da seção do canal $\left(A_{s t}\right)$,

$$
\boldsymbol{\aleph}=\frac{A_{c p}}{A_{s t}} \cdot 100 \%
$$


3 - um parâmetro de distância do corpo imerso em relação às bordas do canal $\gamma$ dado por $\gamma=\frac{s}{H}$.

Além desses tres parâmetros, ainda há que se considerar as distâncias do cilindro à entrada $\left(X_{m o n}\right)$ e à saída $\left(X_{j u s}\right)$ do canal, de maneira que escoamento esteja totalmente desenvolvido quando encontre o cilindro e de maneira que a condição de saída do escoamento do canal não interfira nos fenômenos a jusante do cilindro. Cheng, Tsuei e Chow (1994) e Williamson (1996) tomam, como dimensões para o canal para experimentos com cilindros, largura do canal de $20 \mathrm{D}$ e comprimento do canal $60 \mathrm{D}$ com posicionamento do centro do cilindro a $20 \mathrm{D}$ da entrada e $40 \mathrm{D}$ da saída. Uma nomenclatura para configuração padrão é mostrada na figura (5.4).

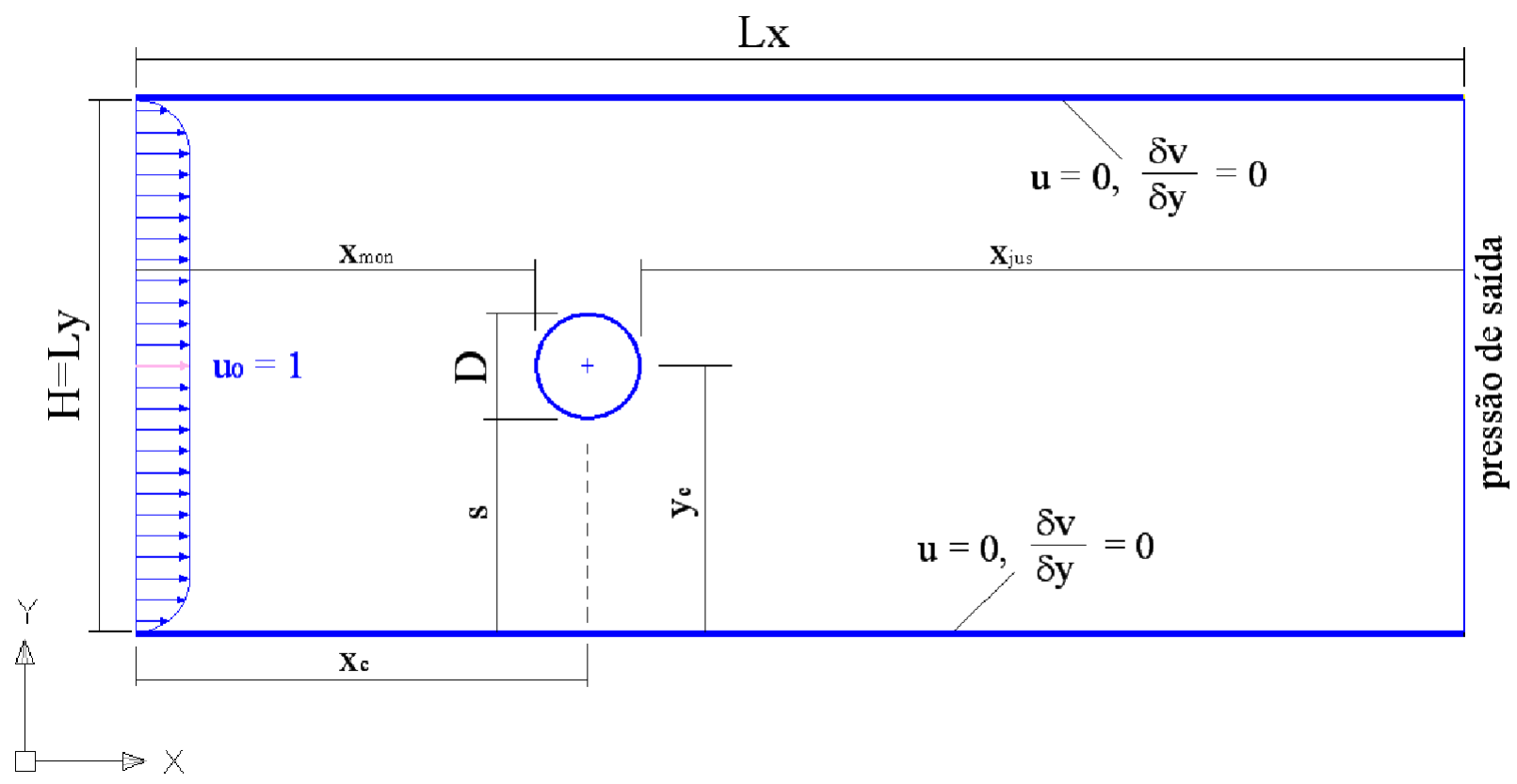

Figura 5.4: Características do canal para simulação

\subsection{Estudo de escoamento sobre uma seção de um cilindro}

O problema de escoamento ao redor de seções circulares, ou cilindros de comprimento infinito, tem sido tratado na literatura para verificar e validar algorítmos computacionais em Dinânica dos Fluidos, principalmente para escoamentos incompressíveis, como por exemplo, os trabalhos de Dennis e Chang (1970), Fornberg (1980), Saiki e Biringen (1996), Baek e 
Sung (1998), Silva, Silveira-Neto e Damasceno (2003), Kang (2003), Souza (2005), Marques, Doricio, Bueno, Greco Júnior e Souza (2006), Padrino e Joseph (2006), Purtell, Klebanoff e Buckley (1981), Doricio, Marques e Greco Júnior (2007), dentre outros. Esse tipo de geometria tem sido usada para modelagem devido à facilidade para adequação à malha conformal (ou conforme) para discretizar o domínio euleriano, pois evita processos de interpolação e fornece ótima precisão num érica. No entanto, a maior parte das geometrias apresentam dificuldades de modelagem utilizando malha conformal com a técnica de diferenças finitas. Neste contexto, o método da fronteira virtual passa a ser mais atrativo devido à fraca dependência geométrica entre as malhas euleriana e lagrangiana. Buscou-se trabalhar com razão de bloqueio e configuração dos parâmetros de simulação do canal de forma a se conseguir maior eficiência computacional sem perda da qualidade da informação.

\subsubsection{Estudo de escoamento ao redor de uma seção prismática quadrada, estacionária}

Condições de arrasto e de supressão de vibrações de um corpo imerso em um escoamento tem sido assunto importante em muitas áreas da engenharia, principalmente em aerodinâmica. Arrasto e vibração de um corpo que se move em um fluido ou está submerso em um escoamento estão intimamente relacionados com a formação de vórtices na esteira do corpo. Os principais aspectos que caracterizam um corpo imerso em um escoamento em aerodinâmica é a dimensão da região de separação do escoamento, o coeficiente de arrasto e o fenômeno do desprendimento de vórtices. O processo de formação de vórtices induz flutuação das forças aerodinâmicas sobre o corpo e isso pode causar vibração em estruturas, o que pode levar à fadiga de material e falha estrutural.

Um ponto a ser analisado no modelo de fronteira virtual refere-se ao termo forçante que não consegue uma imediata e perfeita velocidade zero em qualquer ponto onde for aplicado, mas, naturalmente, resulta em evoluções temporais e variações espaciais do campo de velocidade no domínio da interface fluido-estrutura. As velocidades residuais são consideradas como desvios do escoamento ou do conjunto de pontos onde a velocidade deveria ser zero. Esses desvios 
são devido às perturbações no domínio do escoamento e ao tempo de resposta. Dessa forma é importante analisar se o modelo consegue absorver essas velocidades residuais cuja grandeza seja fração insignificante do escoamento principal.

Tome-se um corpo prismático com seção transversal quadrada, imerso perpendicularmente em um escoamento com velocidade uniforme e constante $u_{\infty}$ em que o escoamento é parcialmente bloqueado por esse corpo prismático de base quadrada e, por tratar-se de um canal, é também chamado de escoamento confinado ao redor de cilindro com seção transversal quadrada. Os parâmetros investigados foram os perfis de velocidade e linhas de corrente do domínio computacional. A literatura que trata escoamentos sobre cilindros de base quadrada, apresenta também análises da razão de forma, razão de aspecto de bloqueio, efeitos do bloqueio sobre a distribuição de pressão e o coeficiente de arrasto, e frequência de emissão de vórtices (número de Strouhal). De acordo com Lindquist, Almeida, Mansur e Neto (2000),

aumentando-se a razão de bloqueio acima de $\boldsymbol{\aleph}=10 \%$ observa-se que os padrões da esteira apresentam algumas diferenças em relação aos casos com $\boldsymbol{\aleph}<10 \%$ e verifica-se o surgimento das primeiras instabilidades: as bolhas de recirculação são assimétricas, enquanto que a esteira já apresenta pequenas oscilações transversais. Aumentando-se o número de Reynolds para 100, verifica-se a formação da esteira de von Kármán a jusante do cilindro, com vórtices regulares e com aspecto laminar. Já para números de Reynolds superiores a 400, o ponto de descolamento da camada limite localiza-se sobre as arestas de fuga, e não mais sobre as arestas de ataque do cilindro. Nestes casos, observase que os vórtices apresentam instabilidades secundárias tridimensionais, que lhes conferem um aspecto mais difuso. (LINDQUIST, 2000)

No caso estudado no presente trabalho,

$$
\aleph=\frac{A_{c p}}{A_{s t}} \cdot 100 \%=\frac{1}{10} \cdot 100 \%=10 \%
$$

As figuras (5.5) e (5.6) mostram isocontornos instantâneos de vorticidade para número de Reynolds 1000 e razão de bloqueio $\aleph=10 \%$ como resultados experimentais conforme Lindquist, Almeida, Mansur e Neto (2000), e de simulação computacional neste trabalho. A dinâmica de formação de vórtices é simétrica, periódica e está alinhada com o escoamento. Os vórtices são originados a partir de dois fenômenos. Primeiro pela recirculação devido ao escoamento de montante que permanece preso em ambos os lados do cilindro e, pressionado 
pela componente $v$ do campo de velocidades, provoca o descolamento da camada limite. Segundo pelas instabilidades secundárias produzidas pelas unidades de recirculação que chegam à borda de jusante do cilindro de base quadrada e que tornam a esteira de vórtices mais difusa. A sequência apresentada nos itens de $a$ ) a $f$ ) na figura (5.8) mostra, através de linhas de corrente, a formação da esteira de vórtices. Essa formação é influenciada grandemente pelas bordas do clindro de base quadrada.

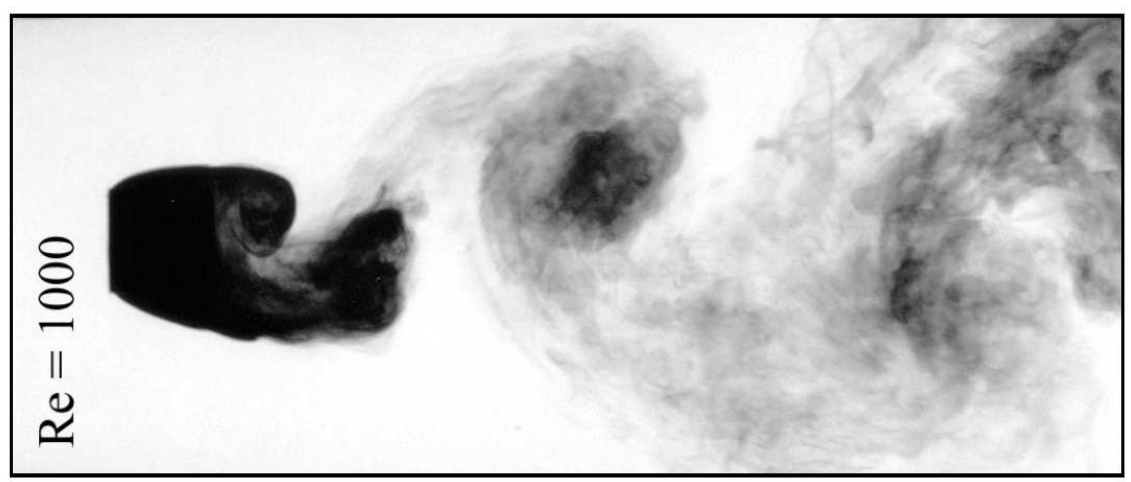

Figura 5.5: Resultado experimental obtido por (LINDQUIST, 2000) - vorticidade, cilindro base quadrada, $\boldsymbol{\aleph}=10 \%$ e $R e=1000$.

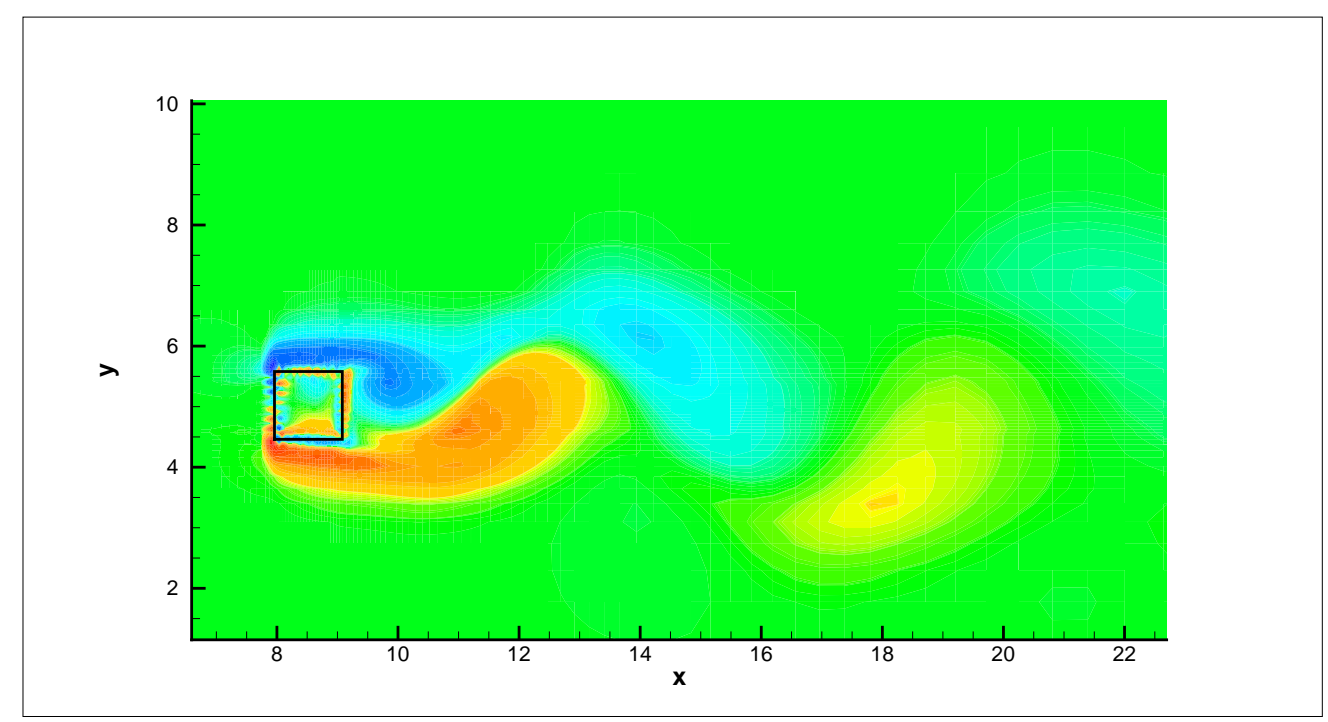

Figura 5.6: Resultado computacional - vorticidade, cilindro de base quadrada, $\boldsymbol{\aleph}=10 \%$ e $R e=$ 1000 .

Nas bordas, em especial no início do escoamento, o pico inicial do campo de velocidades é mais alto; depois do transiente, a velocidade na interface virtual cai rápidamente e as oscilações espaciais são reduzidas ocasionando velocidades residuais significativamente superiores. Este 
fato é de importância em relação à modelagem de contornos afilados. Do ponto de vista positivo, uma malha mais refinada produzirá melhores resultados devido a uma melhor definição do contorno da superfície imersa. Mas, do ponto de vista negativo, a singularidade geométrica se torna mais grave. Se a forma da borda for considerada como um círculo de raio $d x$, o arco se tornará mais cortante quanto menor for $d x$ e o escoamento será submetido a uma curvatura mais acentuada. Assim, os pontos, submetidos ao campo de força, próximos à borda da interface fluido-estrutura deverão enfrentar perturbações constantes significativamente maiores do que $\mathbf{u}_{0}$ e isto poderá piorar a eficiência do sistema de forças. A forma final da borda deverá ser tal que haja equilíbrio entre o erro estático na resposta da fronteira virtual e a aceleração do escoamento ao redor da borda com influências sobre as características do escoamento a jusante.

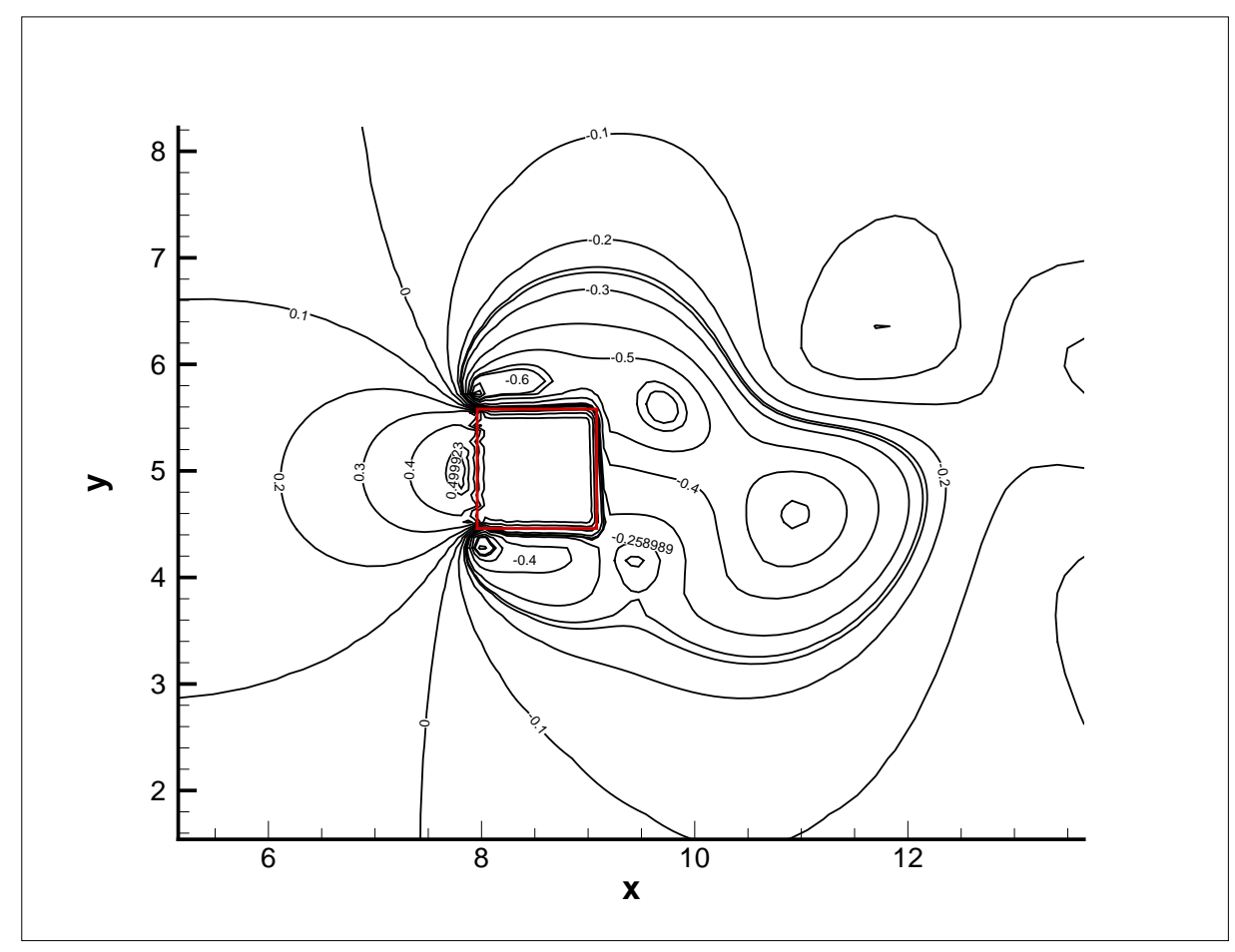

Figura 5.7: Distribuição de pressão para o escoamento ao redor de um cilindro quadrado com $\aleph=10 \%$ e número de Reynolds $R e=1000$.

Apesar do refinamento da malha provocar variações na espessura inicial da camada limite, o estado de equilíbrio é atingido como resposta à função de "feedback", ou seja, para a forma do corpo modelado pelo método da fronteira virtual com o campo de força calculado diretamente nos pontos da malha. 
a)
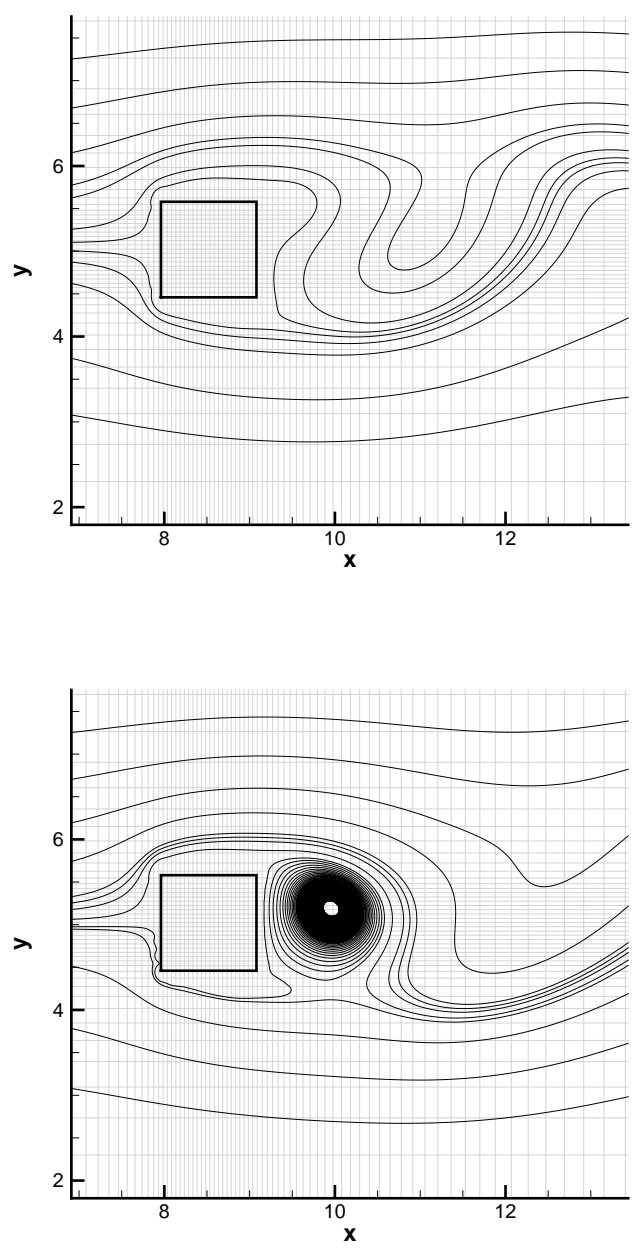

c)

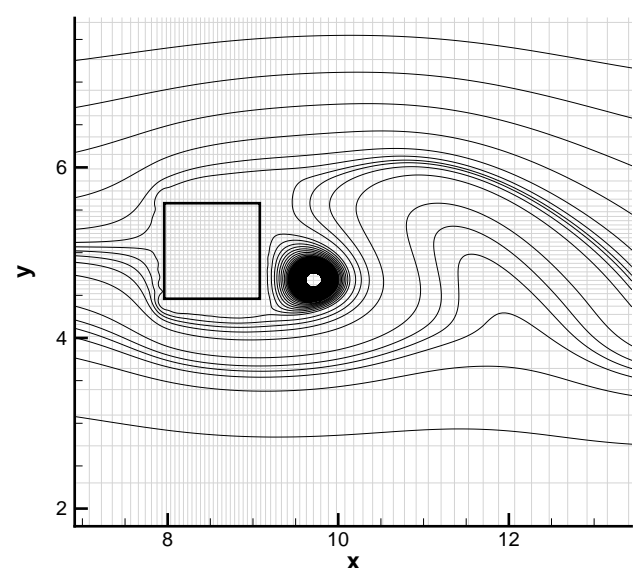

e)

Figura 5.8: Sequência de formação de vórtices ao longo do tempo $\left(t_{1}=42 s, t_{2}=44 s, t_{3}=46 s\right.$, $t_{4}=48 s, t_{5}=50 s$ e $\left.t_{6}=52 s\right)$ - linhas de corrente - cilindro de base quadrada, $\boldsymbol{\kappa}=10 \%$ e $\operatorname{Re}=1000$.

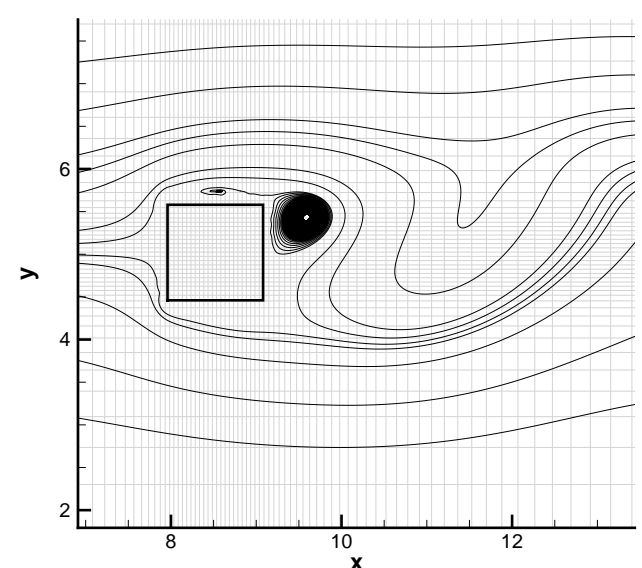

b)

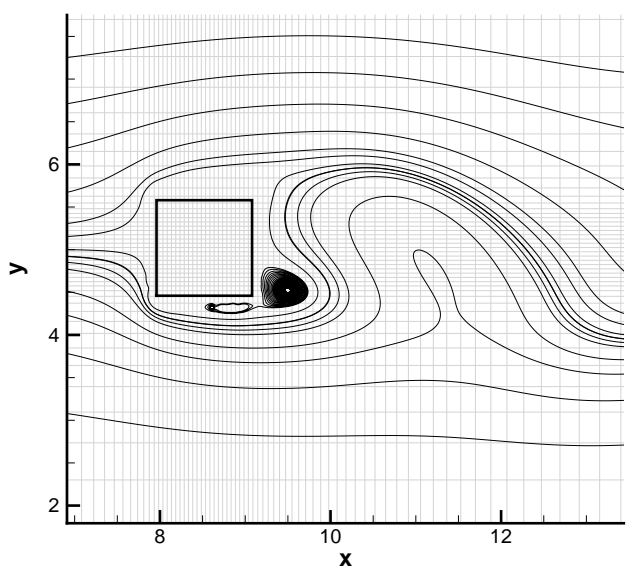

d)

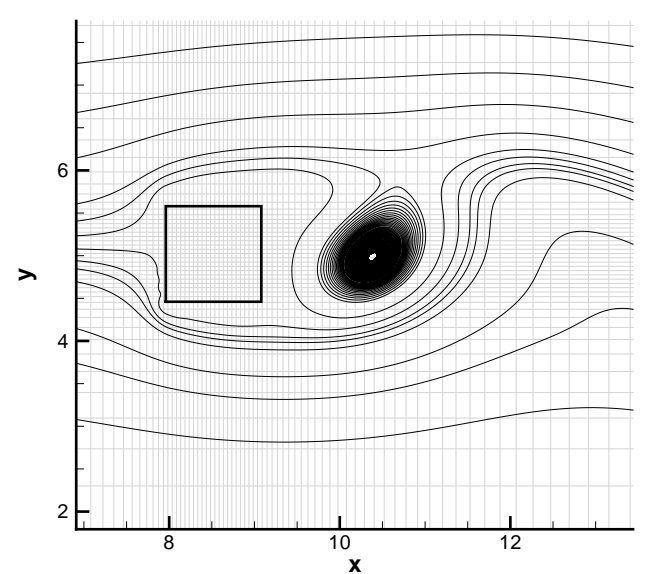

f) 


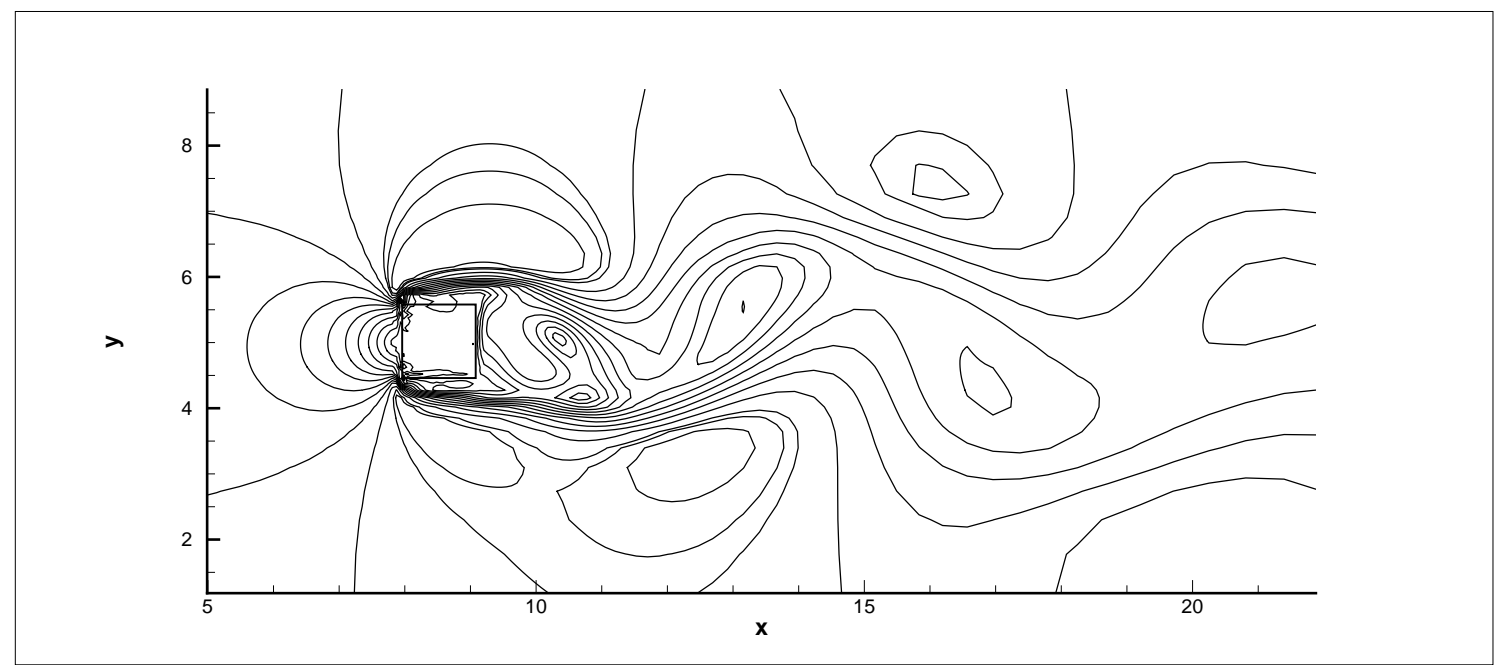

Figura 5.9: Detalhe do perfil da componente $u$ da velocidade - número de Reynolds $R e=1000$.

As figuras (5.9) e (5.7) mostram que os vórtices formam-se sobre as arestas de fuga do cilindro e não mais sobre as arestas de ataque. A análise desse fenômeno pode ser encontrado no trabalho de Margnat e Morinière (2009), como nos casos de número de Reynolds menores $(\operatorname{Re}<400)$.

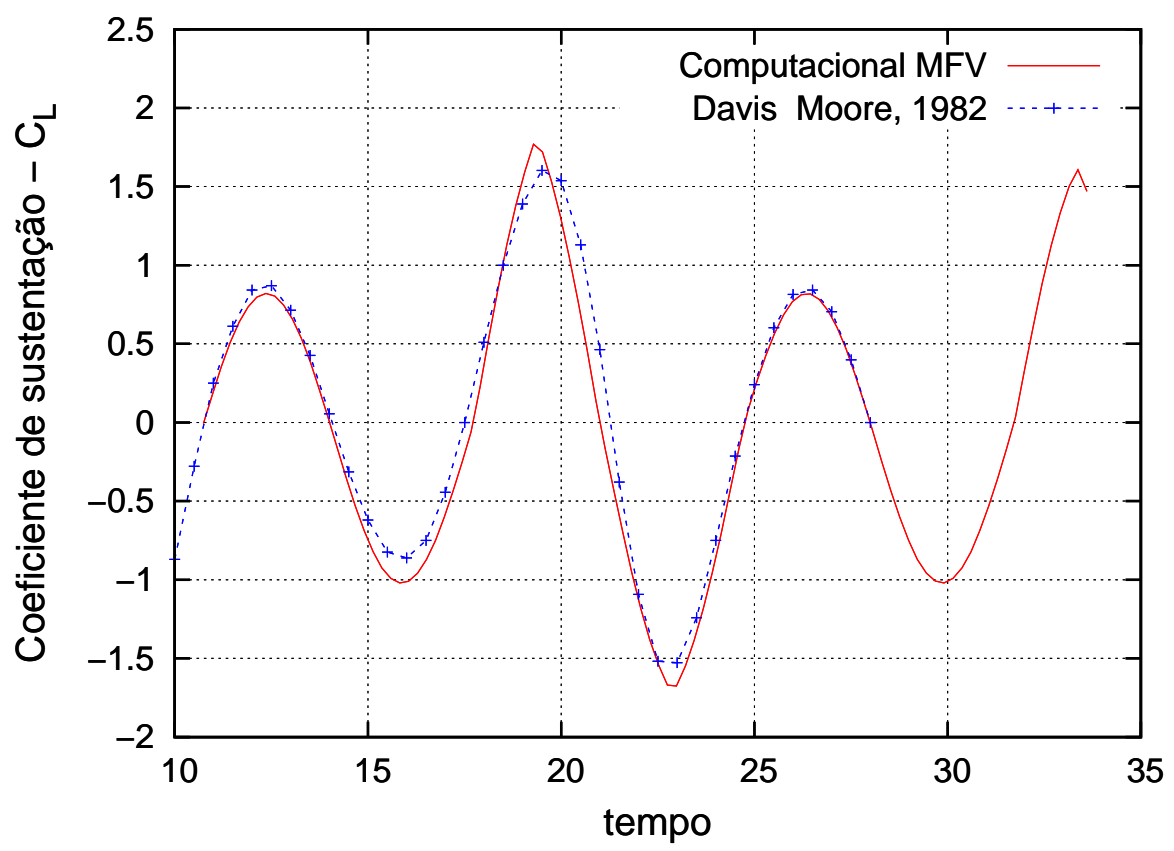

Figura 5.10: Comparativo de coeficiente de sustentação para o cilindro de base quadrada, sujeito a escoamento de $\operatorname{Re}=1000$.

Comparando-se os resultados para coeficiente de sustentação entre os obtidos pelo método da fronteira virtual e os obtidos por Davis e Moore (1982), podemos notar na figura (5.10) que 
o comportamento é semelhante com pequena variação nas condições de sustentação máxima e mínima. O escoamento ao redor do cilindro de base quadrada foi considerado bidimensional, entretanto a esteira de vórtices pode apresentar padrões de emissão tridimensionais, pois pode ser fortemente influenciado pelas condições das extremidades, por exemplo, como quando o cilindro possui as duas extremidades simplesmente engastadas. O estudo da dinâmica de vórtices para escoamentos separados pode ser realizado através da modelagem pelo método da fronteira virtual com condição de não-escorregamento.

\subsubsection{Estudo de escoamento ao redor de um cilindro de seção circular, estacionária}

A escolha dos parâmetros para a simulação do escoamento sobre um cilindro de seção circular, estacionária, foi feita a partir dos trabalhos de Kit, Nikitin, Shmidt e Yakhot (2004) e Zovatto e Pedrizzetti (2001) para o posicionamento da seção circular no canal $\left(H, L_{x}, x_{m o n}\right.$, $x_{j u s}$ e $s$ ) e dos trabalhos de Zdravkovich (1997) e Silvestrini e Lamballais (2002) para a relação entre o diâmetro da seção e o espaçamento da malha ( $D$ e $\Delta_{y}$ ). Ribeiro (2002) faz um tratamento sobre as várias configurações e erros proporcionais entre as escolhas. Cabe ressaltar que o erro entre os valores obtidos pelas simulações e os experimentais dependem fortemente do modelo de discretização adotado e do número de Reynolds.

Nas simulações do escoamento sobre a seção circular estacionária, foram aplicados os seguintes parâmetros: $L_{x}=20 D, H=L_{y}=15 D, x_{c}=6 D, y_{c}=7,5 D, x_{\text {mon }}=5,5 D, x_{j u s}=13,5 D$, $D=10 \Delta_{y}$ e $\Delta_{y}=\Delta_{x}=0,1$, ou seja, domínio retangular $20 \times 15$ unidades adimensionais (u. a.); com a seção circular, de diâmetro 1 u. a. e centrado na posição $x=6,0$ e $y=7,5$. Ainda, condição de entrada de escoamento uniforme, ou seja, $u=1$ e $v=0$; a propriedade $\rho=1$ do fluido foi considerada constante e a mesma para todas as simulações; e a constante $\beta=-200$. A simulação foi realizada para número de Reynolds $R e=1, R E=10, R e=100$ e $R e=400{ }^{1}$.

\footnotetext{
${ }^{1}$ Mais detalhes sobre estas simulações podem ser encontradas no trabalho de Marques, Doricio, Bueno, Greco Júnior e Souza (2006)
} 
As figuras (5.11) e (5.12) mostram os campos de velocidade e pressão para os escoamentos apresentam comportamento coerente com a variação do número de Reynolds, ou seja, para $R e=1$ e $R e=10$ os campos estão bem delineados e estáveis. Conforme Roshko (1953), abaixo de $R e=40$ o escoamento ao redor do cilindro apresenta uma configuração simétrica e com um par de vórtices estáveis atrás do cilindro. A formação de vórtices no intervalo estável ocorre sem transição laminar-turbulento ${ }^{2}$ e consequentemente sem instabilidade na esteira. A partir de $R e=$ 40 até $R e=150$ surge uma nova configuração estável que consiste de uma alternância periódica em formar e quebrar vórtices em uma esteira regular, ou seja, o escoamento circundante quebra periodicamente e alternadamente dos dois lados do cilindro formando vórtices livres que se movem e se organizam a jusante da esteira. A simulação para $R e=100$ mostra o surgimento das instabilidades na esteira e os campos de velocidade e pressão perdem a simetria. Este caso não é uma instabilidade laminar-turbulento, mas duas fases diferentes do escoamento estável e viscoso onde as perturbações da configuração estável são amortecidas.

A partir de $R e=150$, o escoamento começa a apresentar transição de laminar para turbulento. Para entender como esta transição está relacionada com a formação de vórtices, é necessário associar a formação de vórtices com o movimento circulação por trás do cilindro. Há formação de uma camada de vórtices livres nos pontos de separação da camada limite sobre o cilindro e essa camada de vórtices livres provoca recirculação atrás do cilindro e estabelece um equilíbrio que se quebra a intervalos regulares. A transição laminar-turbulento ocorre na separação da camada limite laminar. Cada vórtice que passa à jusante é composto de fluido turbulento. O escoamento somente passará a turbulento para número de Reynolds acima de 2300. A simulação para $R e=400$ mostra uma intensificação na formação de vórtices com características mais fortes de transição.

As figuras (5.13) a (5.14) mostram o campos de vorticidade e o comportamento do escoamento segundo as linhas de corrente e demonstram que, para o número de Reynolds inferior a 40 $(R e=1$ e $R e=10)$, de acordo com a literatura, por exemplo Zdravkovich (1997), o escoamento

\footnotetext{
${ }^{2} \mathrm{O}$ fenômeno de turbulência é primordialmente tridimensional e as simulações bidimensionais conseguem apenas uma aproximação do fenômeno. No caso dos cilindros, quando considerado de comprimento infinito e imerso em um escoamento de laminar, despreza-se os efeitos transversais de interação entre as camadas de fluido.
} 
a)

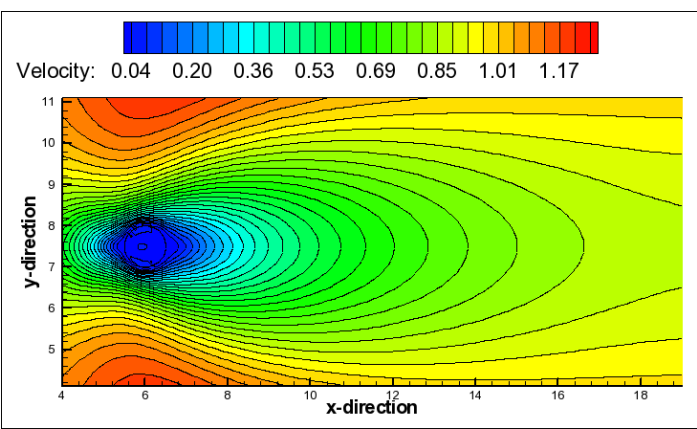

c)

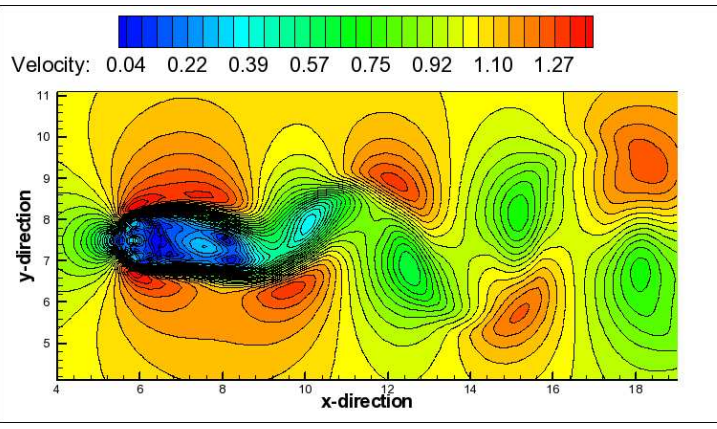

b)

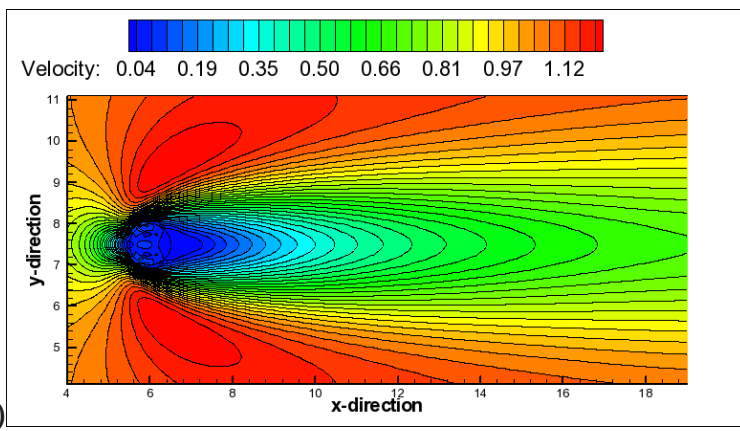

d)

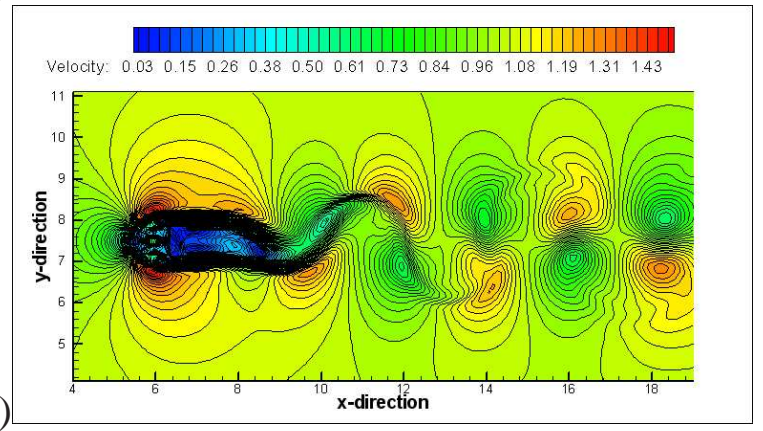

Figura 5.11: Campo de velocidade para a) $\operatorname{Re}=1$, b) $\operatorname{Re}=10$, c) $\operatorname{Re}=100$ and d) $\operatorname{Re}=400$.

a)

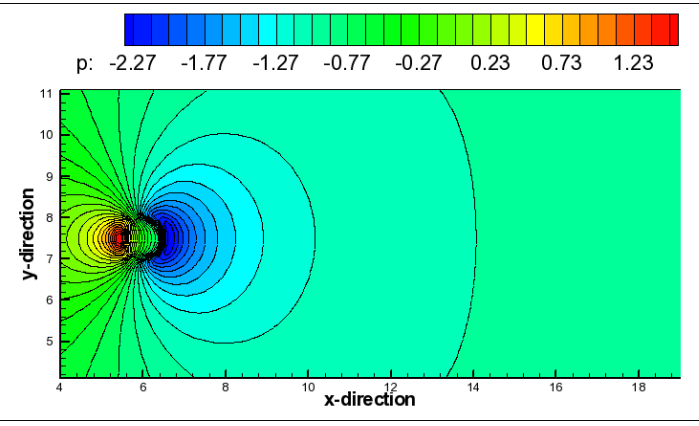

c)

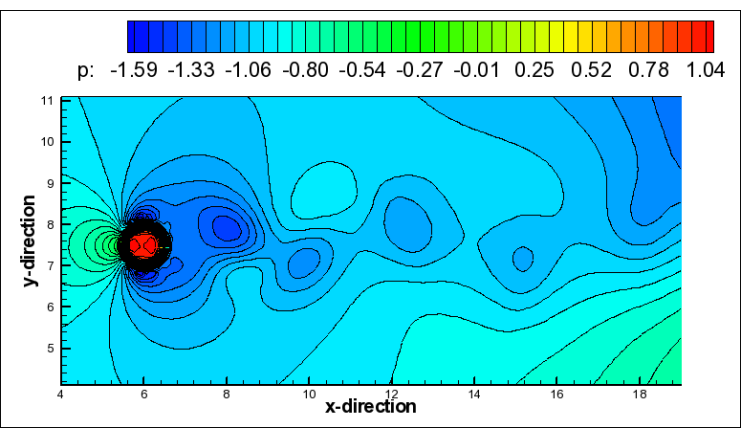

b)

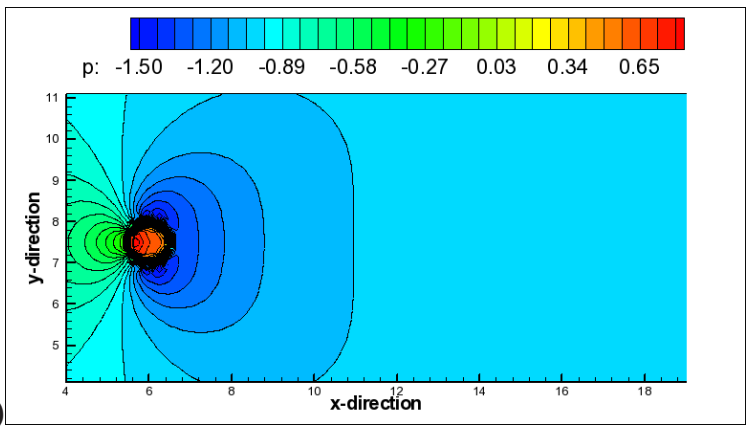

d)

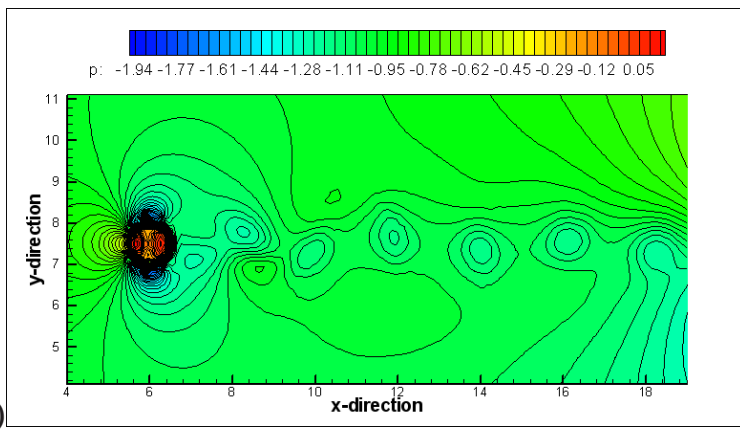

Figura 5.12: Campo de pressão para a) $\operatorname{Re}=1$, b) $\operatorname{Re}=10$, c) $\operatorname{Re}=100$ and d) $\operatorname{Re}=400$. 
ao longo da seção circular atinge o estado estacionário e dois vórtices simétricos são formados por trás do cilindro. Quando o número de Reynolds se torna maior que $40(\operatorname{Re}=100$ e $R e=400)$, o escoamento mostra uma perda de simetria na esteira e redemoinhos alternados são formados.

a)
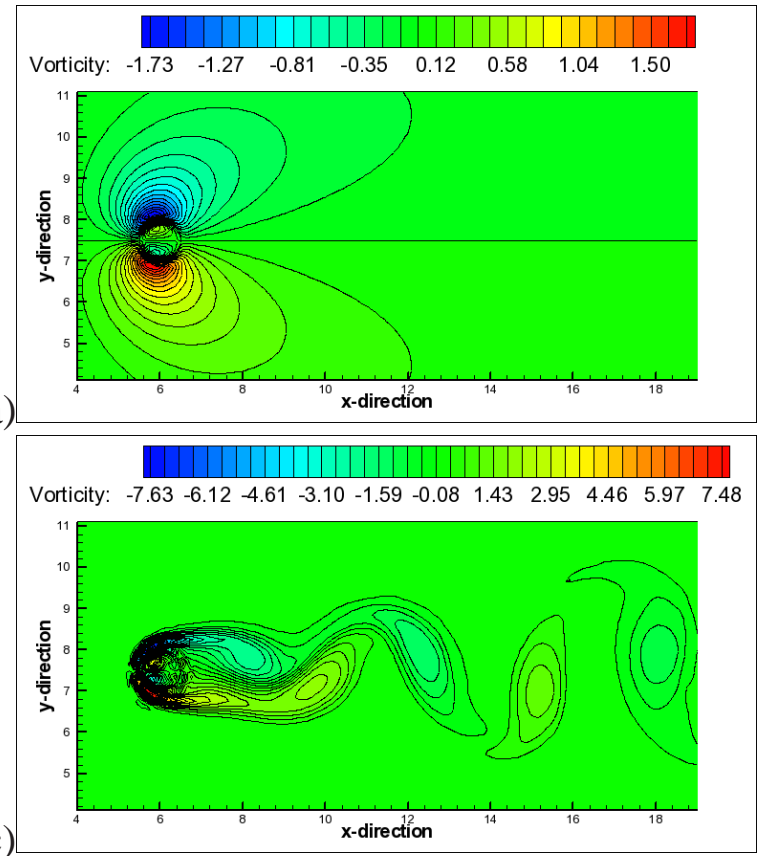

Figura 5.13: Vorticidade para a) $\operatorname{Re}=1$, b) $R e=10$, c) $R e=100$ and d) $R e=400$.

a)

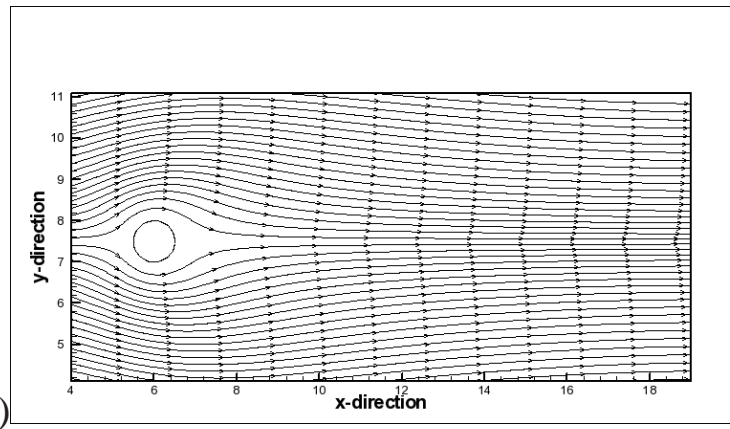

c)

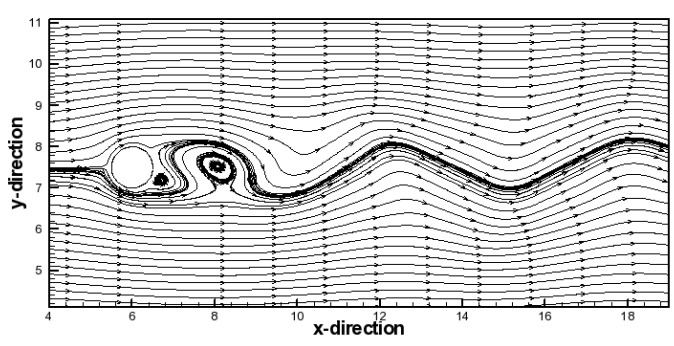

b)

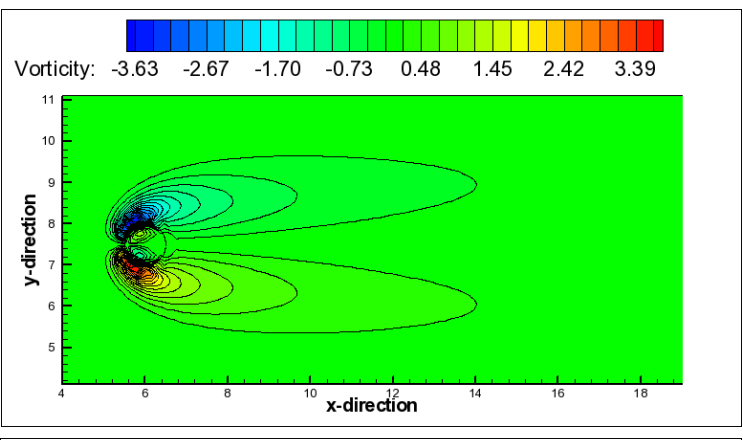

d)

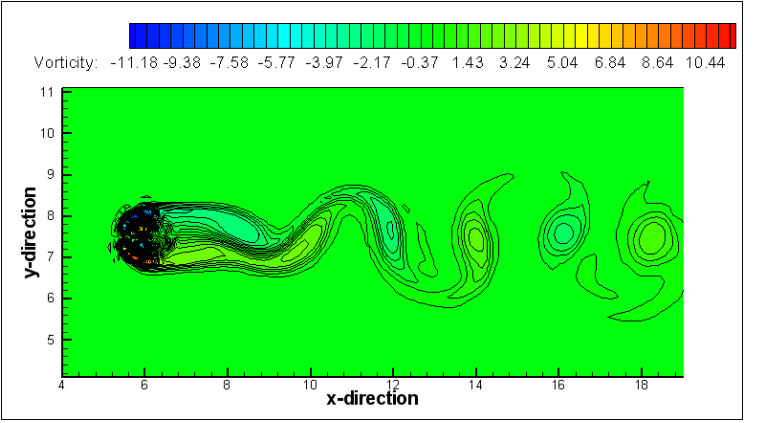

b)

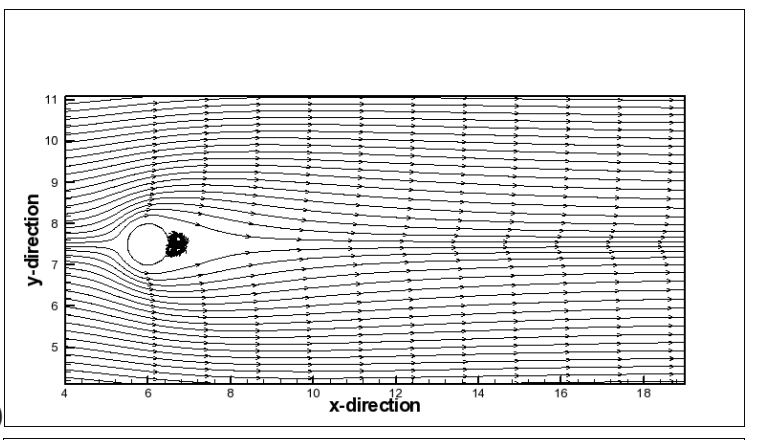

d)

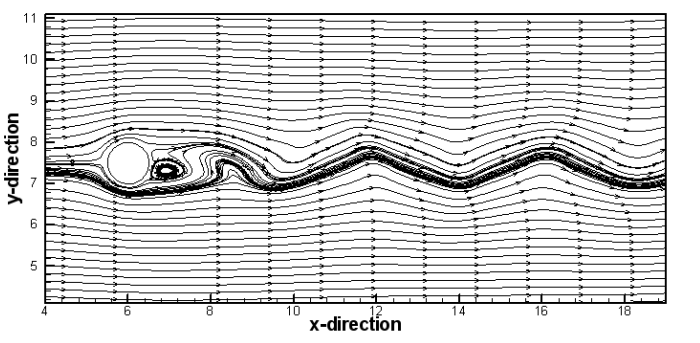

Figura 5.14: Linha de corrente para a) $\operatorname{Re}=1$, b) $\operatorname{Re}=10$, c) $\operatorname{Re}=100$ and d) $\operatorname{Re}=400$.

A comparação entre os coeficientes de arrasto obtidos e os resultados experimentais - Zahm (1922), Tritton (1959), Clift, Grace e Weber (1978) - e computacionais - Dennis e Chang 
(1970), Fornberg (1980), Saiki e Biringen (1996) e Silva, Silveira-Neto e Damasceno (2003) apresentados na tabela (5.2), mostram que o método da fronteira virtual é capaz de capturar o fenômeno de escoamento sobre uma seção cilíndrica, no entanto, conforme se observa na Tabela (5.2), os resultados se distanciam dos resultados comparativos à medida que o escoamento fica menos viscoso e mais convectivo. A razão desse comportamento deve-se ao fato da influência da razão de bloqueio e aumento da margem de erro da simulação numérica devido ao método numérico VONOS, que conforme Silva, Silveira-Neto e Damasceno (2003), aumentando-se o número de Reynolds há necessidade de melhorar o refinamento da malha.

Tabela 5.2: Comparação dos coeficientes de arrasto com resultados experimentais e computacionais.

\begin{tabular}{l|l|c|c|c|c}
\hline \hline \multicolumn{5}{c}{$C_{D}$} \\
\hline \multirow{3}{*}{ Experimental } & Re & 1 & 10 & 100 & 400 \\
& (ZAHM, 1922) & 10.6 & 2.69 & 1.43 & 1.28 \\
& (TRITTON, 1959) & 11.05 & 2.91 & 1.28 & - \\
& (CLIFT, 1978) & - & - & 1.24 & - \\
\hline \multirow{3}{*}{ Computacional } & (DENNIS; CHANG, 1970) & - & 2.846 & 1.056 & - \\
& (FORNBERG, 1980) & - & - & 1.058 & - \\
& (SAIKI; BIRINGEN, 1996) & - & - & 1.26 & 1.18 \\
& (SILVA, 2003) & - & 2.81 & 1.39 & - \\
& & & & & \\
\hline \multirow{2}{*}{ Presente trabalho } & Método da Fronteira Virtual & 15.76 & 3.46 & 1.37 & 1,06 \\
& & & & & \\
\hline \hline
\end{tabular}

A figura (5.15) mostra a distribuição de pressão sobre a superfície do cilindro para os escoamentos de número de Reynolds $R e=1, R e=10, R e=100$ e $R e=400$. Para o caso de $R e=100$ também são apresentados os resultados obtidos por Fornberg (1980). Pode-se verificar uma boa aproximação entre os resultados obtidos por Fornberg (1980) e pelo método da fronteira virtual. O coeficiente de sustentação em função do tempo, para os diferentes números de Reynolds, pode ser observado na figura (5.16) e podemos notar que para $R e=1 \mathrm{e}$ $R e=10$ o escoamento é estável e passa a instável para $R e=100$ e $R e=400$, conforme também 


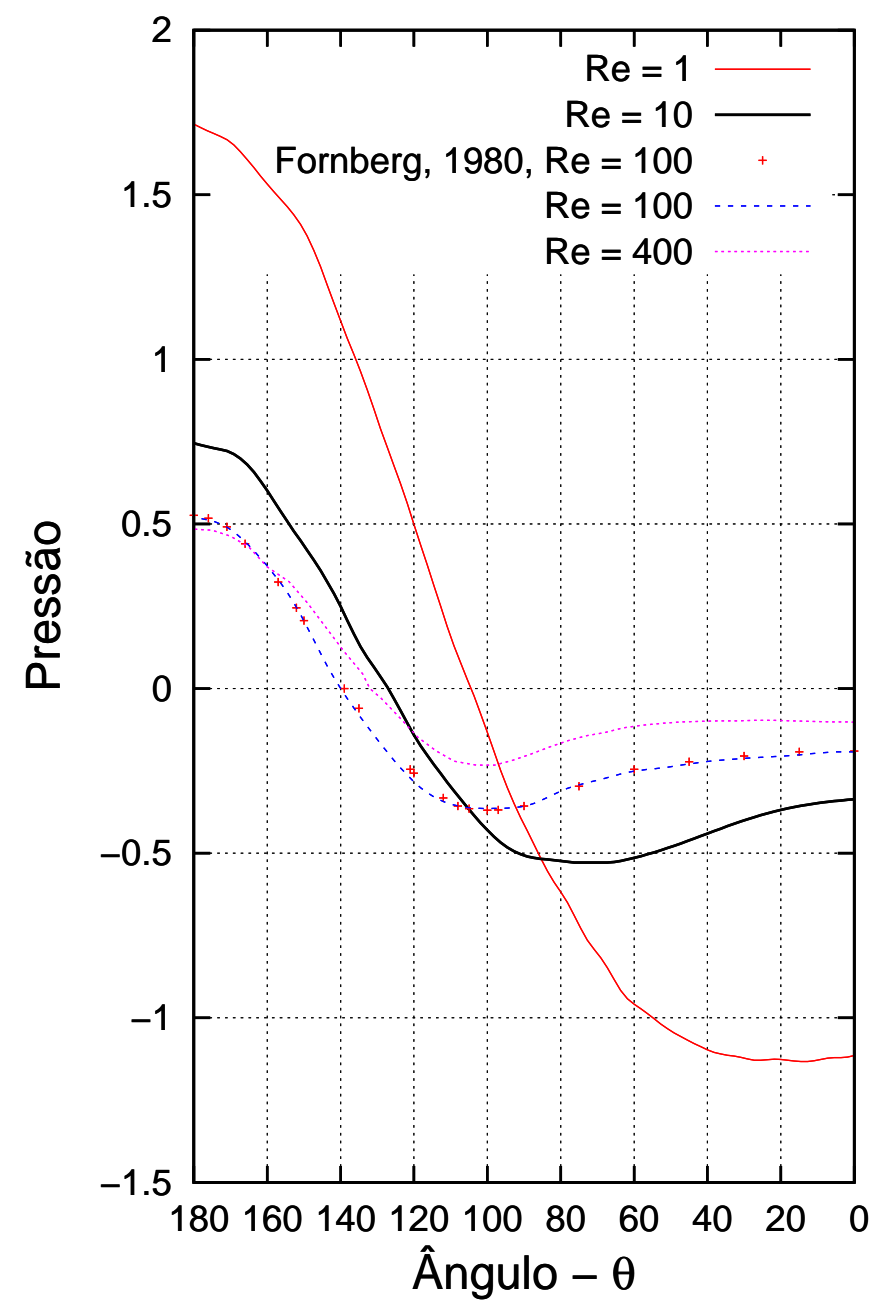

Figura 5.15: Curvas de distribuição de pressão sobre a superfície do cilindro.

pode ser notado nos trabalhos de Silva, Silveira-Neto e Damasceno (2003) e Saiki e Biringen (1996).

É interessante observar que apesar da resolução $D=10 \Delta$ (o recomendado pela literatura é de 18ム), esta foi adotada, no caso de escoamento sobre cilindro estacionário, em função dos ganhos computacionais e da precisão obtida devido aos erros inerentes do modelo tais como o fato de que a fronteira não fica exatamente locada, porque o campo de força pode não responder rapidamente à mudança do escoamento, e porque garante-se que a velocidade é zero no ponto onde é medida, mas não se pode garantir o mesmo entre pontos da fronteira. De acordo com Goldstein, Handler e Sirovich (1993) a medida, com precisão, das forças na fronteira nem sempre é possível e, de acordo com Saiki e Biringen (1996), isto ocorre devido às técnicas de suavização do campo de força que distorcem os resultados no entorno da fronteira. 


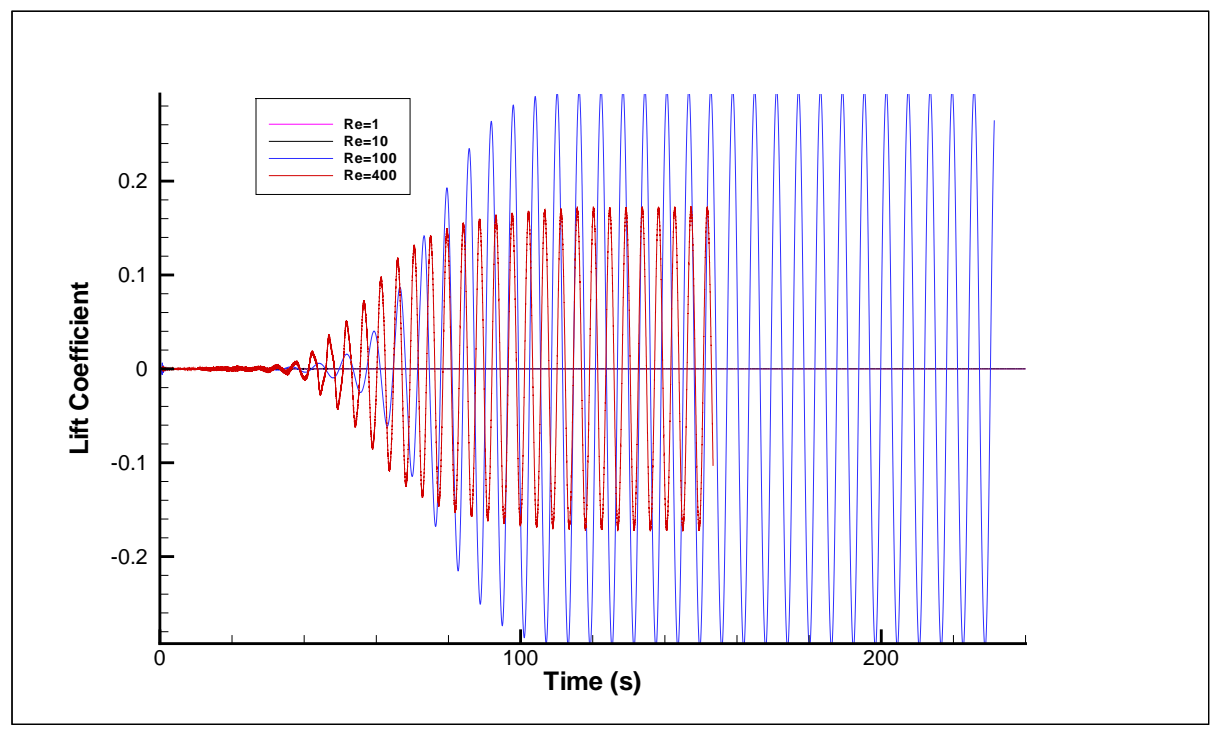

Figura 5.16: Comparações do coeficiente de sustentação.

\subsubsection{Estudo de escoamento ao redor de um cilindro de seção circular, oscilante}

Uma das preocupações na utilização de um sistema computacional para simulação em dinâmica de fluidos é sua capacidade de capturar variações no comportamento do escoamento. Apesar de exigir pequenos passos no tempo, devido à rigidez de grande parte dos problemas de fronteiras imersas (GOLDSTEIN, 1993), o método da fronteira virtual tem-se expandido e utilizado para um grande número de outros problemas que envolvem a relação fluidoestrutura. Muitos estudos têm mostrado que a frequência de oscilação rotativa forçada de um cilindro pode provocar efeitos significativos na frequência de formação dos vórtices, mais especificamente se houver condição de sincronização, ou seja, uma oscilação rotativa forçada igual ou muito próxima da frequência natural de formação de vórtices, chamada de condição de sincronização, produz uma mudança brusca no ângulo de fase entre o coeficiente de sustentação não estacionário, $C_{L}$, e o deslocamento do cilindro. O fenômeno ocorre para $\frac{f_{e}}{f_{o}} \sim 1$, onde $f_{s}$ é a frequência de excitação e $f_{o}$ é a frequência de formação de vórtices para o clindro estacionário.

Para um cilindro isolado e fixo, em todos os casos onde uma esteira estável pode ser identificada, verifica-se um único padrão de emissão de vórtices desprendidos de cada lado do corpo. Este modo de emissão, já observado por Bernard (1908) e Kármán (1911), é conhecido como 
modo $2 S$. Esta nomenclatura significa que dois vórtices isolados são desprendidos do corpo para a esteira em um ciclo de emissão. O comportamento dinâmico da esteira $2 S$ de um cilindro isolado é bem conhecido. Além da região de formação próxima ao cilindro, verifica-se um longo trecho à jusante onde a esteira se desenvolve com um padrão $2 S$ estável. A esteira de vórtices de um cilindro isolado é alterada quando o corpo passa de uma configuração estática para um comportamento de oscilações rotativas. Basicamente, os padrões de emissão de vórtices da esteira estão relacionados à amplitude e frequência destas oscilações. Williamson e Roshko (1988) mapearam os padrões de emissão de vórtices em função destes dois parâmetros. Eles impuseram oscilações forçadas a um cilindro rígido e observaram padrões de esteira diferentes do modo $2 S$ encontrado para um cilindro fixo. Três padrões distintos foram verificados: o modo $2 S$ ("two single"); o modo $2 P$ ("two pairs"); e o modo $P+S$ ("pair+single"). No modo $2 S$ dois vórtices isolados são desprendidos para cada ciclo de emissão. No modo $2 P$, dois pares de vórtices são desprendidos para a esteira em cada ciclo. No modo $P+S$, uma composição de um vórtice isolado e um par de vórtices são desprendidos do cilindro em cada ciclo de emissão. Apesar de todos estes padrões de emissão de vórtices terem sido observados para um cilindro isolado com oscilação rotativa forçada, nem todos eles são verificados quando um cilindro isolado está livre para oscilar rotativamente ao escoamento. Um cilindro oscilando livremente apresenta apenas os modos $2 S$ e $2 P$ para a faixa de velocidades de interesse deste trabalho. Os demais modos ilustram a variedade de fenômenos envolvidos na formação da esteira. Um dos fenômenos que ocorre quando um cilindro está oscilando é a captura da frequência de emissão de vórtices pela frequência desta oscilação. Esta faixa onde a frequência de emissão é capturada pela frequência de oscilação do corpo é denominada faixa de sincronização (ou “lock-in”).

Para as simulações com o cilindro submetido à oscilação forçada, a frequência de Strouhal foi utilizada como parâmetro de referência para a análise de frequência de desprendimento de vórtices além do coeficiente de sustentação. Nas simulações de Baek e Sung (1998) pode-se observar os valores de $C_{L}$ máximo nas regiões de lock-on para os ângulos de rotação forçada de $15^{\circ}, 30^{\circ}$ e $60^{\circ}$. Williamson (1996), Barnes (2000), Mittal e Kumar (2003), e Padrino e Joseph (2006) mostram que para uma determinada faixa de frequência e amplitude de oscilação do 
cilindro, é possível garantir certo controle sobre os mecanismos de instabilidade que induzem a ocorrência do fenômeno de geração e desprendimento de vórtices.

Neste trabalho, busca-se examinar estes efeitos aplicando ao cilindro uma oscilação forçada conhecida, de forma que se possa verificar a relação entre as frequências induzidas e as frequências de desprendimento, analisando as variações na vorticidade e nos coeficientes de arrasto e sustentação para um escoamento com número de Reynolds, $R e=110$. Este número de Reynolds foi escolhido para permitir a comparação dos resultados computacionais aos resultados experimentais Williamson e Roshko (1988) e outros resultados computacionais tais como os apresentados por Lu e Dalton (1996), Baek e Sung (1998), H.M.Blackburn e Henderson (1999), Williamson e Govardhan (2004) e Stewart, Leontini, Hourigan e Thompson (2005). Além disso, para este número de Reynolds, o escoamento ainda é laminar e a formação de vórtices ainda é predominantemente bidimensional.

Foi usada uma malha retangular regular uniforme com domínio de $20 \times 10$. A fronteira imersa (cilindro) foi discretizada com 40 pontos. Cada elemento possui tamanho $0.1 \times 0.05$, totalizando $200 \times 200$ elementos, ou seja, 40000 elementos. O centro do cilindro é posicionado no ponto coordenado 6,5 na direção $x$ e 5 na direção $y$ (ver 5.17). As amplitudes angulares máximas de rotação são de $\theta_{\max }=30^{\circ} \theta_{\max }=60^{\circ}$ e as frequências de oscilação da rotação são $f=0.14, f=0.17$ e $f=0.2$, adimensionalizadas pela frequência natural, $f_{0}$. Essas frequências foram escolhidas para comparação com os resultados obtidos por Baek e Sung (1998).

O cilindro é rotacionado e um ponto na superfície do cilindro produz uma trajetória de forma senoidal no tempo com uma frequência rotacional forçada $f_{s}$, conforme esquema mostrado na figura $5.17 \mathrm{c}$ ), e a equação da velocidade de um ponto na fronteira é dada por:

$$
\frac{\partial \varphi}{\partial t}=\theta \pi f_{s} \cos \left(2 \pi f_{s} t\right)
$$

onde $\theta$ é o deslocamento angular máximo e $t$ é o tempo, adimensionais. A adimensionalização é feita por meio do diâmetro $D$ do cilindro. 


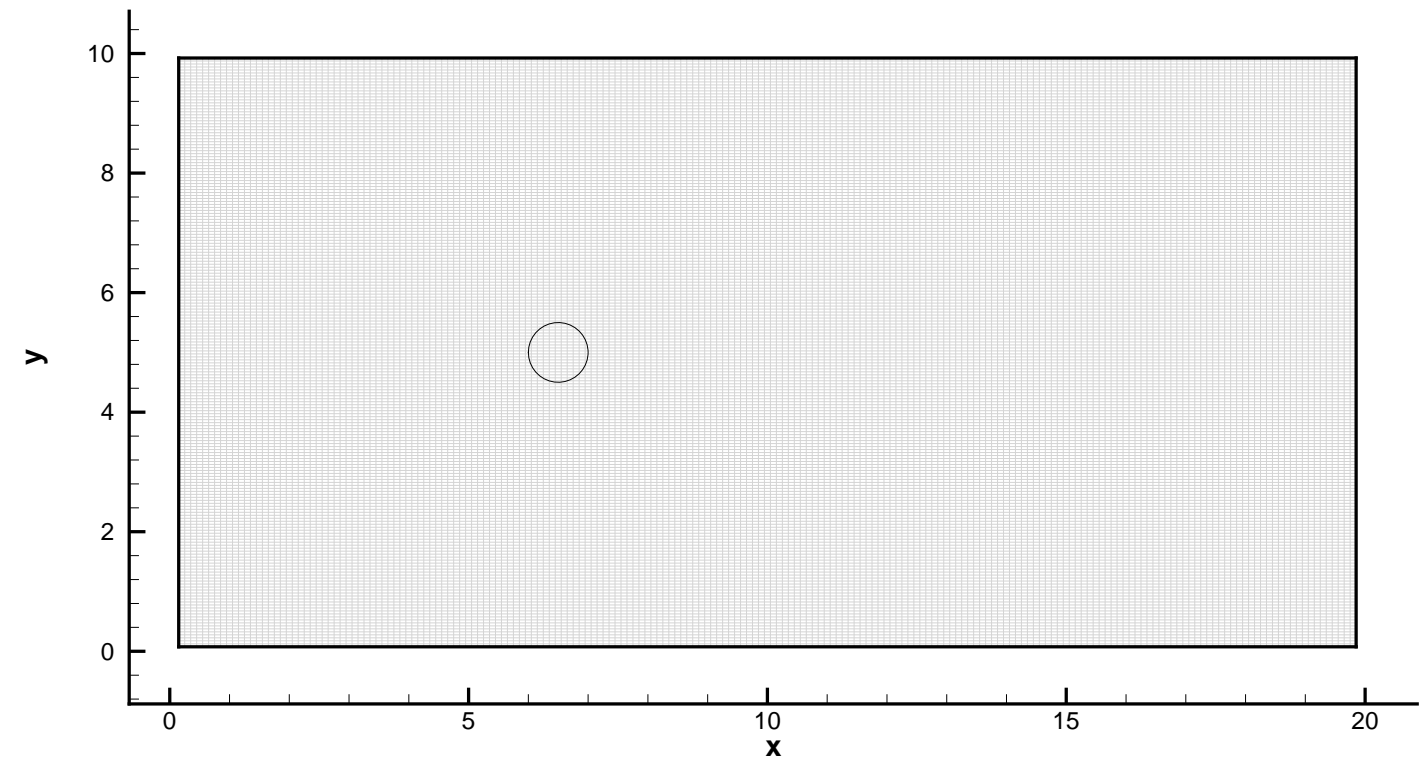

a)

b)

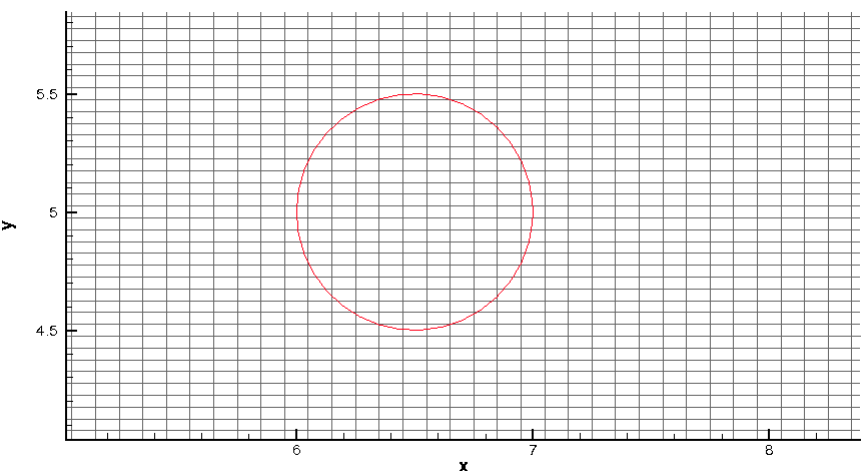

c)

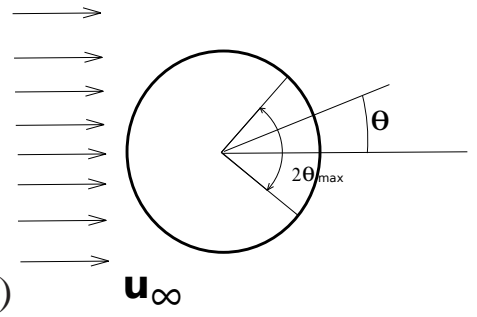

Figura 5.17: a) Malha computacional, b) malha ampliada próximo ao cilindro e c) Esquema de rotação do clindro

A simulação para o caso do cilindro estacionário, para o número de Reynolds $R e=110$, fornece os valores da tabela 5.3:

Tabela 5.3: Valores de $C_{D}, C_{L}$ e $S t$ experimentais e computacionais para o cilindro estacionário.

\begin{tabular}{l|l|c|c|c}
\hline \hline \multicolumn{2}{|c|}{ Coeficiente } & $C_{D}$ & $C_{L}$ & $S t$ \\
\hline \multirow{2}{*}{ Experimental } & (WILLIAMSON; ROSHKO, 1988) & 1.28 & - & 0.17 \\
& & & & \\
\hline \multirow{2}{*}{ Computacional } & (LU; DALTON, 1996) & 1.31 & 0.422 & 0.171 \\
& (MENEGHINI; BEARMAN, 1995) & 1.23 & 0.59 & 0.167 \\
& Met. Front. Virtual (MARQUES, 2006) & 1.33 & 0.428 & 0.173 \\
& & & & \\
\hline \hline
\end{tabular}


De acordo com Williamson e Roshko (1988), para um regime bidimensional e laminar $(50 \leq R e \leq 160)$ em que haja formação de vórtices, uma curva simples $S t-R e$ pode ser obtida pela fórmula $S t=-3.3265 / R e+0.1816+0.16 R e$. O valor, 0.173 , obtido pela simulação com $R e=110$ apresenta boa aproximação ao obtido pela fórmula $-S t=0.169$. Para se obter a condição de "lock-in", as simulações têm que utilizar valores de $\frac{f_{s}}{f_{o}}$ variando de 0.7 a 1.15 e $\frac{A}{D}$ de 0.025 a 0.6, que correspondem ao chamado "lock-in" primário, de acordo com Meneghini e Bearman (1995). Para a simulação do cilindro com oscilação forçada foram usadas: $f_{s}=0.17$, $f_{s}=0.14$ e $f_{s}=0.2, A=0.4$ e relação $\frac{f_{s}}{f_{o}}=0.81, \frac{f_{s}}{f_{o}}=0.98$ e $\frac{f_{s}}{f_{o}}=1.15$.

A análise do coeficiente de sustentação indica a mudança da formação de vórtices devido a frequência forçada de oscilação do cilindro. A tabela 5.4 mostra os resultados para os valores de $C_{L}$ máximo comparados aos resultados de Baek e Sung (1998) (computacional) para as amplitudes de $\theta_{\max }=30^{\circ}$ e $\theta_{\max }=60^{\circ}$, respectivamente. Conforme pode ser observado, obtevese boa aproximação para as frequências $f_{s}=0.14, f_{s}=0.17$ e $f_{s}=0.2$.

Tabela 5.4: Resultados para $C_{L}$ máximo e $C_{D}$ médio.

\begin{tabular}{|c|c|c|c|c|c|c|}
\hline \multicolumn{7}{|c|}{$\overline{\overline{C_{L}}}$} \\
\hline$\theta_{\max }$ & \multicolumn{3}{|c|}{$30^{\circ}$} & \multicolumn{3}{|c|}{$60^{\circ}$} \\
\hline$f_{s}$ & 0.14 & 0.17 & 0.2 & 0.14 & 0.17 & 0.2 \\
\hline (BAEK; SUNG, 1998) & 0.75 & 1.1 & 0.49 & 1.4 & 1.6 & 0.81 \\
\hline Fronteira Virtual & 0.71 & 1.17 & 0.61 & 1.4 & 1.58 & 0.71 \\
\hline \multicolumn{7}{|c|}{$\mathbf{C}_{\mathbf{D}}$} \\
\hline Fronteira Virtual & 1.58 & 1.39 & 1.40 & 1.76 & 1.63 & 1.54 \\
\hline
\end{tabular}

A Tabela 5.4 mostra também os resultados para o valor médio do coeficiente de arrasto e pode-se observar que o coeficiente de arrasto aumenta quando ocorre o fenômeno de sincronização e/ou o aumento da frequência de oscilação. Da figura 5.18 podemos notar que para o caso de $\theta_{\max }=30^{\circ}$ e $f_{s}=0.14$ houve sincronização com o aumento do $C_{L}$ e do $C_{D}$, mas não de forma intensa, devido à frequência de oscilação forçada estar abaixo da frequência natural de emissão

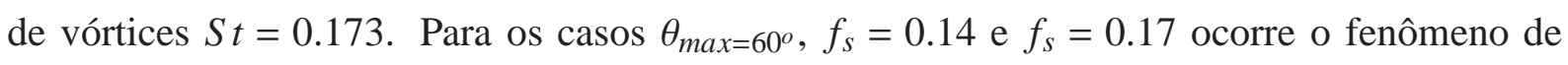


sincronização com aumento expressivo de $C_{L}$ e $C_{D}$. Para os casos $\theta_{\max =30^{\circ}}, f_{s}=0.17$ e $f_{s}=0.2$ e $\theta_{\max =60^{\circ}}, f_{s}=0.2$ não ocorre sincronização, mas a emissão de vórtices fora de sincronia perturba os coeficientes de arrasto e sustentação.

a)

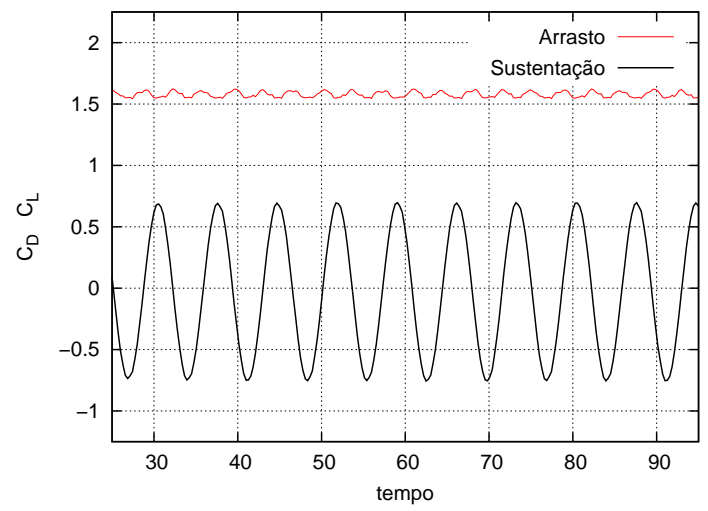

c)
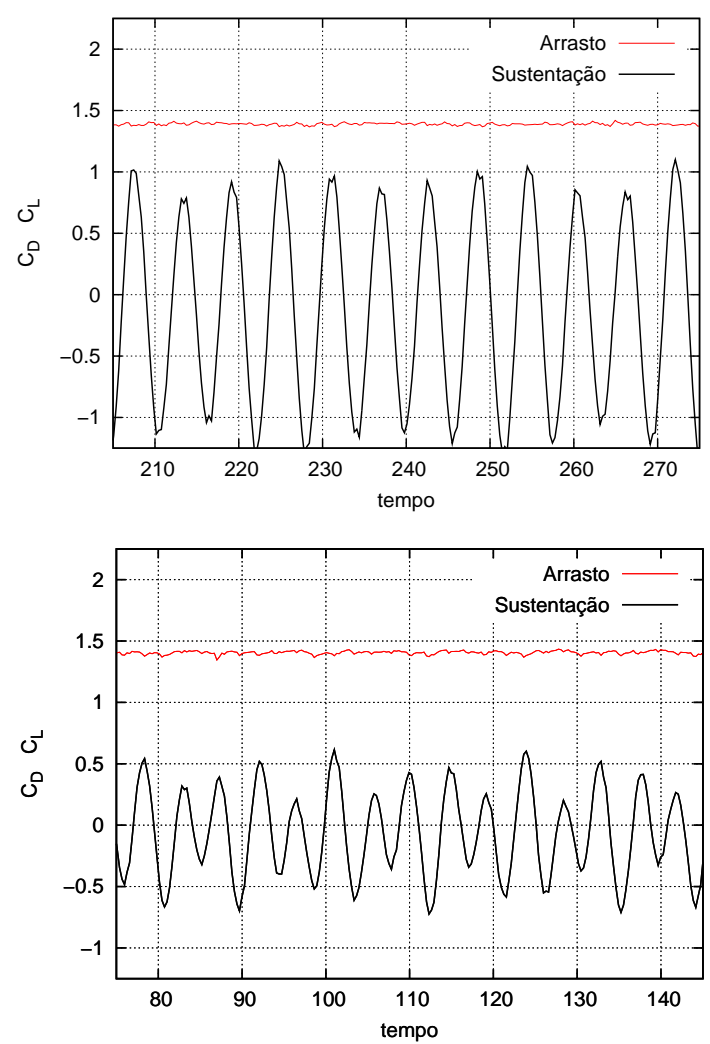

b)
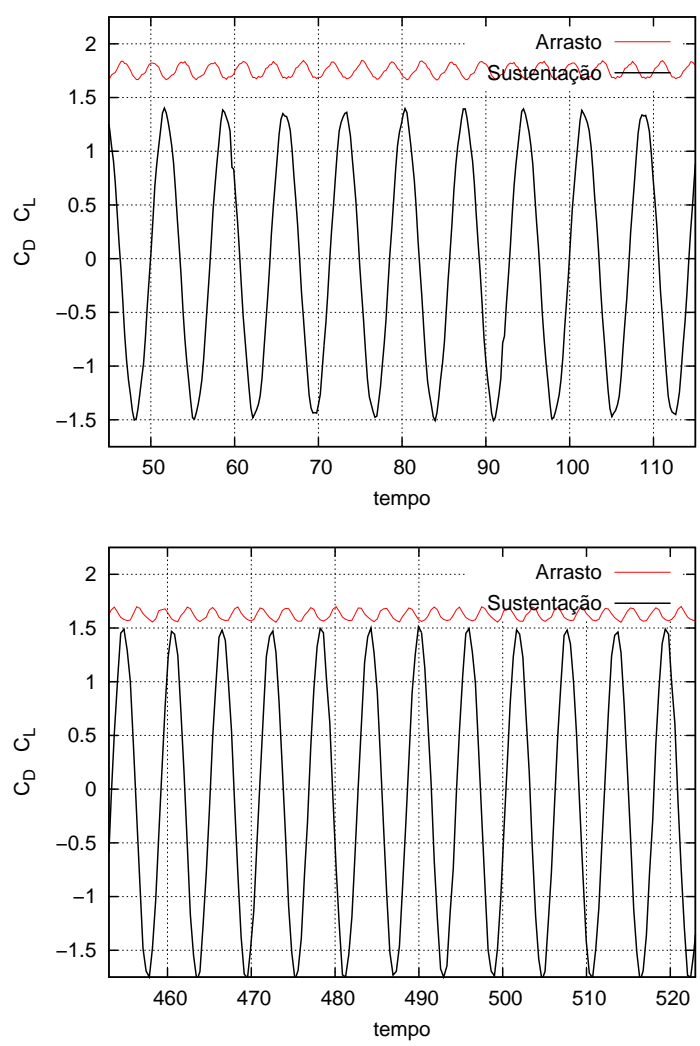

d)

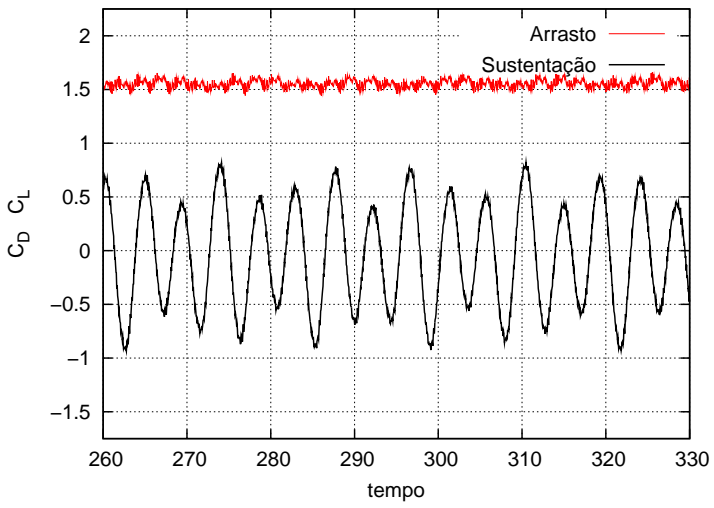

Figura 5.18: Evolução de $C_{L}$ e $C_{D}$ : a) $\theta_{\max }=30^{\circ}$ e $f_{s}=0.14$, b) $\theta_{\max }=60^{\circ}$ e $f_{s}=0.14$, c) $\theta_{\max }=30^{\circ}$ e $f_{s}=0.17$, d) $\theta_{\max }=60^{\circ}$ e $f_{s}=0.17$, e) $\theta_{\max }=30^{\circ}$ e $f_{s}=0.2$, f) $\theta_{\max }=60^{\circ} \mathrm{e}$ $f_{s}=0.2$

Para avaliar a influência da sincronização na formação de vórtices tomou-se o modo " $2 S$ " e os estágios da relação $\frac{f_{s}}{f_{o}}$ "pré-crítico" e "pós-crítico". Uma observação, esta nomenclatura, 
usada por Williamson e Roshko (1988), não deve ser confundida com a terminologia de números de Reynolds pré-crítico e pós-crítico.

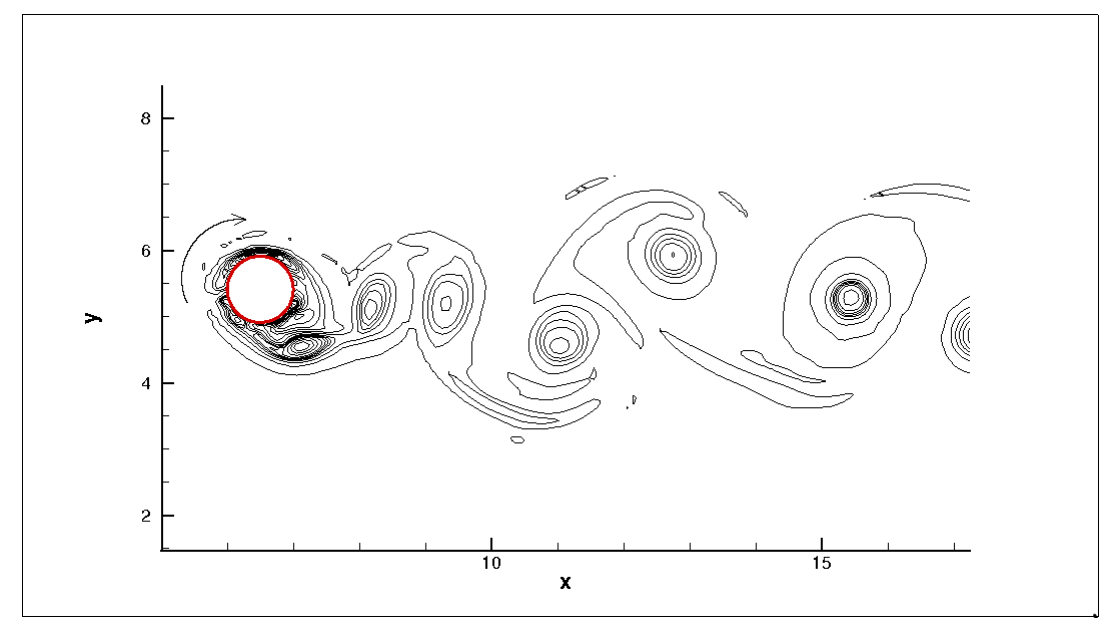

Figura 5.19: Modo 2S pré-crítico. $\theta_{\max }=60^{\circ}$ e $F_{S}=0,17$

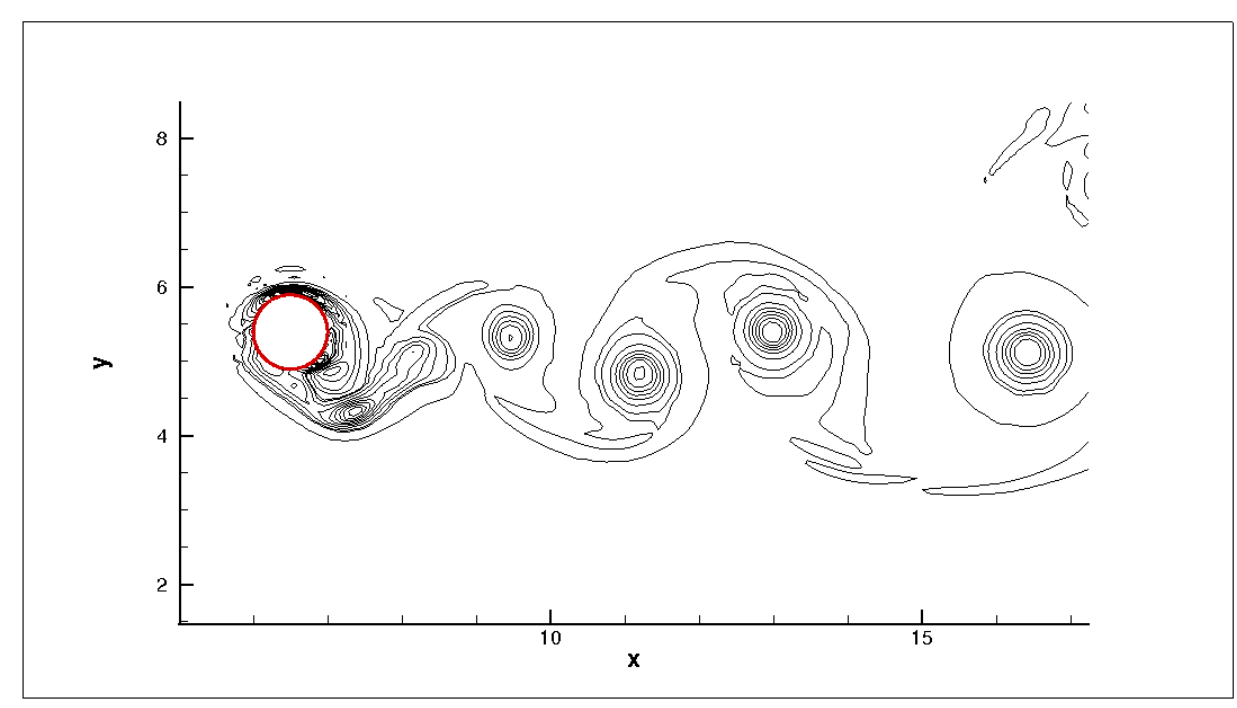

Figura 5.20: Modo 2S. $\theta_{\max }=60^{\circ}$ e $F_{S}=0,17$

As figuras 5.19, 5.20 e 5.21 mostram uma sequência de formação de vórtices para o caso $\theta_{\max }=60^{\circ}$ com oscilação forçada $f_{s}=0.17$. Comparando-se as figuras $5.19,5.20$ e 5.21 com a figura 5.13 o efeito da oscilação na formação dos vórtices explicada. A aceleração do fluido é devida a rotação do cilindro que aumenta a recirculação e acelera o escoamento na esteira de vórtices. A variação na formação de vórtices depende da condição de oscilação forçada. Quando a condição de frequência forçada é menor que a frequência natural de von Kármán, os vórtices são formados na mesma direção da rotação forçada correspondente. Quando o fenômeno ocorre na vizinhança da frequência natural, a formação do vórtice muda para a 


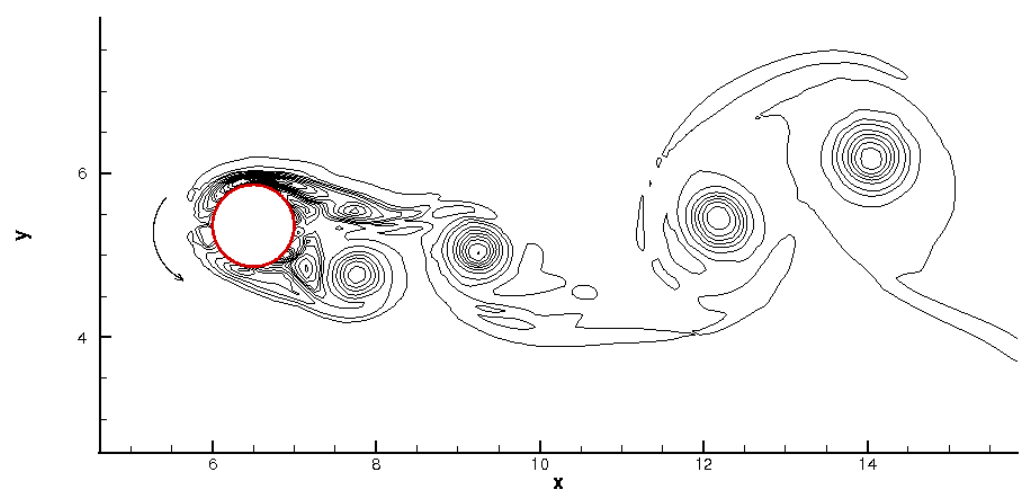

Figura 5.21: Modo 2S pós-crítico. $\theta_{\max }=60^{\circ}$ e $F_{S}=0,17$

direção oposta à da rotação forçada. Para frequências maiores que a natural e com a aceleração adequada, os vórtices são formados e seguem na direção contrária à de rotação do cilindro.

\subsection{Estudo de escoamento ao redor de uma seção de aerofólio NACA0012 estacionária}

A seção típica de aerofólio NACA0012, desenvolvida por National Advisory Committee for Aeronautics (NACA), é bastante usada para a validação de códigos numéricos aplicáveis a geometrias complexas. A seção NACA0012 será utilizada para estudar a aplicabilidade do Método da Fronteira Virtual para o estudo de flutter através da validação do código numérico implementado para escoamentos ao redor desse tipo de geometria, devido sua simplicidade e bibliografia disponível com dados experimentais e de simulações computacionais, o que facilita a comparação dos resultados obtidos. No entanto, a bibliografia não é vasta para o caso de escoamentos incompressíveis e com número de Reynolds ultrabaixo. O perfil geométrico do aerofólio NACA0012 foi modelado utilizando o mapeamento por funções conforme descrito no trabalho de Jacobs, Ward e pinkerton (1933):

$$
\pm y=\frac{0,12}{0,2}\left(0,2969 \sqrt{x}-0,126 x-0,35160 x^{2}+0,2843 x^{3}-0,1015 x^{4}\right)
$$




\subsubsection{Validação da malha não uniforme através de uma seção circular uniforme estacionária}

O Método da Fronteira Virtual foi aplicado para simular o escoamento ao redor de um cilindro com número de Reynolds $R e=10$. Os coeficientes de arrasto e sustentação são comparados com os valores experimentais apresentados por Zahm (1922), Tritton (1959) e computacionais apresentados por Rojas, Casanova, Pino e Feria (2005). Para a simulação foi usado um domínio euleriano retangular $10 \times 30$ com resolução mínima de malha de $h_{x}=$ $h_{y}=0.02$, varáveis adimensionalisadas, condição de contorno nos limites inferior e superior $\delta u / \delta y=0$ and $v=0$, escoamento uniforme com $u=1$ and $v=0$ na entrada ("inflow") e a equação de Poisson para a pressão foi resolvida por meio gradiente bi-conjugado. O centro do cilindro circular foi posicionado nas coordenadas $x=8.5$ and $y=5.0$ no no domínio computacional

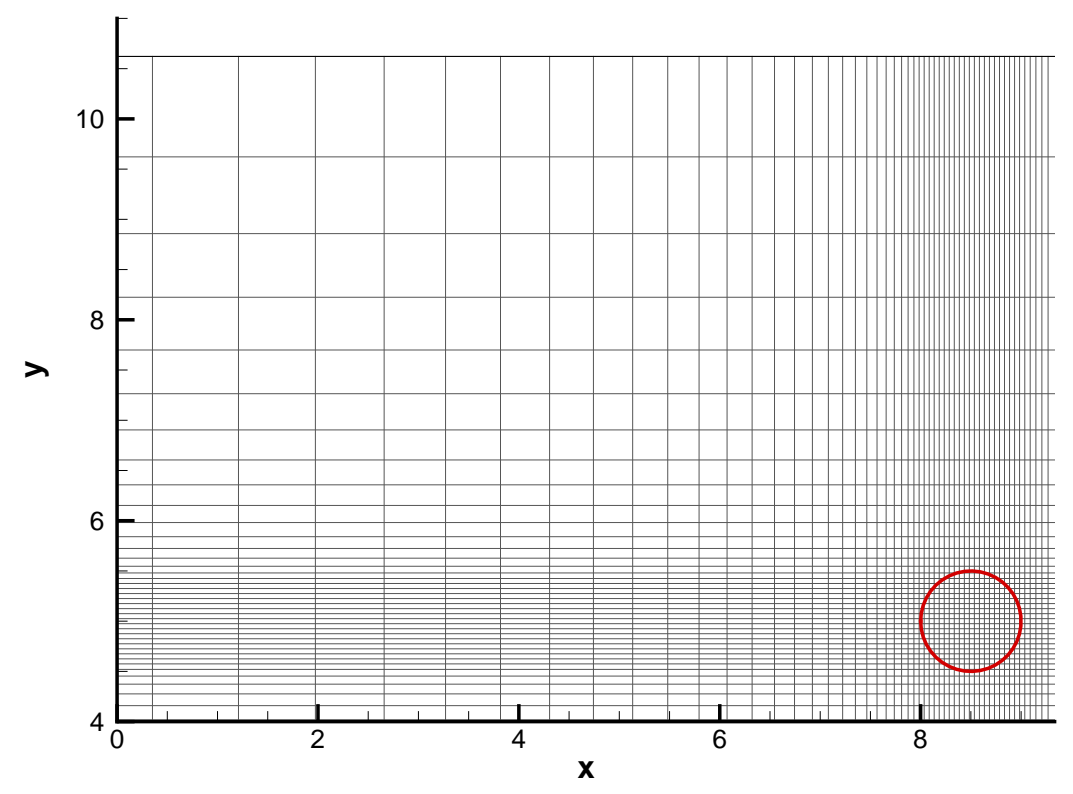

Figura 5.22: Detalhe do cilindro no domínio computacional

Os resultados mostrados nas figuras 5.23(a) e 5.23(b) indicam o comportamento clássico de distribuição de velocidades ao redor do cilindro. As linhas de corrente, figura 5.24(a), mostram que há um início de formação de vórtices axissimétricos, mas sem energia suficiente para desprendimento devido a viscosidade elevada. De acordo com Rojas, Casanova, Pino e Feria (2005), o comprimento do vórtice formado é da ordem de 0.285 vezes o diâmetro do 

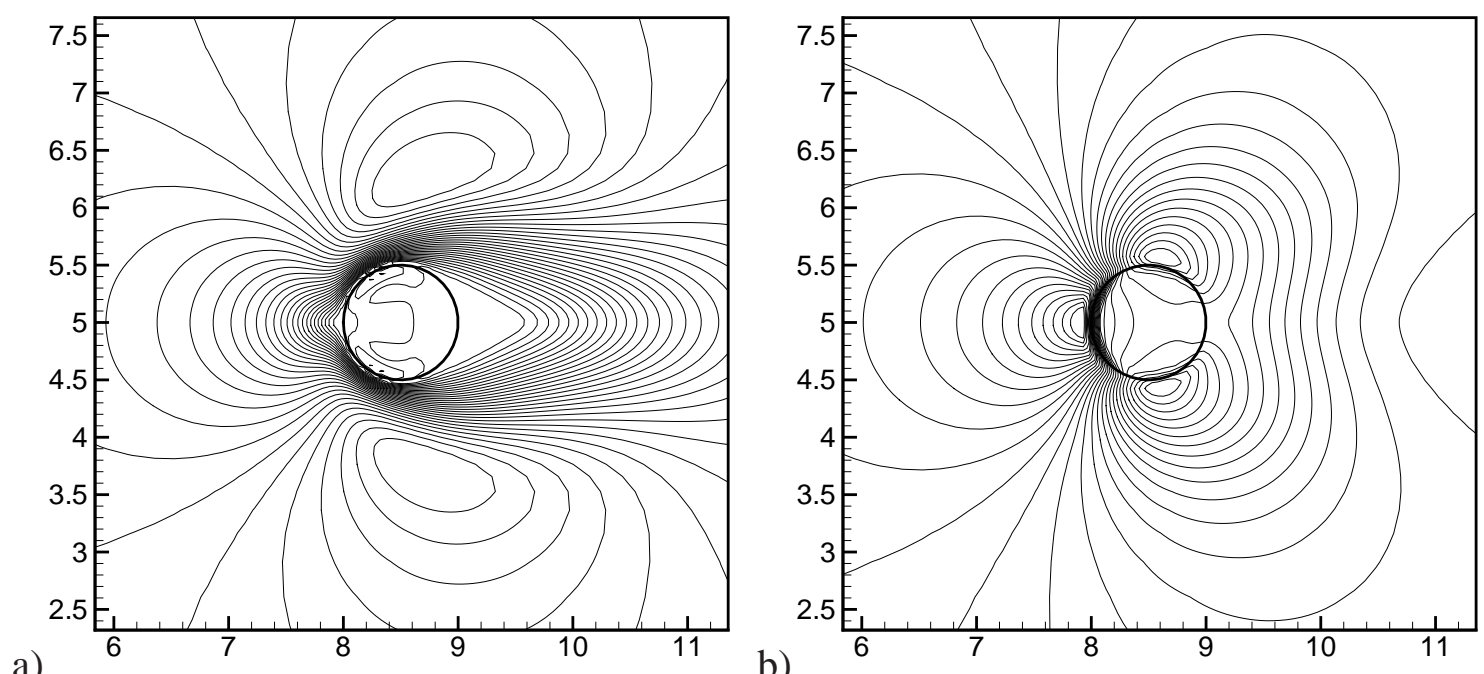

Figura 5.23: a) Campo de velocidade para o escoamento ao redor do cilindro, $\operatorname{Re}=10$. b) campo de pressão para o escoamento ao redor do cilindro, $R e=10$.

a)

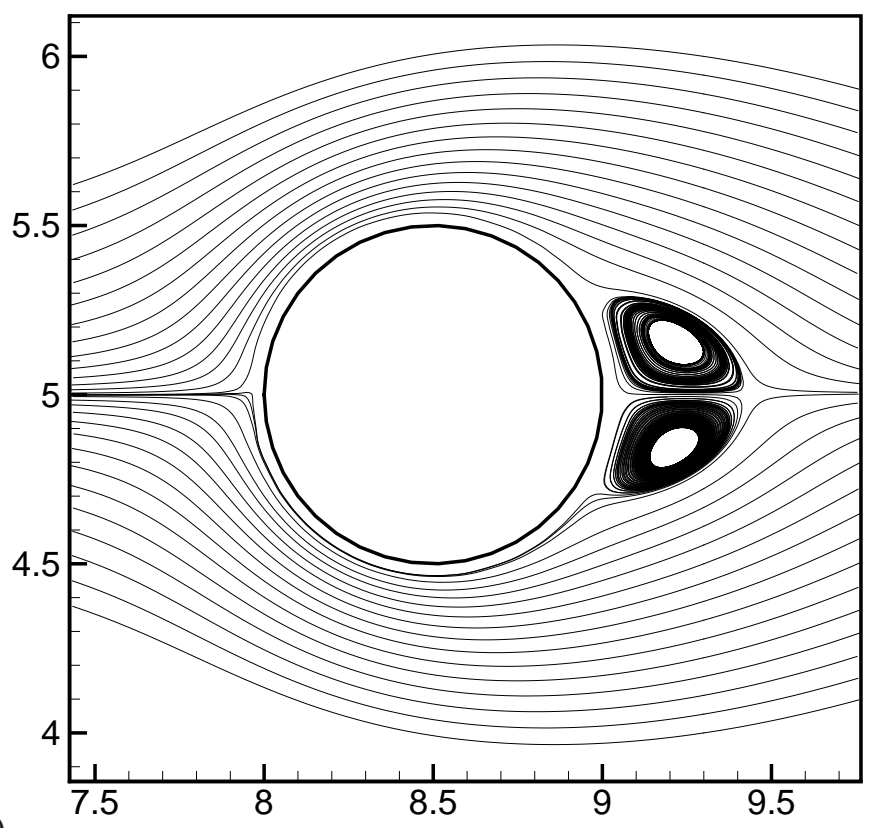

b)

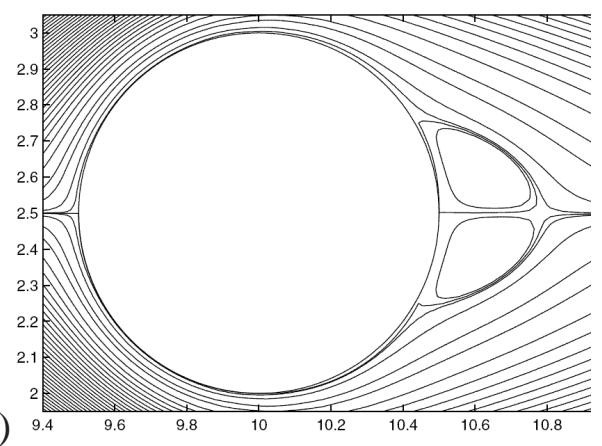

Figura 5.24: a) Linhas de corrente para o escoamento ao redor do cilindro, $R e=10$. b) Detalhe apresentado por Sanmiguel et al, $R e=10$.

cilindro e esta dimensão pode ser aproximada, com boa precisão, nas figuras 5.24(a) (resultado da simulação) e 5.24(b) (resultado apresentado por Rojas, Casanova, Pino e Feria (2005)). Essa alternativa de geração da malha implementada é conveniente para resolver este tipo de problema com bons resultados. Os resultados numéricos do coeficiente de arrasto, para o número de Reynolds $R e=10$, podem ser observados na tabela 5.5 e podemos notar que o resultado 
obtido na simulação é consistente com os valores reportados pela literatura, no entanto há a necessidade de maior refinamento da malha computacional para verificação da precisão e mensuração do esforço computacional.

Tabela 5.5: Comparação do coeficiente de arrasto obtido com os resultados experimentais e computacionais.

\begin{tabular}{l|l|c}
\hline \hline \multicolumn{2}{c}{$C_{D}$} & 10 \\
\hline \multirow{3}{*}{ Experimental } & $\operatorname{Re}$ & 2.69 \\
& $($ ZAHM, 1922) & 2.91 \\
& (TRITTON, 1959) & \\
\hline \multirow{3}{*}{ Computacional } & (DENNIS; CHANG, 1970) & 2.846 \\
& (SILVA, 2003) & 2.81 \\
& (MARQUES, 2006) & 3.46 \\
\hline \multirow{2}{*}{ Malha não uniforme } & Método da Fronteira Virtual & 3.02 \\
\hline \hline
\end{tabular}

\subsubsection{Perfil de aerofólio NACA 0012}

Normalmente, os resultados experimentais para aerofólio NACA 0012 são mais abundantes para altos números de Reynolds e problemas aplicados a escoamentos compressíveis. Neste trabalho, as aplicações do perfil NACA0012 estão relacionados a microaeronaves e à hidrodinâmica. Os resultados experimentais e computacionais são escassos para número de Reynolds muito baixos (ultra-low Reynolds numbers) e normalmente estão direcionados para fenômenos específicos, por exemplo cavitação no caso hidrodinâmico. De acordo com Mueller (1999), e tomando o comprimento da corda do aerofólio como medida para adimensionalização, temos uma classificação do tipo de escoamento, conforme mostrado na tabela 5.6

Conforme Schroeder e Baeder (2005), na escala de microaeronaves trabalha-se na faixa de número de Reynolds entre 1.000 e 100.000 e a seção de aerofólio necessária para produzir a sustentação suficiente deve ter bastante curvatura. Incialmente testa-se perfis simétricos (por 
Tabela 5.6: Características do escoamento para número de Reynolds

\begin{tabular}{|c|c|c|}
\hline Número de Reynolds & $\begin{array}{l}\text { Exemplos de voos } \\
\text { no intervalo }\end{array}$ & $\begin{array}{l}\text { Condição da camada } \\
\text { limite/separação }\end{array}$ \\
\hline $1.000<\operatorname{Re}<10.000$ & $\begin{array}{l}\text { - Mosca doméstica } \\
\text { - Aeromodelo indoor }\end{array}$ & $\begin{array}{c}\text { - Escoamento totalmente laminar. } \\
\text { - muito difícil a indução } \\
\text { de turbulência. }\end{array}$ \\
\hline $10.000<\operatorname{Re}<30.000$ & $\begin{array}{l}\text { - Planadores lançados } \\
\text { manualmente }\end{array}$ & $\begin{array}{l}\text { - Completamente laminar, não foram } \\
\text { encontrados métodos artificiais } \\
\text { para induzir turbulência. } \\
\text { - Quando ocorre separação não há } \\
\text { recuperação da camada limite. }\end{array}$ \\
\hline $30.000<\operatorname{Re}<70.000$ & $\begin{array}{l}\text { - MAV's } \\
\text { - Aeromodelos }\end{array}$ & $\begin{array}{l}\text { - Separação laminar com transição } \\
\text { para escoamento turbulento - pode causar } \\
\text { histerese em aerofólios espessos. } \\
\text { - Perturbação artificial da camada } \\
\text { limite para provocar escoamentos } \\
\text { turbulentos tem sido bem sucedida na } \\
\text { redução do número de Reynolds } \\
\text { crítico no dorso. }\end{array}$ \\
\hline $70.000<\operatorname{Re}<200.000$ & $\begin{array}{l}\text { - Pequenas aeronaves } \\
\text { rádio controladas }\end{array}$ & $\begin{array}{l}\text { - Obtenção de escoamento extensivamente } \\
\text { laminar com melhor desempenho } \\
\text { aerodinâmico do perfil. } \\
\text { - A separação laminar é dependente da } \\
\text { geometria das características do escoamento. }\end{array}$ \\
\hline
\end{tabular}

exemplo NACA0012 e NACA0015) e a partir dos resultados da simulação preliminar buscase seções mais adequadas ao modelo completo (por exemplo EPPLER 387 e Müller). Para o número de Reynolds 1.000 a seção NACA 0012 atende às necessidades da simulação preliminar e foi escolhida por sua simplicidade, simetria e aplicações na área de microaeronaves (BORIA, 2009) o que facilita muito a comparação dos resultados obtidos pelo método numérico com resultados obtidos por outros simuladores. 
Dados experimentais para número de Reynolds ultrabaixo não são frequentes na literatura, pois a maior parte dos ensaios trata de modelos com condições usuais de voo, quando muito para escalas reduzidas, como por exemplo o trabalho de Patil, Khan e Gupta (2008) que apresenta resultados para várias seções de aerofólios provenientes de testes em túnel de vento de massa específica variável com número de Reynolds variando de 10.000 a 100.000. Os resultados mostram a variação dos coeficientes de sustentação e de arrasto devido a variação do ângulo de ataque. Para a implementação dessa verificação, as condições iniciais, de contorno e características do escoamento são as mesmas usadas para o caso da simulação do cilindro em malha não uniforme, com posicionamento do perfil do aerofólio como mostrado na Figura 5.25. As simulações foram realizadas com números de Reynolds 10, 100, 800, 1000 e 1200 para
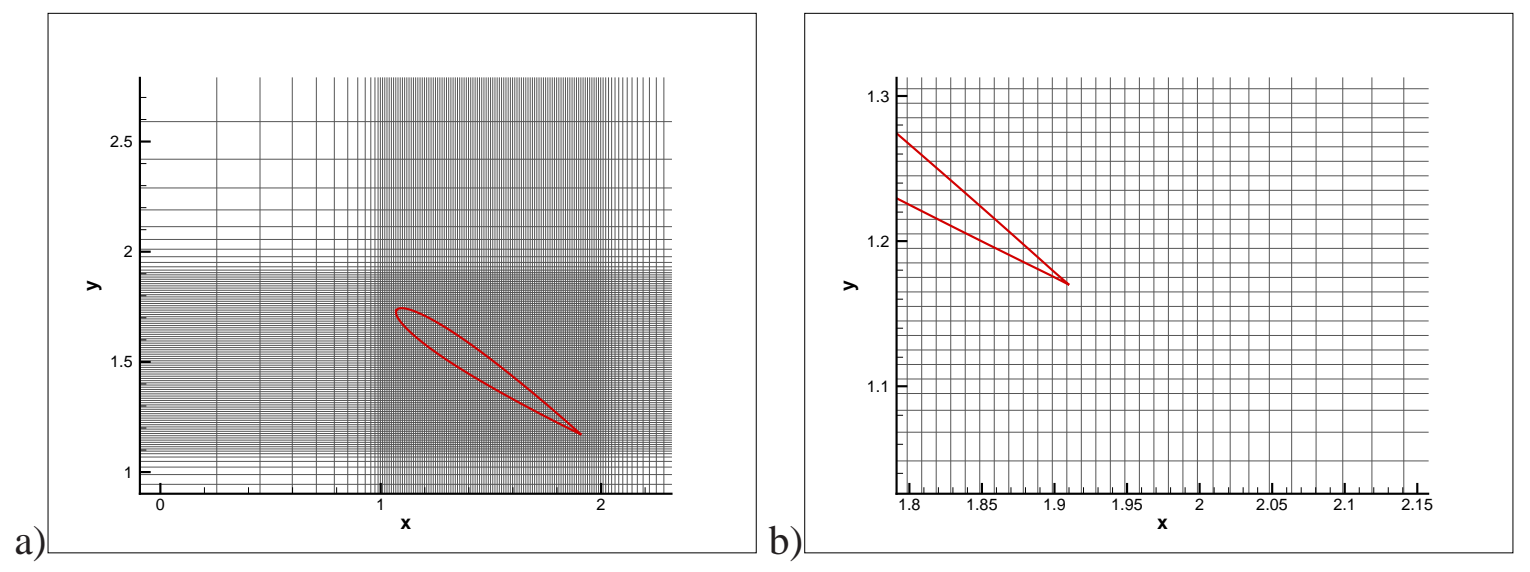

Figura 5.25: a) Seção de aerofólio NACA0012 com malha não uniforme b) Detalhe do bordo de fuga

mostrar a eficiência da alternativa de geração de malha escolhida e a aplicabilidade do Método da Fronteira Virtual a este tipo de problema. Para cada tipo de escoamento simulado (número de Reynolds diferentes), resultados dos campos de velocidades, de pressão, linhas de corrente e coeficiente de pressão são apresentados. As figuras 5.26a), 5.26b) e 5.27c) mostram os campos de pressão para o escoamento ao redor de um aerofólio perfil NACA0012 com números de Reynolds 10, 100 e 800 respectivamente.

O trabalho de Guermond e Quartapelle (1997) usa como exemplo para validação o caso do aerofólio NACA0012 submetido a escoamento de fluido incompressível com número de Reynolds 1.000 e mostra as distribuições dos campos de velocidade $u$ e pressão para ângulo de 

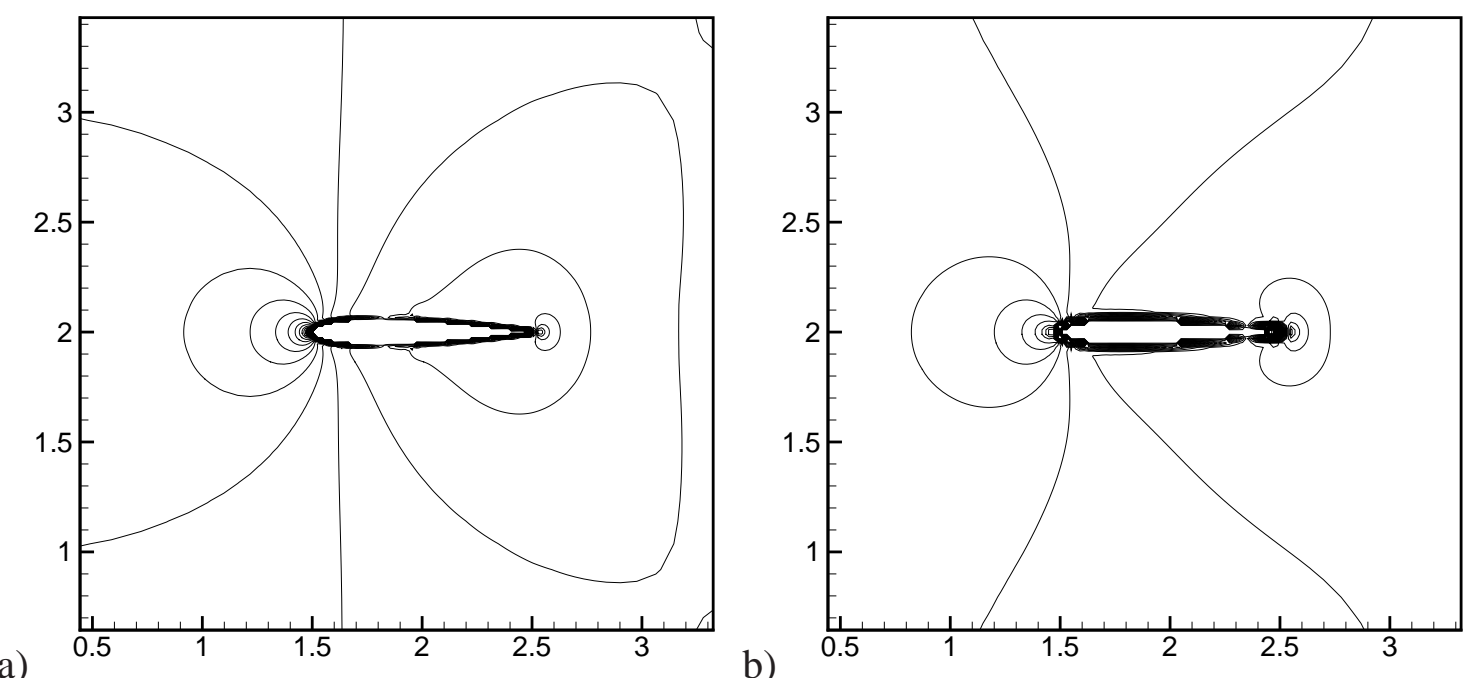

Figura 5.26: a) Campo de pressão, $R e=10$. b) campo de pressão, $R e=100$.
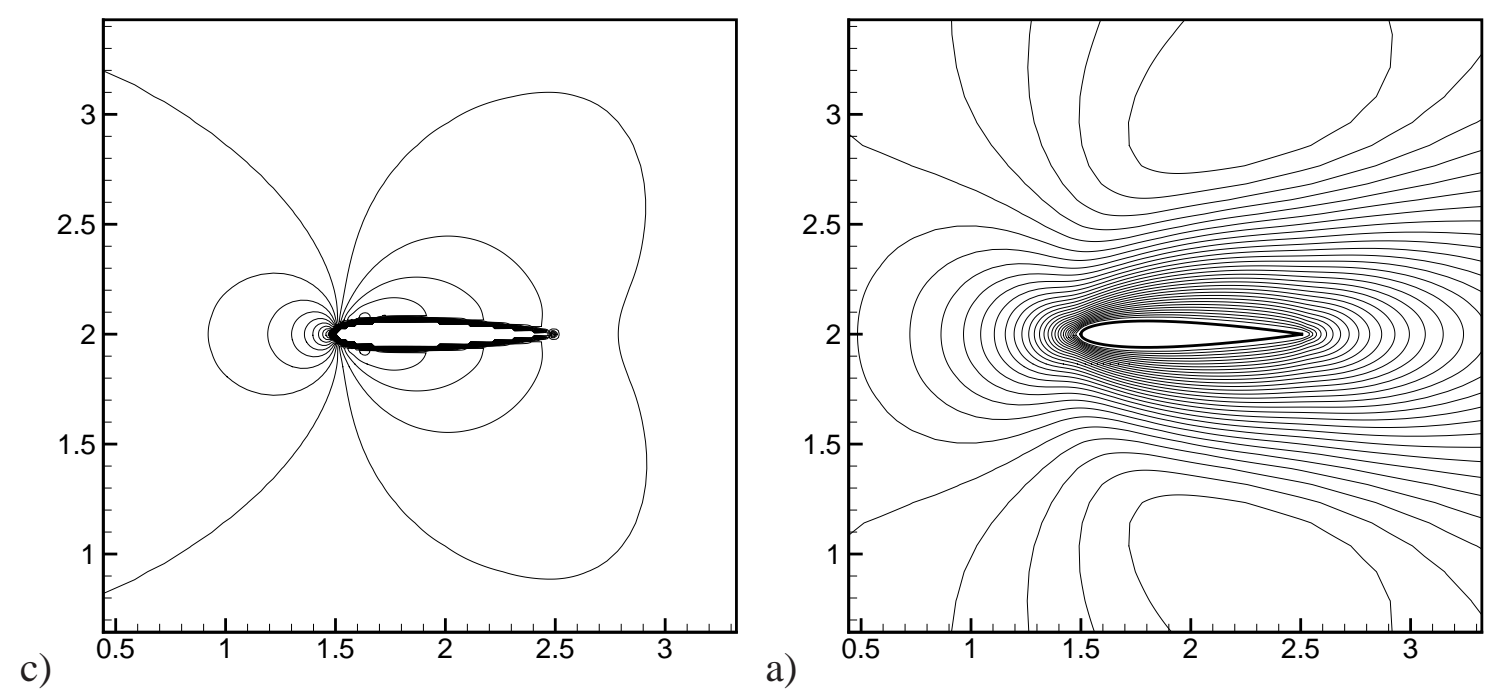

Figura 5.27: c) Campo de pressão, $R e=800$. a) campo de velocidades, $R e=10$.

ataque de 34 graus. Para as simulaçãoes com o MFV utilizou-se uma malha com espaçamento não uniforme $216 \times 250$ com $\Delta x_{\min }=0,01, \Delta y_{\min }=0,01, \Delta x_{\max }=0,36$ e $\Delta y_{\max }=0,36$ sobre um domínio $6 \times 3$ unidades adimensionais, figura 5.25. A figura 5.31, mostra o campo de velocidade $u$ para o ângulos de ataque $\alpha=34$ obtido pelo MFV e o resultado apresentado por Guermond e Quartapelle (1997).

Com relação ao campo de velocidade $u$, o método da fronteira virtual apresenta uma "camada" ao redor da seção de aerofólio como resultado do processo de interpolação do campo de força do domínio lagrangiano para o euleriano por intermédio da função delta suavizada. 
b)
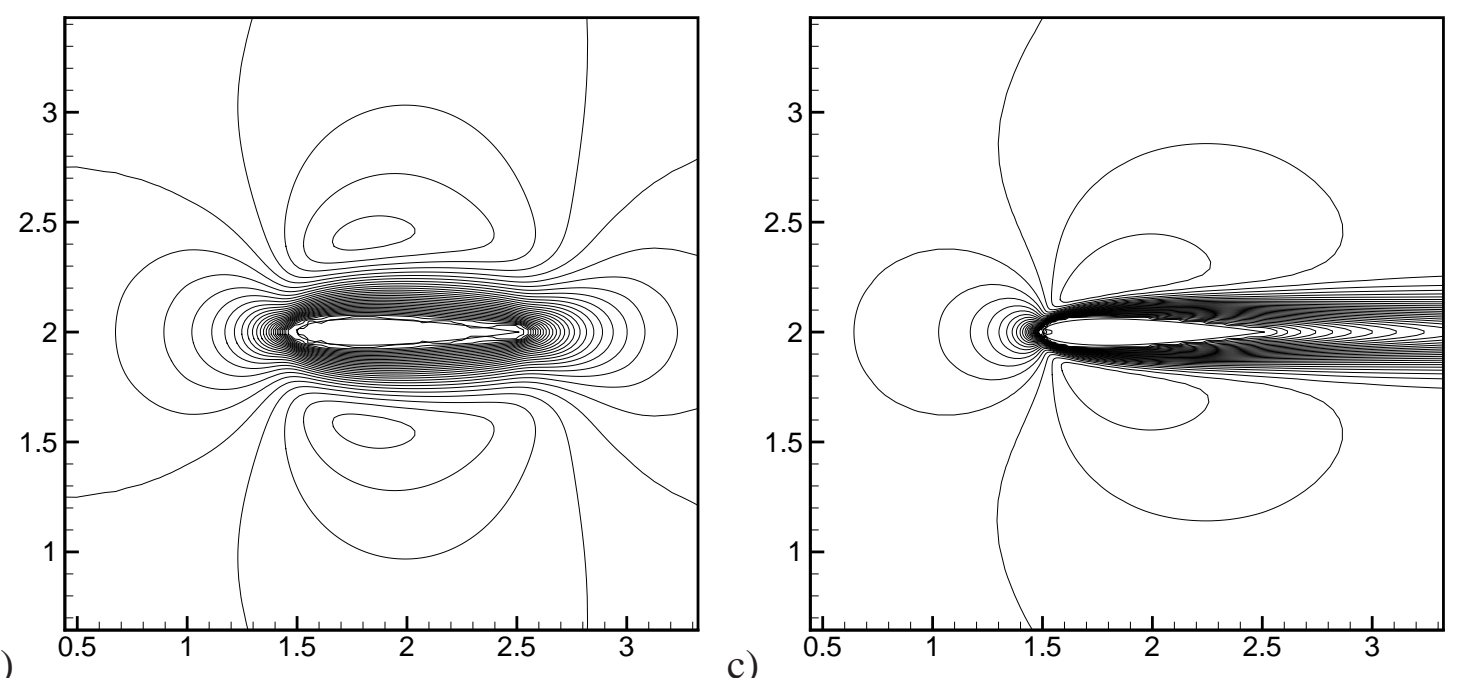

Figura 5.28: b) Campo de velocidades, $R e=100$. c) campo de velocidades, $R e=800$.

a)

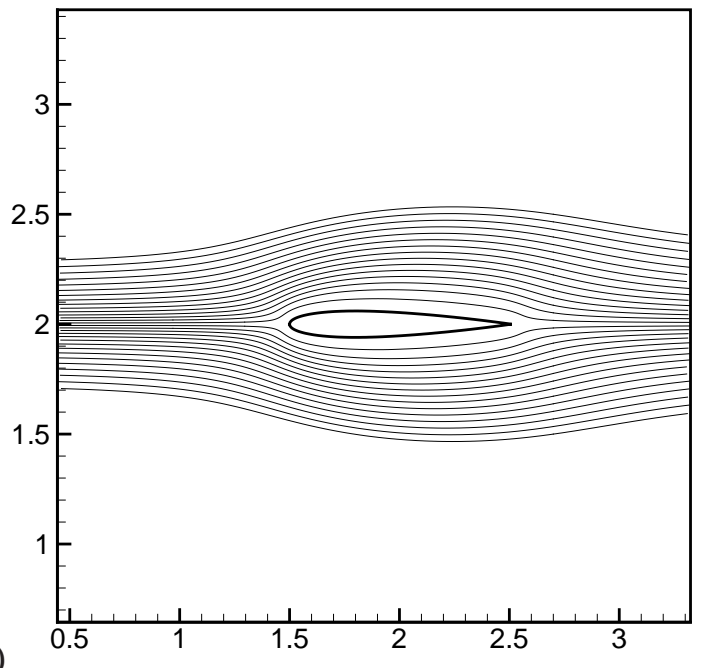

b)

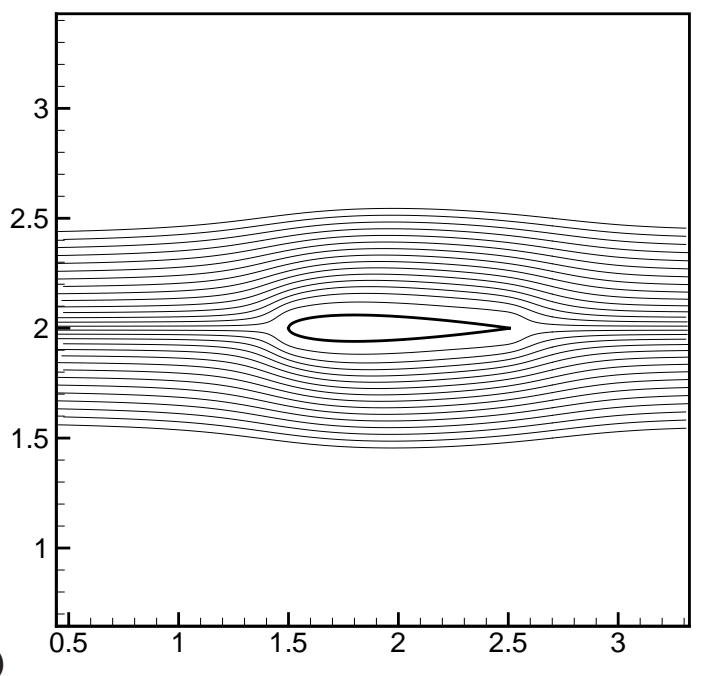

Figura 5.29: a) Linhas de corrente, $R e=10$. b) Linhas de corrente, $R e=100$.

Alguns trabalhos, tais como Leveque e Li (1997), Li e Lai (2001) e Tseng e Ferziger (2003), tentam resolver esse problema impondo explicitamente a condição de contorno, contudo isso faz com que o efeito interativo, natural dos métodos de fronteiras imersas, entre o fluido e a estrutura se perca. Apesar dessa ressalva, as características qualitativas do escoamento não são afetadas, conforme pode-se observar nas figuras 5.32 a 5.34 .

Um resultado importante nas simulações é o campo de pressões que pode ser observado no escoamento e próximo à fronteira imersa. As figuras 5.35 e 5.36 mostram os resultados do campo de pressão do escoamento obtidos pelo MFV para o número de Reynolds 1.000 


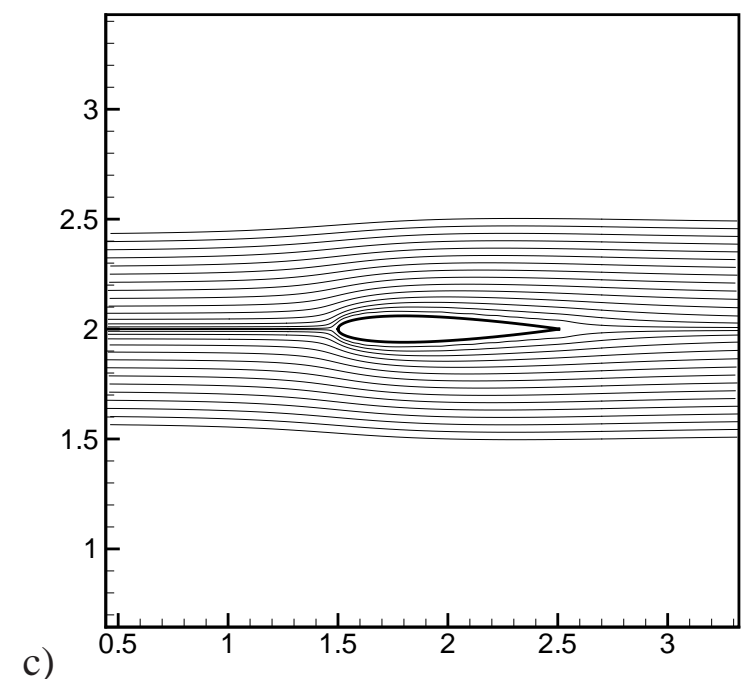

Figura 5.30: a) Campo de velocidades, $R e=800$.
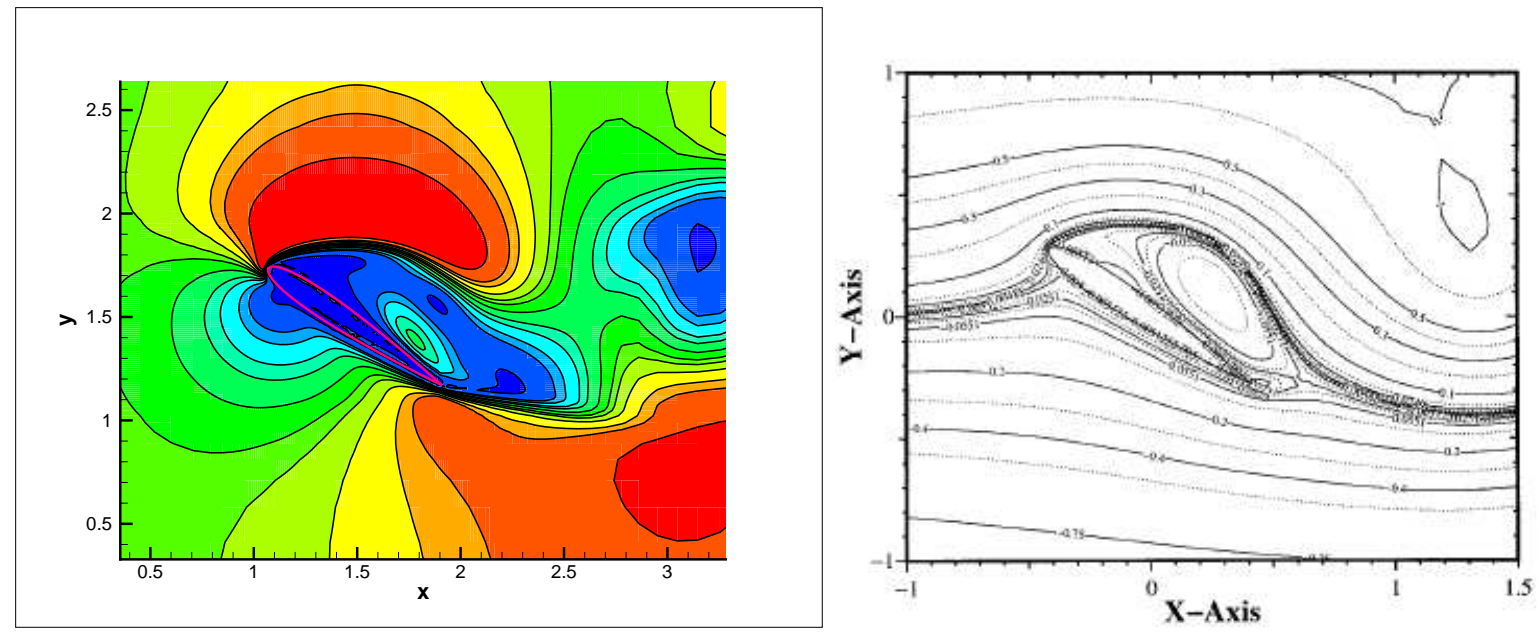

Figura 5.31: a) Campo de velocidade u para a seção de aerofólio NACA0012 com $\alpha=34$ graus: MFV, b) Guermond e Quartapelle (1997)

com ângulos de ataque de $\alpha=0, \alpha=16$ e $\alpha=34$. Para o ângulo de ataque $\alpha=34$ podemos comparar os resultados apresentado por Guermond e Quartapelle (1997) e obtido pelo MFV quanto à posição e dimensão da recirculação. No caso do MVF, quando seguimos a evolução do campo de pressão do ângulo de ataque $\alpha=16$ para $\alpha=34$, podemos notar que as linhas de pressão do extradorso não fecham sobre a fronteira. Isto ocorre devido à influência da suavização do campo de força na região do bordo de fuga do aerofólio e devido à dificuldade de se conseguir refinamento adequado da malha computacional para geometrias afiladas (bordo de fuga do aerofólio). 
a)

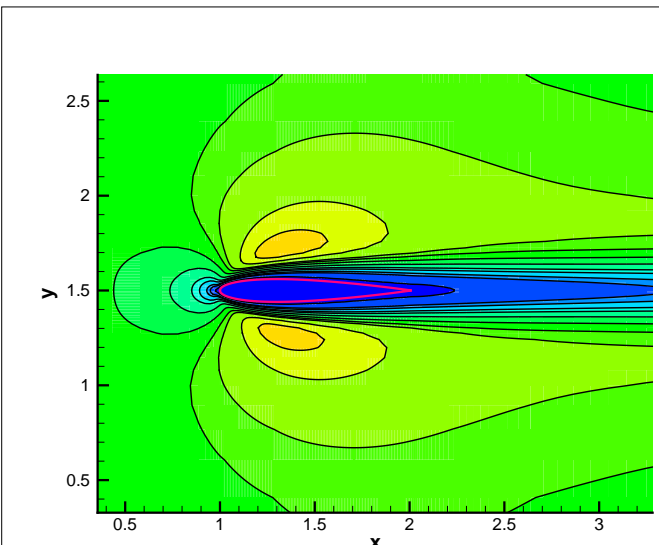

Figura 5.32: a) Campo de velocidade para a seção de aerofólio NACA 0012: $\alpha=0$ graus, b) $\alpha=2$ graus.

a)

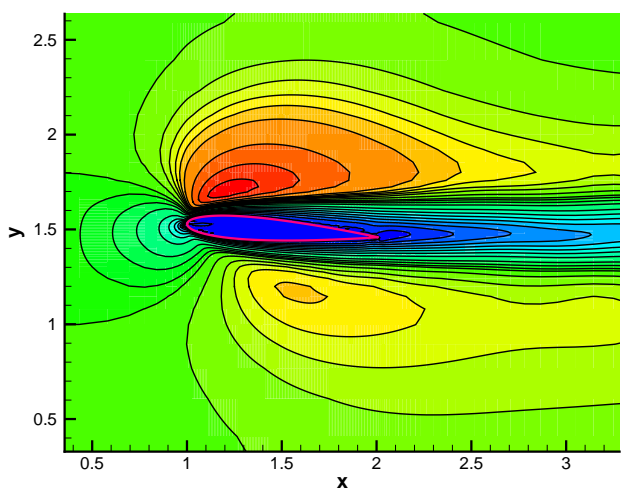

Figura 5.33: a) Campo de velocidade para a seção de aerofólio NACA 0012: $\alpha=4$ graus, b) $\alpha=8$ graus.
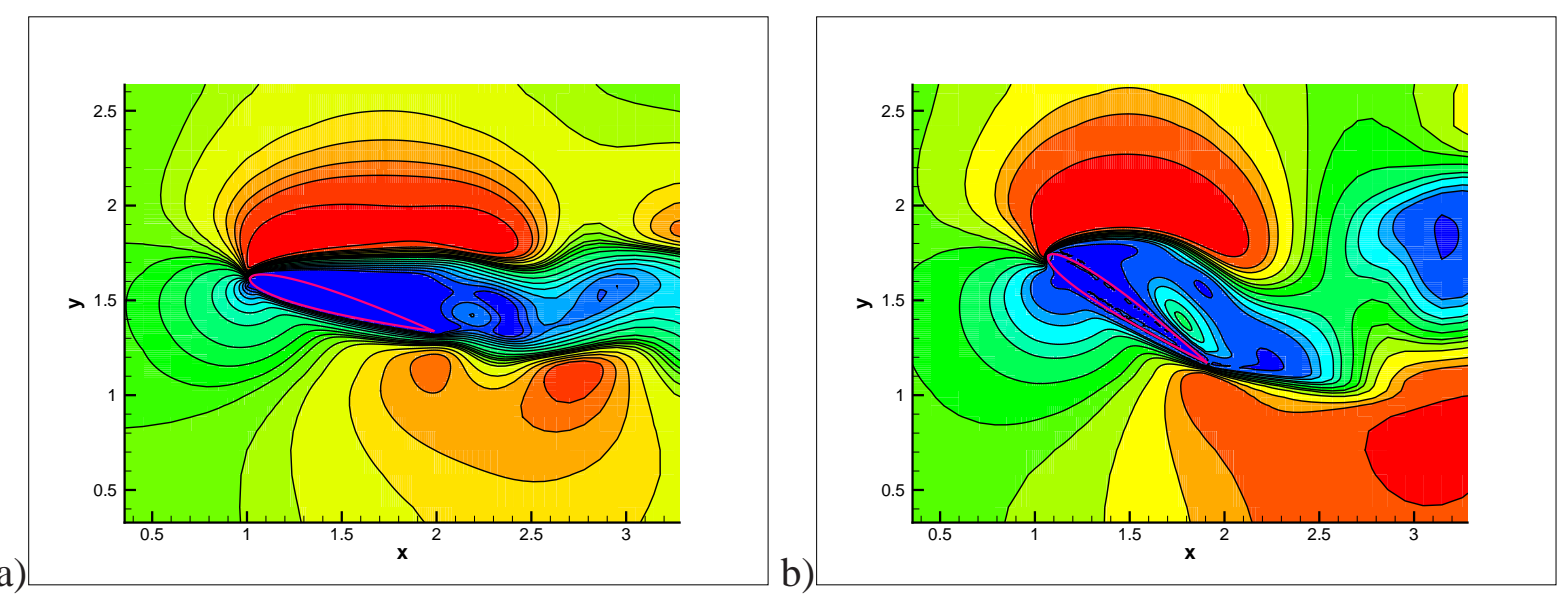

Figura 5.34: a) Campo de velocidade para a seção de aerofólio NACA 0012: $\alpha=16$ graus, b) $\alpha=34$ graus. 

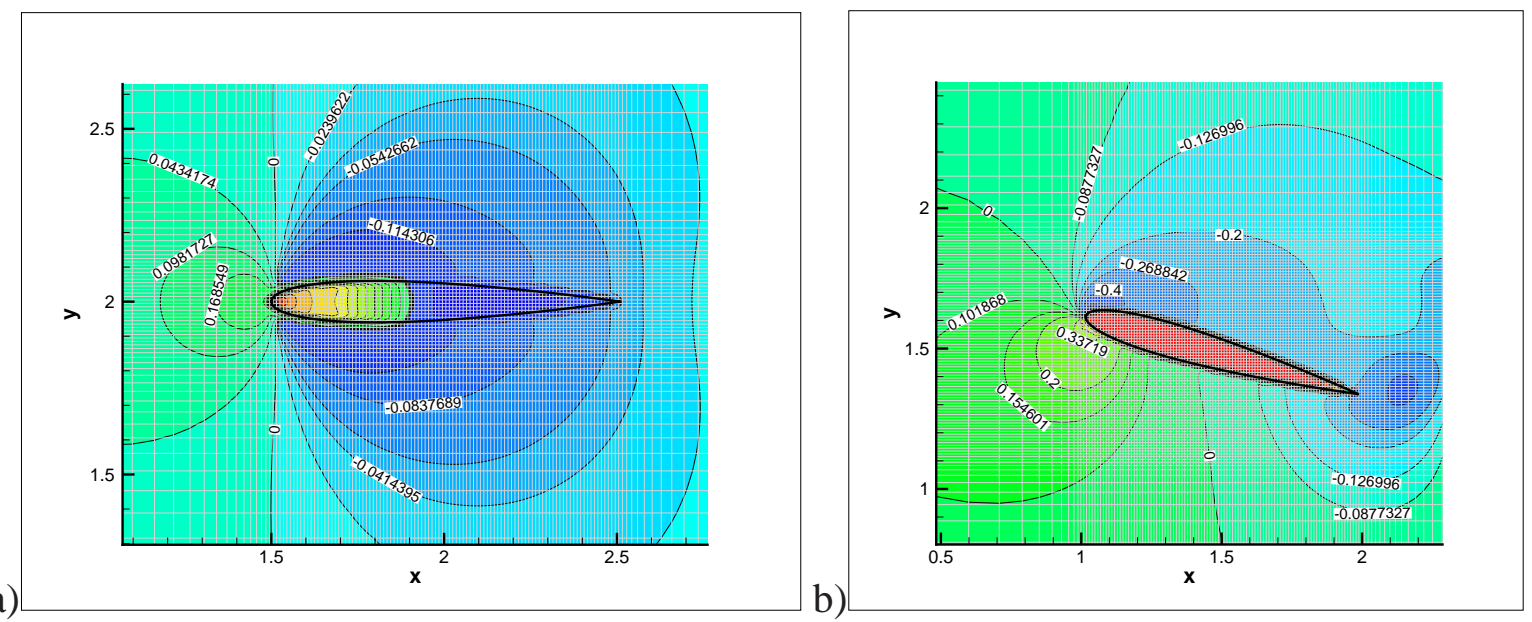

Figura 5.35: a) Campo de pressão próximo á seção de aerofólio NACA 0012: $\alpha=0$ graus, b) $\alpha=16$ graus.
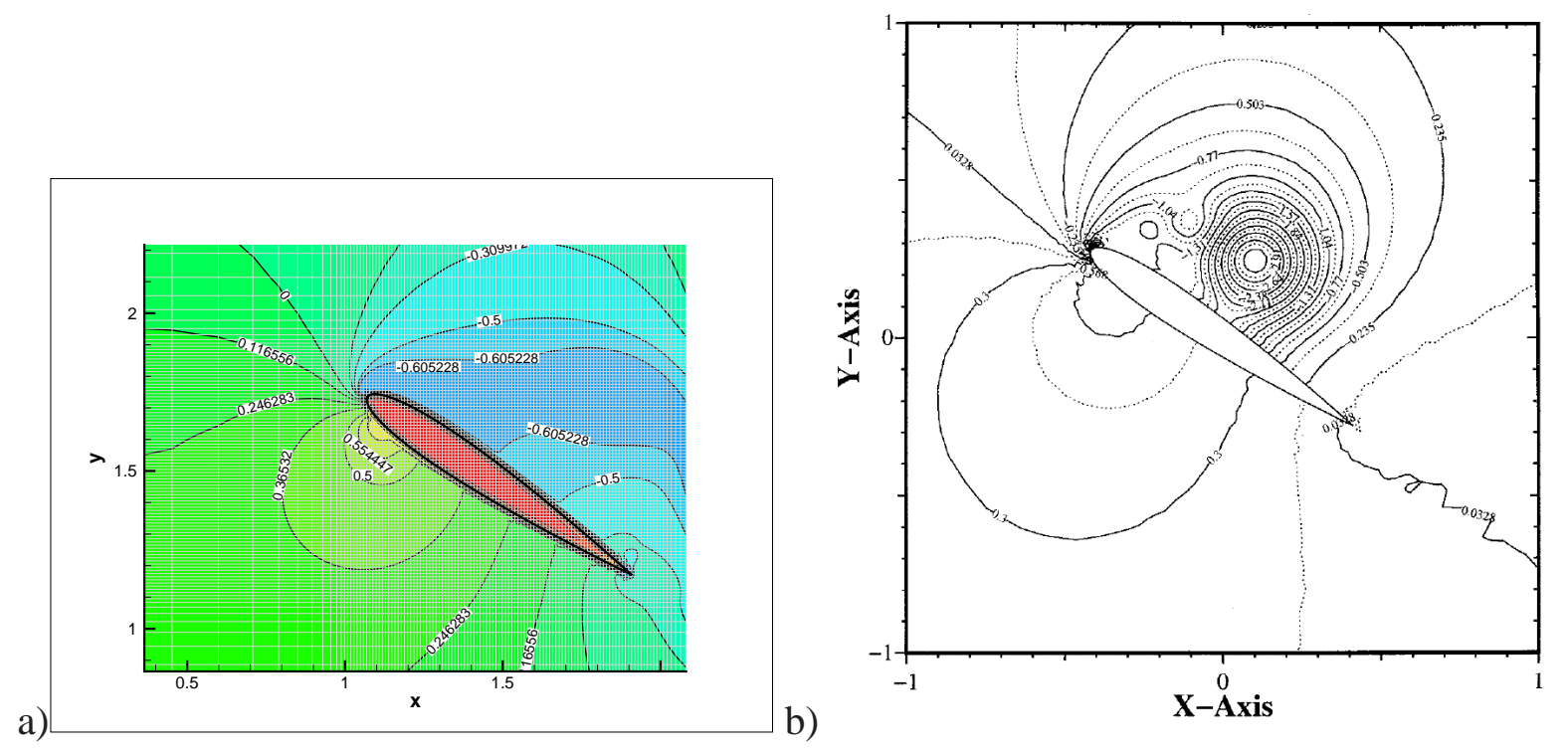

Figura 5.36: a) Campo de pressão próximo à seção de aerofólio NACA 0012: $\alpha=34$ graus, b) resultado apresentado por Guermond e Quartapelle (1997).

Na superfície da fronteira imersa o campo de pressões pode ser analisado através do coeficiente de pressão que é dado por

$$
C_{p}=\frac{p-p_{\infty}}{\frac{1}{2} \rho u_{\infty}^{2}}
$$

onde $p$ é a pressão, $p_{\infty}$ é a pressão do escoamento livre, $\rho$ é a massa específica do fluido e $u_{\infty}$ é a velocidade de escoamento livre. Os resultados obtidos pelo Método da Fronteira Virtual por intermédio da distribuição do coeficiente de pressão em torno da seção de aerofólio foram comparados com os resultados obtidos pelos simuladores Xfoil (DRELA, 2008) e XFLR5 
(SOURCEFORGE.NET, 2008). A escolha destes simuladores, para comparação de resultados, se deve ao fato de serem de domínio livre e bastante utilizados por projetistas amadores que trabalham com desenvolvimento de aeromodelismo e que cuja modelagem se aproxima dos caso de MAV's. O campo de pressão na superfície da seção de aerofólio foi obtido por interpolação bi-linear das quatro células computacionais eulerianas mais próximas do ponto lagrangiano contendo o respectivo ponto.

a)

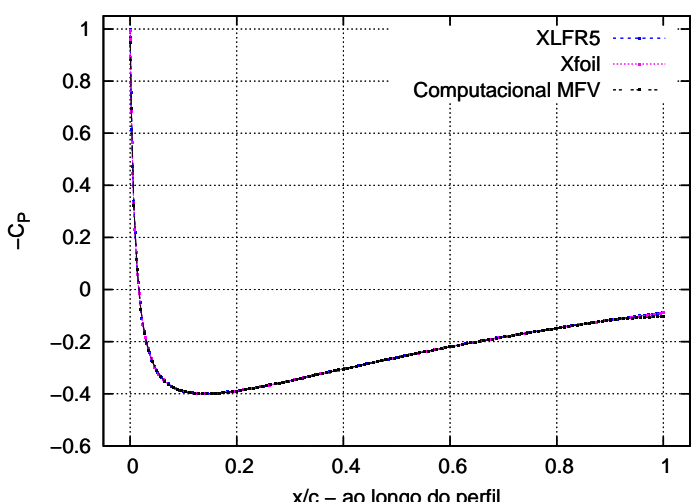

b)

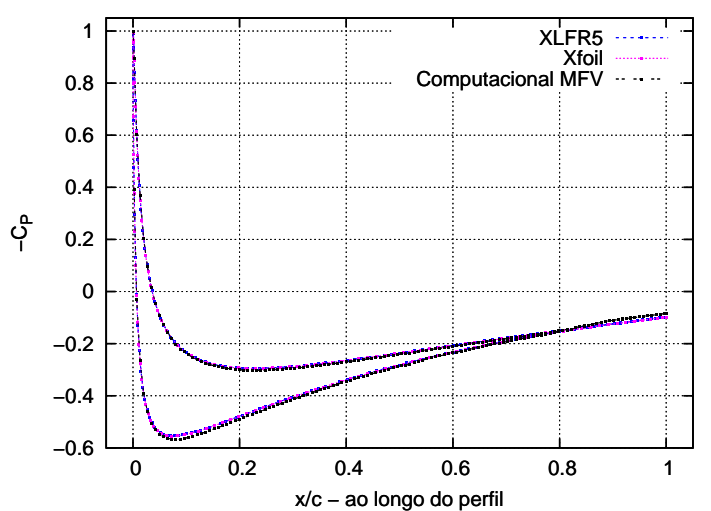

Figura 5.37: a) Coeficiente de pressão $C_{p}$ ao longo da superfície da seção de aerofólio NACA 0012: $\alpha=0$ graus, b) $\alpha=2$ graus.

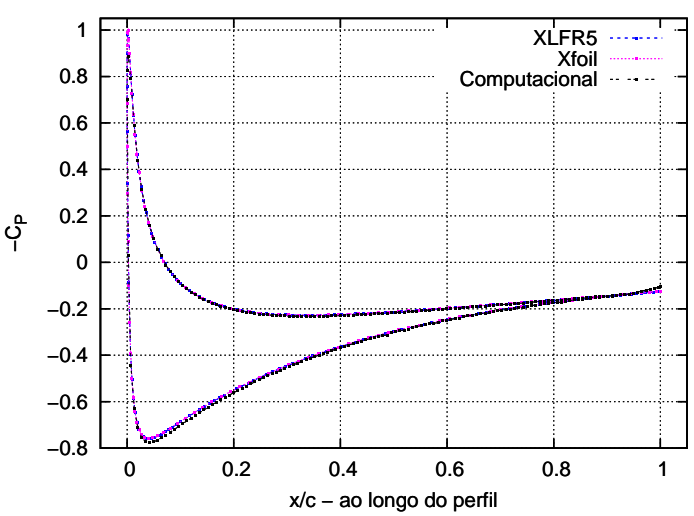

a)

Figura 5.38: a) Coeficiente de pressão $C_{p}$ ao longo da superfície da seção de aerofólio NACA 0012: $\alpha=4$ graus, b) $\alpha=8$ graus.

Os resultados obtidos, mostrados nas figuras (5.37) a (5.39), indicam que houve boa concordância entre o MFV e os outros simuladores. Isso demonstra que o método desenvolvido é capaz de representar bem a distribuição de pressão sobre a superfície da seção de aerofólio. É importante observar que a magnitude da pressão próxima ao bordo de ataque é menor nos resultados do MFV devido à falta de maior refinamento de malha nessa região. Também 
a)

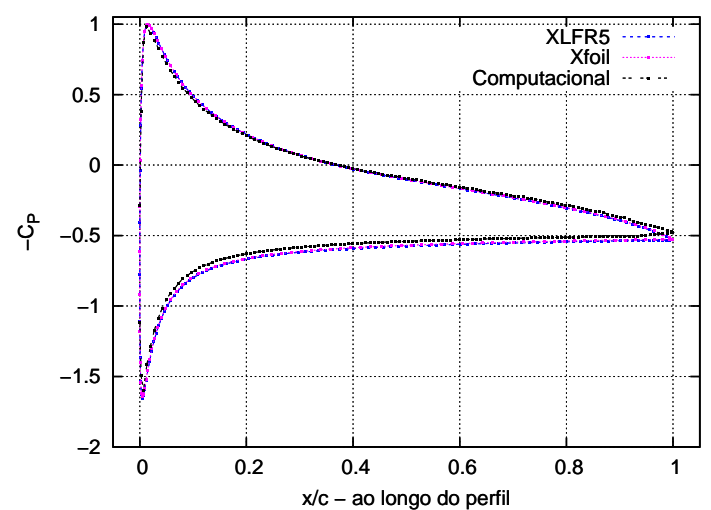

b)

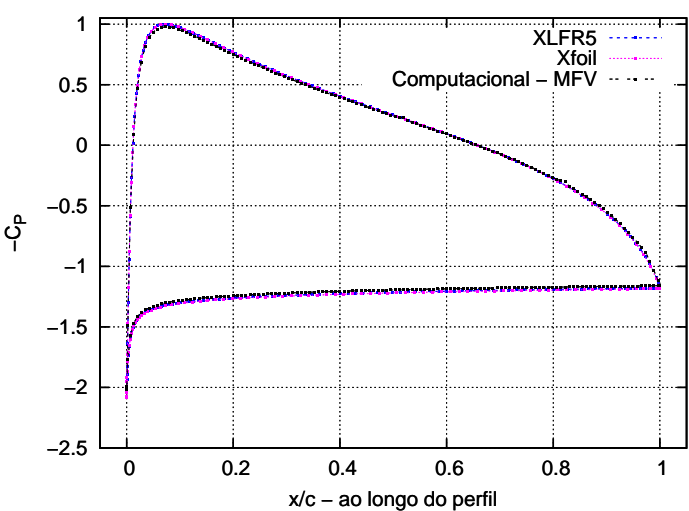

Figura 5.39: a) Coeficiente de pressão $C_{p}$ ao longo da superfície da seção de aerofólio NACA 0012: $\alpha=16$ graus, b) $\alpha=34$ graus.

podemos observar que há variação na magnitude dos resultados próximos ao bordo de fuga devido à sobreposição da função delta de suavização. Levando em consideração os bons resultados obtidos pela distribuição de pressão, considera-se como validado o método numérico MFV para resolver escoamento ao redor de seções de aerofólios do tipo NACA 0012 para número de Reynolds ultrabaixo.

Quantitativamente, os resultados obtidos para o coeficiente de arrasto $C_{D}$ foram comparados aos resultados obtidos de simulações nos softwares Xfoil e XFLR5, conforme a tabela 5.7.

Tabela 5.7: Resultados computacionais para coeficiente de arrasto.

\begin{tabular}{l|c|c|c}
\hline \hline \multirow{2}{*}{$\begin{array}{l}\text { Angulo } \\
\text { de ataque }\end{array}$} & \multicolumn{3}{|c}{$C_{D}$} \\
\cline { 2 - 4 } & Xfoil & XFLR5 & MFV \\
\hline \hline & & & \\
2 & 0.11822 & 0.1181 & 0.120578 \\
4 & 0.11958 & 0.1194 & 0.123674 \\
8 & 0.12414 & 0.1239 & 0.128040 \\
16 & 0.14664 & 0.1462 & 0.149235 \\
34 & 0.22757 & 0.2260 & 0.240625 \\
& 0.43323 & 0.4514 & 0.486582 \\
\hline \hline
\end{tabular}

Os resultados obtidos pelo MFV mostram-se consistentes quando comparados aos obtidos pelos softwares Xfoil e XFLR5. 


\subsubsection{Estudo do comportamento de um perfil NACA0012 submetido a escoamento com número de Reynolds ultrabaixo}

Dentro do propósito de validação do método da fronteira virtual, um dos fenômenos muito estudados é o comportamento do escoamento na transição para turbulento. Este fenômeno é inerentemente tridimensional e a análise da camada limite é a forma mais adequada para esse estudo. O modelo aplicado neste trabalho não é o mais adequado para abordar a análise da camada limite sem apresentar erros significativos para grandes ângulos de ataque, no entanto, se considerarmos um perfil uniforme e sem arestas, a simulação bidimensional nos ajuda a obter uma boa compreensão do desenvolvimento da instabilidade do escoamento, separação e desprendimento de vórtices, (ALAM, 2010). Nesse caso, os resultados aproximados servem para mostrar a aplicabilidade do método e fornecer parâmetros para o estudo de escoamento com número de Reynolds ultrabaixo sobre um perfil aerodinâmico NACA0012. Os efeitos da camada limite e turbulência são características de um fenômeno puramente tridimensional. De acordo com Ferziger (2000), a simulação numérica direta (Direct Numeric Simulation - DNS) é o método mais preciso para simular escoamentos turbulentos. Na DNS, basta resolver as equações de Navier-Stokes e tratar exatamente todas as condições impostas sobre o escoamento. Nestes casos, para resolver todas as escalas de turbulência é necessário um número de graus de liberdade relacionados ao número de pontos da malha computacional, excessivamente elevados para números de Reynolds de interesse prático. A DNS se torna interessante, por exemplo, quando a aplicação é restrita aos escoamentos de baixos números de $R e$, (análise de projetos de MAV que tratam de números de Reynolds ultrabaixo) ou quando o custo computacional é alto para o estudo tridimensional, então utiliza-se de simulação bidimensional para uma primeira aproximação do comportamento do escoamento.

O trabalho de Mittal e Balachandar (1995) mostra uma comparação dos resultados de simulações bidimendional e tridimensional de escoamento ao longo de um cilindro com base elíptica. Quanto ao arrasto, há uma variação de $1 \%$ a $39 \%$, respectivamente para ângulos de ataque $0^{\circ}$ a $45^{\circ}$, mostrando que, quantitativamente, o coeficiente de arrasto na simulação bidimensional é maior do que na simulação tridimensional. Se o escoamento não apresenta separação sobre a 
superfície imersa, não há, virtualmente, nenhuma diferença entre as simulações bidimensional e tridimensional. A variação do coeficiente de arrasto ocorre por que a tensão de cisalhamento na simulação bidimensional é significativamente maior do que na simulação tridimensional, pois a tensão de cisalhamento diminui com o aumento da "tridimensionalidade" do fenômeno, no caso da esteira do cilindro circular para $260<R e<1500$. De acordo com Silvestrini e Lamballais (2002), a principal dificuldade, para simulação desses fenômenos, é obter uma descrição precisa da dinâmica da estrutura turbulenta com uma forma realista da geometria do corpo, ou seja, do tipo de malha aplicada.

Conforme Svacek, M e Horacek (2007), o comportamento do escoamento a jusante do aerofólio depende do número de Reynolds e do ângulo de ataque $\alpha$. De acordo com Nakano, Fujisawa, Oguma, Takagi e Lee (2007), o escoamento ao longo do aerofólio, para baixos números de Reynolds, está totalmente ligado quando o ângulo de ataque $\alpha<2^{\circ}-3^{\circ}$. A separação começa a ocorrer perto do bordo de fuga do lado de sucção para além de $\alpha=2^{\circ}-3^{\circ}$ e a separação da camada limite é laminar. Com o aumento de $\alpha$, o ponto de separação se move em direção ao bordo de fuga e $C_{L}$ cresce relativamente rápido. A transição à turbulência na camada de cisalhamento ocorre inicialmente na cauda da separação da camada limite e se desloca em direção ao ponto de separação. $\mathrm{O} C_{L}$ continua a crescer, embora menos rapidamente. Próximo do ângulo $\alpha$ de estol, a transição à turbulência se aproxima do ponto de separação e a camada limite de separação reata e forma a bolha de separação. Esta bolha caminha para o bordo de fuga e diminui de tamanho e quanto mais próximo do ângulo de estol, maior é a sustentação. Quando ocorre o fenômeno de estol, a bolha de separação se rompe e há uma queda brusca de sustentação. Depois do estol o escoamento continua separado no bordo de fuga e não reata; a sustentação cresce novamente com o aumento de $\alpha$.

\subsubsection{Configuração, parâmetros do escoamento e resultados}

O comportamento aerodinâmico de um MAV a números de Reynolds ultrabaixo (da ordem de $10^{3}$ ) é consideravelmente diferente à de uma aeronave convencional e considera-se três hipóteses sobre o campo de escoamento: o escoamento é incompressível; o escoamento é 
totalmente laminar, devido ao número de Reynolds ultrabaixo e à geometria de interesse; e o campo do escoamento é constante. Foi usada uma malha retangular cartesiano não regular $216 \times 250$ com $\Delta x_{\min }=0,01, \Delta y_{\min }=0,01, \Delta x_{\max }=0,35$ e $\Delta y_{\max }=0,35$ em um domínio $6 \times 3$ unidades adimensionais, conforme Marques, Doricio e Greco Júnior (2008). O centro geométrico do aerofólio NACA0012 foi posicionado no ponto de coordenadas 1,5 na direção $x$ e 1,5 na direção $y$, figura 5.25a), com número de Reynolds 1.000 .

A velocidade de escoamento livre $u_{\infty}$, pressão de escoamento livre $p_{\infty}$ e o comprimento da corda do aerofólio $c$, foram selecionados como parâmetros de referência para adimensionalização. O limite a montante está distante de uma corda do bordo de ataque do aerofólio, os limites inferior e superior estão distantes de um comprimento de corda a partir da superfície do perfil aerodinâmico, o limite de saída está localizado a quatro comprimentos de corda a jusante do bordo de fuga e a condição de não-deslizamento foi aplicada sobre a superfície do aerofólio. $\mathrm{O}$ escoamento é laminar e viscoso, a camada limite é bastante grossa e tomada como uma fração significativa do comprimento da corda. A separação do escoamento á possível mesmo para pequenos ângulos de ataque e na ausência de separação, o escoamento será totalmente laminar.

Os pressupostos da camada limite laminar são: a espessura da camada limite é suficientemente pequena para o perfil $(c>>\delta)$, o componente da velocidade longitudinal é maior que o componente transversal $(u>>v)$; o gradiente de pressão transversal é negligenciado $\left(\frac{\delta P}{\delta y}=0\right)$, a força peso é negligenciada e o gradiente de velocidade longitudinal no sentido transversal é muito maior do que o de velocidade transversal $\left(\frac{\delta u}{\delta y}>>\frac{\delta v}{\delta y}\right)$. A simulação começa a partir de um campo de escoamento constante que não é a solução das equações governantes e pode levar a uma perturbação inicial residual devido à solução numérica. Se essa perturbação não se dissipar, pode haver aumento da instabilidade dos resultados, mesmo se todas as condições de contorno especificadas forem estáveis e sem perturbações externas aplicadas. Valores experimentais para o comportamento do perfil de aerofólio NACA0012 sujeito a escoamento incompressível para números de Reynolds ultrabaixos são tratados por Huabg, Wu, Jeng e Chen (2001) e Purtell, Klebanoff e Buckley (1981). Nesses trabalhos, há uma variação no ângulo de ataque até $90^{\circ} \mathrm{e}$ uma análise do fenômeno da bolha de separação (figura 5.40b). A região próxima da superfície 
do aerofólio, $u=0$, é caracterizada por $u$ negativa, ou seja, por um escoamento de direção contrária à do escoamento livre. Surge uma assimetria no escoamento reverso a partir da região de escoamento de recirculação perto do bordo de ataque até perto do bordo de fuga.

O maior valor obtido por Huabg, Wu, Jeng e Chen (2001), para número de Reynolds $R e=$ 1200, para $\frac{u}{u_{\infty}}$ foi de $\frac{u_{\min }}{u_{\infty}}=1,489$ a $-0,34$. Purtell, Klebanoff e Buckley (1981) obtiveram, para número de Reynolds $R e=1340, \frac{u_{\min }}{u_{\infty}}=0,382$. Computacionalmente, para o MFV e número de Reynolds $R e=1000$, obteve-se $\frac{u_{\min }}{u_{\infty}}=0,5051$. As velocidades máximas $u_{\max }$ à esquerda e à direita das camadas de cisalhamento, próximas aos bordos de ataque e fuga, e a velocidade mínima de $u_{\min }$ na recirculação estão relacionadas ao arrasto, um aumento na magnitude de $u_{\max }$ e/ou $u_{\min }$ corresponde a um aumento no arrasto, como mostrado na tabela 5.8. Aumentando-se o ângulo de ataque, aumenta-se a sustentação, mas, ao mesmo tempo, aumenta-se também o arrasto devido ao aumento da área projetada. A tabela 5.8 apresenta a dependência do $C_{L}$ ao ângulo de ataque $\alpha$ e na figura 5.40a) os resultados estão dispostos juntamente com os valores apresentados por Alam, Zhou, Yang, Guo e Mi (2010) para $R e=5,3 \times 10^{3}$.

\begin{tabular}{l|c|c|c|c|c|c|c|c|}
\hline Angulo de ataque $\alpha$ & 0 & 2 & 4 & 8 & 10 & 16 & 20 & 30 \\
\hline$C_{L}$ & 0 & 0.1221 & 0.2639 & 0.4254 & 0.4650 & 0.6644 & 1.0284 & 1.4444 \\
\hline$C_{D}$ & 0.1232 & 0.1239 & 0.1286 & 0.1590 & 0.2801 & 0.3006 & 0.5414 & 1.0537 \\
\hline
\end{tabular}

Tabela 5.8: Resultados computacionais para coeficiente de arrasto e coeficiente de sustentação.

a)

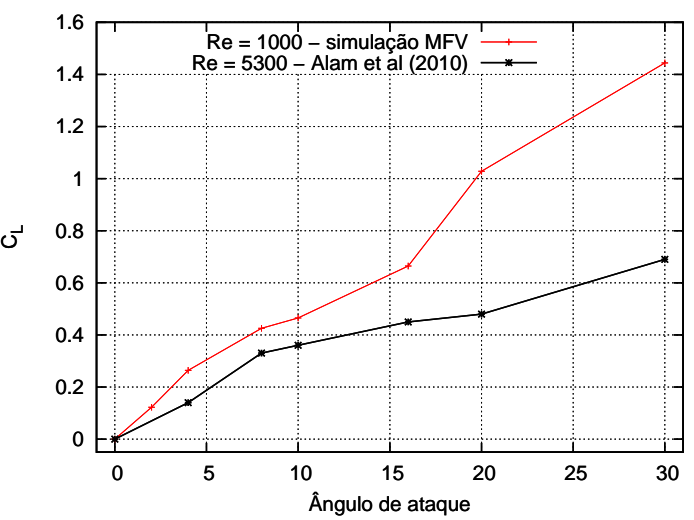

b)

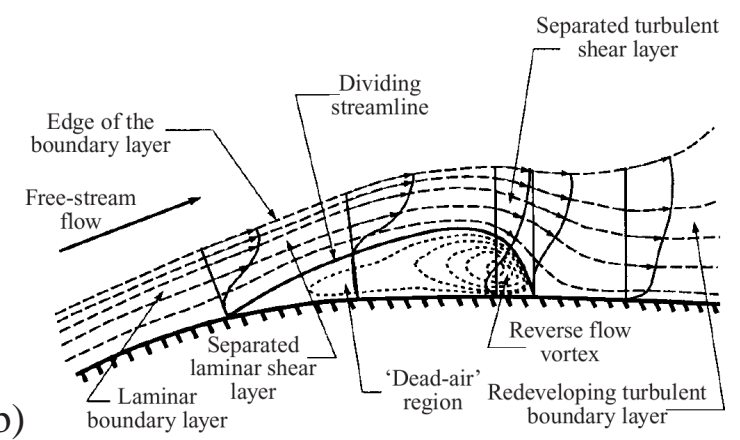

Figura 5.40: a) Dependencia de $C_{L}$ e $\alpha$; b) Esquema da bolha de separação laminar (HORTON 1968)

Considerando o comportamento do campo de velocidade, as figuras 5.41(a) a 5.41(h) mostram os contornos da velocidade $u$ na direção principal do escoamento para diferentes 
ângulos $\alpha(\operatorname{com} R e=1000)$. A evolução da estrutura de escoamento com $R e$ ultrabaixo não foi encontrada na literatura. Huabg, Wu, Jeng e Chen (2001) observaram cinco escoamentos diferentes, dependendo do $\alpha\left(0^{\circ}<\alpha<90^{\circ}\right)$ para $R e=1.2 \times 10^{3}$ a $2,3 \times 10^{3}$. O escoamento para $\alpha<3^{o}$ resultou em um escoamento completamente colado em todo o comprimento do aerofólio sem a formação de vórtices, como mostrado nas figuras 5.41(a) e 5.41(b). A formação de vórtices a partir do bordo de fuga foi observada para $3^{\circ}<\alpha<8^{\circ}$, quando o escoamento é separado na superfície de sucção entre os bordos de ataque e fuga, como mostrado nas figuras 5.41(c) e 5.41(d). Para $8^{\circ}<\alpha<17^{\circ}$, a camada limite na superfície de sucção no escoamento separado entre os bordos de ataque e fuga, há a formação de rolamento de vórtices na superfície e, eventualmente, formação de uma sequência de vórtices alternados, como mostrado nas figuras 5.41(e) e 5.41(f). Para $17^{\circ}<\alpha<60^{\circ}$, ocorre o engrossamento da camada limite a partir da advecção à jusante do perfil, como mostrado nas figuras 5.41(g) e 5.41(h). Os contornos da vorticidade instantânea, para $\alpha=2^{\circ}$ e $\alpha=34^{\circ}$ são mostrados nas figuras 5.42(a) e figura 5.42(b), onde a presença dos vórtices é visível na superfície superior do aerofólio. Os vórtices são gerados através do aumento da perturbação a jusante do escoamento na direção principal ao longo da superfície do perfil aerodinâmico. A simulação não apresentou indícios de transição de pequenas escalas ou na direção vertical. Também pode-se notar que o escoamento na esteira apresenta o componente de vorticidade atuando do bordo de ataque para o bordo de fuga nas superfícies superior e inferior do aerofólio e o crescimento da perturbação devido ao desprendimento de vórtices.

O comportamento do escoamento em torno do aerofólio está diretamente ligado ao ângulo $\alpha$. Se $\alpha$ for muito pequeno, o escoamento está totalmente colado e ação viscosa é menos eficaz. As figuras 5.43 (a, e, c, g) e as figuras 5.43 (b, d, f, h) mostram as linhas de corrente para $\alpha=10^{\circ}$ e $\alpha=20^{\circ}$, respectivamente. Aumentando o ângulo $\alpha$, o escoamento, a partir do bordo de ataque, é retardado e a região de recirculação aumenta. A esteira é altamente dependente das característica dos parâmetros relacionados ao $C_{L}$. O $C_{L}$ cresce de $\alpha=0^{o}$ até $\alpha=3^{\circ}$ e com o aumento de $\alpha$ há aumento do comprimento da formação de vórtices na direção principal do escoamento. A região de recirculação está ausente até $\alpha=10^{\circ}$, como observado nas figuras 


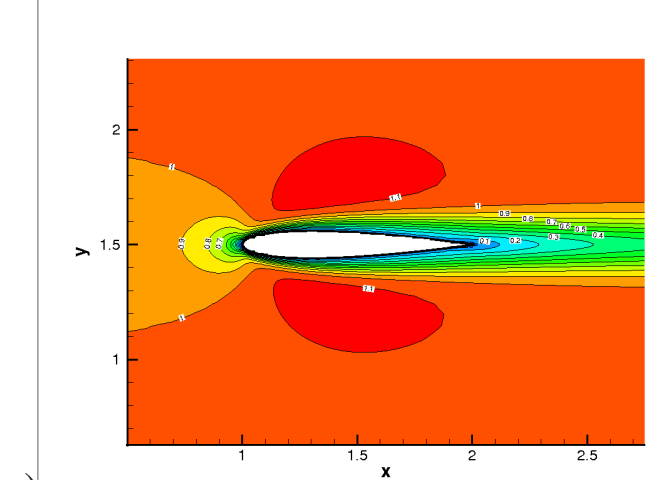

a)

c)

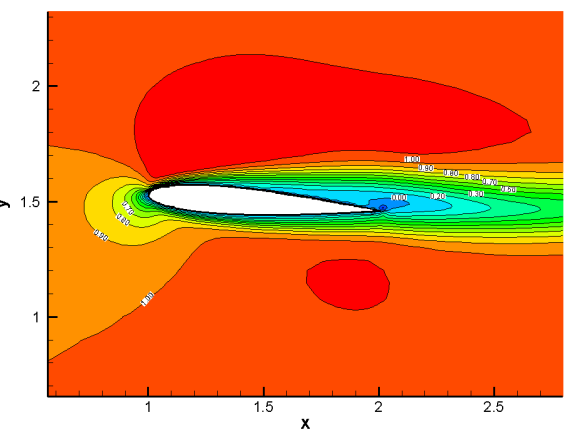

e)

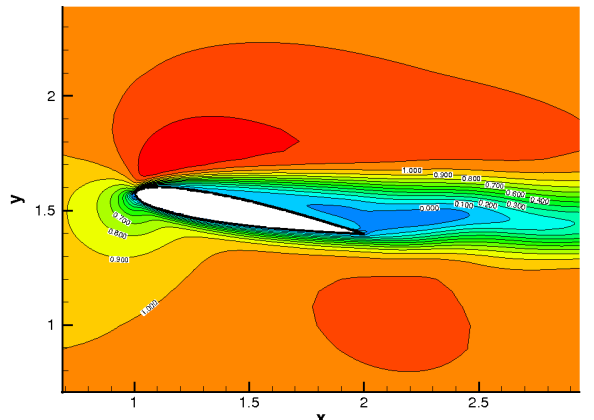

g)

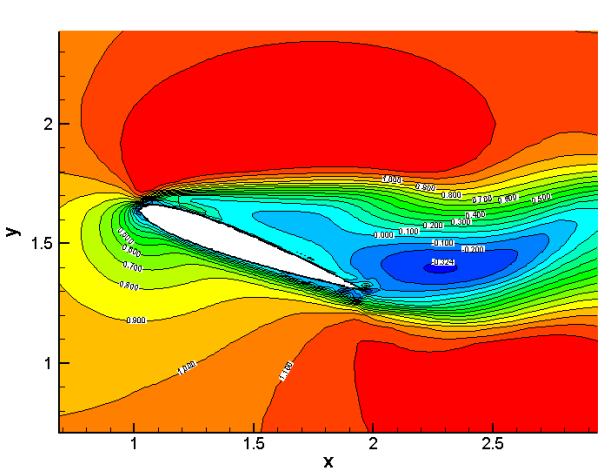

b)

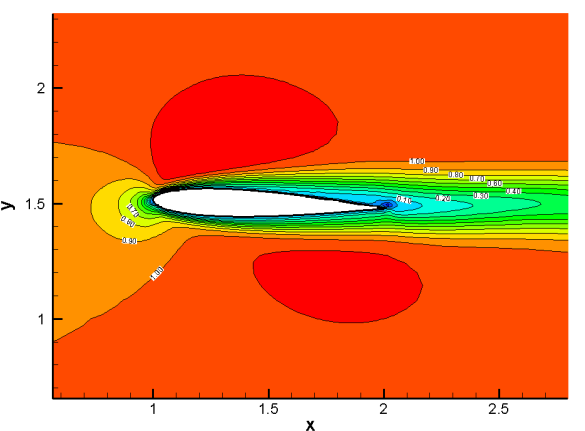

d)

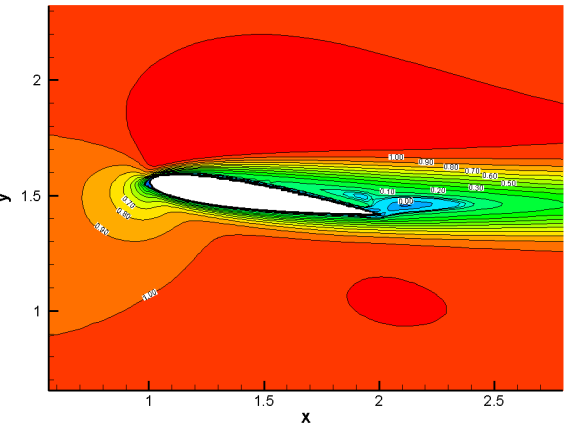

f)
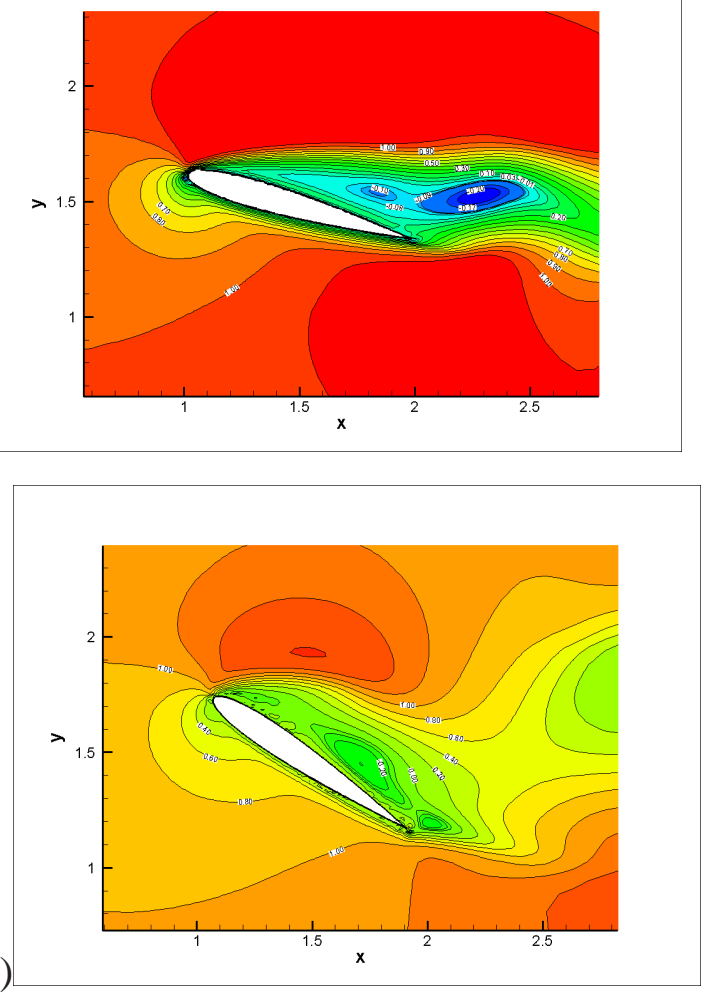

Figura 5.41: Campo de velocidade $u-\alpha$ : a) $0^{o}$; b) $2^{o}$; c) $4^{o}$; d) $8^{o}$; e) $10^{o}$; f) $16^{o}$; g) $20^{o}$ e h) $34^{o}$.

5.41 (a, b, c, d, e) e figuras 5.43 (a, c , e, g). A região de recirculação de $\alpha=20^{\circ}$ para $\alpha=34^{\circ}$ aumenta com o aumento de $\alpha$ e está consistente com a variação do $C_{L}$, (figura 5.40 e tabela 5.8). 
a)

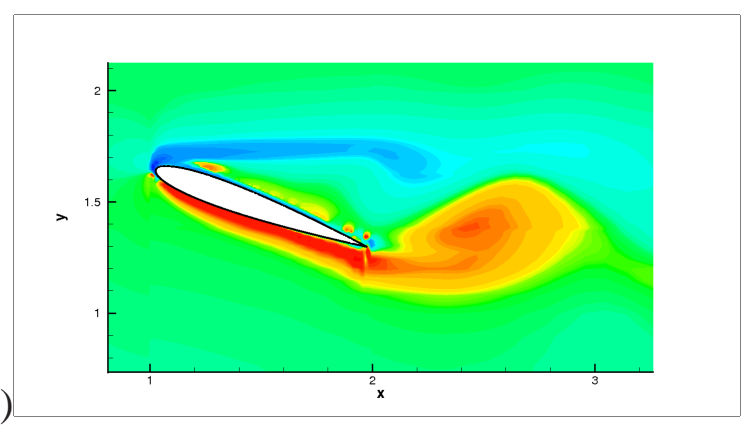

b)

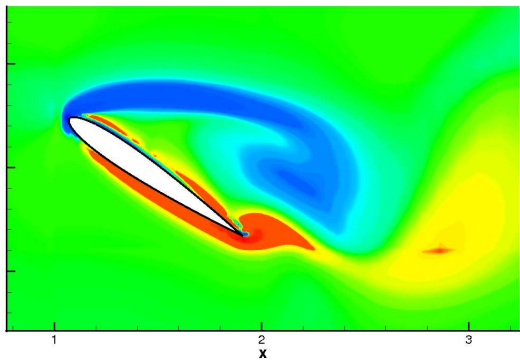

Figura 5.42: Campo de vorticidade: a) $\alpha=20^{\circ}$; b) $\alpha=34^{0}$.

Para avaliar o fenômeno da separação, foram analisados os casos para os ângulos de ataque $\alpha=2^{\circ}, \alpha=8^{\circ}, \alpha=10^{\circ}, \alpha=20^{\circ}$ and $\alpha=34^{\circ}$, ou seja, o caso onde não há separação - apenas camada limite laminar; o caso em que há instabilidade inicial, mas não ocorre separação; e o caso em que a separação ocorre. As figuras 5.44(a,b), 5.44(c,d) e 5.44(e,f) mostram a espessura da camada limite $\left(\delta^{*}\right)$, produzida pelo MFV e software Xfoil, e a distribuição do componente $u$ do campo de velocidade. As figuras 5.43(a,c,e,g) mostram os casos limites onde não ocorre separação e as figuras 5.43(b,d,f,h) a evolução para a separação.

Podemos concluir que o método da fronteira vitual é capaz de produzir resultados consistentes para a análise do comportamento do escoamento no entorno do perfil de aerofólio. A partir dos resultados obtidos neste capítulo, podemos considerar como validado o método da fronteira virtual. 
a)

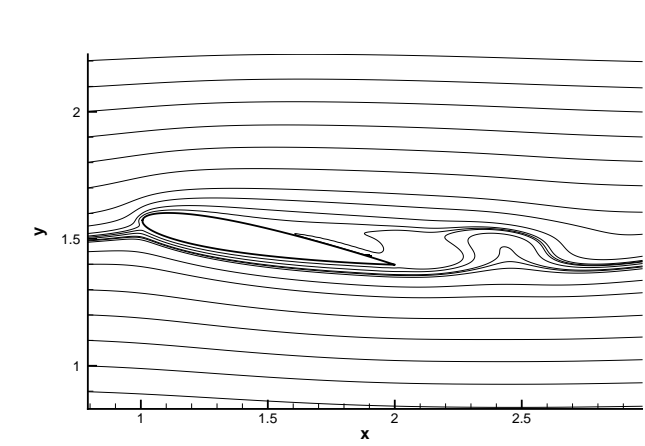

c)

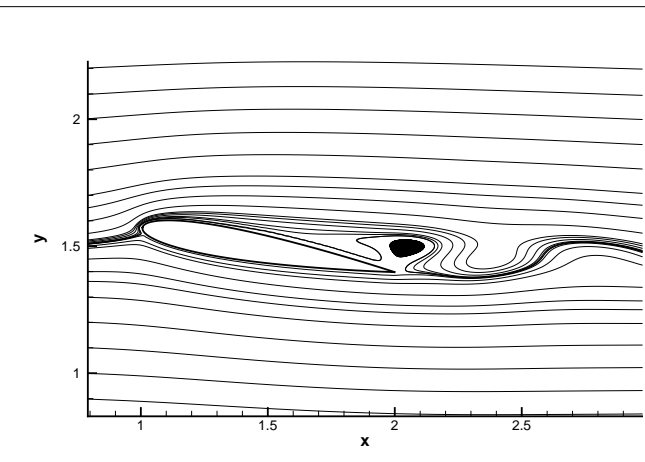

e)

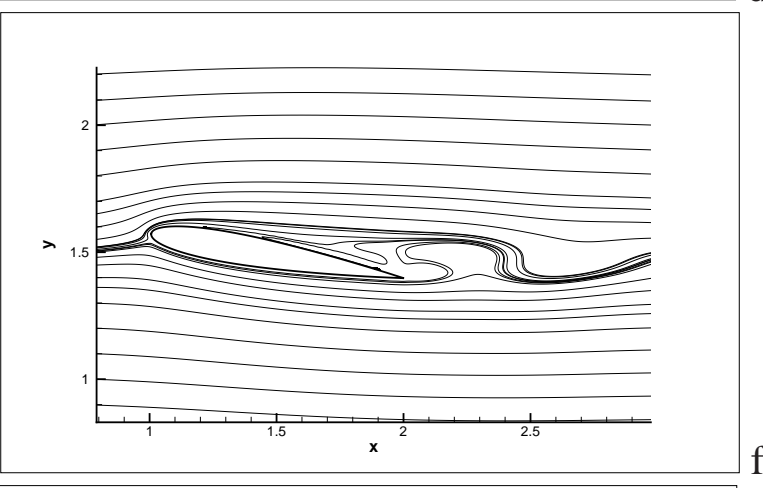

g)

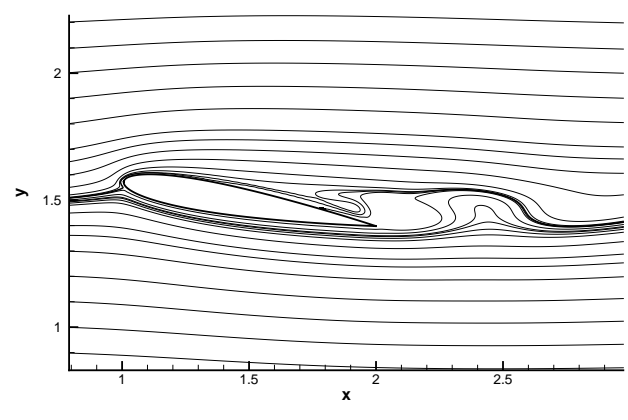

b)

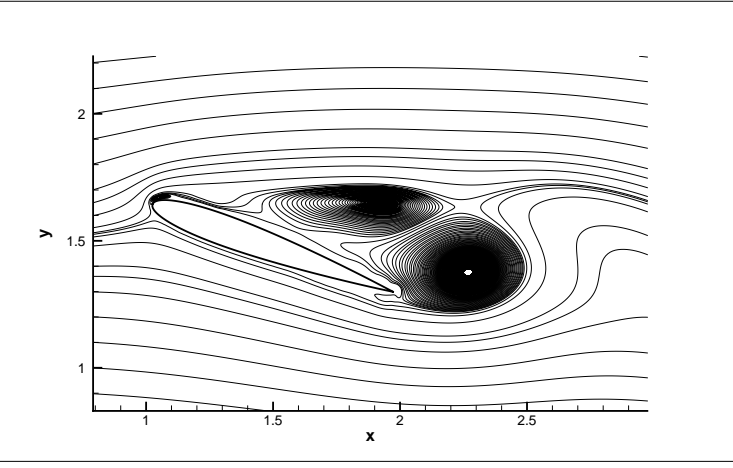

d)

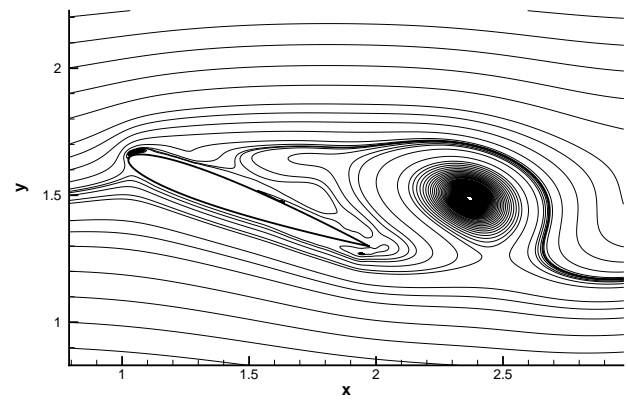

f)

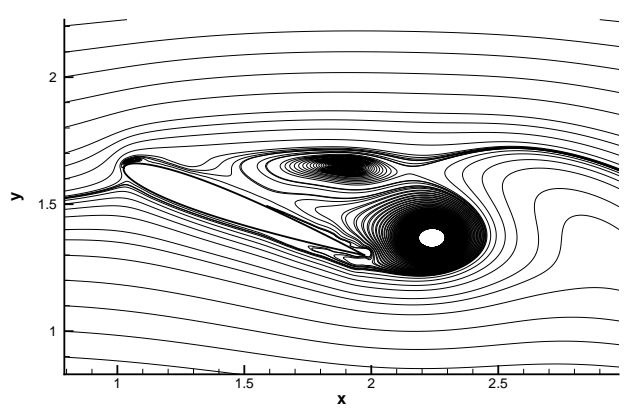

h)

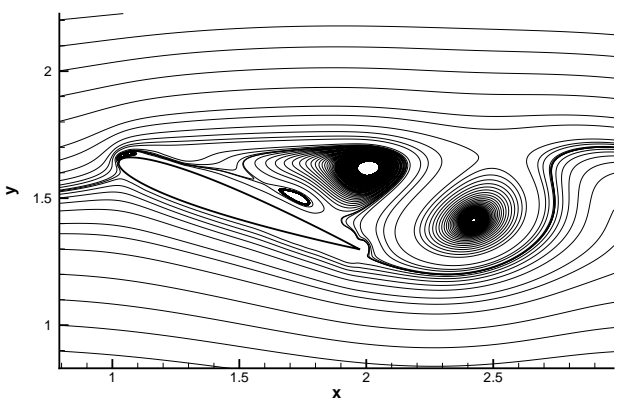

Figura 5.43: Linhas de corrente para: a) $\alpha=10^{\circ}$; b) $\alpha=20^{\circ}$. 
a)
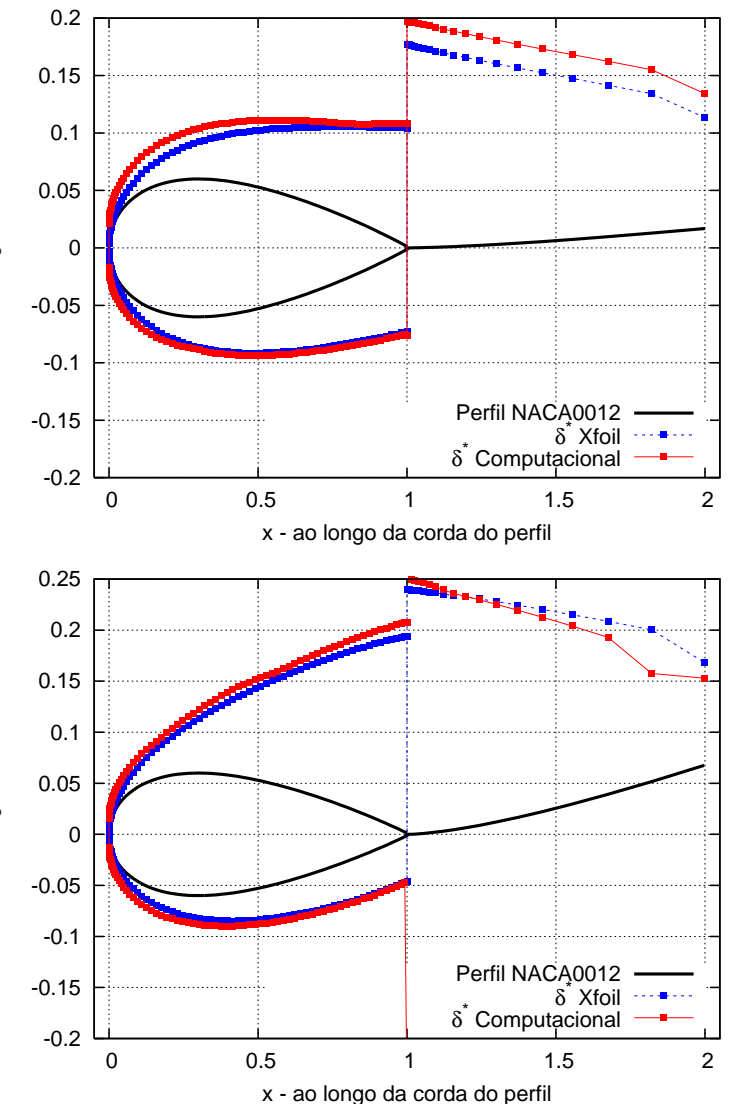

c)

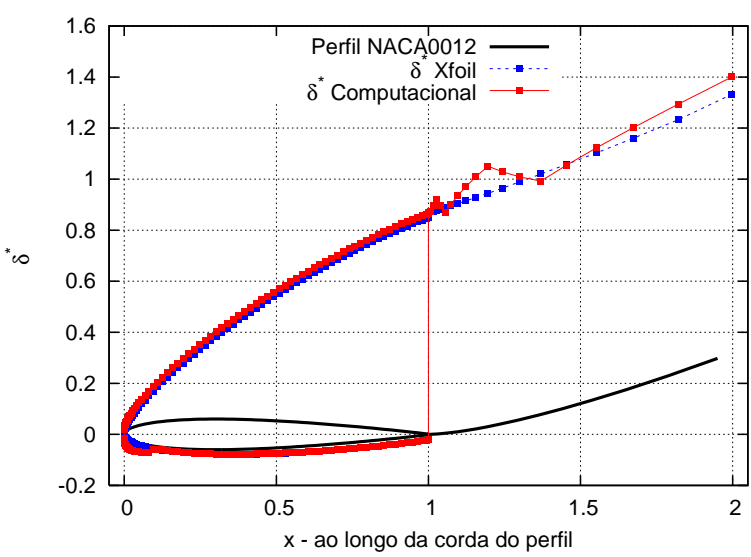

b)

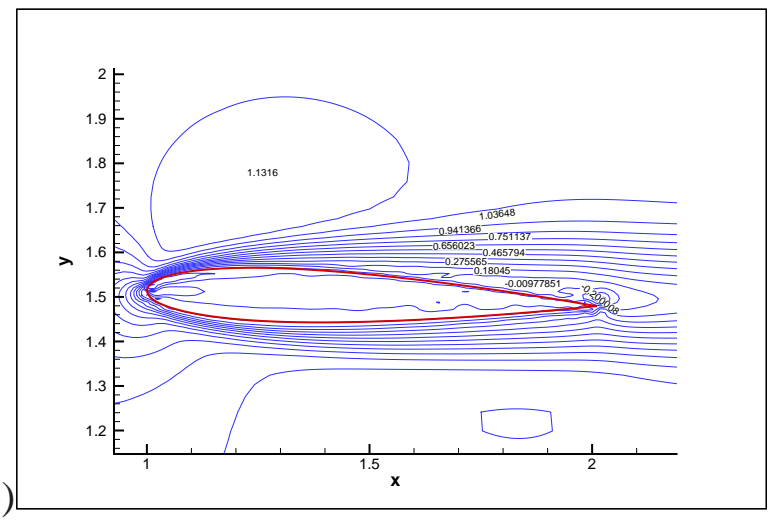

d)

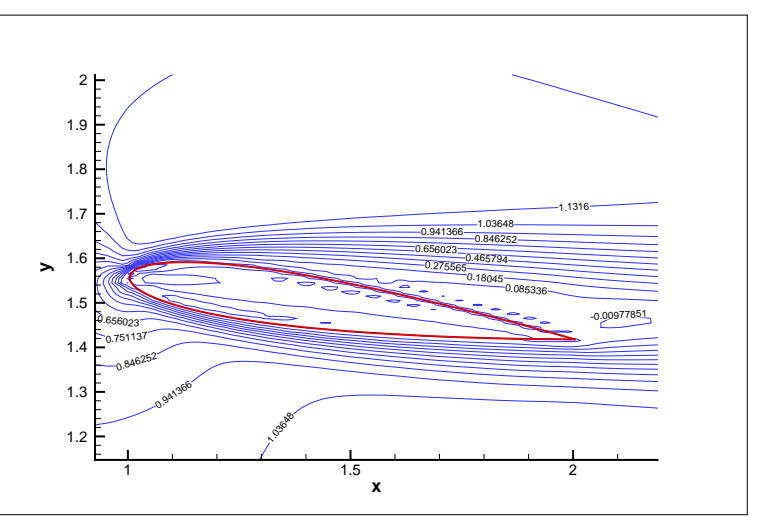

f)

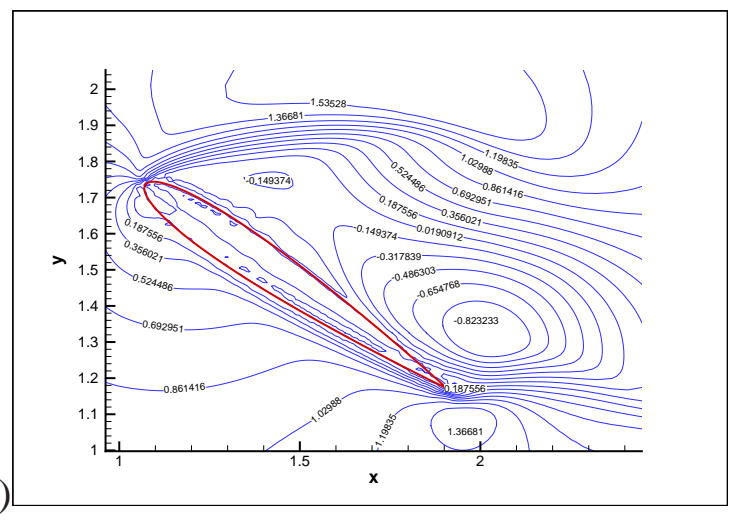

Figura 5.44: Espessura da camada limite- MFV $\times$ Xfoil e distribuição do componente $u$ para ângulos de ataque $2^{\circ}, 8^{\circ}$ e $34^{\circ}$. 


\section{Comportamento aerodinâmico de aerofólio submetido à oscilação forçada}

Um problema, dentro da área de CFD, considerado de interesse prático é a estimação de forças devidas a escoamentos transientes atuando em corpos oscilantes, (SCANLAN, 2000). Nesta categoria, e pertinente ao estudo de MAV's, estão os modelos de "bater asas" e os efeitos de rajada para os modelos de asa fixa ou rotativas. Uma forma de estudar estes fenômenos é usar análise modal. Seja um sistema de $n$ graus de liberdade com a mesma quantidade de frequências naturais, sendo que para cada uma delas, existe um estado de vibração correspondente conhecido como modo de vibrar. Os termos matemáticos relacionados com essas quantidades são conhecidos como autovalores e autovetores, os quais são determinados a partir de um sistema de $n$ equações de movimento e têm certas propriedades dinâmicas associadas ao sistema. O modo de vibrar é um estado de movimento em que todas as massas, em sistemas não contínuos, oscilam alcançando deslocamentos máximos e passando por suas posições de equilíbrio simultaneamente, ou ainda, é um estado onde todas as partes móveis do sistema oscilam em fase com uma dada frequência.

A consideração do movimento de bater de asas, como um sistema de propulsão alternativo, leva em conta que a instabilidade aerodinâmica a baixo número de Reynolds gera sustentação e e consequentemente propulsão. Uma das dificuldades nesse estudo está associada ao regime de transição na faixa de baixa velocidade. Outra dificuldade é a simulação de voo das aves/insetos reais cujos movimentos complexos são simplificados pelo uso de modelos básicos ou seja, aerofólios, com movimentos de arfagem e elevação. Os modelos combinam esses movimentos 
e obtem a pressão gerada e a eficiência de propulsão. Assim, a aerodinâmica pode ser vista como um sistema de entrada/saída onde as variáveis cinemáticas de voo são as entradas e as forças aerodinâmicas são as saídas. Estudos anteriores mostraram que o modelo de Theodorsen para aerodinâmica da placa plana pode ser usada como comparativo de arfagem e elevação para resultados bidimensionais; escoamento de baixo número de Reynolds; frequência reduzida, $k$, não muito grande, $k<2$; e ângulo de ataque efetivo inferior ao ângulo crítico (ângulo a partir do qual há perda de sustentação).

A simulação envolve escoamento de número de Reynolds $R e=1.000$ atuando sobre um perfil de aerofólio tipo NACA0012 sujeito, simultaneamente, a translação vertical e rotação em torno de um pivô produzindo oscilação forçada harmônica, de forma a produzir deslocamento senoidal de arfagem e elevação, como descrito, por exemplo, no trabalho de Ohmi, Coutanceau, Daube e Loc (1991). O problema é essencialmente o mesmo da aerodinâmica estática exceto para o fato de que a posição vertical agora é uma função do tempo, figura 6.1, e que quando combinado com a arfagem procura reproduzir o modelo de vôo de uma libélula, onde $\alpha(t)$ é o

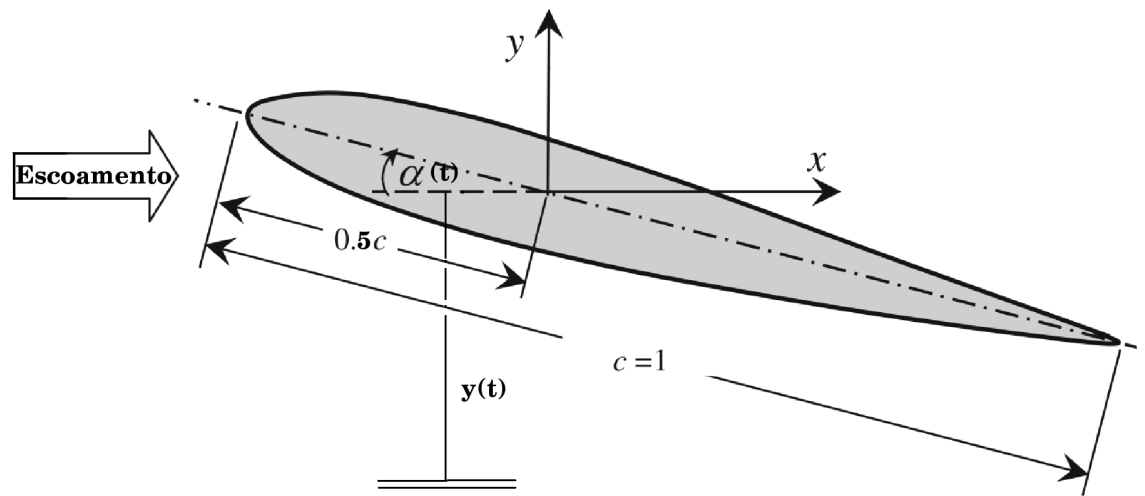

Figura 6.1: Modelo para simulação com oscilação forçada

ângulo geométrico de ataque medido entre a corda da seção e a direção do escoamento livre, $y(t)$ é o deslocamento vertical do centro de rotação do perfil do aerofólio, $A_{y}$ é a amplitude vertical, $A_{\alpha}$ amplitude de arfagem, $f_{\alpha}$ frequência de arfagem, $f_{y}$ frequência de elevação e $t$ tempo. A adimensionalização é feita a partir da corda do aerofólio: comprimento $c^{*}=\frac{c}{c}$, amplitude de oscilação $A^{*}=\frac{A}{c}$, velocidade do escoamento incidente $V^{*}=\frac{V}{u_{\infty}}$ 
Uma abordagem para tratar este tipo de fenômeno consiste da identificação das forças relacionadas àquelas que o escoamento exerce sobre o movimento do aerofólio, mais especificamente sobre um perfil (seção bidimensional) de aerofólio. Uma limitação desse processo é pressupor uma relação linear entre as funções de força e as leis do movimento do aerofólio de modo que a permitir a superposição/decomposição em dois graus de liberdade. Esta limitação restringe a abordagem a movimentos de pequena amplitude, ou seja, o aerofólio poderá sofrer oscilações suaves com baixa frequência em escoamento uniforme de velocidade livre $u_{\infty}$. $\mathrm{O}$ movimento cinemático é descrito pelas equações 6.1 e 6.2:

$$
\begin{gathered}
\alpha(t)=\alpha_{0}+A_{\alpha} \cos \left(2 \pi f_{\alpha} t+\varphi_{\alpha}\right) \\
y(t)=A_{y} \operatorname{sen}\left(2 \pi f_{y} t+\varphi_{y}\right)
\end{gathered}
$$

O ângulo de ataque é um dos fatores mais importantes na prescrição do movimento do aerofólio e para o caso de combinar elevação e arfagem teremos uma relação entre $f_{\alpha}$ e $f_{y}$ chamada de taxa de elevação-arfagem dada por $f_{r}=\frac{f_{\alpha}}{f_{y}}$. Os parâmetros adimensionais para esta configuração serão o número de Reynolds; a amplitude de elevação normalizada $h=\frac{A_{y}}{c}$; a frequência reduzida, adimensionalizada pela corda do aerofólio, $k=\frac{2 \pi f_{h} c}{u_{\infty}}$; e $k h=\pi S t$ que é também igual à velocidade de pico de elevação normalizada pela velocidade de escoamento livre. A equação que combina os dois movimentos é dada por:

$$
\left.\alpha_{e}=\alpha_{0}+\frac{A_{\alpha}}{\arctan \left[\max \frac{\left(\frac{\partial y(t)}{\partial t}\right)}{u_{\infty}}\right]} \arctan \left[2 \pi f_{\alpha} c \frac{A_{\alpha}}{u_{\infty}}\right] \cos \left[2 \pi\left(f_{\alpha}\right) t+\varphi_{\alpha}\right)\right]+\arctan \left[2 \pi f_{y} c \frac{A_{y}}{u_{\infty}} \operatorname{sen}\left(2 \pi f_{y} t+\varphi_{y}\right)\right]
$$

onde $\alpha_{0}$ é o ângulo médio de arfagem, $\varphi_{\alpha}$ é a defasagem de arfagem e $\varphi_{y}$ é a defasagem para elevação. Tomando-se $c=1, u_{\infty}=1, \alpha_{0}=0$ e $\varphi_{\alpha}=0$, teremos:

$$
\left.\alpha_{e}=\frac{A_{\alpha}}{\arctan \left[\max \left(\frac{\partial y(t)}{\partial t}\right)\right]} \arctan \left(2 \pi f_{\alpha}\right) \cos \left(2 \pi f_{\alpha}\right) t\right]+\arctan \left[2 \pi f_{y} A_{y} \operatorname{sen}\left(2 \pi f_{y} t+\varphi_{y}\right)\right]
$$

De forma esquemática, a combinação dos movimentos de elevação e arfagem, dada pela equação 6.4, para duas relações de frequências está mostrada na figura 6.2. Considerou-se 
$A_{y}=0,1 c$, para a figura $6.2 \mathrm{a}$ ) o ponto pivotante foi posicionado em $0,5 c$ e para a figura $6.2 \mathrm{~b}$ ) o ponto pivotante foi posicionado em $0,25 c$.
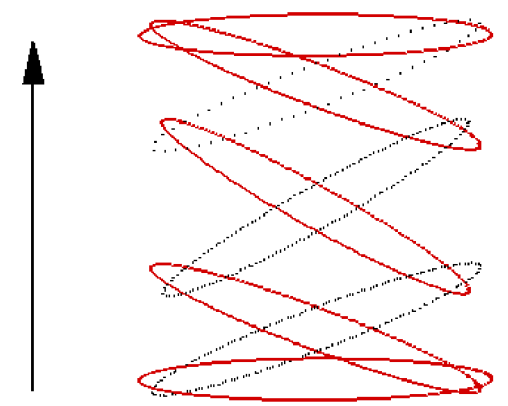

a)
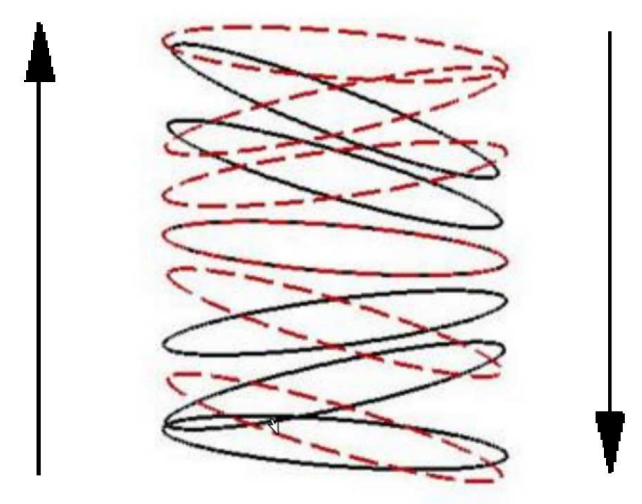

b)

Figura 6.2: Esquema de combinação de movimentos de elevação e arfagem para a) $f_{r}=1$ e b) $f_{r}=2$

Conforme proposto por Kang, Aono, Trizila, Baik, Rausch, Bernal, Ol e Shyy (2009), a frequência reduzida, $K=\pi f=0,25$, deveria ser a adotada, pois é motivada pelas condições do tipo do bater de asas do vôo dos pássaros. Embora o número de Strouhal correspondente, $S t=2 f A_{y}=0,08$, esteja abaixo da faixa de eficiência de propulsão máxima, essas condições de escoamento estão no limite superior de "estol dinâmico" apontado na literatura, onde a principal aplicação aerodinâmica é a hélice de helicóptero e, para onde muitos modelos tradicionais de análise em aeronáutica tendem a se concentrar. Como é tomado muitas vezes em aplicações motivadas pela maximização da propulsão pela eficiência do movimento de arfagem e elevação, se o movimento de arfagem tiver adequada defasagem em relação movimento de elevação acaba reduzindo ou cancelando o ângulo de ataque induzido pela elevação, $\arctan \frac{\partial y(t)}{\partial t}$ e consequentemente fazendo com que $\alpha \approx \alpha_{e}$. Ainda de acordo com Kang, Aono, Trizila, Baik, Rausch, Bernal, Ol e Shyy (2009), a amplitude de arfagem, $A_{\alpha}$ dever ser computada a partir de $0.6=A_{\alpha} /[\max (\partial y(t) / \partial t)]$

Neste trabalho o ponto pivotante está posicionado a $0,5 c$ e a prescrição da frequência reduzida tomada de forma a abranger, para fins de comparação de resultados, alguns resultados da literatura para número de Reynolds ultra baixo. As frequências na arfagem $f_{s}$ foram de 
$1 \mathrm{~Hz}, 2 \mathrm{~Hz}, 5 \mathrm{~Hz}, 10 \mathrm{~Hz}, 15 \mathrm{~Hz}$ e $20 \mathrm{~Hz}$; com oscilação vertical de $\pm 0,1$ do comprimento da corda; arfagem de $\pm 2^{\circ}, \pm 3^{\circ}, \pm 5^{\circ}, \pm 10^{\circ}$ e $\pm 30^{\circ}$; e atraso de fase de $90^{\circ}$ entre a oscilação vertical e a arfagem. A malha, condições iniciais e de contorno são as mesmas que as já usadas no caso do aerofólio estacionário.

A figura 6.4 mostra uma sequência de gráficos de linhas de corrente para arfgem de $\alpha=$ \pm 2 e frequências de $2 \mathrm{~Hz}, 5 \mathrm{~Hz}, 15 \mathrm{~Hz}$ e $20 \mathrm{~Hz}$. Pode-se notar que o aumento da frequência passa a atrapalhar a esteira de vórtices e há aumento do coeficiente de arrasto, conforme figuras 6.3a), 6.3b) e 6.3c), e consequentemente de sustentação. Especificamente para o caso em que a arfagem é de $\pm 10^{\circ}$, a figura mostra a variação de $C_{L}$ e pode ser comparado com os resulatdos obtidos por Johnson e Tezduya (1994). A figura 6.5 mostra uma sequência, do lado esquerdo

a)

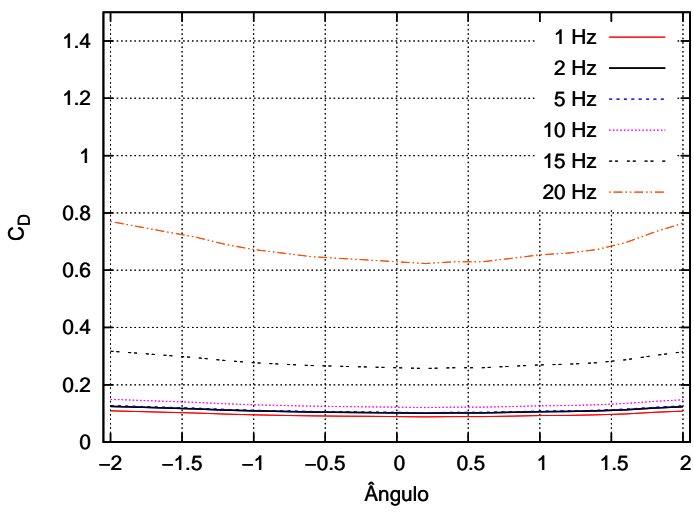

b)

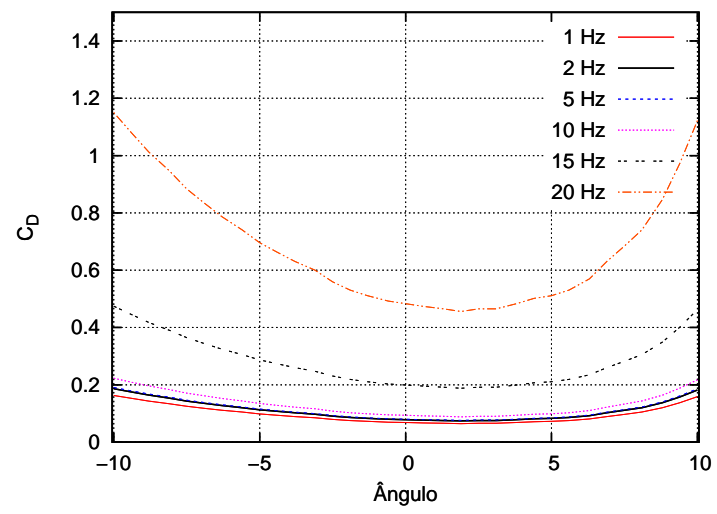

c)

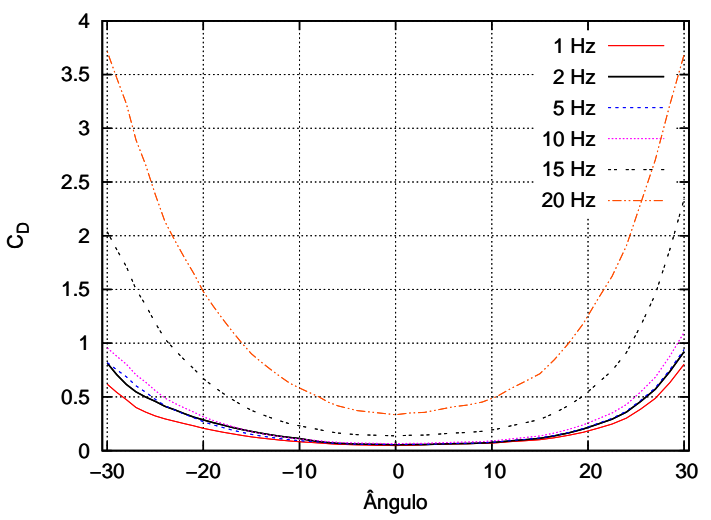

Figura 6.3: Distribuição de $C_{D}$ para $\alpha= \pm 2^{\circ}, \alpha= \pm 10^{\circ}$ e $\alpha= \pm 30^{\circ}$ com frequências de $1 \mathrm{~Hz}$, $2 \mathrm{~Hz}, 5 \mathrm{~Hz}, 10 \mathrm{~Hz}, 15 \mathrm{~Hz}$ e $20 \mathrm{~Hz}$.

gráficos de vorticidade e do lado direito gráficos de linhas de corrente, de meio ciclo para arfagem $\alpha= \pm 10$ e frequêcia $f_{s}=1 \mathrm{~Hz}$. Pode-se notar que o problema não apresenta grandes variações no comportamento de esteira de vórtices. A figura 6.6 mostra uma sequência de 
um ciclo completo para o caso em que a arfagem é de $\alpha= \pm 30$ e frequência $f_{s}=1 \mathrm{~Hz}$. Apesar do grande ângulo $\alpha$, a sequência mostra também um comportamento sem grandes variações provocadas pela oscilação, mas com formação de recirculação no extra-dorso e intra-dorso, alternadamente, próximos ao bordo de ataque, conforme pode ser visualizado na figura 6.7.

a)

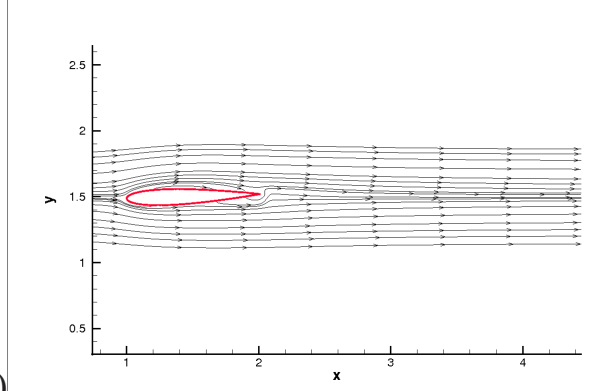

c)

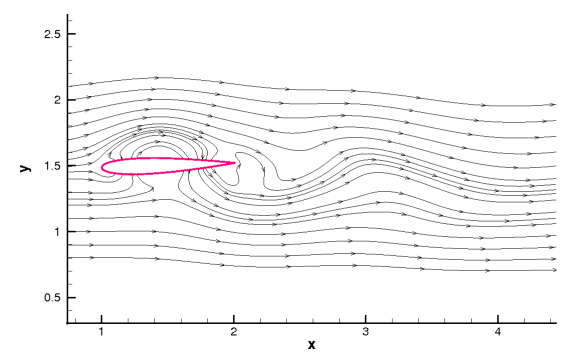

b)

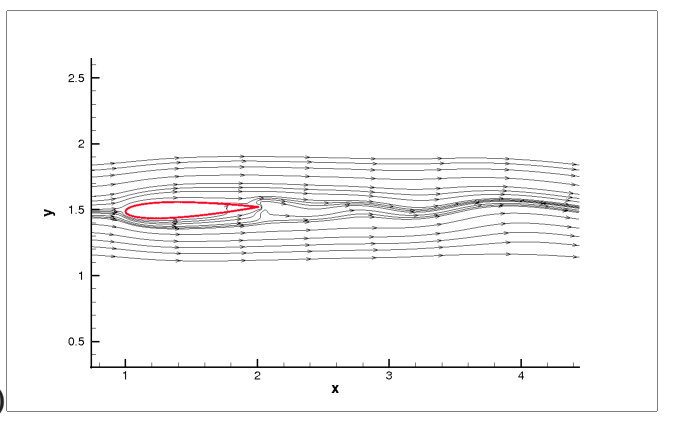

d)

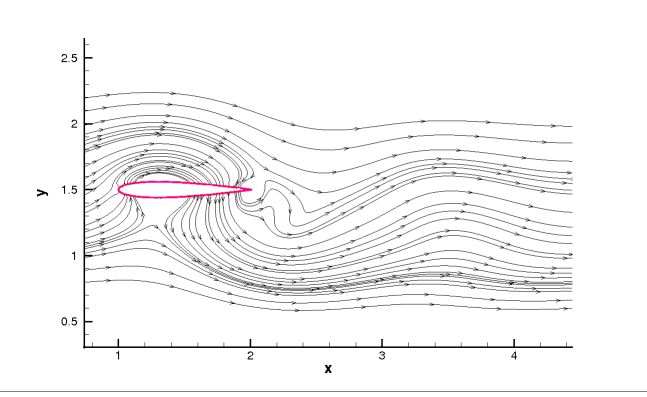

Figura 6.4: Linhas de corrente para os casos de a) $\alpha=-2^{0}, f_{s}=2 \mathrm{~Hz}$, b) $\alpha=-2^{\circ}, f_{s}=5 \mathrm{~Hz}$, c) $\alpha=-2^{o}, f_{s}=10 \mathrm{~Hz}$ e d) $\alpha=-2^{\circ}, f_{s}=15 \mathrm{~Hz}$.

A figura 6.8 mostra os resultados computacionais obtidos para número de Reynolds $R e=$ 1200, $\alpha=30^{\circ}$ e $f_{s}=5 \mathrm{~Hz}$ e os resultados experimentais obtidos por Webb (2009) a partir do trabalho de Ohmi, Coutanceau, Daube e Loc (1991). O comportamento obtido pela simulação computacional está bastante próximo do experimental.

\subsection{Estudo de flutter}

Efeitos aeroelásticos são os resultados de interações de forças aerodinâmicas, estruturais, inerciais e elásticas, isto é, forças aerodinâmicas induzidas ou que induzem deformações estáticas ou dinâmicas na estrutura. Se a estrutura, quando imersa em um escoamento, permanece perfeitamente rígida, não está sujeita a problemas aeroelásticos. No entanto, as estruturas são, de alguma forma, flexíveis e, quando imersas em um escoamento, essa flexibilidade é fundamentalmente responsável por vários tipos de fenômenos aeroelásticos, dentre eles o flutter. 

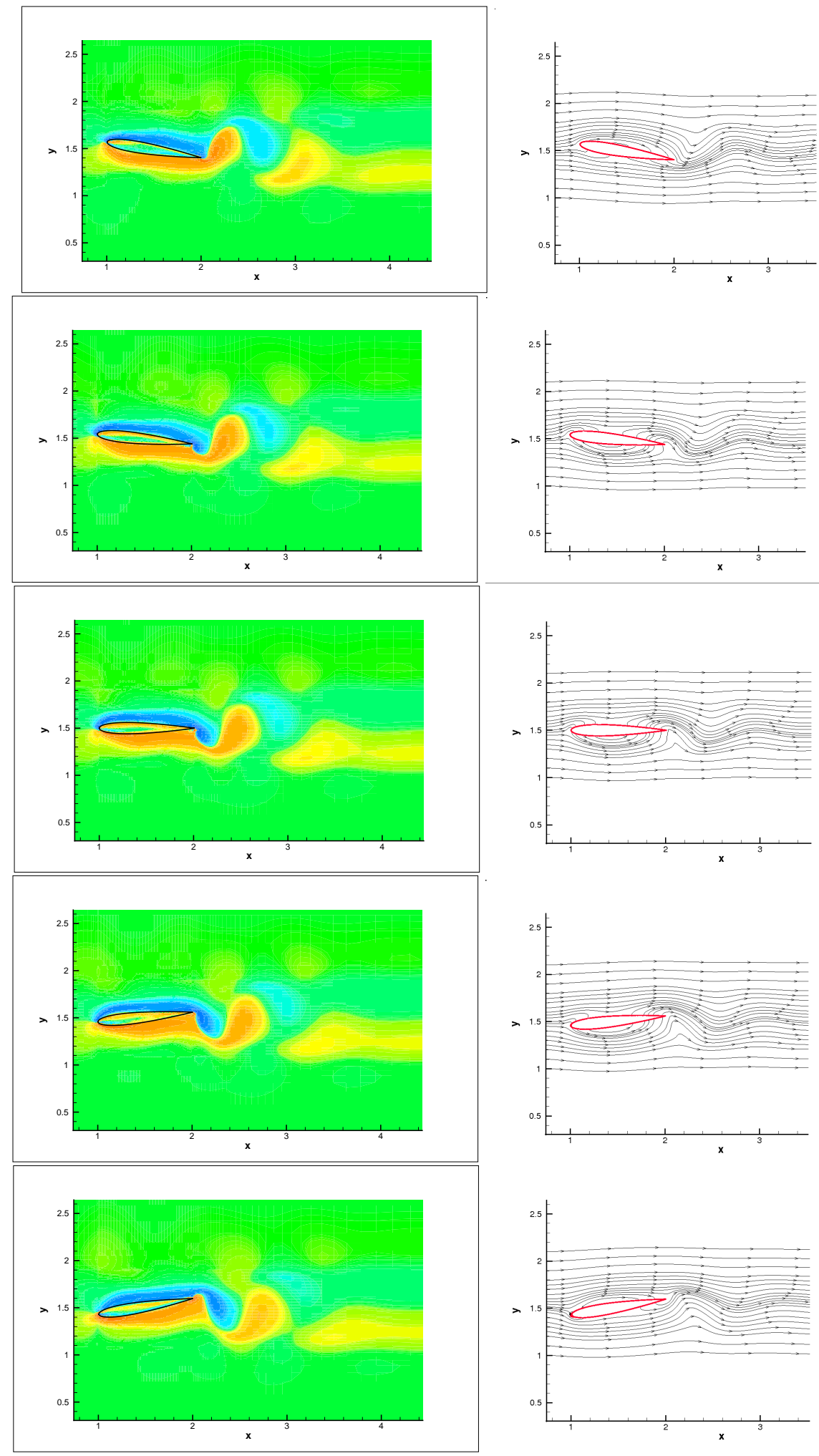

Figura 6.5: Sequência de um ciclo para oscilação forçada com $\alpha=10^{\circ}$ e $f_{s}=1 \mathrm{~Hz}$ 


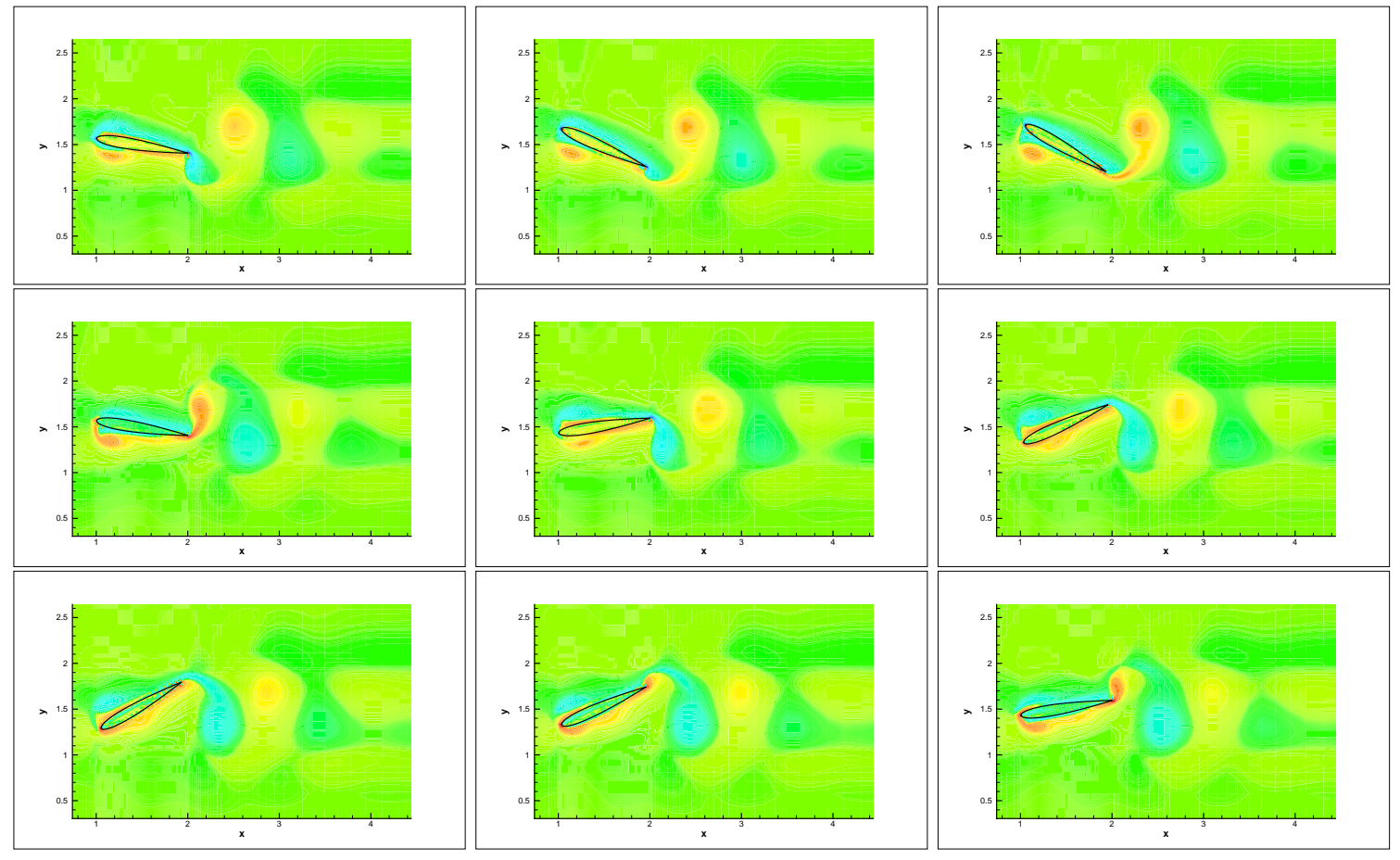

Figura 6.6: Sequência de um ciclo para oscilação forçada com $\alpha=30^{\circ}$ e $f_{s}=1 \mathrm{~Hz}$

a)

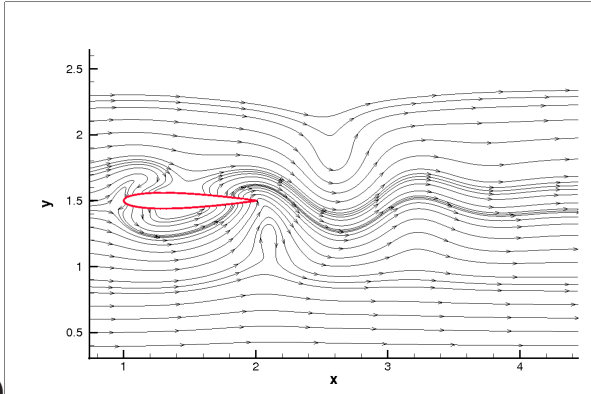

c)

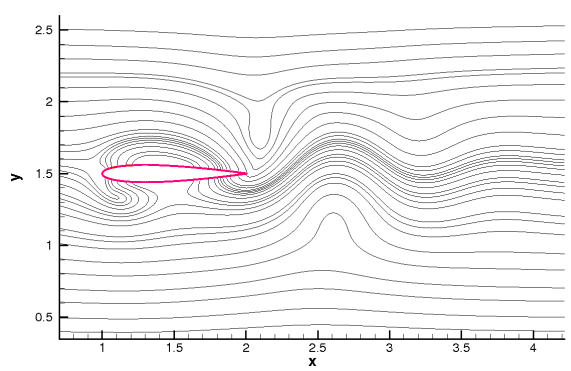

b)

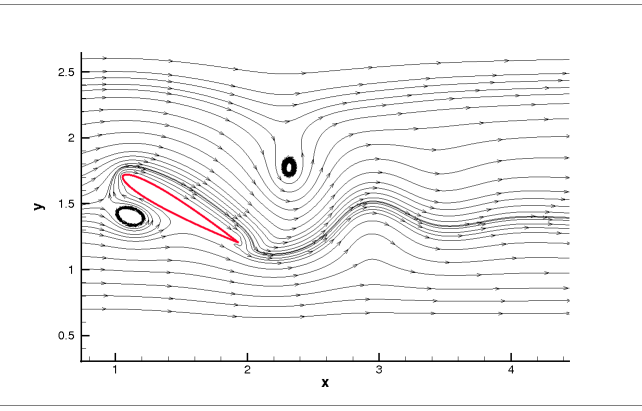

d)

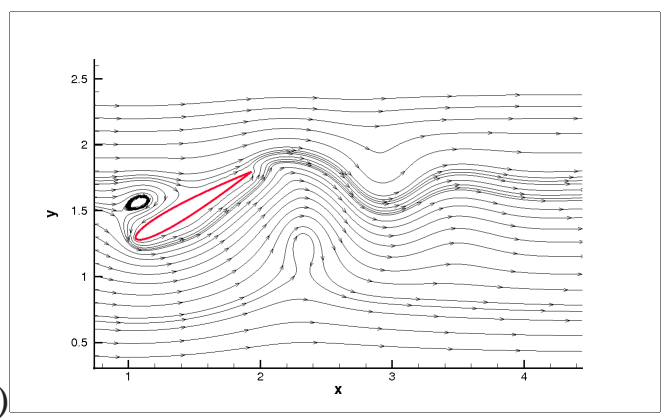

Figura 6.7: Linhas de corrente para os casos de a) $\alpha=0^{\circ}$, b) $\alpha=30^{\circ}$, c) $\alpha=0^{\circ}$ e d) $\alpha=-30^{0}$, $\operatorname{com} f_{s}=1 \mathrm{~Hz}$ 

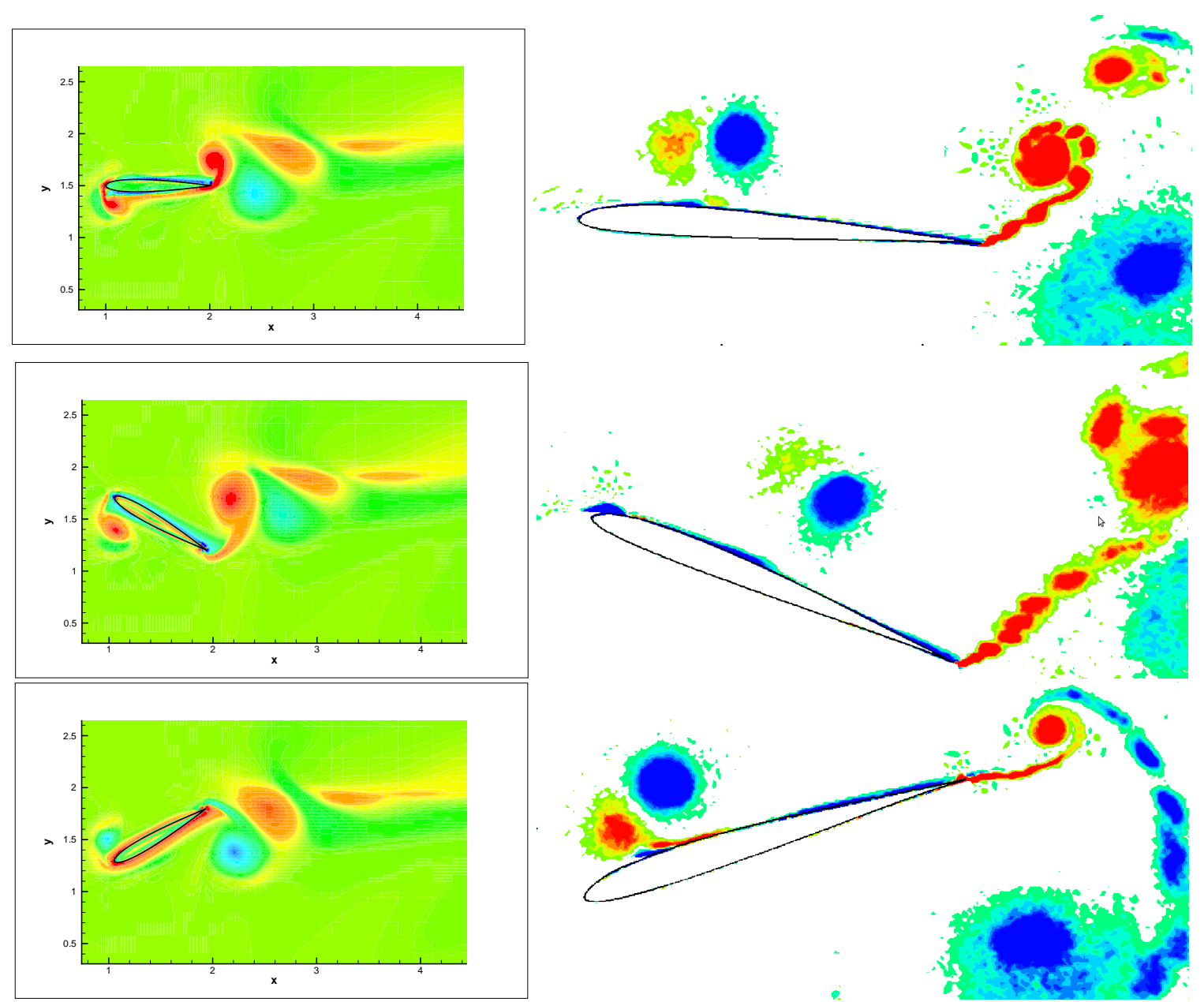

Figura 6.8: Resultados computacionais $R e=1200, \alpha=30^{\circ}$ e experimentais (WEBB, 2009) 
O fenômeno de flutter é geralmente observado nas asas e superfícies de controle, pois estes tipos de estruturas estão sujeitas a grandes cargas aerodinâmicas. O flutter é produzido devido a forças que são geradas a partir dos desvios dinâmicos de uma estrutura elástica no estado indeformado (BISPLINGHOFF, 1955). Na análise e desenvolvimento de sistemas mecânicos, o comportamento dinâmico estrutural do modelo pode ser descrito por seus parâmetros modais, ou seja, suas frequências naturais, modos de vibrar e razões de amortecimento. A análise modal convencional, empregada para investigar o comportamento dinâmico de uma estrutura, é embasada em três hipóteses:

a) linearidade do comportamento dinâmico: a resposta da estrutura para uma combinação de forças aplicadas simultaneamente é equivalente à soma das respostas de cada força atuando individualmente;

b) Invariância no tempo: os parâmetros físicos da estrutura são constantes;

c) Observabilidade: a relação entrada/saída medida contém informações suficientes para determinar o comportamento dinâmico do modelo.

Os sistemas dinâmicos aplicados a uma seção de aerofólio são mostrados pelos modelos da figura 6.9. Uma seção transversal típica de um aerofólio é mostrada na 6.9(b). O que justifica o escoamento aerodinâmico bidimensional em torno da seção é a consideração de uma asa hipotética de extensão infinita. As propriedades do aerofólio, por unidade nessa asa de extensão infinita, basicamente permanecem iguais em qualquer lugar arbitrário da seção ao longo da extensão, onde $c$ é o comprimento da corda do aerofólio, $x_{c p}$ é a posição do centro de pressão, $x_{c m}$ é a posição do centro de massa, $O$ é a posição do centro do eixo de torção (pivô) e $h$ e $\alpha$ denotam os deslocamentos de elevação e arfagem, respectivamente. A integração das forças aerodinâmicas são sustentação, $L$ (positivo para cima) e momento de arfagem $M$ (positivo no sentido horário - nariz para cima) atuando no ponto de torção $O$. O momento de inércia da seção em torno do eixo de torção, pivô $O$, é dado por $I_{\alpha}$. As rigidezes da molas nos movimentos vertical e torcional são, respectivamente, indicadas por $k_{h}$ e $k_{\alpha}$ e, se considerado o 
amortecimento, os correspondentes coeficientes de amortecimento estrutural são denotados por $c_{h}$ e $c_{\alpha}$. onde $\alpha$ é ângulo de arfagem e $\alpha_{e}$ é o ângulo efetivo de ataque.

a)
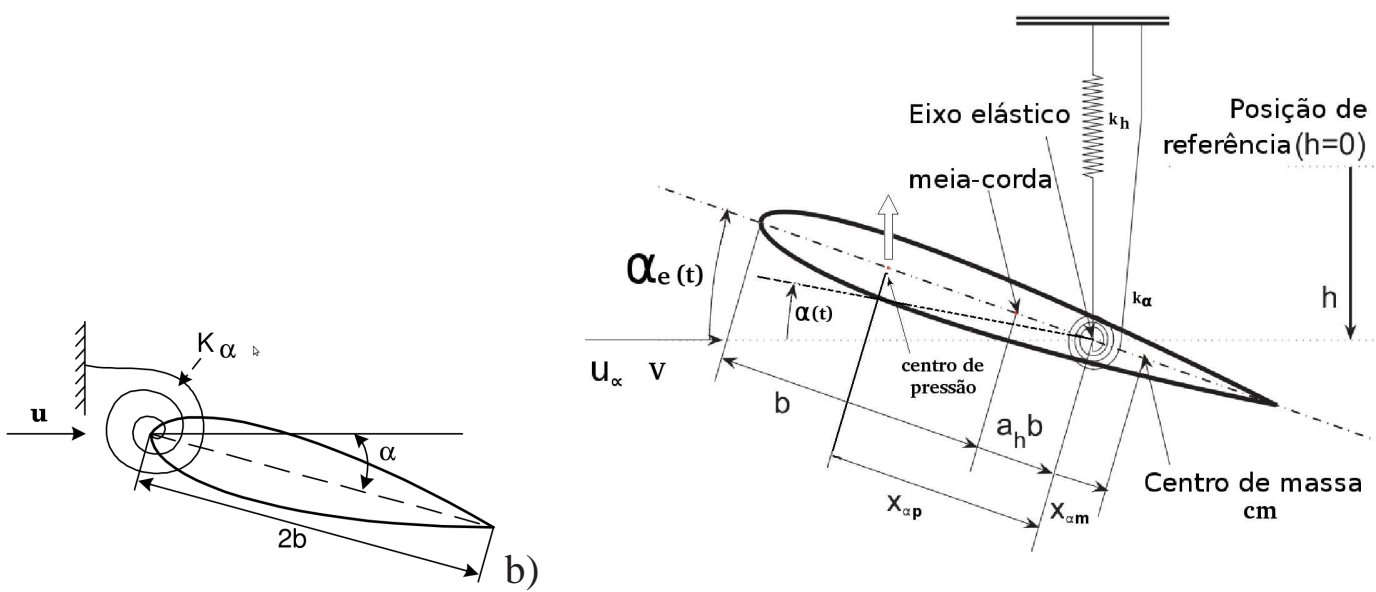

Figura 6.9: Modelos dinâmicos com a) um grau de liberdade e b) dois graus de liberdade, (BISPLINGHOFF, 1955).

Basicamente o flutter é definido por uma velocidade crítica $V$ e uma frequência crítica $\omega_{f}$, onde $V$ é a velocidade frontal do fluido que incide sobre a estrutura e $\omega_{f}$ é a frequência natural de vibração (oscilações harmônicas simples) de uma determinada estrutura imersa em um escoamento sob determinadas condições de sustentação. A solução da vibração conduz a um problema de autovalor complexo onde dois números característicos determinam a velocidade e a frequência.

Dentro desta categoria, um caso para teste refere-se à análise bidimensional de uma seção de aerofólio vibrando em uma asa de comprimento infinito de uma aeronave, conhecido como problema clássico de aerofólio fino associado a oscilação aerodinâmica. Busca-se obter as respostas do comportamento aerodinâmico de um aerofólio fino sob a oscilação suave em um escoamento incompressível com número de Reynolds ultra baixo.

Uma primeira abordagem para o problema de flutter é a modelagem de um aerofólio rígido de corda unitária. O aerofólio é tomado como sendo articulado por uma mola de torção no bordo de ataque, como mostrado na figura 6.9(a). Toma-se como posição não deformada do 
aerofólio aquela em que o ângulo de ataque é zero em um escoamento de baixa velocidade. A equação de movimento para este sistema é dada por:

$$
I_{\alpha} \frac{\partial^{2} \alpha}{\partial t^{2}}+k_{\alpha} \alpha=M_{y}
$$

onde $I_{\alpha}$ que, neste caso, é o momento de inércia da seção em torno do bordo de ataque e $M_{y}$ é o momento aerodinâmico, no bordo de ataque, devido a $\alpha(t)$. A oscilação do aerofólio é considerada como harmônica com frequência $\omega$, amplitude $\alpha_{0}$ e tempo $t$.

$$
\alpha=\alpha_{0} e^{i \omega t}
$$

A solução da equação 6.5 depende da formulação das forças aerodinâmicas, frequência e velocidade de flutter, obtidas na aerodinâmica não estacionária, que tem como base a teoria do fluido potencial com pequenas perturbações. Usualmente trabalha-se com estruturas mais complexas e o modelo de flutter com apenas um grau de liberdade não atende às necessidades de projeto.

\subsubsection{Modelagem de flutter para um sistema de dois graus de liberdade}

A agitação de um aerofólio (como um bater de asas) pode gerar empuxo sob certas combinações de frequência e amplitude de oscilação. Pode-se ter uma ideia intuitiva de como o empuxo é gerado observando a direção do escoamento, que é frequentemente utilizado em aerodinâmica para o cálculo do arrasto induzido. Considere um aerofólio oscilando como mostrado na figura 6.10. Na figura pode-se notar o ângulo $\alpha$, ângulo de arfagem (ou geométrico) entre o aerofólio e a corda média na direção do escoamento principal. O movimento de "bater" induz a um escoamento junto da superfície do aerofólio. Devido ao movimento de oscilação, o aerofólio encontra o escoamento desviado local, que é a superposição dos escoamentos principal e o induzido. Durante a elevação, o escoamento nas proximidades do aerofólio é desviado para cima em relação ao escoamento principal, e o vetor sustentação, que fica perpendicular ao sentido do escoamento local, é inclinado para a frente. E essa elevação inclinada contribui para a geração de empuxo. Da mesma forma, o escoamento é inclinado para 
baixo durante o movimento de elevação e a sutentação (negativa) induz o empuxo também. A figura 6.10 apresenta um esquema simples para o entendimento da geração de empuxo, mas seu cálculo requer ferramentas de análise que considere as forças viscosas e a aerodinâmica não estacionária. Durante a oscilação forçada o aerofólio está sujeito a uma força instantânea por

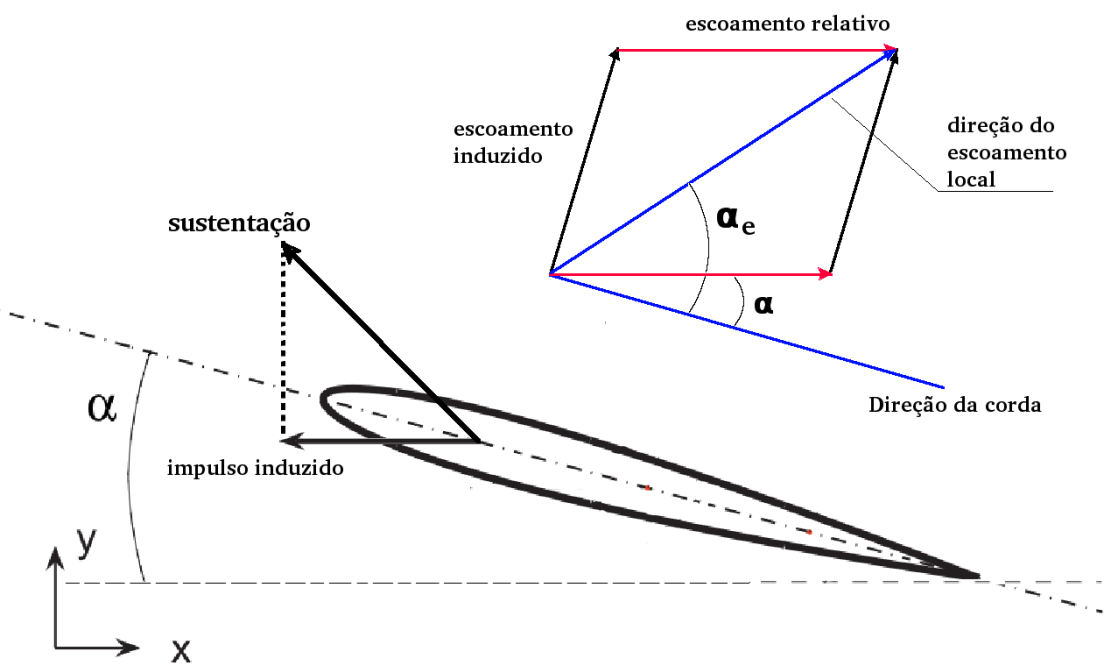

Figura 6.10: Empuxo a partir da oscilação forçada.

unidade de comprimento à vante, na direção transversal, momento de arfagem em torno do pivô e potência instantânea, as quais serão tratadas mais abaixo.

O aerofólio pode se mover na direção vertical (elevação) e rotacionar no plano (arfagem). Pode-se obter as forças aerodinâmicas de duas maneiras: pela análise dos movimentos acoplados ou pela análise dos movimentos de arfagem e elevação separadamente. A cinemática do movimento de um aerofólio pode ser representada como uma combinação harmônica dos movimentos de arfagem e elevação e podem ser descritos do seguinte modo:

$$
\frac{h(t)}{c}=h_{0} \operatorname{sen}\left(\omega t+f_{h}\right) \quad \alpha_{e}(t)=\alpha_{0} \cos \left(\omega t+f_{\alpha}\right)
$$

onde $h_{0}$ é a amplitude de elevação, adimensionalizada pela corda $c$ do aerofólio, $\alpha(t)$ representa o movimento de arfagem com amplitude $\alpha_{0}$ e frequência $\omega$. O ângulo de ataque resultante entre arfagem e elevação é definido como $\alpha_{e}(t)=\alpha_{\alpha}-\alpha_{h}$. No estudo do oscilação forçada, dois 
parâmetros adimensionais têm sido empregados na literatura: frequência reduzida e comprimento de escala. A frequência reduzida é definida como

$$
k=\frac{\omega c}{2 u_{\infty}} \quad \text { ou } \quad k=\frac{\pi f c}{u_{\infty}}
$$

que está associada ao número de Strouhal, definido por Anderson, Streitlien, Barret e Triantafyllou (1998) como

$$
S t=\frac{2 f c h_{0}}{u_{\infty}}
$$

onde $u_{\infty}$ é a velocidade de escoamento livre.

Já o comprimento de escala está associado à corda $c$ e amplitude de deslocamento $c h_{0}, S t$ e $k$ caracterizam o tempo relativo e as escalas de comprimento. Na oscilação forçada, o ângulo de ataque cinemático ou efetivo $\alpha_{e}(t)$ é relativo ao pivô e é definido como:

$$
\alpha_{e}(t)=\alpha(t)+\tan ^{-1}\left(-\frac{1}{u_{\infty}} \frac{\partial h(t)}{\partial t}\right)=\alpha_{0} \cos \left(\omega t+f_{\alpha}\right)+\tan ^{-1}\left(\pi S \operatorname{sen}\left(\omega t+f_{h}\right)\right)
$$

onde os dois termos que compõem o ângulo de ataque efetivo são, respectivamente, o ângulo relativo ao movimento de arfagem e o ângulo relativo ao movimento de elevação. Por definição, o ângulo de ataque cinemático é exclusivamente determinado pela velocidade de escoamento livre e pelo movimento aerofólio, sem considerar o efeito de esteira. Conforme Lian e Shyy (2007) negligencia-se os efeitos do escoamento ao longo do tempo, o que pode ser visto ao se comparar o efeito do número de Strouhal sobre o ângulo de ataque. Para um número de Strouhal pequeno, a contribuição do movimento de elevação é pequena, e o ângulo de ataque cinemático de ataque segue a forma de uma função senoidal. À medida que aumenta o número de Strouhal, o ângulo de ataque cinemático deixa de ter a forma senoidal, ver gráfico no trabalho de Lian e Shyy (2007).

Para mostrar uma das forças aerodinâmicas, força de sustentação provocada pelos movimentos de de arfagem e elevação, foram simulados os casos de oscilação forçada de um perfil de aerofólio tipo NACA0012 submetido a elevação de amplitude $0,1 c$ e arfagem de $\alpha= \pm 2^{\circ}$, conforme pode ser visto nas figuras 6.11(a) e 6.11(b). Theodorsen (1935) apresentou expressões analíticas para a sustentação dependente do tempo, momento e empuxo para uma placa plana 


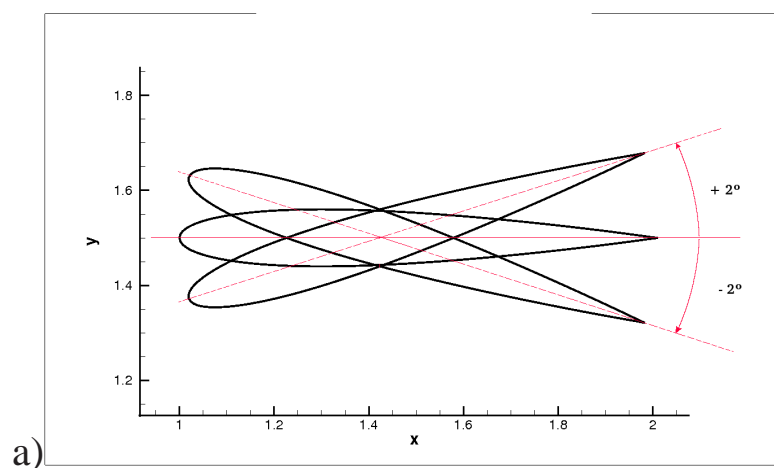

Figura 6.11: Movimentos de arfagem, $\pm 2^{\circ}$, e elevação de $0,1 c$.

arfando e elevando senoidalmente em um escoamento potencial bidimensional, detalhes dessa formulação também podem podem ser obtidos no trabalho de Lobitz (2005). A análise, embora tenha limitações, é um bom ponto de partida para estudar um aerofólio com oscilação forçada e será usada como parâmetro de comparação.

O pivô foi posicionado a $0,5 c$ e número de Reynolds $R e=1000$. As figuras 6.12(a), 6.12(c), 6.12(e) e 6.12(g) mostram a variação no tempo do coeficiente de sustentação $C_{L}$ para arfagem de $\alpha= \pm 2^{\circ}$ com frequências de $1 \mathrm{~Hz}, 2 \mathrm{~Hz}, 5 \mathrm{~Hz}$ e $10 \mathrm{~Hz}$. As figuras 6.12(b), 6.12(d), 6.12(f) e 6.12(h) mostram a evolução do coeficiente de sustentação $C_{L}$ para elevação com frequência de $1 \mathrm{~Hz}, 2 \mathrm{~Hz}, 5 \mathrm{~Hz}$ e $10 \mathrm{~Hz}$.

As figuras 6.13(a) a 6.13(d) mostram as envoltórias para o coeficiente de pressão $C_{P}$ (máximas) para o caso de oscilação forçada $\operatorname{com} \alpha= \pm 2^{\circ}$ e frequências de $1 \mathrm{~Hz}, 2 \mathrm{~Hz}, 5 \mathrm{~Hz}$ e $10 \mathrm{~Hz}$.

A tabela 6.1 mostra os valores máximo e médio para os coeficientes, $C_{L}, C_{D}$ e $C_{P}$, a partir dos quais se obtem as forças aerodinâmicas.

Para o estudo de flutter com dois graus de liberdade, considere-se um sistema composto por aerofólio, como no caso de um grau de liberdade, mas além do movimento de torção também será incluido o movimento de translação no sentido vertical, ou seja, o modelo mecânico consiste de molas de flexão e de torção que são presas no eixo elástico do modelo de aerofólio, ambas sem amortecedores. A resposta da estrutura é tomada como linear. A seção de aerofólio usada foi NACA0012 em um escoamento com velocidade $\mathbf{u}_{\infty}$, como mostrado na figura 6.9(b). 


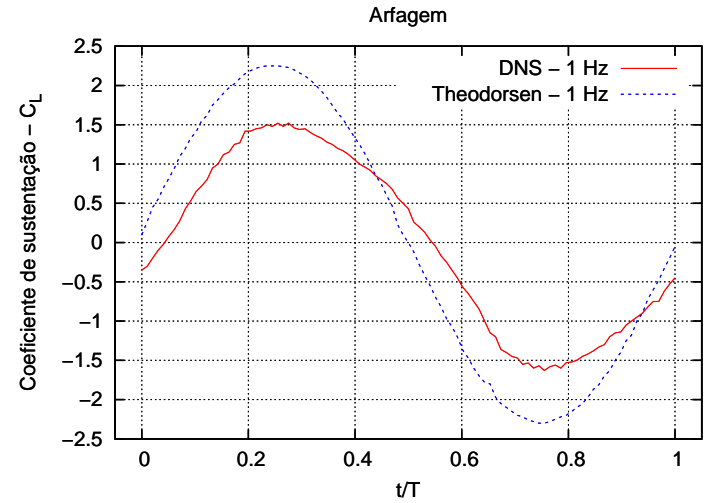

a)

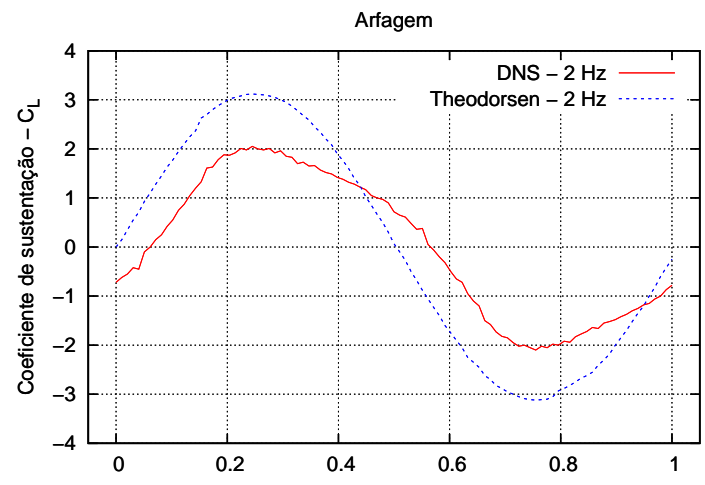

c)

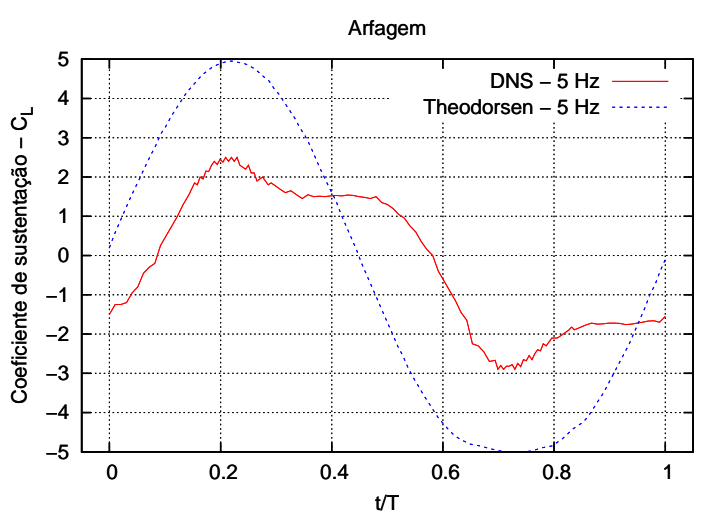

e)

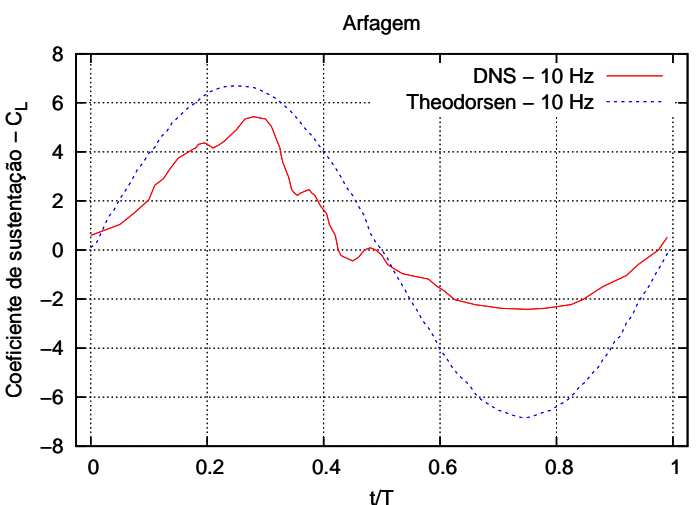

b)
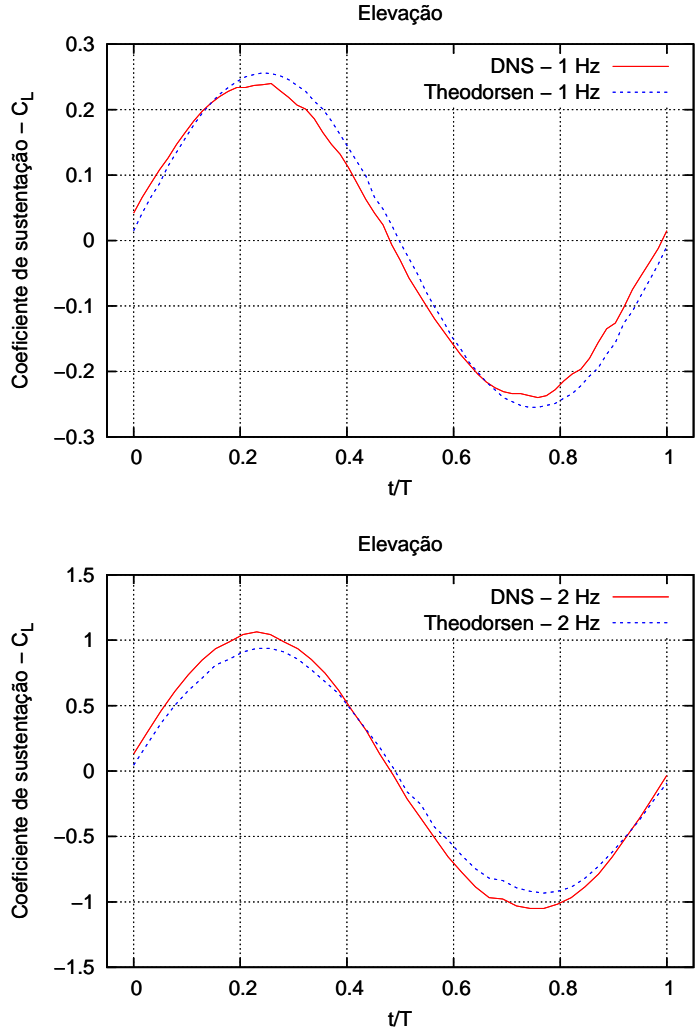

d)

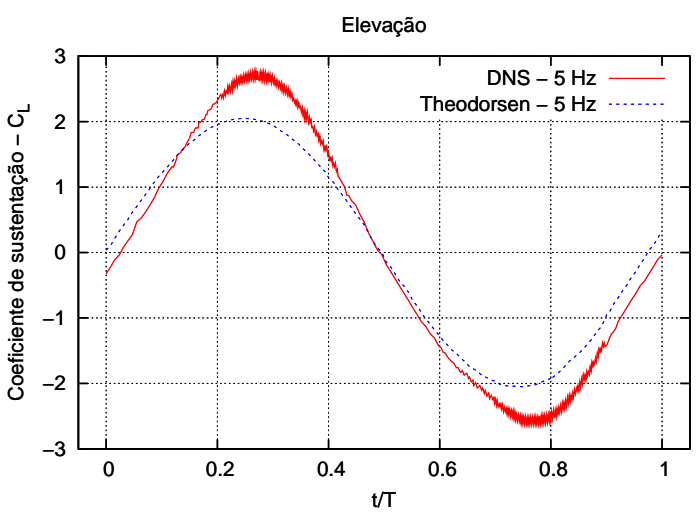

f)

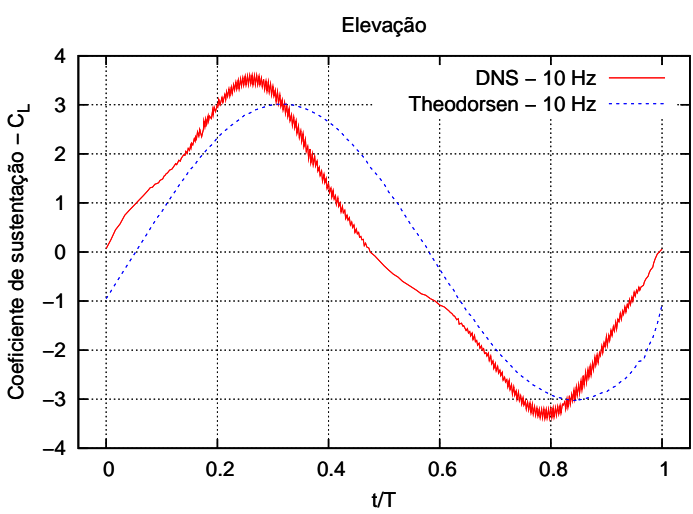

h)

g)

Figura 6.12: Evolução do $C_{L}$ para arfagem de $\pm 2^{\circ}$, elevação de $0,1 c$ e frequências de $1 \mathrm{~Hz}, 2 \mathrm{~Hz}$, $5 \mathrm{~Hz}$ e $10 \mathrm{~Hz}$. 

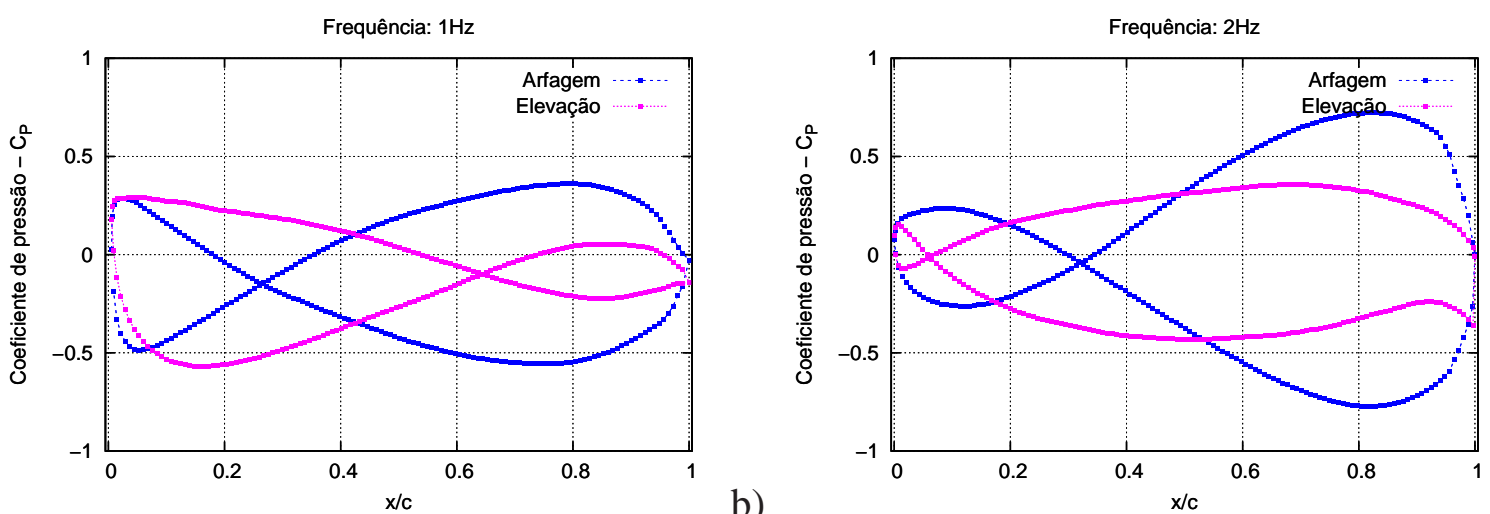

a)

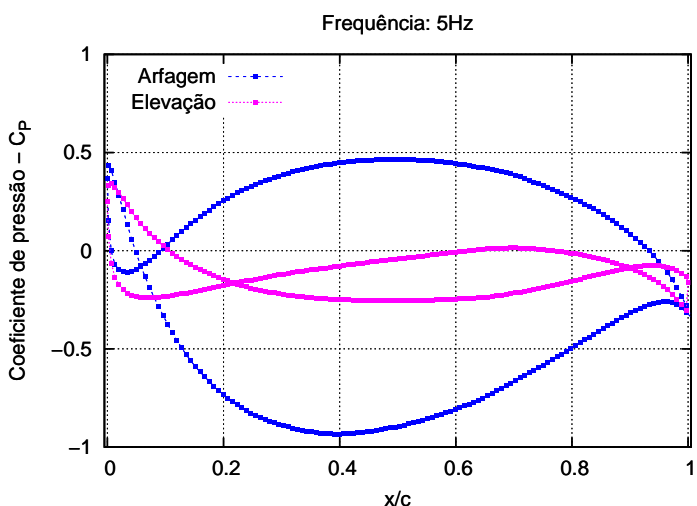

b)

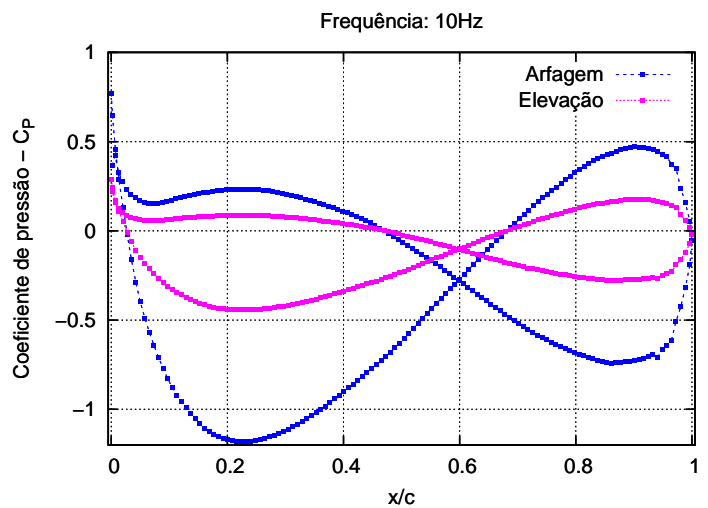

c)

Figura 6.13: Coeficiente de pressão $C_{P}$ para arfagem de $\pm 2^{\circ}$, elevação de $0,1 c$ e frequências de $1 \mathrm{~Hz}, 2 \mathrm{~Hz}, 5 \mathrm{~Hz}$ e $10 \mathrm{~Hz}$.

Tabela 6.1: Valores de $C_{L}, C_{D}, C_{P}$ e $C_{M}$ obtidos da simulação

\begin{tabular}{c|c|c|c|c|c|c|c}
\hline \hline Frequência $H z$ & movimento & $C_{\text {Lmax }}$ & $C_{\text {Lmed }}$ & $C_{\text {Dmax }}$ & $C_{\text {Dmed }}$ & $C_{\text {Pmax }}$ & $C_{\text {Mmax }}$ \\
\hline \multirow{2}{*}{1} & arfagem & 1,507 & 0 & 0,131 & 0,121 & 0,421 & 0,0051 \\
& elevação & 0,236 & 0 & 0,1225 & 0,118 & 0,305 & 0,0312 \\
\hline \multirow{2}{*}{2} & arfagem & 2,015 & 0 & 0,182 & 0,137 & 0,763 & 0,0466 \\
& elevação & 1,206 & 0,013 & 0,130 & 0,122 & 0,413 & 0,1825 \\
\hline \multirow{2}{*}{5} & arfagem & 2,418 & $-0,015$ & 0,445 & 0,2735 & 0,491 & 0,0263 \\
& elevação & 2,721 & 0,018 & 0,141 & 0,132 & 0,398 & 0,5625 \\
\hline \multirow{2}{*}{10} & arfagem & 5,228 & 1,524 & 1,676 & 1,3225 & 0,723 & 0,7576 \\
& elevação & 3,501 & 0,032 & 0,154 & 0,141 & 0,412 & 1,6943 \\
\hline \hline
\end{tabular}

A deflexão de elevação no eixo elástico é denotada por $h$, tomando como positivo o sentido de cima para baixo e $\alpha$ é o ângulo de ataque (ângulo entre a direção do escoamento e a corda) e é dito positivo quando tomado no sentido horário. O comprimento da corda é denotado por $c$ e a semi-corda como $b=\frac{1}{2} c$. O eixo elástico está localizado a uma distância $a_{h} b$ da meiacorda, enquanto o centro de massa está localizado a uma distância $x_{c m}$ do eixo elástico (sentido 
positivo a partir do bordo de ataque do aerofólio). O momento de inércia da seção em torno do eixo de torção (eixo elástico, pivô) é dada por $I_{\alpha}$.

Para a seção de aerofólio de massa $m$ e momento de inércia em torno do centro de massa, $I_{c m}$ (momento estático de massa, por unidade de extensão), a energia cinética $T$ é dada por:

$$
T=\frac{1}{2} m\left(\frac{d h}{d t}-x_{c m} \frac{d \alpha}{d t}\right)^{2}+\frac{1}{2} I_{c m}\left(\frac{d \alpha}{d t}\right)
$$

A energia potencial, $\mathcal{P}$, do sistema é dada por

$$
\mathcal{P}=\frac{1}{2} k_{h} h^{2}+\frac{1}{2} k_{\alpha} \alpha^{2}
$$

Assim, a lagrangiana é dada por

$$
\mathcal{L}=T-\mathcal{P}=\frac{1}{2} m\left(\frac{d h}{d t}+x_{c m} \frac{d \alpha}{d t}\right)^{2}+\frac{1}{2} I_{c m}-\frac{1}{2} k_{h} h^{2}-\frac{1}{2} k_{\alpha} \alpha^{2}
$$

A equação do movimento para o aerofólio com dois graus de liberdade (elevação $h$ e arfagem $\alpha$ ) pode ser obtida através da equação de Lagrange (sistema conservativo) como:

$$
\begin{aligned}
& \frac{d}{d t} \frac{\partial \mathcal{L}}{\partial \frac{d h}{d t}}-\frac{\partial \mathcal{L}}{\partial h}=L \\
& \frac{d}{d t} \frac{\partial \mathcal{L}}{\partial \frac{d \alpha}{d t}}-\frac{\partial \mathcal{L}}{\partial \alpha}=M
\end{aligned}
$$

que leva à seguinte equação do movimento para o aerofólio

$$
\left[\begin{array}{cc}
m & -m x_{c m} \\
-m x_{c m} & I_{\alpha}
\end{array}\right]\left\{\begin{array}{c}
\frac{\partial^{2} h}{\partial t^{2}} \\
\frac{\partial^{2} \alpha}{\partial t^{2}}
\end{array}\right\}+\left[\begin{array}{cc}
k_{h} & 0 \\
0 & k_{\alpha}
\end{array}\right]\left\{\begin{array}{l}
h \\
\alpha
\end{array}\right\}=\left\{\begin{array}{c}
L \\
M
\end{array}\right\}
$$

$\operatorname{com} I_{\alpha}=I_{c m}+m x_{c m}^{2}$. Tomando

$$
\mathbb{M}=\left[\begin{array}{cc}
m & -m x_{c m} \\
-m x_{c m} & I_{\alpha}
\end{array}\right], \quad \mathbb{K}=\left[\begin{array}{cc}
k_{h} & 0 \\
0 & k_{\alpha}
\end{array}\right], \quad \mathbb{U}=\left\{\begin{array}{l}
h \\
\alpha
\end{array}\right\} \quad e \quad \mathbb{F}=\left\{\begin{array}{c}
L \\
M
\end{array}\right\},
$$


onde $\mathbb{M}$ é a matriz de massa, $\mathbb{K}$ é a matrix de rigidez, $\mathbb{U}$ o vetor deslocamento e $\mathbb{F}$ é o vetor de forças, então, a equação do movimento pode ser reescrita como:

$$
[\mathbb{M}]\left\{\frac{\partial^{2} \mathbb{U}}{\partial t^{2}}\right\}+[\mathbb{K}] \quad\{\mathbb{U}\}=\{\mathbb{F}\}
$$

Note-se que a matriz de rigidez é diagonal porque o ponto de apoio está no centro de flexão, onde a elevação e a arfagem são estaticamente desacoplados. A sustentação e o momento aerodinâmico no pivô, por unidade de extensão, são dados pelas expressões:

$$
\begin{aligned}
L & =\frac{1}{2} \rho u_{\infty}^{2} c C_{L}=\frac{1}{2} \rho u_{\infty}^{2} c \frac{\partial C_{L}}{\partial \alpha} \alpha_{e} \\
M & =\frac{1}{2} \rho u_{\infty}^{2} c C_{L} x_{c p}=\frac{1}{2} \rho u_{\infty}^{2} c^{2} \frac{\partial C_{L}}{\partial \alpha} \alpha_{e} l=C_{M} \frac{1}{2} \rho u_{\infty}^{2} c^{2}
\end{aligned}
$$

onde $C_{L}$ e $C_{M}$ são os coeficientes de sustentação e de momento respectivamente. Da teoria de aerofólios finos, podemos obter que o gradiente de sustentação para um aerofólio fino de comprimento infinito em um escoamento bidimensional incompressível é $\frac{\partial C_{L}}{\partial \alpha}=2 \pi$.

As equações de Lagrange para sistema não-conservativo são dadas por:

$$
\frac{d}{d t} \frac{\partial \mathcal{L}}{\partial\left(\frac{d u_{i}}{d t}\right)}-\frac{\partial \mathcal{L}}{\partial u_{i}}+\frac{D E}{\partial\left(\frac{d u_{i}}{d t}\right)}=F_{i}
$$

onde $D E$ é a energia de dissipação do sistema, dada por

$$
D E=\frac{1}{2} \xi_{h}\left(\frac{d h}{d t}\right)+\frac{1}{2} \xi_{\alpha}\left(\frac{d \alpha}{d t}\right)
$$

e que dará a equação 6.22, na forma matricial:

$$
\left[\begin{array}{cc}
m & -m x_{c m} \\
-m x_{c m} & I_{\alpha}
\end{array}\right]\left\{\begin{array}{c}
\frac{\partial^{2} h}{\partial t^{2}} \\
\frac{\partial^{2} \alpha}{\partial t^{2}}
\end{array}\right\}+\left[\begin{array}{cc}
\xi_{h} & 0 \\
0 & \xi_{\alpha}
\end{array}\right]\left\{\begin{array}{c}
\frac{d h}{d t} \\
\frac{d \alpha}{d t}
\end{array}\right\}\left[\begin{array}{cc}
k_{h} & 0 \\
0 & k_{\alpha}
\end{array}\right]\left\{\begin{array}{c}
h \\
\alpha
\end{array}\right\}=\left\{\begin{array}{c}
L \\
M
\end{array}\right\}
$$

$\mathrm{ou}$

$$
[\mathbb{M}]\left\{\frac{\partial^{2} \mathbb{U}}{\partial t^{2}}\right\}+[\mathbb{D}] \quad\left\{\frac{\partial \mathbb{U}}{\partial t}\right\}[\mathbb{K}] \quad\{\mathbb{U}\}=\{\mathbb{F}\}
$$

onde $[\mathbb{D}]=\left[\begin{array}{cc}\xi_{h} & 0 \\ 0 & \xi_{\alpha}\end{array}\right]$ é a matriz de amortecimento. 
Em princípio, as forças aerodinâmicas na equação de movimento, equação 6.24 , são instáveis na natureza e o modelo computacional para simulação desse tipo de fenômeno deve ser adequado para gerar essas forças no tempo. As modificações apropriadas nas expressões para gerar essas forças, na formulação clássica de flutter, considera as condições aerodinâmicas de amortecimento envolvendo os componentes das velocidades de elevação e arfagem que influenciam o ângulo efetivo de ataque. Assim, o aerofólio é submetido à aerodinâmica de amortecimento, além de seu próprio amortecimento estrutural viscoso. Formulação para o caso compressível e modelo da placa palna de Theodorsem podem ser encontrados no trabalho de Mukherjee, Manjuprasad, Sharma, Rana e Oncar (2008).

As equações de movimento apresentadas acimas (equações 6.17 a 6.24) podem ser resolvidas através de dois métodos: a) método clássico, método do autovalor direto para a equação diferencial de segunda ordem para o caso do sistema não amortecido e do método de estado do espaço para a equação de primeira ordem equivalente para o caso do sistema amortecido; e b) tempo de simulação, abordagem de integração direta. Neste trabalho, abordaremos o método clássico com aproximação do autovalor direto para o caso de sistema não-amortecido, ou seja, esta abordagem simplificada pode dar uma primeira estimativa do limite de vibração onde expressões aerodinâmicas são usados para aproximar as cargas aerodinâmicas instáveis, sem incorporar as condições aerodinâmicas de amortecimento. A equação 6.17, com as forças dadas pela equação 6.20 , reduz-se a:

$$
\left[\begin{array}{cc}
m & -m x_{c m} \\
-m x_{c m} & I_{\alpha}
\end{array}\right]\left\{\begin{array}{c}
\frac{\partial^{2} h}{\partial t^{2}} \\
\frac{\partial^{2} \alpha}{\partial t^{2}}
\end{array}\right\}+\left[\begin{array}{cc}
k_{h} & 0 \\
0 & k_{\alpha}
\end{array}\right]\left\{\begin{array}{c}
h \\
\alpha
\end{array}\right\}=\frac{1}{2} \rho_{\infty} u_{\infty}^{2} c \frac{\partial C_{L}}{\partial \alpha}\left\{\begin{array}{c}
\alpha \\
x_{c p} \alpha
\end{array}\right\}
$$

e com o vetor deslocamento dependente do tempo expresso por $\left\{\begin{array}{c}h \\ \alpha\end{array}\right\}=\left\{\begin{array}{c}h_{0} \\ \alpha_{0}\end{array}\right\} e^{\lambda t}$ obteremos

$$
\left[\left[\begin{array}{cc}
m & -m x_{c m} \\
-m x_{c m} & I_{\alpha}
\end{array}\right] \lambda^{2}+\left[\begin{array}{cc}
k_{h} & 0 \\
0 & k_{\alpha}
\end{array}\right]+\frac{1}{2} \rho_{\infty} u_{\infty} c \frac{\partial C_{L}}{\partial \alpha}\left[\begin{array}{cc}
0 & -1 \\
0 & -x_{c p}
\end{array}\right]\right]\left\{\begin{array}{c}
h_{0} \\
\alpha_{0}
\end{array}\right\}=\left\{\begin{array}{l}
0 \\
0
\end{array}\right\}
$$


que em notação matricial produz

$$
\left[[\mathbb{K}]+[\mathbb{A}]+\lambda^{2}[\mathbb{M}]\right]\left\{\begin{array}{c}
h_{0} \\
\alpha_{0}
\end{array}\right\}=0
$$

onde $[\mathbb{A}]$ é a matriz aerodinâmica e $[\mathbb{A}]=\frac{1}{2} \rho_{\infty} u_{\infty} c \frac{\partial C_{L}}{\partial \alpha}\left[\begin{array}{cc}0 & -1 \\ 0 & -x_{c p}\end{array}\right]$

A solução não trivial da equação 6.27 implica que

$$
\operatorname{Det}\left[[\mathbb{K}]+[\mathbb{A}]+\lambda^{2}[\mathbb{M}]\right]=0
$$

que acarreta tres possibilidades para a estabilidade do sistema:

- para escoamento com velocidade subcrítica, com ausência de amortecimento, ambos autovalores $\left(-\lambda^{2}\right)$ são reais e positivos e, portanto, os valores para $\lambda^{2}$ são reais e negativos, ou seja o parâmetro $\lambda= \pm i \omega$ é puramente imaginário. Dois correspondentes valores distintos de $\lambda$ puramente imaginários retornam frequências circulares dos dois ramos modais em radianos/segundo. O sistema vibra de forma constante com o movimento harmônico simples em cada um dos dois ramos resultantes dos modos de vibração (vibrações livres) natural.

- depois da velocidade crítica $\left(u_{\infty}>V\right)$ os parâmetros $\lambda$ ocorrem como conjugados complexos $\lambda=\lambda_{r} \pm i \lambda_{i}$ em que um deles tem parte real positiva $\lambda_{r}>0$ e que as oscilações do ramo modal apropriado são instáveis, caracterizadas pelo aumento da amplitude no tempo. Quando $u_{\infty}=V$, fronteira de flutter, $\lambda_{r}=0$, tem-se simplesmente movimento harmônico simples.

- a instabilidade do tipo divergência é indicada pela condição em que a parte imaginária de $\lambda$ desaparece, $\lambda_{i}=\omega=0$.

Olhando apenas o movimento de arfagem e elevação, a condição estável é representada na figura 6.14(a), um diagrama de fase e frequência das oscilações verticais e de torção da seção, onde a taxa de frequência da oscilação acoplada elevação/torção é igual a 0,5, ou seja, 
o movimento cíclico de torção é duas vezes mais rápido que o movimento cíclico de elevação. A figura mostra que a oscilação de torção completa dois ciclos: da deflexão zero, até a máxima positiva, a zero, à máxima negativa e volta a zero, no mesmo tempo em que a oscilação vertical completa um ciclo total.

A condição crítica de flutter é mostrada na figura 6.14(b), um diagrama de fase e frequência das oscilações onde os movimentos são de 90 graus fora de fase e razão de frequência é de 1,0, ou seja, os dois movimentos alcançam seus deslocamentos máximos, positivos ou negativos, em diferentes tempos ( $90^{\circ}$ de defasagem), enquanto as frequências de elevação e arfagem são iguais ou quase iguais. Qualquer aumento na velocidade fará com que o ângulo de fase se torne menor que $90^{\circ}$, permitindo acoplamento aerodinâmico e, portanto, oscilações divergentes. Com a condição de instabilidade (flutter completo), ambos os movimentos atingirão seus deslocamentos máximos ao mesmo tempo (movimento em fase), e cada movimento irá, aerodinamicamente, reforçar o movimento do outro. A figura 6.14(c) apresenta um diagrama de fase e frequência da condição de vibração completa, onde os dois movimentos estão em fase e na mesma frequência. Tal deslocamento angular, no seu máximo, tende a produzir deslocamento vertical $h$ ainda maior a cada ciclo.

Para ângulos pequenos $x_{\alpha m} \approx x_{c m}$, então, de forma resumida, as equações de movimento da seção típica, conforme Greco Júnior (1996), são dadas por:

$$
\left\{\begin{array}{l}
m \frac{\partial^{2} h}{\partial t^{2}}+m x_{c m} \frac{\partial^{2} \alpha}{\partial \alpha^{2}}+K_{h} h=L, \\
m x_{c m} \frac{\partial^{2} h}{\partial t^{2}}+I \frac{\partial^{2} \alpha}{\partial t^{2}}+K_{\alpha} \alpha=M,
\end{array}\right.
$$

onde $f_{h}$ é a frequência natural de translação não acoplada, $f_{\alpha}$ é a frequência natural de torção. Os movimentos de translação $h$ e torção $\alpha$ são tomados como harmônicos e existe uma defasagem entre eles devido às cargas aerodinâmicas, $m$ é a massa da seção típica, $I$ é o momento de inércia, $x_{c m}$ é a distância do centro de massa ao centro de rotação, $K_{h}$ é a rigidez em translação, $h$, e $K_{\alpha}$ é a rigidez em torção, $\alpha$. $L$ é a força de sustentação e $M$ é o momento de arfagem. 

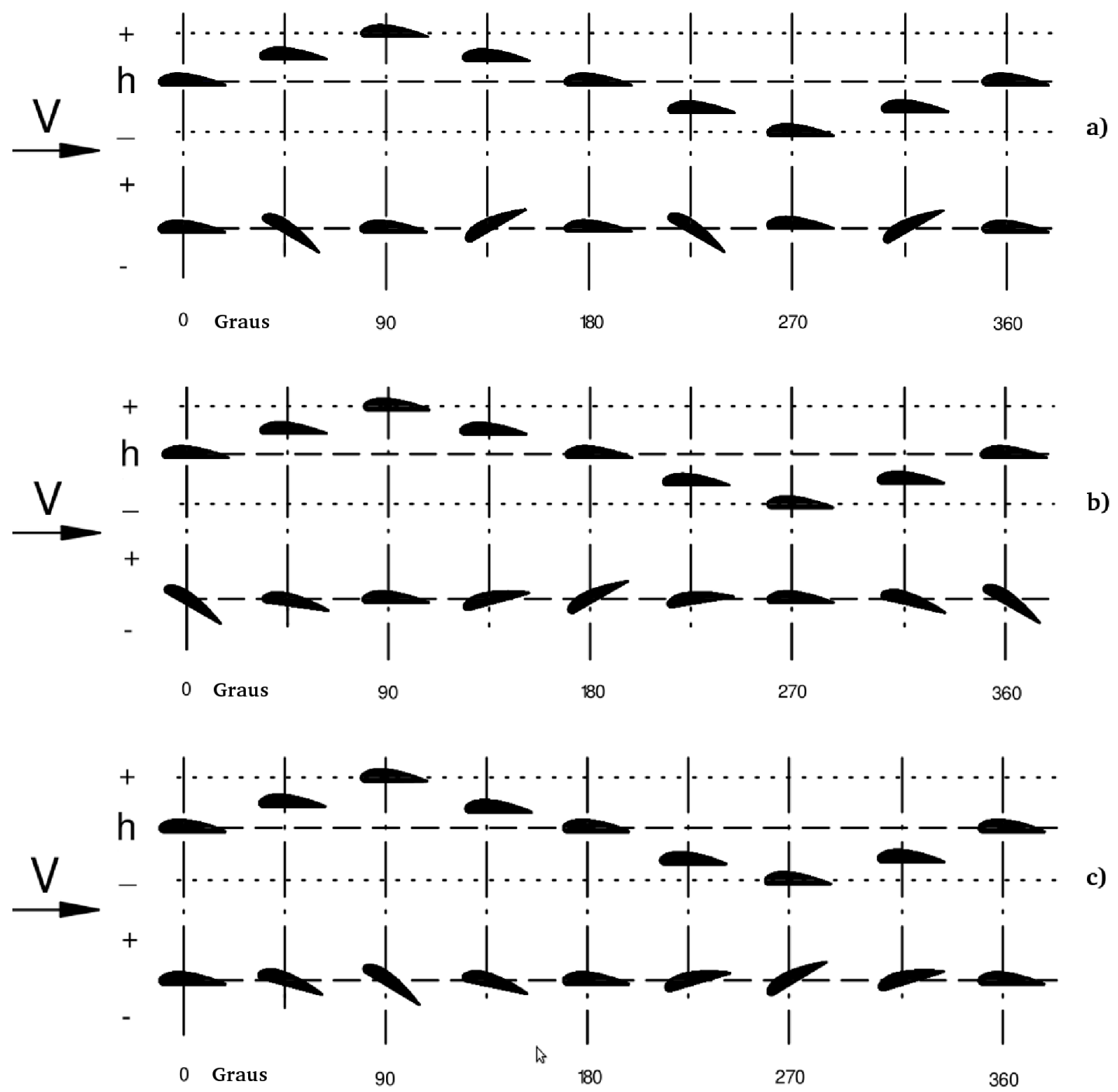

Figura 6.14: Relação entre as oscilaçãoes de arfagem e elevação e a estabilidade (flutter).

Para movimento harmônico amortecido e usando uma aproximação linear para a relação entre forças aerodinâmicas e variáveis de movimento

$$
\left\{\begin{array}{l}
h=\tilde{h} e^{\lambda t}, \\
\alpha=\tilde{\alpha} e^{\lambda t}, \\
L=\tilde{L}(\tilde{h}, \tilde{\alpha}) e^{\lambda t}=\left(\tilde{L}_{\tilde{\alpha}} \tilde{\alpha}+\tilde{L}_{\tilde{h}} \tilde{h}\right) e^{\lambda t}, \\
M=\tilde{M}(\tilde{h}, \tilde{\alpha}) e^{\lambda t}=\left(\tilde{M}_{\tilde{\alpha}} \tilde{\alpha}+\tilde{M}_{\tilde{h}} \tilde{h}\right) e^{\lambda t} .
\end{array}\right.
$$


onde $\tilde{\alpha}, \tilde{L}$ e $\tilde{M}$ são números complexos que definem amplitudes e ângulos de fase em relação a $h$. Então, omitindo a barra de amplitude, teremos:

$$
\left\{\begin{array}{l}
m \lambda_{h}^{2}+m x_{c m} \lambda^{2} \alpha+K_{h} h=L_{\alpha} \alpha+L_{h} h \\
m x_{c m} \lambda_{h}^{2}+I \lambda^{2} \alpha+K_{\alpha} \alpha=M_{\alpha} \alpha+M_{h} h
\end{array}\right.
$$

na forma matricial,

$$
\left[\begin{array}{cc}
K_{h}+m \lambda^{2}+L_{h} & -m x_{c m} \lambda^{2}-L_{\alpha} \\
m x_{c m} \lambda^{2}-M_{h} & K_{\alpha}+I \lambda^{2}-M_{\alpha}
\end{array}\right] \cdot\left[\begin{array}{c}
h \\
\alpha
\end{array}\right]=\left[\begin{array}{l}
0 \\
0
\end{array}\right]
$$

A estabilidade do sistema é dada pela solução de

$$
\left|\begin{array}{cc}
K_{h}+m \lambda^{2}-L_{h} & m x_{c m} \lambda^{2}-L_{\alpha} \\
m x_{c m} \lambda^{2}-M_{h} & K_{\alpha}+I \lambda^{2}-M_{\alpha}
\end{array}\right|=0 .
$$

Os valores $\lambda$ possuem a forma

$$
\lambda=(\zeta+i) \omega_{d}=(\zeta+i) k \frac{V_{\infty}}{c}
$$

onde $\omega_{d}$ é a frequência de oscilação amortecida e $\zeta$ é a razão de amortecimento. Então, para uma dada frequência reduzida $k$, é possível extrair os autovalores, a razão de amortecimento $\zeta$ e a velocidadede escoamento correspondente $u_{\infty}$. A frequência reduzida é especificada na simulação aerodinâmica com oscilação forçada por $k=\frac{\omega_{d}}{u_{\infty}}$, onde $c$ é o comprimento característico (corda da seção no caso bidimensional). Assim, para cada simulação aerodinâmica, é possível obter uma solução das equações de flutter.

Para o cálculo dos autovalores $\lambda$ foram simulados os casos de elevação e arfagem, independentemente, com os parâmetros e características mostradas na tabela 6.2. A força total sobre o aerofólio é uma combinação de pressão e forças viscosas. A força de pressão em cada ponto no aerofólio é encontrada a partir do $C_{p}$ e as forças viscosas são dadas pela derivada da velocidade tangencial com relação à normal, $\frac{\partial u}{\partial n}$. Uma vez que a pressão e forças viscosas são conhecidas em cada ponto, elas são integradas numericamente para encontrar os componentes da força total e do momento, $M$, do aerofólio. 


\subsubsection{Resultados para flutter}

A determinação do flutter depende de elementos da estrutura do sistema, tais como a massa, momento de inércia, dentre outros. Tomando como referência a figura 6.15 e a partir dos dados apresentados por Kurtulus, David, Farcy e Alemdaroglu (2008), não por se tratar de análise semelhante, mas por proximidade entre os moldelos tratados, usaremos os valores apresentados da tabela 6.2. Por se tratar de uma demonstração, muitas configurações de parâmetros poderiam ser adotadas. Alguns parâmetros foram escolhidos, como as constantes de mola, de forma que a frequência natural para elevação seja $2 \mathrm{~Hz}$ e para arfagem seja $0,5 \mathrm{~Hz}$ tal que $f_{h}$ e $f_{\alpha}$ produzam oscilações com as velocidades reduzidas de interesse. Ao invés de

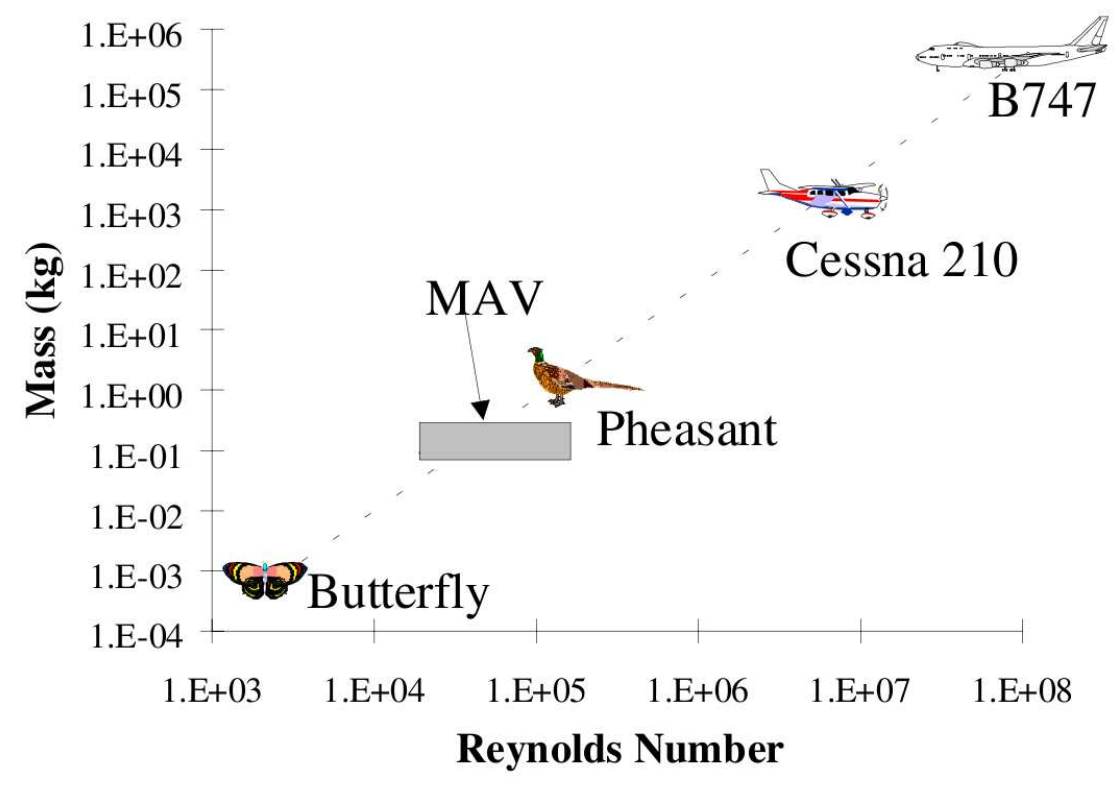

Figura 6.15: Relação entre os tipos de aeronaves (MUELLER, 1999).

usar as quantidades dimensionais na equação 6.34, foi considerado mais conveniente tratar o problema na forma adimensional. Além dos parâmetros já adimensionalizados (por exemplo $K)$, tomou-se a corda $c$ como padrão de escala, $u_{\infty}$ como velocidade característica e $\frac{\rho u_{\infty}^{2}}{2}$ como pressão característica. O tempo característico é dado por $\frac{t u_{\infty}}{c}$, a velocidade característica $V^{*}=\frac{u_{\infty}}{c \pi f}$ e a normalização das equações fornece a massa adimensional e o momento de inércia $(\bar{M}$ e $\bar{I})$ e frequências reduzidas $\left(\bar{f}_{h}\right.$ e $\left.\bar{f}_{\alpha}\right)$. Na prática, os valores de $f_{h}$ e $f_{\alpha}$ são escolhidos tais que o aerofólio sofra oscilações com as velocidades reduzidas de interesse e $M$ e $I$ são 
sintonizados para que as cargas sejam maiores (quando forem reduzidas) ou menores (quando forem aumentadas) sobre o aerofólio.

Tabela 6.2: Propriedades do aerofólio usadas nas simulações

\begin{tabular}{l|l}
\hline \hline \multirow{5}{*}{ Geometria } & $\begin{array}{l}\text { Perfil de aerofólio NACA0012 (simétrico), Corda } c=0,06 m, c^{*}=1, \\
\text { Posição do pivô, } x_{O}=0,5 c=0,03 m, \\
\text { Centro aerodinâmico em } 1 / 4 \text { da corda, distância do eixo elástico ao centro } \\
\text { aerodinâmico } a_{h} b=\frac{a_{h} b}{c}=0,25 \\
\text { Distância do centro de massa }=0,4429 c=0,02657 m \\
\text { Distância do eixo elástico ao centro de massa } x_{c m}=0,00343 m\end{array}$ \\
\hline \multirow{2}{*}{ escoamento } & $\begin{array}{l}\text { Velocidade de escoamento livre, } u_{\infty}=0,017 \mathrm{~m} / \mathrm{s} \\
\text { Número de Reynolds, } R e=1000\end{array}$ \\
\hline \multirow{2}{*}{ elevação } & $\begin{array}{l}\text { Angulo de ataque médio } \alpha_{0}=0^{\circ} \\
\text { Amplitude do ângulo de ataque, } \alpha_{A}=4^{\circ}\end{array}$ \\
\hline \multirow{2}{*}{ Inércia } & $\begin{array}{l}h_{0}=0 \\
\text { Amplitude de elevação, } h=0,1 c\end{array}$ \\
& $\begin{array}{l}\text { Massa, } m=0,01567 \mathrm{~kg} \\
\text { Rigidez da mola de torção } k_{\alpha}=0,1547 \mathrm{kgm} / \mathrm{s}^{2} \\
\text { Momento de inércia com relação ao eixo de rotação, } \sqrt{\frac{I_{\alpha}}{m c^{2}}}=0,2102, \\
I_{\alpha}=2,493 \times 10^{-6} \mathrm{kgm}^{2} \\
\text { Momento de inércia com relação ao centro de massa, } I_{c m}=I_{\alpha}-m x_{c m}^{2} \\
I_{c m}=2,306 \times 10^{-6}, \text { se } m \text { uniformente distribuída, } I=\frac{m c^{2}}{12}, \text { então, } \\
I=4,701 \times 10^{-6} \mathrm{kgm}^{2}, \text { como } I_{c m}<I, \text { então a massa do aerofólio está } \\
\text { concentrada em torno da parte central do aerofólio. }\end{array}$ \\
\hline \hline
\end{tabular}

Para a determinação dos parâmetros de flutter foram realizadas simulações para extrair os valores das forças aerodinâmicas. As figuras 6.16(a), 6.16(c), 6.16(e) e 6.16(g) mostram os valores de $C_{L}$ para arfagem e o desenvolvimento da senoide ao longo do tempo para a rotação $\alpha$. As figuras 6.16(b) , 6.16(d), 6.16(f) e 6.16(h) mostram os valores de $C_{L}$ para elevação e o desenvolvimento da senoide ao longo do tempo para o deslocamento $h$. A tabela 6.3 mostra os valores máximos obtidos para a sustentação e momento de arfagem e para sustentação e momento de elevação. Para as frequências de $0,5 \mathrm{~Hz}, 0,75 \mathrm{~Hz}, 1 \mathrm{hz}$ e $2 \mathrm{~Hz}$ mediu-se as frequências reduzidas que serão utilizadas no cálculo dos autovalores. Os resultados para os autovalores $\lambda$ estão mostrados na tabela 6.4. Os valores obtidos para os autovalores $\lambda$ mostram 


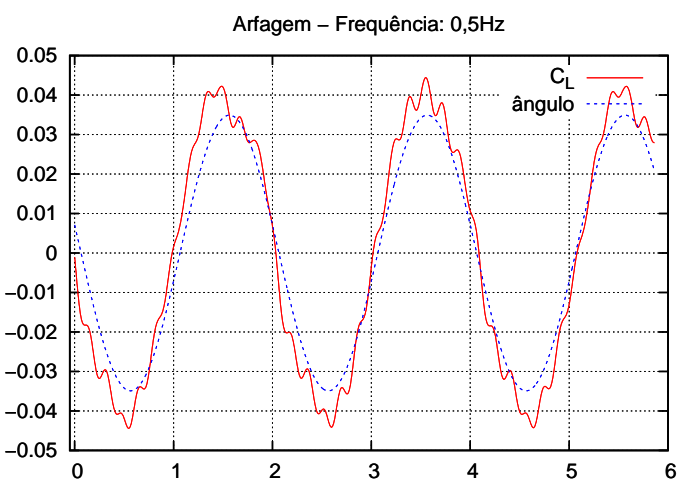

a)

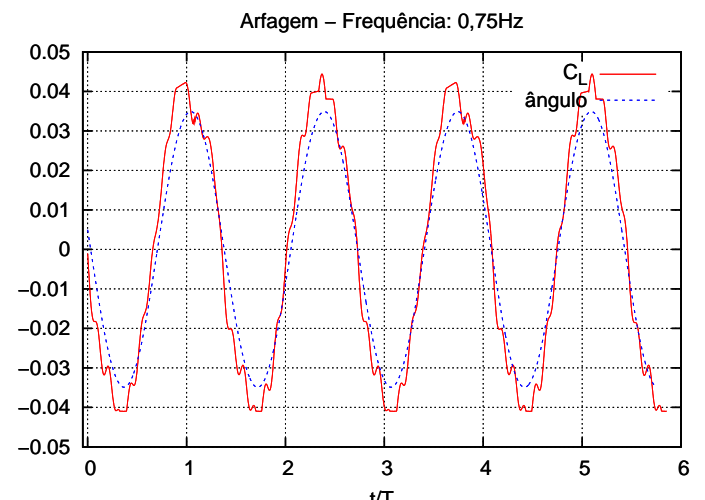

c)

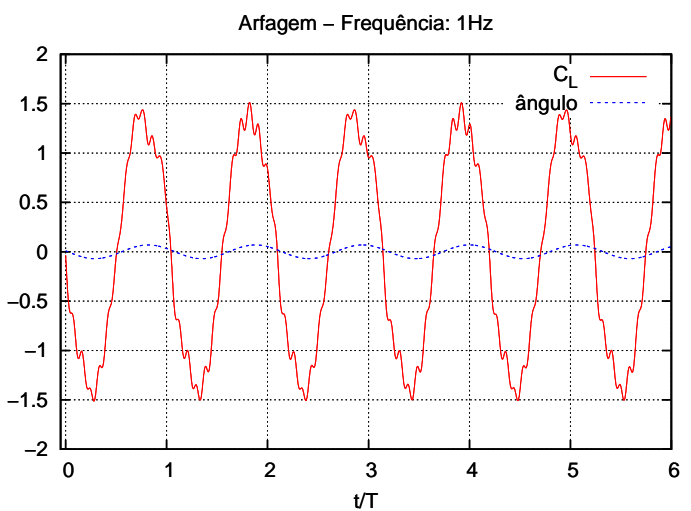

e)

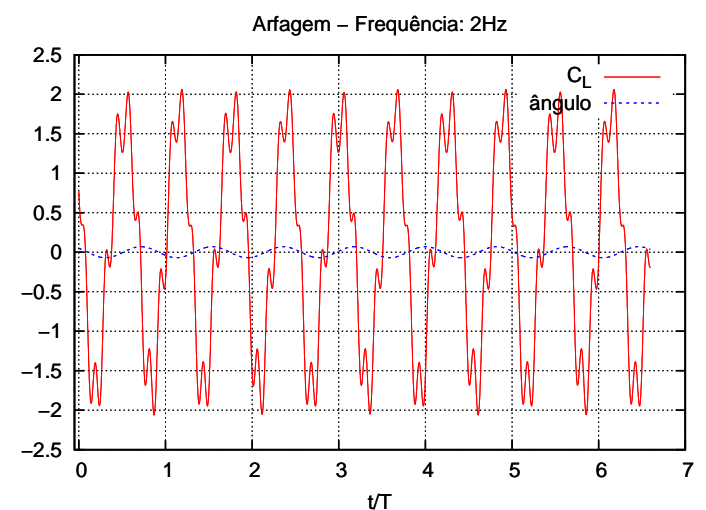

g)

h)

b)

d)
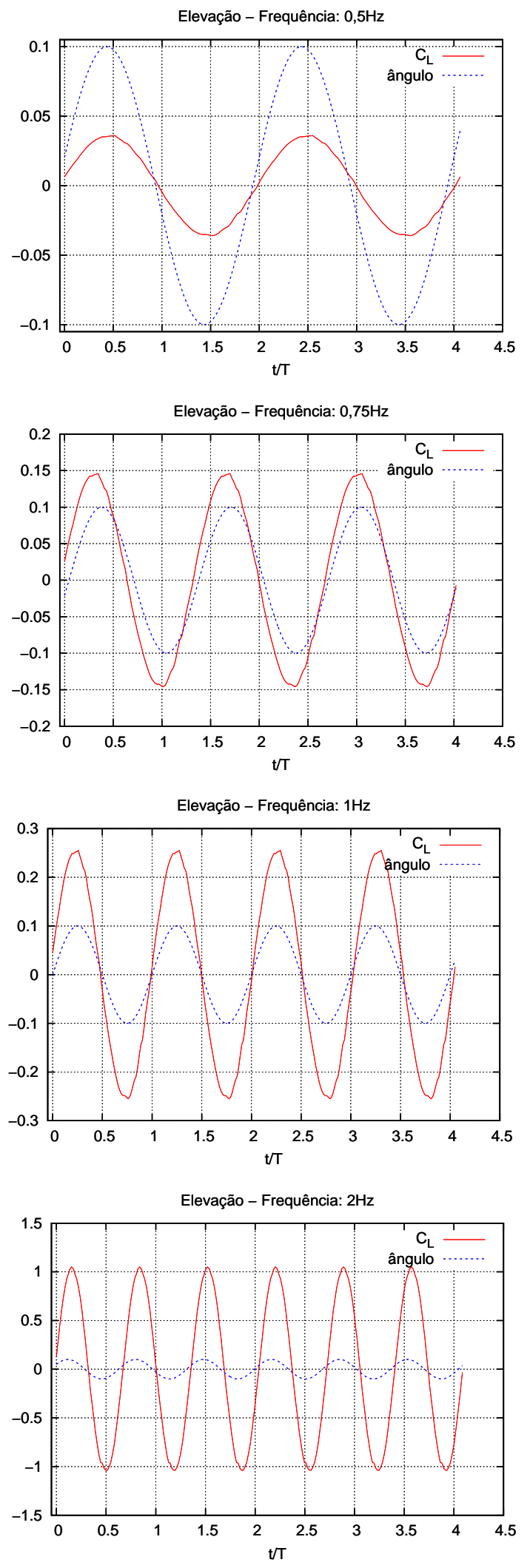

Figura 6.16: Resultados para determinação da frequência reduzida para arfagem de $\pm 2^{\circ}$, elevação de $0,1 c$ e frequências de $0,5 \mathrm{~Hz}, 0,75 \mathrm{~Hz}, 1 \mathrm{~Hz}$ e $2 \mathrm{~Hz}$. 
Tabela 6.3: Resultados das simulações - sustentação, momento e defasagem

\begin{tabular}{c|c|c|c|c|c|c|c|c|c|}
\hline \hline \multicolumn{2}{c|}{ Frequência } & \multicolumn{4}{c|}{ Sustentação e Momento } & \multicolumn{4}{c}{ Defasagem } \\
\hline $\mathrm{Hz}$ & Reduzida & $L_{\alpha}$ & $M_{\alpha}$ & $L_{h}$ & $M_{h}$ & $L_{\alpha}$ & $L_{h}$ & $M_{\alpha}$ & $M_{h}$ \\
\hline 0,5 & 2,356 & 0,0476 & 0,00510 & 0,0306 & 0,0312 & $3,9^{\circ}$ & $9,9^{\circ}$ & $8,3^{\circ}$ & $5,2^{\circ}$ \\
0,75 & 3,534 & 0,3687 & 0,0466 & 0,145 & 0,182 & $12,1^{o}$ & $35,7^{\circ}$ & $17,1^{o}$ & $7,5^{o}$ \\
1,0 & 4,712 & 1,1056 & 0,0262 & 0,6159 & 0,562 & $34,1^{o}$ & $56,6^{\circ}$ & $38,2^{\circ}$ & $18,6^{\circ}$ \\
2,0 & 9,425 & 3,0172 & 0,7576 & 1,96 & 1,69 & $73,8^{\circ}$ & $74,1^{o}$ & $62,3^{\circ}$ & $37,7^{\circ}$ \\
\hline \hline
\end{tabular}

Tabela 6.4: Resultados das simulações - autovalores

\begin{tabular}{c|c|c|c|c}
\hline \hline Frequência & $0,5 \mathrm{~Hz}$ & $0,75 \mathrm{~Hz}$ & $1 \mathrm{~Hz}$ & $2 \mathrm{~Hz}$ \\
\hline parte real $\lambda_{r}$ & 0 & 0 & 0 & 0 \\
\hline parte imaginária $\lambda_{i}$ & $\pm 0,518$ & $\pm 0,425$ & $\pm 0,342$ & $\pm 0,248$ \\
\hline \hline
\end{tabular}

que a velocidade do escoamento é subcrítica, ou seja, os autovalores possuem apenas parte imaginária. Também pode-se observar que há uma tendência à diminuição da magnitude dos autovalores, ou seja, para frequências mais altas poder-se-á atingir a velocidade crítica de flutter. 


\section{Conclusão}

Este trabalho compreende quatro partes, não na sequência mas na forma de tratamento:

- a motivação científica, construção de uma revisão bibliográfica relativa ao tema das fronteiras imersas, passando pela modelagem e estratégias de solução das equações governantes, e um modelo de verificação;

- o estudo das condições necessárias às simulações de escoamento a baixos números de Reynolds; à interação fluido-estrutura; à construção de um código computacional para o método da fronteira virtual; e à validação através da escolha de casos disponíveis na literatura;

- a modelagem e implementação de um problema de instabilidade - flutter - através de oscilação forçada; e

- as simulações propriamente ditas, suas especificidades e análise dos resultados pela comparação com os obtidos por outros autores através de experimentos e simuladores.

Neste trabalho foi estudado e implementado um método de fronteira imersa (método da fronteira virtual) para condições de contorno de não escorregamento utilizando discretização espacial por diferenças finitas e discretização no tempo pelo método de Runge-Kuta de ordem 4. O objetivo buscado foi o de conseguir uma ferramenta computacional eficiente para simulação de problemas aerolásticos. Inicialmente as simulações foram realizadas com malha regular para corpos imersos rombudos (cilindros). Devido à forma delgada do aerofólio, a malha regular foi substituída por uma malha não regular para melhor refinamento na região da fronteira imersa, o que permitiu obter ganho computacional e melhor precisão dos resultados. Foi feita uma revisão do modelo de fronteira virtual e as principais estratégias para solução das equações de NavierStokes. As derivadas espaciais foram calculadas pelo método de diferenças finitas (método 
MAC) e o sitema linear resolvido, para malha regular, pelo método do gradiente conjugado e, para malha não regular, pelo método do gradiente biconjugado. Os cálculos temporais foram realizados com um método de Runge-Kutta de ordem 4.

A partir do desenvolvimento do código foi realizada a verificação. A verificação do código computacional e do modelo de fronteira imersa foi realizada através do método da solução manufaturada. O método da solução manufaturada foi aplicada à malha euleriana e a um caso particular do método da fronteira virtual. A escolha particular do modelo do corpo imerso de forma quadrada deveu-se à facilidade de implementação, mas pode ser estendido à geometrias mais complexas sem prejuízo das confiabilidade do modelo. As condições de contorno foram mantidas e não houve simplificação das equações envolvidas. A ordem do erro mostrou decréscimo da malha mais grossa para a malha fina e, para norma infinita, ficou em torno de $10^{-6}$ na malha mais fina. Os resultados não atingiram a faixa assintótica teórica esperada da ordem formal de discretização. O esquema VONOS pode chegar a ordem 2 e o obtido na verificação ficou abaixo, mas bem próximo de 2 . O teste do caso particular indicou que se a solução manufaturada convergiu para a mesma solução incorporando o modelo de interesse, a ordem do erro se mantéve a mesma.

A validação do método foi feita por meio de comparações qualitativas e quantitativas de resultados experimentais e computacionais disponíveis na literatura. O método conseguiu capturar e representar grande parte dos comportamentos da estrutura aeronáutica submetida ao escoamento, principalmente perfil de velocidades do escoamento, efeitos devido à oscilação da estrutura imersa, distribuição de pressões sobre a superfície da seção do corpo imerso e coeficientes aerodinâmicos devido à sustentação e arrasto. Os resultados obtidos são bastante promissores, pois os valores conseguidos nas simulações têm dispersão abaixo de $20 \%$ em relação aos valores apresentados pela literatura disponível e que, na maioria dos casos, são experimentais ou ainda tratam do problema como tridimensional. As aproximações conseguidas demonstram que a metodologia pode ser aplicada na previsão do comportamento de modelos, com restriçãoes, de estruturas aeronáuticas. 
O método da fronteira virtual foi usado para determinar o comportamento e estabilidade de uma seção de asa fixa de um MAV através da técnica de imposição de movimento forçado senoidal para induzir perturbação em condições de voo e captura da reação correspondente do perfil do aerofólio. Explorar testes de oscilações forçadas são uma forma alternativa de determinação de parâmetros de estabilidade de um MAV, experimentalmente. O desenvolvimento teórico da técnica de oscilações forçadas utiliza uma perturbação senoidal simples para condições de voo do veículo. A resposta correspondente a esta perturbação também é assumida como sendo senoidal na natureza. Devido a essas hipóteses, as características de estabilidade do perfil de asa do veículo podem ser determinadas a partir de uma aproximação da resposta de força aerodinâmica.

Um resultado significante é a importância da resolução apropriada de malha. As simulações mostraram que, apesar da malha ser fina o suficiente para simulação de escoamento sobre corpos rombudos (cilindros) não o foram para capturar plenamente os efeitos do escoamento no bordo de fuga de um aerofólio com ângulos de ataque elevados, devido à superposição da função $\delta$ de suavização. Da mesma forma, a malha se mostrou-se adequada para ângulos de ataque fixos até $10^{\circ}$, mas não refinada o suficiente para cálculos de perda dinâmica, pois a dinâmica de separação e desprendimento de vórtices demanda mais pontos de malha para capturar os efeitos de camada limite, tal como a bolha de separaçã. A escolha do perfil de aerofólio NACA0012 deveu-se à sua simetria e resultados disponíveis para comparação de valores para arrasto e sustentação, casos do aerofólio com ângulos de ataque fixo $\left(\alpha\right.$ de $\left.0^{\circ} a 34^{\circ}\right)$ e sujeito a oscilação forçada ( $\pm \alpha$ de $2^{\circ}$ a $20^{\circ}$ com frequência variando de 1 a $20 \mathrm{~Hz}$ ). Para a faixa de número de Reynolds ultrabaixo, foi possível comparar resultados experimentais do comportamento de esteira de vórtices para variações do ângulo de ataque e para oscilação forçada. A capacidade de obtenção de informações detalhadas sobre o campo do escoamento instável global produziu resultados úteis que podem ser usadas para aplicações preliminares em modelos de MAV. Finalmente, o fenômeno de flutter bidimensional foi simulado a fim de testar a aplicação de imposição de condições arbitrárias na simulação. 
Um caso teste foi investigado. O perfil de aerofólio NACA 0012 foi submetido a oscilação forçada em um escoamento de fluido incompressível de número de Reynolds ultrabaixo. A análise foi realizada para perfil estacionário submetido a alguns ângulos de ataque e depois para o perfil sob oscilação forçada com pequeno ângulo de ataque $\left(2^{\circ}\right)$ considerando-se separadamente arfagem e elevação. O modelo para a determinação dos parâmetros de flutter foi o de autovalores e as frequências da resposta aeroelástica corresponderam bem para baixas frequências de baixas oscilações, quando comparado com os resultados experimentais, como por exemplo os obtidos por Webb (2009). O movimento de arfagem produziu maior instabilidade que o de elevação e isto pode ser observado pelos valores obtidos para os momentos aerodinâmicos.

Os resultados adquiridos no desenvolvimento deste trabalho consolidaram a consecução de um código computacional com o cruzamento das dimensões teórica e computacional para aplicação em um problema de aeroelasticidade. A partir destes conhecimentos podemos propor novos desafios para aplicações relevantes em trabalhos futuros:

1. Avaliação da potencialidade da técnica para outros tipos de problemas aerolásticos como, por exemplo, casos de oscilação livre.

2. Aplicação da metodologia para dados obtidos em experimentos em túnel de vento.

3. Inclusão de fenômenos mais complexos e dinâmicos em uma formulação de fronteira virtual que produza respostas comparáveis á formulação original, ou seja, definição de outras formulações que represente melhor a física real.

4. Modelagem de transição usando fronteita virtual para solução das equações de camada limite e integral definindo os parâmetros da camada limite laminar e aplicando recursos computacionais para redução do tempo de simulação (método multigrid algébrico e paralelização mais eficiente).

5. Estender o modelo de fronteira virtual para análise de modelos aeroelásticos tridimensionais, com inclusão de geração de malha mais eficiente.

6. Desenvolvimento de modelo de dinâmica estrutural para fronteira virtual com mais graus de liberdade. 


\section{Referências Bibliográficas}

ALAM, M. M.; ZHOU, Y.; YANG, H. X.; GUO, H.; MI, J. The ultra-low reynolds number airfoil wake. Exp Fluids, v. 48, p. 81-103, 2010.

ALMGREN, A. S.; BELL, J. B.; SZYMCZAK, W. G. A numerical method for the incompressible navier-stokes equations based on an approximate projection. SIAM Journal on Scientific Computing, v. 17, n. 2, p. 358-369, 1996.

ANDERSON, J. D. Computational Fluid Dynamics: the Basics with Applications. [S.1.]: McGraw-Hill, 1995.

ANDERSON, J. J. D. Fundamentals aerodynamics. [S.1.]: McGraw-Hill, 1985.

ANDERSON, J. M.; STREITLIEN, K.; BARRET, D. S.; TRIANTAFYLLOU, M. S. Oscillating foils of high propulsive efficiency. Journal of Fluid Mechanics, v. 360, p. 41-72, 1998.

ARTHURS, K. M.; MOORE, L. C.; PESKIN, C. S.; PITMAN, E. B.; LAYTON, H. E. Modeling arteriolar flow and mass transpot using the immersed boundary method. Journal of Computational Physics, v. 147, p. 402-440, 1998.

BAEK, S.-J.; SUNG, H. J. Numerical simulation of the flow behind a rotary oscillating circular cilinder. Physics of Fluids, v. 10, n. 4, p. 869-876, 1998.

BARNES, F. H. Vortex shedding in the wake of a rotating circular cylinder at low Reynolds numbers. Journal of Applied Physics, v. 33, p. L141-L144, 2000.

BELL, J.; COLLELA, P.; GLAZ, H. M. A second-order projection method for the incompressible navier-stokes equations. Journal of Computational Physics, v. 85, p. 257-283, 1989.

BENEVENUTTI, L. B.; SILVESTRINI, J. H. Estudo numÃ@)rico do escoamento atrav'es de um cilindro oscilante utilizando o método de fronteiras imersas. In: MecÃ ;nica Computacional Vol XXV, pp. 207-216, Santa Fe, Argentina. [S.1.: s.n.], 2006.

BEYER JÚNIOR, R. P. A computational model of the cochlea using the immersed boundary method. Journal of Computational Physics, v. 98, p. 145-162, 1992.

BEYER JÚNIOR, R. P.; LEVEQUE, R. J. Analysis of a one-dimensional model for the immersed boundary method. Journal of Numerical Analysis, v. 29, p. 332-364, 1992.

BIRCH, J. M.; DICKSON, W. B.; DICKINSON, M. H. Force production and flow structure of the leading edge vortex on flapping qings at high and low reynolds numbers. The Journal of Experimental Biology, v. 207, p. 1063-1072, 2004. 
BISPLINGHOFF, R. L.; ASHLEY, H.; HALFMAN, R. L. Aeroelasticity. New York/London: Addison Wesley Publishing Company, Inc, 1955.

BOND, R. B.; KNUPP, P. M.; OBER, C. C. A manufactured solution for verifying cfd boundary conditions. In: 43rd AIAA Aerospace Sciences Meeting and Exhibit. [S.1.: s.n.], 2005.

BORIA, F.; STANFORD, B.; BOWMAN, W.; IFJU, P. Evolutionary optimization of a morphing wing with wind tunnel hardware-in-the-loop. In: 47th AIAA Aerospace Science Meeting, Orlando, Florida. [S.1.: s.n.], 2009.

BOTTINO, D. C. Modeling viscoelastic networks and cell deformation in the context of the immersed boundary method. Journal of Computational Physics, v. 147, p. 86-113, 1998.

BUARQUE, D. C.; SCHETTINI, E. B. C.; SILVESTRINI, J. H. Two-dimensional numerical simulation of flows over a virtual wavy surface. In: 18th International Congress of Mechanical Engineering, Ouro Preto, MG. [S.1.: s.n.], 2005.

BUENO, A. P. F.; DORICIO, J. L.; MARQUES, A. C. H.; de Paula, I. B.; CATALANO, F. M.; Greco Júnior, P. C. Pressure measurements in oscillatory NACA12 airfoil: experimental and computational results. In: Proceedings of the $19^{\text {th }}$ International Congress of Mechanical Engineering. [S.1.: s.n.], 2007.

CHENG, M.; TSUEI, H. E.; CHOW, K. L. Experimental study on flow interference phenomena of cylinder/cylinder and cylinder/plane arrangements. ASME, Flow-Induced Vibration, p. 173-184, 1994.

CHORIN, A. Numerical solution of the navier-stokes equations. Mathematics of Computation, v. 22, p. 745-762, 1968.

CLIFT, R.; GRACE, J.; WEBER, M. Bubbles, Drops and Particles. [S.1.]: Academic Press, 1978.

DAVIS, R. W.; MOORE, E. F. A numerical study of vortex shedding from retangles. Journal of Fluid Mechanics, v. 116, p. 475-506, 1982.

DENNIS, S. R.; CHANG, G. Numerical solutions for steady flow past a xcircular cylinder at reynolds numbers up to 100. Journal of Fluid Mechanics, v. 42, p. 471-489, 1970.

DICKINSON, M. H. The effects of wing rotation on unsteady aerodynamic performance at low reynolds numbers. The Journal of Experimental Biology, v. 192, p. 179-206, 1994.

DIETZ, G.; SCHEWE, G.; MAI, H. Experiments on heave and pitch limit cycle oscillations of a supercritical airfoil close to the transonic dip. Journal of Fluids and Structures, v. 19, p. $1-16,2004$.

DILLON, R.; FAUCI, L. J.; GAVER, D. A microscale model of bacterial swimming, chemotaxis and substrate transport. J. Theor. Biol., v. 177, p. 325-340, 1995.

DORICIO, J. L. Estudo da aplicabilidade do método de fronteira imersa no cálculo das derivadas aerodinâmicas nÃ£o estacionárias para análise de Flutter com as equações de Euler para fluxo compressível. Tese (Doutorado) — EESC - Universidade de São Paulo, 2009. 
DORICIO, J. L.; MARQUES, A. C. H.; Greco Júnior. Simulação de escoamento incompressível ao redor de um cilindro oscilante: comparação entre os métodos da fronteira virtual e da fronteira imersa. In: Proceedings of the $28^{\text {th }}$ Latin American Congress on Computational Methods in Engineering. [S.1.: s.n.], 2007.

DOWELL, E. H.; JR., H. C. C.; SCANLAN, R. H.; SISTO, F. A Modern Course in Aeroelasticity. Dordrecht/Boston/London: Kluwer Academic Publishers, 1989. ISBN 0-7923-0062-9.

DRELA, M. XFOIL Subsonic Airfoil Development System. 2008. Online; accessed outubro-2009. Disponível em: <http://web.mit.edu/drela/Public/web/xfoil/>.

ELLINGTON, C. P. The aerodynamics of hovering insect flight. Philosophical Transactions of the Royal Society of London, v. 305, n. I, II, III, IV, V e VI, p. 1-181, 1984.

FADLUN, E. A.; VERZICCO, R.; ORLANDI, P.; MOHD-YUSOF, J. Combined immersedboundary finite-difference methods for three-dimensional complex flow simulations. Journal of Computational Physics, v. 161, p. 35-60, 2000.

FAUCI, L.; PESKIN, C. S. Computational model of aquatic animal locomotion. J. Comput. Phys., v. 77, p. 85-108, 1988.

FERZIGER, J. H. Simulation of turbulence: Techniques and possibilities. In: Anais da II Escola Brasileira de Primavera Transição e Turbulência, ETT 2000. [S.1.: s.n.], 2000.

FISCHBORN, M.; KUO-PENG, P.; SADOWSKY, N.; BASTOS, J. P. A.; TREVISAN, J.; GAVIOLI, G. A. Comparação de desempenho do bicg e bicgstab em clusters de computadores. In: MOMAG - Belo Horizonte. [S.1.: s.n.], 2006.

FOGELSON, A. L.; PESKIN, C. S. A fast numerical method for solving the three-dimensional stokes' equations in the presence of suspended particles. J. Comput. Phys., v. 79, p. 50-69, 1988.

FORNBERG, B. A numerical study of steady viscous flow past a circular cylinder. Journal of Fluid Mechanics, v. 98, p. 819-855, 1980.

FORTUNA, A. O. Técnicas Computacionais para Dinâmica dos Fluidos: Conceitos Básicos e Aplicações. [S.1.]: Editora da Universidade de São Paulo, 2000.

GILMANOV, A.; SOTIROPOULOS, F.; BALARAS, E. A general reconstruction algorithm for simulating flows with complex $3 \mathrm{~d}$ immersed boundaries on cartesian grids. Journal of Computational Physics, v. 191, n. 2, p. 660-669, 2003.

GOLDSTEIN, D.; HANDLER, R.; SIROVICH, L. Modeling a no-slip flow boundary with an external force field. Journal of Computational Physics, v. 105, p. 354-366, 1993.

Greco Júnior, P. C. Transonic Flutter and Limit Cycle Oscillations. Tese (Doutorado) Universidade de São Paulo/University of Kansas, 1996.

GRIFFITH, B. E.; PESKIN, C. S. On the order of accuracy of the immersed boundary method: High order convergence rates for sufficiently smooth problems. Journal of Computational Physics, v. 208, p. 75-105, 2005. 
GRIGORIADIS, D. G. E.; BARTZIS, J. G.; GOULAS, A. Efficient treatment of complex geometries for large eddy simulations of turbulent flows. Computers E Fluids, v. 33, p. 201-222, 2004.

GUERMOND, J.-L.; QUARTAPELLE, L. Calculation of incompressible viscous flows by an unconditionally stable projection fem. Journal of Computational Physics, v. 132, p. 12-33, 1997.

HANCOCK, G. H.; WRIGHT, J. R.; SIMPSON, A. On the teaching of the principles of wing flexure-torsion flutter. Aeronautical Journal, v. 88, n. 888, p. 285-305, 1985.

HARLOW, F.; WELCH, J. E. Numerical calculation of time-dependent viscous incompressible flow of fluid with a free surface. Phys. Fluids, v. 8, p. 2182-2189, 1965.

HEUN, K. Neue methode zur approximativen integration der differentialgleichungen einer unabhängingen veränderlichen. Z. Math. Phys., v. 45, p. 23-38, 1900.

H.M.BLACKBURN; HENDERSON, R. A study of two-dimensional flow past an oscillating cylinder. Journal of Fluid Mechanics, v. 385, p. 255-286, 1999.

HUABG, R. F.; WU, J. Y.; JENG, J. H.; CHEN, R. C. Surface flow and vortex shedding of an impulsively started wing. Journal of Fluid Mechanics, v. 441, p. 265-292, 2001.

JACOBS, E. N.; WARD, K. E.; PINKERTON, R. N. The characteristics of 78 related airfoil sections from tests in the variable-density wind tunnel. [S.1.], 1933. v. 460.

JOHNSON, A. A.; TEZDUYA, T. E. Mesh update strategies parallel finite element computations and interfaces of flow problems with moving boundaries. Computer Methods in Applied Mechanics and Engineering., v. 119, p. 73-94, 1994.

JUNG, E.; PESKIN, C. S. Two-dimensional simulations of valveless pumping using the immersed boundary method. SIAM J. Sci. Comput., v. 23, n. 1, p. 19-45, 2001.

KANG, C.; AONO, H.; TRIZILA, P.; BAIK, Y.; RAUSCH, J. M.; BERNAL, L.; OL, M. V.; SHYY, W. Modeling of pitching and pluging airfoils at reynolds number between 10000 and 60000. In: Proceedings of the 27th AIAA Applied Aerodynamics Conference - AIAA 2009-4100. [S.1.: s.n.], 2009.

KANG, S. Characteristics of flow over two circular cylinders in a side-by-side arrangement at low reynolds numbers. Physics of Fluids, v. 15, n. 9, 2003.

KIM, J.; KIM, D.; CHOI, H. An immersed-boundary finite-volume method for simulations of fow in complex geometries. Journal of Computational Physics, v. 171, p. 132-143, 2001.

KIT, E.; NIKITIN, N. V.; SHMIDT, V. M.; YAKHOT, A. Application of a virtual-boundary method for the numerical study of oscillations developing behind a cylinder near a plane wall. Fluid Dynamics, v. 39, n. 1, p. 61-68, 2004.

KURTULUS, D. F.; DAVID, L.; FARCY, A.; ALEMDAROGLU, N. Aerodynamic characteristics of flapping motion in hover. Experiments in Fluids, v. 44, p. 23-36, 2008.

KUTTA, W. Beitrag zur näherungsweisen integration totaler differentialgleichungen. Z. Math. Phys., v. 46, p. 435-453, 1901. 
LAI, M.-C.; PESKIN, C. S. An immersed boundary method with formal second-order accuracy and reduced numerical viscosity. Journal of Computational Physics, v. 160, p. 705-719, 2000.

LEE, C. Stability characteristics of the virtual boundary method in three-dimensional applications. Journal of Computational Physics, v. 184, p. 559-591, 2003.

LEE, L.; LEVEQUE, R. J. An immersed interface method for incompressible navier-stokes equations. SIAM J. Sci. Comput., v. 25, n. 3, p. 832-856, 2003.

LELE, S. K. Compact finite difference schemes with spectral-like resolution. Journal of Computational Physics, v. 103, p. 16-42, 1992.

LEVEQUE, R. J.; LI, Z. Immersed interface methods for stokes flow with elastic boundaries or surface tension. SIAM J. Sci. Comput., v. 18, n. 3, p. 709-735, 1997.

LI, Z.; LAI, M.-C. The immersed interface method for the navier-stokes equations with singular forces. Journal of Computational Physics, v. 171, p. 822-842, 2001.

LIAN, Y.; SHYY, W. Aerodynamics of low reynolds number plunging airfoil under gusty environment. In: Proceedings of the 45th AIAA Aerospace Sciences Meeting and Exhibit AIAA 2007-71. [S.1.: s.n.], 2007.

LINDQUIST, C.; ALMEIDA, O.; MANSUR, S. S.; NETO, A. S. Estudo numérico e experimental do escoamento ao redor de cilindros de base retangular: influência da razão de forma. In: Anais do VIII Congresso Brasileiro de Engenharia e Ciências Térmicas ENCIT2́O00, Associação Brasileira de Ciências Mecânicas - ABCM , CD-ROM, paper code: s16p20, pp.1-10, Porto Alegre. [S.1.: s.n.], 2000.

LINNICK, M. M. Investigation of Actuators for use in Active Flow Control. Dissertação (Mestrado), 1999.

LINNICK, M. N.; FASEL, H. F. A high-order immersed boundary method for unsteady incompressible flow calculations. AIAA 2003-1124, 2003.

LIU, H.; KAWACHI, K. A numerical study of insect flight. Journal of Computational Physics, v. 146, p. 124-156, 1998.

LIU, H.; KAWACHI, K.; ELlingTON, C. P.; BERG, C. V. den; WILlMOTT, A. A computational fluid dynamic study of hawkmoth hovering. The Journal of Experimental Biology, v. 201, p. 461-477, 1998.

LOBITZ, D. W. Parameter sensitivities affecting the flutter speed of a mw-sized blade. Journal of Solar Energy Engineering, v. 127, n. 4, p. 538-549, 2005.

LU, X.-Y.; DALTON, C. Calculation of the timing of vortex formation from an oscillating cylinder. Journal of Fluids and Structures, v. 10, p. 527-541, 1996.

MAÎTRE, O. P.; SCANLAN, R. H.; KNIO, O. M. Estimation of the flutter derivatives of an naca airfoil by means navier-stokes simaulation. Journal of Fluids and Structures, v. 17, p. $1-28,2003$.

MANTEUFFEL, T. A.; WHITE, A. B. The numerical solution of second-order boundary value problems on nonuniform meshes. Mathematics of Computational, v. 47, p. 511-535, 1986. 
MARGNAT, F.; MORINIÈRE, V. Behaviour of an immersed boundary method in unsteady flowsover sharp-edged bodies. Computers $\mathcal{E}$ Fluids, v. 38, p. 1065-1079, 2009.

MARQUES, A. C. H.; DORICIO, J. L.; BUENO, A. P. F.; Greco Júnior, P. C.; SOUZA, L. F. de. Numerical simulation of two-dimensional flows over a circular cylinder: Immersed boundary and virtual boundary methods. In: Proceedings of the $27^{\text {th }}$ Latin American Congress on Computational Methods in Engineering. [S.1.: s.n.], 2006.

MARQUES, A. C. H.; DORICIO, J. L.; Greco Júnior, P. C. Método da fronteira virtual: simulação de escoamento incompressível sobre aerofólio naca0012 com malha não uniforme. In: Proceedings of the $29^{\text {th }}$ Iberian Latin American Congress on Computational Methods in Engineering. [S.1.: s.n.], 2008.

MAYBURY, W. J.; LEHMAN, F. O. The fluid dynamics of flight control by kinematic phase lag variation between two robotic insect wings. The Journal of Experimental Biology, v. 207, p. 4707-4726, 2004.

MCQUEEN, D. M.; PESKIN, C. S.; YELLIN, E. L. Fluid dynamics of the mitral valve: Physiological aspects of a mathematical model. Amer. J. Physiol., v. 242, p. H1095-H1110, 1982.

MEISNER, J. S.; MCQUEEN, D. M.; ISHIDA, Y.; VETTER, H. O.; BORTOLOTTI, U.; STROM, J. A.; FRATER, R. W. M.; PESKIN, C. S.; YELLIN, E. L. Effects of timing of atrial systole on lv filling and mitral valve closure: Computer and dog studies. Amer. J. Physiol., v. 249, p. H604-H619, 1985.

MENEGHINI, J. R.; BEARMAN, P. W. Numerical simulation of high amplitude oscilatory flow about a circular cylinder. Journal of Fluid and Structures, v. 9, p. 435-455, 1995.

MEÛLEN, R. vander. The Immersed Boundary Method for the (2D) Incompressible Navier-Stokes Equations. Dissertação (Mestrado) — Delft University of Technology, 2006.

MILLER, L. A.; PESKIN, C. S. When vortices stick: an aerodynamic transition in tiny insect flight. The Journal of Experimental Biology, v. 207, p. 3073-3088, 2004.

MITTAL, R.; BALACHANDAR, S. Effect of three-dimensionality on the lift and drag of nominally two-dimensional cylinders. Physics of Fluids, v. 7, n. 8, p. 1841-1865, 1995.

MITTAL, S.; KUMAR, B. Flow past a rotating cylinder. Journal of Fluid Mechanics, v. 476, p. 303-334, 2003.

MOHD-YUSOF, J. Development of immersed boundary methods for complex geometries. Annual Research Briefs, 1998.

MUELLER, T. J. Aerodynamic measurements at low reynolds numbers for fixed micro-air vehicles. In: RTO AVT/VKI Special Course, VKI, Belgium, September 13-17. [S.1.: s.n.], 1999.

MUKHERJEE, S.; MANJUPRASAD, M.; SHARMA, N. K.; RANA, D.; ONCAR, A. K. The domain simulation of airfoil flutter in the subsonic regime using fluid structure couplinh through panel method. [S.1.], 2008. STTD0825. 
NAKANO, T.; FUJISAWA, N.; OGUMA, Y.; TAKAGI, Y.; LEE, S. Experimental study on flow and noise characteristics of naca 0018 airfoil. Journal of Wind Engineering and Industrial Aerodynamics, v. 95, p. 511-531, 2007.

OBERKAMPF, W. L.; TRUCANO, T. G. Verification and validation in computational fluid dynamics. Progress in Aeroespace Sciences, v. 38, n. 3, p. 181-274, 2002.

OHMI, K.; COUTANCEAU, M.; DAUBE, O.; LOC, T. P. Further experiments on vortex formation around an oscillating and translating airfoil at large incidences. Journal of Fluid Mechanics, v. 255, p. 607-630, 1991.

PADRINO, J. C.; JOSEPH, D. D. Numerical study of the steady-state uniform flow past a rotating cylinder. Journal of Fluid Mechanics, v. 557, p. 191-223, 2006.

PATIL, D. J.; KHAN, I. M.; GUPTA, B. K. Numerical simulations of low reynolds number flow around micro air vehicle. In: Proceedings of the International Conference on Aerospace Science and Technology, Bangalore, India. [S.1.: s.n.], 2008.

PEIRÓ, J.; GALVANETTO, U.; CHANTHARASENAWONG, C. Assessment of added mass effects on flutter boundaries using the leishman beddoes dynamic stall model. Journal of Fluids and Structures, v. 26, p. 814-840, 2010.

PESKIN, C. S. Flow Patterns around Heart Valves: A digital computer method to solve the equations of motion. Tese (Doutorado) - Albert Eistein College of Medicine, 1972.

PESKIN, C. S. The immersed boundary method. Acta Numerica, v. 11, p. 479-517, 2002.

PESKIN, C. S.; PRINTZ, B. F. Improved volume conservation in the computation of flows with immersed elastic boundaries. Journal of Computational Physics, v. 105, p. 33-46, 1993.

PURTELL, L. P.; KLEBANOFF, P. S.; BUCKLEY, F. T. Turbulent boundary layer at low reynolds number. Phys. Fluids, v. 24, n. 5, p. 802-811, 1981.

RAYNER, J. M. V. Vortex theory of animal flight i - vortex wake of a hovering animal. Journal of Fluid Mechanics, v. 91, p. 697-730, 1979.

RIBEIRO, P. A. R. Desprendimento de Vórtices e Controle em Esteira de Cilindros por Simulação Numérica Direta. Dissertação (Mestrado) - Instituto de Pesquisas Hidráulicas Universidade Federal do Rio Grande do Sul, 2002.

ROACHE, P. J. Verification of codes and calculations. AIAA Journal, v. 36, p. 696-702, 1998.

ROCHA, J. C. Um Controlador de Flutter Baseado em Lógica Difusa. Dissertação (Mestrado) — EESC - Universidade de São Paulo, 2003.

ROJAS, E. S.; CASANOVA, J. O.; PINO, C. del; FERIA, R. F. A cartesian grid finite-difference method for $2 \mathrm{~d}$ incompressible viscous flows in irregular geometries. Journal of Computational Physics, v. 204, p. 302-318, 2005.

ROMA, A. M. A Multilevel Self Adaptive Version of the Immersed Boundary Method. Tese (Doutorado), 1996.

ROSHKO, A. On Development of Turbulent Wakes from Vortex Streets. [S.1.], 1953. v. 2913. 
ROSTAMI, M. J. V.; SAGHAFIAN1, M.; SEDAGHAT, A.; MIANSARI, M. Numerical investigation of turbulent flow over a stationary and oscillatory NACA0012 airfoil using overset grids method. 2010. Published online in Wiley InterScience (www.interscience.wiley.com). Disponível em: <http://www.citeulike.org/doi/10.1002/fld.2332>.

ROY, C. J.; NELSON, C. C.; OBER, C. C. Verification of euler/navier-stokes codes using the method of manufactured solutions. International Journal for Numerical Methods in Fluids, v. 44, p. 599-620, 2004.

RUNGE, C. über die numerische auflösung von differential-gleichungen. Math. Ann., v. 46, p. 167-178, 1895.

SAIKI, E. M.; BIRINGEN, S. Numerical simulation of a cylinder in uniform flow: Application of a virtual boundary method. Journal of Computational Physics, v. 123, p. 450-465, 1996.

SANE, S. P. The aerodynamics of insect flight. The Journal of Experimental Biology, v. 206, p. 4191-4208, 2003.

SANE, S. P. Induced airflow in flying insects. The Journal of Experimental Biology, v. 209, p. 32-42, 2006.

SANE, S. P.; DICKINSON, M. H. The control of flight force by a flapping wing: lift and drag production. The Journal of Experimental Biology, v. 204, p. 2607-2626, 2001.

SCANLAN, R. H. Motion-related body-force function in two-dimensional low speed flow. Journal of Fluids and Structures, v. 14, p. 49-63, 2000.

SCHROEDER, E. J.; BAEDER, J. D. Using computational fluid dynamics for micro-air vehicle airfoil validation and prediction. In: Proceedings of the 23rd AIAA Applied Aerodynamics Conference, Toronto-Ontario, Canada. [S.1.: s.n.], 2005.

SILVA, A. L. F. L.; SILVEIRA-NETO, A.; DAMASCENO, J. J. R. Numerical simulation of two-dimensional flow over a circular cylinder using the immersed boundary method. Journal of Computational Physics, v. 189, p. 351-370, 2003.

SILVA, H. G. da; MEDEIROS, M. A. F. de; SOUZA, L. F. de. Verification of a mixed high-order accurate dns code for laminar turbulent transition by the method of manufactured solutions. International Journal for Numerical Methods in Fluids, v. 64, n. 3, p. 336-354, 2010 .

SILVESTRINI, J. H.; LAMBALLAIS, E. Direct numerical simulation of wakes with virtual obstacles. In: Proceedings of the XI Congress on Numerical Methods and their Applications.Bariloche, Argentina. [S.l.: s.n.], 2000.

SILVESTRINI, J. H.; LAMBALLAIS, E. Direct numerical simulation of wakes with virtual cylinders. International Journal of Computational Fluid Dynamics, v. 16, n. 4, p. 305-314, 2002.

SOURCEFORGE.NET. XFLR5 Airfoil and Wing Analysis Tool. 2008. Online; accessed outubro-2008. Disponível em: <http://xflr5.sourceforge.net/xflr5.htm>. 
SOUZA, L. F. de. Numerical simulation of a flow over a circular cylinder using immersed boundary method in vorticity-velocity formulation. In: 18TH INTERNATIONAL CONGRESS OF MECHANICAL ENGINEERING. [S.1.], 2005.

STEWART, B.; LEONTINI, J.; HOURIGAN, K.; THOMPSON, M. Vortex wakeand energy transitions of an oscillating cylinder at low reynolds number. Anziam Journal, v. 46(E), p. C181-C195, 2005.

SUNG, J.; YOO, J. Y. Near-wake vortex motions behind a circular cylinder at low reynolds number. Journal of Fluids and Structures, v. 17, p. 261-274, 2003.

SVACEK, P.; M, M. F.; HORACEK, J. Numerical simulation of flow induced aerofoil vibrations with large amplitudes. Journal of Fluids and Structures, v. 23, p. 391-411, 2007.

THEODORSEN, T. General Theory of Aerodynamic Instability and Mechanism of Flutter, [S.1.], 1935. v. 496.

TOMÉ, M. F.; MCKEE, S. Gensmac: A computational marker-and-cell method for free surface flows in general domains. Journal Comput. Phys., v. 110, p. 171-186, 1994.

TRITTON, D. J. Experiments on the flow past a circular cylinder at low reynolds numbers. Journal of Fluid Mechanics, v. 6, p. 547-567, 1959.

TSENG, Y.-H.; FERZIGER, J. H. A ghost-cell immersed boundary method for flow in complex geometry. Journal of Computational Physics, v. 192, n. 2, p. 593-623, 2003.

TURKEL, E. Accuracy of schemes with nonuniform meshes for compressible fluid-flows. Journal of Applied Numerical Methods, v. 2, p. 529-550, 1986.

VARONOS, A.; BERGELES, G. Development and assessment of a variable order nonoscilatory scheme for convection term discretization. International Journal for Numerical Methods in Fluids, v. 26, p. 1-16, 1998.

VIECELLI, J. A method including arbitrary external boundaries in the mac incompressible fluid computing technique. Journal of Conputational Physics, v. 4, p. 543-551, 1969.

VIECELLI, J. A computing method for incompressible flows bounded by moving walls. Journal of Conputational Physics, v. 8, p. 119-143, 1971.

WANG, Z. J. Two dimensional mechanism for insect hovering. Physics Review Letters, v. 85, p. 2216-2219, 2000.

WANG, Z. J.; BIRCH, J. M.; DICKINSON, M. H. Unsteady forces and flows in low reynolds number hovering flight: two-dimensional computations vs robotic wing experiments. The Journal of Experimental Biology, v. 207, p. 449-460, 2004.

WEBB, C. H. Separation and Vorticity Transport in Massively-Unsteady Low Reynolds Number Flows. Dissertação (Mestrado) — Wright State University, 2009.

WETTON, B. R. Error analysis for chorin's original fully discrete projection method and regularizations in space and time. SIAM Journal on Numerical Analysis, v. 34, n. 5, p. 1683-1697, 1997. 
WILLIAMSON, C.; GOVARDHAN, R. Vortex-induced vibrations. Ann. Rev. Fluid Mechanics, v. 36, p. 413-455, 2004.

WILLIAMSON, C.; ROSHKO, A. Vortex formation in the wake of a oscillating cylinder. Journal of Fluids and Structures, v. 2, p. 355-381, 1988.

WILLIAMSON, C. H. K. Vortex dynamics in the cylinder wake. Annual Review Fluid Mechanics, v. 28, p. 477-539, 1996.

WILLIAMSON, J. H. Low-storage runge-kutta schemes. Journal of Computational Physics, v. 35, p. 48-62, 1980.

YE, T.; MITTAL, R.; UDAYKUMAR, H. S.; SHYY, W. Incompressible flows with complex immersed boundaries. Journal of Computational Physics, v. 156, p. 209-240, 1999.

ZAHM, A. F. Flow and Drag Formulas for Simple Quadrics. [S.1.], 1922.

ZBIKOWSKI, R. On aerodynamic modelling of an insect - like flapping wring in hover for micro air vehicles. Philosophical Transactions of the Royal Society of London, v. 360, p. 273-290, 2002.

ZDRAVKOVICH, M. M. Flow around circular cylinders. New York: Oxford University Press, 1997.

ZOVATTO, L.; PEDRIZZETTI, G. Flow about a circular cylinder between parallel walls. Journal of Fluid Mechanics, v. 440, p. 1-25, 2001. 


\section{Apêndice A - Termos Fonte}

Termos fonte da solução manufaturada calculados na Seção 4.2:

$$
\begin{aligned}
& \mathscr{F}_{1}(x, y)=2\left(\left(\cos \left(\frac{x}{2}\right) \frac{y^{3}}{3}-\frac{3}{2} \cos \left(\frac{x}{2}\right) y^{2}-2 y^{2} \cos \left(\frac{y}{2}\right)+16 \cos \left(\frac{y}{2}\right)+8 y \operatorname{sen}\left(\frac{y}{2}\right)-12 \operatorname{sen}\left(\frac{y}{2}\right)+6 \cos \left(\frac{y}{2}\right) y\right)\right. \\
& \left.x \frac{(x-3)}{200}+1.0\right)\left(\frac{\left(-\operatorname{sen}\left(\frac{x}{2}\right) \frac{y^{3}}{6}+\frac{3}{4} \operatorname{sen}\left(\frac{x}{2}\right) y^{2}\right) x \frac{(x-3)}{200}+\left(\cos \left(\frac{x}{2}\right) \frac{y^{3}}{3}-\frac{3}{2} \cos \left(\frac{x}{2}\right) y^{2}-2 y^{2} y \cos \left(\frac{y}{2}\right)\right.}{200}\right. \\
& +\frac{\left.16 \cos \left(\frac{y}{2}\right)+8 y \operatorname{sen}\left(\frac{y}{2}\right)-12 \operatorname{sen}\left(\frac{y}{2}\right)+6 \cos \left(\frac{y}{2}\right) y\right) \frac{(x-3)}{200}+\left(\cos \left(\frac{x}{2}\right) \frac{y^{3}}{3}-\frac{3}{2} \cos \left(\frac{x}{2}\right) y^{2}-2 y^{2} \cos \left(\frac{y}{2}\right)\right.}{200} \\
& \left.+\frac{16 \cos \left(\frac{y}{2}\right)+8 y \operatorname{sen}\left(\frac{y}{2}\right)-12 \operatorname{sen}\left(\frac{y}{2}\right)+6 \cos \left(\frac{y}{2}\right) y x}{200}\right)+\left(\cos \left(\frac{x}{2}\right) y^{2}-3 \cos \left(\frac{x}{2}\right) y+y^{2} \operatorname{sen}\left(\frac{y}{2}\right)-3 y \operatorname{sen}\left(\frac{y}{2}\right)\right) \\
& x(x-3)\left(-x(x-3) \frac{-\operatorname{sen}\left(\frac{x}{2}\right) \frac{y^{4}}{24}+\operatorname{sen}\left(\frac{x}{2}\right) \frac{y^{3}}{4}}{400}\right. \\
& -\frac{\left(\cos \left(\frac{x}{2}\right) \frac{y^{4}}{12}-\cos \left(\frac{x}{2}\right) \frac{y^{3}}{2}-4 y^{2} \operatorname{sen}\left(\frac{y}{2}\right)+96 \operatorname{sen}\left(\frac{y}{2}\right)-32 \cos \left(\frac{y}{2}\right) y+48 \cos \left(\frac{y}{2}\right)+12 y \operatorname{sen}\left(\frac{y}{2}\right)\right)(x-3)}{400} \\
& \left.-\frac{\left(\cos \left(\frac{x}{2}\right) \frac{y^{4}}{12}-\cos \left(\frac{x}{2}\right) \frac{y^{3}}{2}-4 y^{2} \operatorname{sen}\left(\frac{y}{2}\right)+96 \operatorname{sen}\left(\frac{y}{2}\right)-32 \cos \left(\frac{y}{2}\right) y+48 \cos \left(\frac{y}{2}\right)+12 y \operatorname{sen}\left(\frac{y}{2}\right)\right) \frac{x}{200}+\operatorname{sen}(2 x)}{200}\right) \\
& +\left(\left(\cos \left(\frac{x}{2}\right) \frac{y^{3}}{3}-\frac{3}{2} \cos \left(\frac{x}{2}\right) y^{2}-2 y^{2} \cos \left(\frac{y}{2}\right)+16 \cos \left(\frac{y}{2}\right)+8 y \operatorname{sen}\left(\frac{y}{2}\right)-12 \operatorname{sen}\left(\frac{y}{2}\right)+6 \cos \left(\frac{y}{2}\right) y\right) x \frac{(x-3)}{200}+1\right) \\
& \left(-\left(-\operatorname{sen}\left(\frac{x}{2}\right) \frac{y^{3}}{6}+\frac{3}{4} \operatorname{sen}\left(\frac{x}{2}\right) y^{2}\right) x \frac{(x-3)}{200}-\left(\cos \left(\frac{x}{2}\right) \frac{y^{3}}{3}-\frac{3}{2} \cos \left(\frac{x}{2}\right) y^{2}-2 y^{2} \cos \left(\frac{y}{2}\right)+16 \cos \left(\frac{y}{2}\right)+8 y \operatorname{sen}\left(\frac{y}{2}\right)\right.\right. \\
& \left.-12 \operatorname{sen}\left(\frac{y}{2}\right)+6 \cos \left(\frac{y}{2}\right) y\right) \frac{(x-3)}{200}-\left(\cos \left(\frac{x}{2}\right) \frac{y^{3}}{3}-\frac{3}{2} \cos \left(\frac{x}{2}\right) y^{2}-2 y^{2} \cos \left(\frac{y}{2}\right)+16 \cos \left(\frac{y}{2}\right)+8 y \operatorname{sen}\left(\frac{y}{2}\right)\right. \\
& \left.\left.-12 \operatorname{sen}\left(\frac{y}{2}\right)+6 \cos \left(\frac{y}{2}\right) y\right) \frac{x}{200}\right)+\left(\cos (x) \frac{y^{3}}{3}-\frac{3}{2} \cos (x) y^{2}\right) x^{2}(x-3)+2\left(\operatorname{sen}(x) \frac{y^{3}}{3}-\frac{3}{2} \operatorname{sen}(x) y^{2}\right. \\
& \left.+y^{2} \operatorname{sen}(y)-2 \operatorname{sen}(y)+2 \cos (y) y-3 \cos (y)-3 y \operatorname{sen}(y)\right) x(x-3.0)+\left(\frac{y^{3} \operatorname{sen}(x)}{3}-\frac{3}{2} y^{2} \operatorname{sen}(x)+y^{2} \operatorname{sen}(y)\right. \\
& -2 \operatorname{sen}(y)+2 \cos (y) y-3 \cos (y)-3 y \operatorname{sen}(y)) x^{2}-\frac{1}{R e}\left(\left(-\cos \left(\frac{x}{2}\right) \frac{y^{3}}{12}+\frac{3}{8} \cos \left(\frac{x}{2}\right) y^{2}\right) x \frac{(x-3)}{200}\right.
\end{aligned}
$$




$$
\begin{aligned}
& +\left(-\operatorname{sen}\left(\frac{x}{2}\right) \frac{y^{3}}{6}+\frac{3}{4} \operatorname{sen}\left(\frac{x}{2}\right) y^{2}\right) \frac{(x-3)}{100}+\left(-\operatorname{sen}\left(\frac{x}{2}\right) \frac{y^{3}}{6}+\frac{3}{4} \operatorname{sen}\left(\frac{x}{2}\right) y^{2}\right) \frac{x}{100}+\cos \left(\frac{x}{2}\right) \frac{y^{3}}{300} \\
& -\frac{3}{200} \cos \left(\frac{x}{2}\right) y^{2}-y^{2} \frac{\cos \left(\frac{y}{2}\right)}{50}+\frac{4}{25} \cos \left(\frac{y}{2}\right)+\frac{2}{25} y \operatorname{sen}\left(\frac{y}{2}\right)-\frac{3}{25} \operatorname{sen}\left(\frac{y}{2}\right)+\frac{3}{50} \cos \left(\frac{y}{2}\right) y+\left(2 \cos \left(\frac{x}{2}\right) y\right. \\
& \left.\left.-3 \cos \left(\frac{x}{2}\right)+2 y \operatorname{sen}\left(\frac{y}{2}\right)+y^{2} \frac{\cos \left(\frac{y}{2}\right)}{2}-3 \operatorname{sen}\left(\frac{y}{2}\right)-\frac{3}{2} \cos \left(\frac{y}{2}\right) y\right) x \frac{(x-3)}{200}\right)
\end{aligned}
$$

$\mathscr{F}_{2}(x, y)=\left(-\operatorname{sen}\left(\frac{x}{2}\right) \frac{y^{3}}{6}+\frac{3}{4} \operatorname{sen}\left(\frac{x}{2}\right) y^{2}\right) x \frac{(x-3)}{200}+\left(\cos \left(\frac{x}{2}\right) \frac{y^{3}}{3}-\frac{3}{2} \cos \left(\frac{x}{2}\right) y^{2}-2 y^{2} \cos \left(\frac{y}{2}\right)+16 \cos \left(\frac{y}{2}\right)\right.$ $\left.+8 y \operatorname{sen}\left(\frac{y}{2}\right)-12 \operatorname{sen}\left(\frac{y}{2}\right)+6 \cos \left(\frac{y}{2}\right) y\right) \frac{(x-3)}{200}+\left(\cos \left(\frac{x}{2}\right) \frac{y^{3}}{3}-\frac{3}{2} \cos \left(\frac{x}{2}\right) y^{2}-2 y^{2} \cos \left(\frac{y}{2}\right)+16 \cos \left(\frac{y}{2}\right)\right.$

$\left.+8 y \operatorname{sen}\left(\frac{y}{2}\right)-12 \operatorname{sen}\left(\frac{y}{2}\right)+6 \cos \left(\frac{y}{2}\right) y\right) \frac{x}{200}-x(x-3) \frac{\left(-\operatorname{sen}\left(\frac{x}{2}\right) \frac{y^{4}}{24}+\operatorname{sen}\left(\frac{x}{2}\right) \frac{y^{3}}{4}\right)}{200}-\left(\cos \left(\frac{x}{2}\right) \frac{y^{4}}{12}\right.$ $\left.-\cos \left(\frac{x}{2}\right) \frac{y^{3}}{2}-4 y^{2} \operatorname{sen}\left(\frac{y}{2}\right)+96 \operatorname{sen}\left(\frac{y}{2}\right)-32 \cos \left(\frac{y}{2}\right) y+48 \cos \left(\frac{y}{2}\right)+12 y \operatorname{sen}\left(\frac{y}{2}\right)\right) \frac{(x-3)}{200}-\left(\cos \left(\frac{x}{2}\right) \frac{y^{4}}{12}\right.$ $\left.-\cos \left(\frac{x}{2}\right) \frac{y^{3}}{2}-4 y^{2} \operatorname{sen}\left(\frac{y}{2}\right)+96 \operatorname{sen}\left(\frac{y}{2}\right)-32 \cos \left(\frac{y}{2}\right) y+48 \cos \left(\frac{y}{2}\right)+12 y \operatorname{sen}\left(\frac{y}{2}\right)\right) \frac{x}{200}+\operatorname{sen}(2 x)$ $+\left(\left(\cos \left(\frac{x}{2}\right) \frac{y^{3}}{3}-\frac{3}{2} \cos \left(\frac{x}{2}\right) y^{2}-2 y^{2} \cos \left(\frac{y}{2}\right)+16 \cos \left(\frac{y}{2}\right)+8 y \operatorname{sen}\left(\frac{y}{2}\right)-12 \operatorname{sen}\left(\frac{y}{2}\right)+6 \cos \left(\frac{y}{2}\right) y\right) x \frac{(x-3)}{200}+1\right)$ $\left(-(x-3) \frac{\left(-\operatorname{sen}\left(\frac{x}{2}\right) \frac{y^{4}}{24}+\operatorname{sen}\left(\frac{x}{2}\right) \frac{y^{3}}{4}\right)}{100}-x \frac{\left(-\operatorname{sen}\left(\frac{x}{2}\right) \frac{y^{4}}{24}+\operatorname{sen}\left(\frac{x}{2}\right) \frac{y^{3}}{4}\right)}{100}-x(x-3) \frac{\left(-\cos \left(\frac{x}{2}\right) \frac{y^{4}}{48}+\cos \left(\frac{x}{2}\right) \frac{y^{3}}{8}\right)}{200}\right.$ $\left.-\cos \left(\frac{x}{2}\right) \frac{y^{4}}{1200}+\cos \left(\frac{x}{2}\right) \frac{y^{3}}{200}+y^{2} \frac{\operatorname{sen}\left(\frac{y}{2}\right)}{25}-\frac{24}{25} \operatorname{sen}\left(\frac{y}{2}\right)+\frac{8}{25} \cos \left(\frac{y}{2}\right) y-\frac{12}{25} \cos \left(\frac{y}{2}\right)-\frac{3}{25} y \operatorname{sen}\left(\frac{y}{2}\right)+2 \cos (2 x)\right)$ $+2\left[-x(x-3) \frac{\left(-\operatorname{sen}\left(\frac{x}{2}\right) \frac{y^{4}}{24}+\operatorname{sen}\left(\frac{x}{2}\right) \frac{y^{3}}{4}\right)}{200}-\left(\cos \left(\frac{x}{2}\right) \frac{y^{4}}{12}-\cos \left(\frac{x}{2}\right) \frac{y^{3}}{2}-4 y^{2} \operatorname{sen}\left(\frac{y}{2}\right)+96 \operatorname{sen}\left(\frac{y}{2}\right)-32 \cos \left(\frac{y}{2}\right) y\right.\right.$ $\left.+48 \cos \left(\frac{y}{2}\right)+12 y \operatorname{sen}\left(\frac{y}{2}\right)\right) \frac{(x-3)}{200}-\left(\cos \left(\frac{x}{2}\right) \frac{y^{4}}{12}-\cos \left(\frac{x}{2}\right) \frac{y^{3}}{2}-4 y^{2} \operatorname{sen}\left(\frac{y}{2}\right)+96 \operatorname{sen}\left(\frac{y}{2}\right)-32 \cos \left(\frac{y}{2}\right) y\right.$ $\left.\left.+48 \cos \left(\frac{y}{2}\right)+12 y \operatorname{sen}\left(\frac{y}{2}\right)\right) \frac{x}{200}+\operatorname{sen}(2 x)\right]\left[-\left(-\operatorname{sen}\left(\frac{x}{2}\right) \frac{y^{3}}{6}+\frac{3}{4} \operatorname{sen}\left(\frac{x}{2}\right) y^{2}\right) x \frac{(x-3)}{200}-\left(\cos \left(\frac{x}{2}\right) \frac{y^{3}}{3}\right.\right.$ $\left.-\frac{3}{2} \cos \left(\frac{x}{2}\right) y^{2}-2 y^{2} \cos \left(\frac{y}{2}\right)+16 \cos \left(\frac{y}{2}\right)+8 y \operatorname{sen}\left(\frac{y}{2}\right)-12 \operatorname{sen}\left(\frac{y}{2}\right)+6 \cos \left(\frac{y}{2}\right) y\right) \frac{(x-3)}{200}-\left(\cos \left(\frac{x}{2}\right) \frac{y^{3}}{3}\right.$ $\left.\left.-\frac{3}{2} \cos \left(\frac{x}{2}\right) y^{2}-2 y^{2} \cos \left(\frac{y}{2}\right)+16 \cos \left(\frac{y}{2}\right)+8 y \operatorname{sen}\left(\frac{y}{2}\right)-12 \operatorname{sen}\left(\frac{y}{2}\right)+6 \cos \left(\frac{y}{2}\right) y\right) \frac{x}{200}\right]+\left(\operatorname{sen}(x) y^{2}-3 \operatorname{sen}(x) y\right.$ $\left.+y^{2} \cos (y)-3 \cos (y) y\right) x^{2}(x-3)-\frac{1}{R e}\left[\operatorname{sen}\left(\frac{x}{2}\right) \frac{y^{4}}{800}-\frac{3}{400} \operatorname{sen}\left(\frac{x}{2}\right) y^{3}-\frac{3}{200}(x-3)\left(-\cos \left(\frac{x}{2}\right) \frac{y^{4}}{48} \cos \left(\frac{x}{2}\right) \frac{y^{3}}{8}\right)\right.$ $-\frac{3}{200} x\left(-\cos \left(\frac{x}{2}\right) \frac{y^{4}}{48}+\cos \left(\frac{x}{2}\right) \frac{y^{3}}{8}\right)-x(x-3) \frac{\operatorname{sen}\left(\frac{x}{2}\right) \frac{y^{4}}{96}-\operatorname{sen}\left(\frac{x}{2}\right) \frac{y^{3}}{16}}{200}-4 \operatorname{sen}(2 x)-\left(-\operatorname{sen}\left(\frac{x}{2}\right) \frac{y^{2}}{2}+\frac{3}{2} \operatorname{sen}\left(\frac{x}{2}\right) y\right)$ $x \frac{(x-3)}{200}-\left(\cos \left(\frac{x}{2}\right) y^{2}-3 \cos \left(\frac{x}{2}\right) y+y^{2} \operatorname{sen}\left(\frac{y}{2}\right)-3 y \operatorname{sen}\left(\frac{y}{2}\right)\right) \frac{(x-3)}{200}-\left(\cos \left(\frac{x}{2}\right) y^{2}-3 \cos \left(\frac{x}{2}\right) y\right.$ $\left.\left.+y^{2} \operatorname{sen}\left(\frac{y}{2}\right)-3 y \operatorname{sen}\left(\frac{y}{2}\right)\right) \frac{x}{200}\right]$. 


\section{Apêndice B - Comparativo de velocidade e}

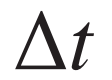

Resultados apresentados por Benevenutti e Silvestrini (2006) e Buarque, Schettini e Silvestrini (2005).

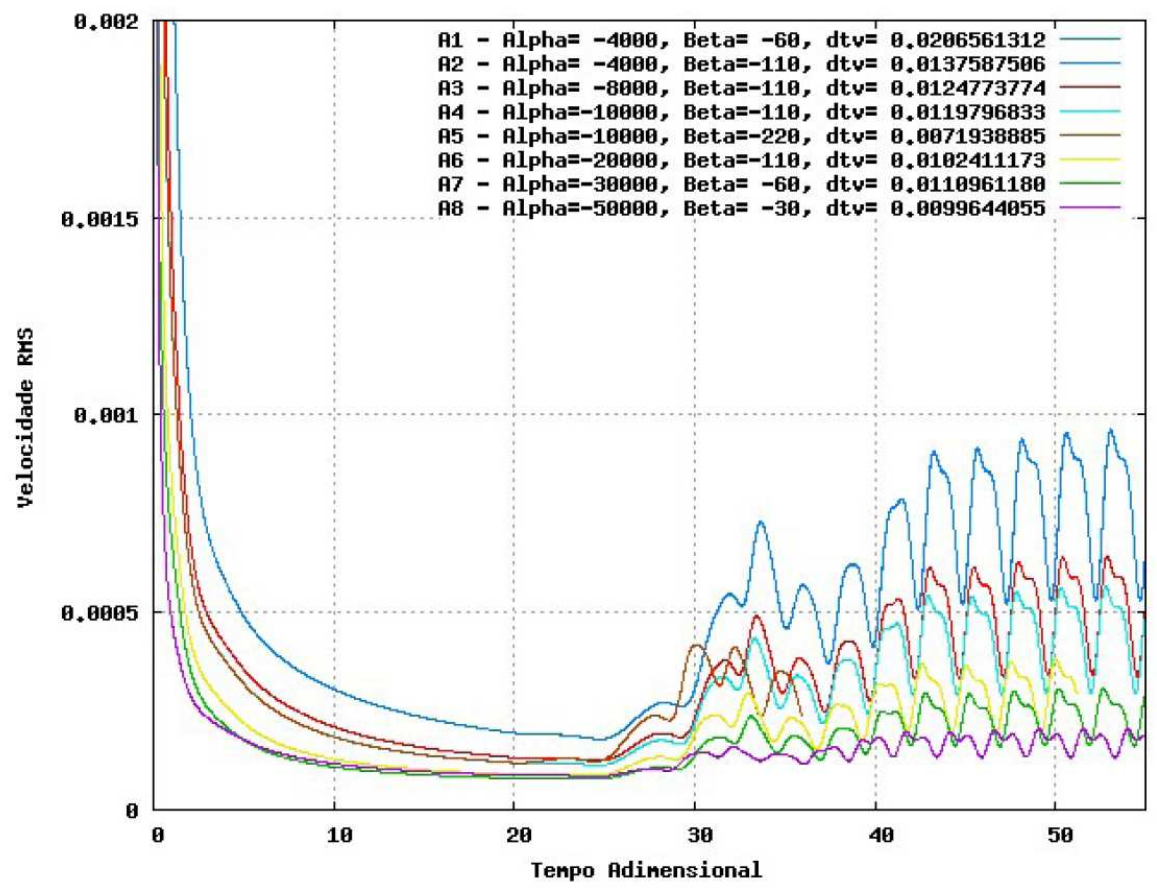

Figura 6.1: Velocidade sobre a superfície do cilindro - Benevenutti e Silvestrini (2006) 


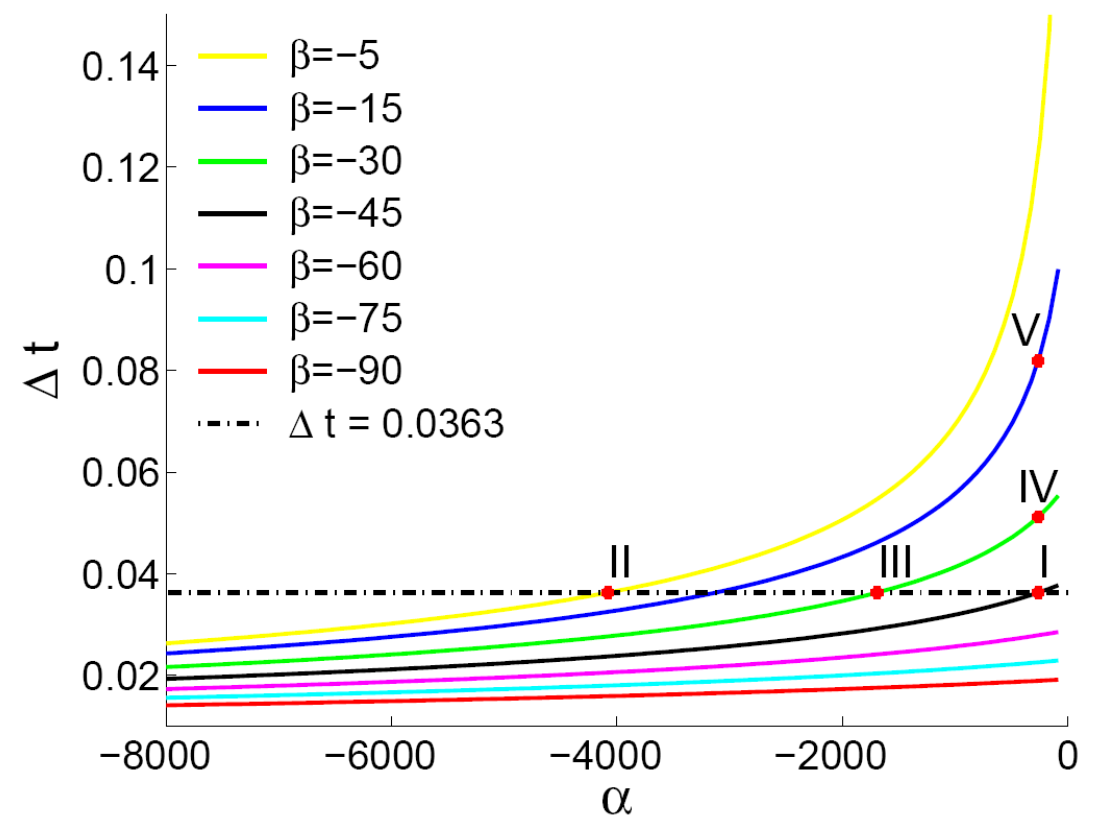

Figura 6.2: $\Delta_{t}$ em função dos parâmetros $\alpha$ e $\beta$ - Buarque, Schettini e Silvestrini (2005) 